\title{
Traditional family planning in Bangladesh
}

\author{
Alan Gray \\ Jamil H. Chowdhury \\ Bruce Caldwell \\ Ahmed Al-Sabir
}

Follow this and additional works at: https://knowledgecommons.popcouncil.org/departments_sbsr-rh

Part of the Health Services Research Commons, and the International Public Health Commons How does access to this work benefit you? Let us know!

\section{Recommended Citation}

Gray, Alan, Jamil H. Chowdhury, Bruce Caldwell, and Ahmed Al-Sabir. 1997. "Traditional family planning in Bangladesh." Dhaka: Population Council. 


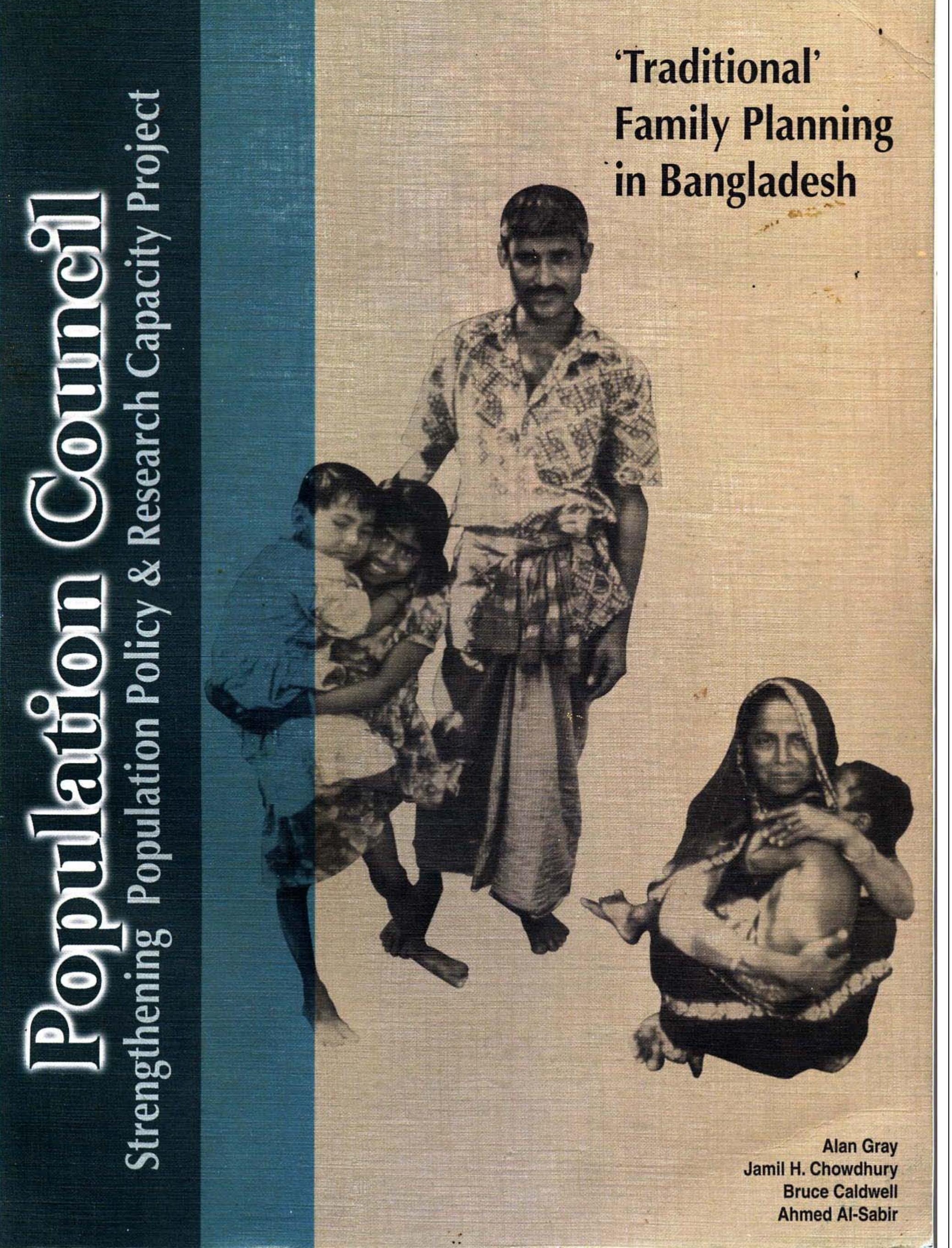




\title{
'TRADITIONAL’ FAMILY PLANNING IN BANGLADESH
}

\author{
Alan Gray \\ Jamil H. Chowdhury \\ Bruce Caldwell \\ Ahmed Al-Sabir
}

A collaborative project of Population Council, Bangladesh, the National Institute of Population Research and Training (NIPORT), the MCH-FP Extension Project, Rural, ICDDR,B, and Associates for Community and Population Research (ACPR), with support from USAID, Dhaka 
Copyright (C) 1997, Population Council, Bangladesh

This is one of a series of studies conducted by Population Council, Bangladesh, under the 'Strengthening Population Policy and Research Capacity' project, for USAID, Dhaka, Cooperative Agreement no. CCP-3050-A-00-4013-00

Published by Population Council, Dhaka, Bangladesh

PO Box 6016, Gulshan, Dhaka 1212

(House CES(B) 21, Road 118, Gulshan)

Telephone 8802881227,886657 , fax 883127, 883132

Email: PCDHAKA@POPCOUNCIL.ORG

Printed by Karshaf Printers (Pvt.) Ltd.

Recommended citation:

Gray, Alan, Chowdhury, Jamil H, Caldwell, Bruce, Al-Sabir, Ahmed, 1997, 'Traditional' Family Planning in Bangladesh, Dhaka: Population Council 


\section{Preface}

The background to this Project was a concern that Bangladesh relies heavily on a handful of contract research organizations to generate most of its population data, and in many cases to provide population policy guidance to the Government. A more desirable situation would be that the country has a number of stable research institutions with well trained researchers capable of conducting policy relevant research for the Government and others.

The objective of the Project then, has been to provide the opportunity to a group of less experienced researchers to gain experience by participating in a number of studies under the guidance of more experienced researchers. In addition to their involvement in every step of the research process, from study design and questionnaire development, through the fieldwork and data collection phase, to writing the final report, these researchers have received formal training in data collection, data analysis, presentation techniques, and other aspects of research from the hands of the senior members of the Project.

In addition to the above mentioned objective of building policy research capacity, a further objective was to make the studies relevant in their own right. For this reason all the studies were designed to focus on issues of current importance as the whole field of population research is evolving to include broader aspects of reproductive health. The titles of the five studies reflect this emphasis:

(i) Opportunities for Integration of RTI/STD Services into FP-MCH Programs.

(n) Strengthening STD Services for Men in an Urban Clinic Based Program.

(iii) Study of Adolescents: Dynamics of Perceptions, Attitudes, Knowledge, and Use of Reproductive Health Care.

(iv) Traditional Family Planning in Bangladesh.

(v) Increasing the Financial Sustainability of Family Planning Service Delivery in Bangladesh

The completion of these five studies from recruitment of the research staff through the initial design, to the production of the final study reports, has taken place over the past twelve to eighteen months. Needless to say this has been a period of intense activity, but we hope the readers will consider the products to be worthwhile.

While we believe this Project' has contributed to the building of the research capacity of our team, there remains the issue of building research institutions for researchers to function in. We encourage the Government, the development partners, and our fellow researchers to continue to strive to achieve this important goal. 


\section{Acknowledgements}

This study was carried out by the Population Council under a USAID-funded project titled 'Strengthening Population Policy and Research Capacity in Bangladesh'. The project commenced in 1995 and will end in July 1997. This study was conducted with the National Institute of Population Research and Training (NIPORT), in collaboration with the MCH-FP Extension Project (Rural) of the International Centre for Diarrhoeal Disease Research, Bangladesh (ICDDR,B). The field study was carried out by Associates for Community and Population Research (ACPR).

The authors of this report wish to acknowledge the contributions made by a large number of people who worked on various aspects of the project. From the Population Council, Dr Sharif undertook valuable literature search work, Ms Unnati Rani Saha worked tirelessly investigating existing survey data, Dr Nazmul Huda and Ms Nahid Kamal contributed timely assistance with translating indepth interviews, and Dr Indrani Pieris did initial work on analysis of the in-depth interview information, at the same time assisting ACPR to manage the translation work. Throughout the project, administrative and support staff of the office ensured that operations proceeded smoothly, and special thanks are due to the contributions of Mr Dipak Shil and Mr Shahinul Islam. From NIPORT, Ms Mita helped with the preparation of data from previous surveys. Dr Indrani Haque from the MCH-FP Extension Project (Rural), ICDDR,B, did a professional job of selecting the samples for the pretest and field study.

The Director of the MCH-FP Extension Project (Rural), ICDDR,B, Professor Barkat-eKhuda, generously extended every assistance that he could to the study. Similarly, the Executive Director of ACPR, Mrs Haidary Kamal, committed all the expertise of her organization to successful completion of the study.

From the office of ACPR, Mr Md. Nurul Islam, Ms Tamanna Tariq, Ms Quamrun Nahar, Ms Rabeya Khan, Ms Momena Begum and Ms Nargis Sultana processed the field data, Mr Md. Moniruddin did the data entry and Ms Rezina Sultana and Mr Abdur Rahim provided administrative support. Mr M.A. Zaman, Prof. M. Amanullah and Ms Zubaida Nasreen translated the in-depth interviews from Bangla to English. The scale of the work contributed by all these people can be appreciated from the fact that the translated in-depth interviews amounted to over 2.6 megabytes of text.

The core of the study is the field data, and those of us (Alan Gray, Jamil Chowdhury and Bruce Caldwell) who had the fortune to spend time at the field sites with the interview teams wish to record our special gratitude for the valuable insights which all of the interview team members contributed in regular discussion sessions which accompanied the work in the field. Many of the ideas presented in this volume arose out of the vigorous exchange of these discussion sessions, and can only be attributed to the survey team as a whole, not to any individual author of the report. Mr S.M. Salamat Ullah, Ms Sonali Sarker, Ms Zebun Nessa and Mr Pijush Kumar Bhattacharjee conducted the pretest interviews. For the main part of the study, Mr S.M. Salamat Ullah and Ms Zebun Nessa provided field supervision and quality control, and Mr Pijush Kumar Bhattacharjee, Mr Nazmul Huda, Ms Tahera Sultana, Ms Mahbuba Hoque, Ms Hasina Khatun, Ms Rowshan Ara Akhter, Mr Kabirul Islam Goldar, Mr Sk. Moinul Bashir and Ms Farida Khanam formed the interview teams. In a very real sense, the study's success is due to the expertise of the field teams. 
We also express our deep gratitude to Mr Ali Noor, Mr M. Nasiruzzaman and Dr Kanta Jamil of USAID, Dhaka, for their close interest in the progress and outcome of this study. Ms Nancy Piet-Pelon, consultant to the Population Council, Bangladesh, took the trouble to read the report in draft form very thoroughly, and her comments have helped to shape the arrangement of the material presented in the report. The collegial support and interest of $\mathrm{Dr}$ Kim Streatfield, Dr Nahid Chowdhury and Dr Ubaidur Rob of the office of the Population Council, Dhaka, is also acknowledged with gratitude. We hope that the study is worthy of the contributions made by so many people.

Dhaka, Bangladesh

June 1997 


\section{Table of contents}

Page

Acknowledgements $\quad$ v

List of abbreviations viii

Chapter 1.

Introduction 1

Chapter 2.

$\begin{array}{ll}\text { Contraceptive Careers in Bangladesh } & 14\end{array}$

Chapter 3.

Family Planning Method Failure $\quad 30$

Chapter 4.

Reported Family Planning Method Use $\quad 50$

Chapter 5.

Source of Information and Correctness of Knowledge about the Safe Period Method

Chapter 6.

Family Planning Before First Birth

Chapter 7.

Religiosity and Method Choice

Chapter 8.

Discussion and Implications for Reproductive Health Policy

Appendix 1.

Survey Questionnaire (Women)

Appendix 2.

Survey Questionnaire (Men)

Appendix 3.

Questionnaire Amendment

Appendix 4.

Supplementary Reports on Family Planning Method Use 


\section{List of Abbreviations}

$\begin{array}{ll}\text { ACPR } & \text { Associates for Community and Population Research } \\ \text { AIDS } & \text { Acquired immune-deficiency syndrome } \\ \text { CPS } & \text { Contraceptive Prevalence Survey } \\ \text { DHS } & \text { Demographic and Health Survey } \\ \text { FP } & \text { Family Planning } \\ \text { FWA } & \text { Family Welfare Assistant } \\ \text { FWC } & \text { Family Welfare Centre } \\ \text { FWV } & \text { Family Welfare Visitor } \\ \text { HIV } & \text { Human immune-deficiency virus } \\ \text { ICDDR,B } & \text { International Centre for Diarrhoeal Disease Research, Bangladesh } \\ \text { IUD } & \text { Intra-uterine device } \\ \text { MCH-FP } & \text { Maternal and Child Health - Family Planning } \\ \text { NIPORT } & \text { National Institute for Population Research } \\ \text { SRS } & \text { Sample Registration System } \\ \text { STD } & \text { Sexually-transmitted disease } \\ \text { THC } & \text { Thana Health Complex } \\ \text { USAID } & \text { US Agency for International Development } \\ \text { WFS } & \text { World Fertility Survey }\end{array}$




\section{Chapter 1. Introduction}

\section{$A^{\text {ims of the study }}$}

The term 'traditional' used in reference to methods of family planning generally means methods, such as withdrawal and periodic abstinence, which do not require contraceptive substances or devices and also do not require clinical procedures. According to estimates by Population Action International, cited by Rogow and Horowitz (1995: 140), in 1991 there were approximately 38 million couples worldwide relying on the method of withdrawal to prevent pregnancy, and a further 30 to 35 million relying on periodic abstinence from sexual intercourse. Together, these constituted perhaps one quarter of all users of temporary methods of family planning worldwide.

In Bangladesh, use of 'traditional' methods plays a similar role in family planning, according to data from the Demographic and Health Survey 1993-1994 (Mitra et al., 1994). Excluding use of more than one method at a time, 11 per cent of women using family planning methods were using periodic abstinence, and a further 5 per cent were using withdrawal. However, since about one quarter of women using any method at all were using permanent methods (sterilization of themselves or their husbands), the proportion using periodic abstinence or withdrawal was more than twenty per cent of users of temporary methods.

The reasons for use of 'traditional' methods at this level has not been investigated in Bangladesh, because of over-riding attention to increasing the prevalence of contraceptive methods perceived to be 'modern'. Given that the use of 'traditional' methods is widespread, what is the level of knowledge among Bangladeshi users about the safe periods of the monthly cycle for the most effective use of the method of periodic abstinence? This method in particular requires specific knowledge to be effective, and there may be a need to improve information available to its users. If correct knowledge of its use is present in the population, how is that information being transmitted now? Even the most preliminary analysis of data from existing surveys demonstrates that people with higher levels of education, and higher economic status, are significantly more likely to use 'traditional' methods, than people with lower education or economic status. What are the factors which cause the higher socioeconomic groups to be the main users of 'traditional' methods? It is evidently not a question of lack of access to modern methods, so is it a question of higher regard for methods which do not require chemical or physical interference with natural functions? If so, why? Young people, especially those without children yet, are also more likely to use 'traditional' methods. Does lack of access to modern methods contribute to the relatively high use of 'traditional' methods among the youngest age groups, or is it that 'traditional' methods less obviously challenge social attitudes, or is there some other reason? If preference for 'traditional' methods is a major reason for their use, what are the implications for family planning program activity in Bangladesh? Why do some people switch between 'traditional' and modern methods? 
None of these questions can be answered adequately from existing survey data, but it is worthwhile to set out a list of topics and questions as the basis for a field study. ${ }^{1}$ These are as follows:

1. Do married adolescent women in Bangladesh experience some problems in access to modern family planning methods, and resort to 'traditional' methods instead? Is the main reason that they have low use of modern methods that use of 'traditional' methods does not challenge traditional or parental attitudes?

2. Apart from the case of adolescents, do women in Bangladesh who use 'traditional' methods of family planning do so because they prefer them to program methods?

3. Is preference for 'traditional' methods more likely to be expressed, either in words or action, by the more educated women and those with higher socio-economic status because

- they understand the side-effects of program methods more fully?

- they have access to information about 'traditional' methods (particularly the safe period method)?

- they see or have experienced problems with the quality of care provided by the family planning program?

4. Is religiosity positively associated with use of 'traditional' methods?

5. Is information about 'traditional' methods, particularly the safe period method, available in the mass media of Bangladesh? Is whatever information that is available more likely to be received and understood by educated women than by uneducated women?

6. Do users of the safe period method generally have a good understanding of the safe periods for successful use of the method?

7. As education levels increase and further socio-economic development occurs in Bangladesh, will 'traditional' methods will become more widely used, rather than less (both in absolute terms and relative to program methods)? Does the answer change if side effects of program methods can be addressed more effectively?

The final topic is speculative and difficult to examine directly, but logical extrapolation from answers to the preceding questions is likely to indicate the answer. If confirmed, the policy implications would be considerable. It is important to note here that the example of Sri Lanka (Caldwell et al., 1987; DeGraff and de Silva, 1991) illustrates that strong and sustainable fertility decline to a level near to the replacement level can be achieved with a heavy component of 'traditional' methods in the method mix. The policy question which this poses about the possible incorporation of advice about 'traditional' methods under the umbrella of the family planning program is discussed in the final chapter of this report.

This report investigates all of these questions at some level, but is aimed specifically at determining the main policy issues and the policy implications of findings.

\footnotetext{
${ }^{1}$ In the original concept paper for the study, these were set out as hypotheses with the intention that they could either be confirmed or rejected, without making any prior judgment about the probability of the outcome.
} 


\section{$F^{\text {ield study }}$}

The field component of this study was undertaken in the 'comparison' areas for ICDDR,B's MCH-FP Extension Project (Rural), in Kesabpur and Bagerphara thanas in the west of Bangladesh near Jessore, and in Satkania thana south-east of Chittagong in the south of the country. These areas were selected because the Extension Project maintained a Sample Registration System (SRS) which was regularly updated and which included details of contraceptive method use among the population of these areas in enough detail to identify current 'traditional' method users and their contraceptive history. Because users of 'traditional' methods constitute only a small proportion of the population of Bangladesh, the data available for people living in these areas could be used to select a sample with a larger number of users of 'traditional' methods than would be found in a random sample of the population.

The method of the field investigation was to be neither a standard demographic survey nor, on the other hand, a standard qualitative study. Rather, we employed an adaptive logical approach to investigate the research topics (which are set out in the previous section of this chapter), through structured in-depth interviews. We allowed the possibility of focusing on particular topics or new topics as the answers to some of the questions became clearer. In the event, a review in the middle stage of the field work resulted in only one minor change to the survey instruments which were employed during the first stage.

The field study was planned to include 150 case studies, with in-depth interviews of six categories of women, their husbands, and their parents-in-law in the case of women aged less than 20 years:

(1) 25 identified current users of 'traditional' methods who were not recorded in the SRS as having used modern methods immediately prior to the adoption of the 'traditional' method,

(2) 25 users of 'traditional' methods who were recorded as having immediately previously used modern methods,

(3) 25 users of modern methods who were recorded as having immediately previously used 'traditional' methods,

(4) 25 users of modern methods who were not recorded as having been former users of 'traditional' methods, immediately previous to adoption of the modern method,

(5) 25 non-pregnant women who had never used a family planning method, 'traditional' or modern,

(6) and 25 non-pregnant women who had used family planning methods in the past but were not identified as current users of either a 'traditional' method or a modern method.

The intention to interview parents-in-law of adolescent women was not included in the final survey design because it was felt that the number of cases would be too small to be useful. While in the field, the study team would also informally seek the views of family planning workers, religious leaders and community leaders on the use of 'traditional' methods; no personal or confidential information would be obtained in this way. 
The outcome of the interviews would be in the form of contextual information for interpretation of the patterns revealed by analysis of existing survey data. The purpose of including the panels of users of modern methods and non-users was to determine to what extent these women might also use or have used 'traditional' methods, and their attitudes towards them, while the users of 'traditional' methods would be questioned also about their understanding of, use and attitudes towards other methods. We expected to locate overlap between the groups, derived from under-reported use of 'traditional' methods, but because of the small scale of the study we did not expect to be able to describe the extent of overlap; instead the focus would be on its nature.

A pretest was held in August 1996 to test the survey questionnaires and procedures to be followed in the field. The test was held in a locality in one of the study areas (Kesabpur thana) to replicate the likely field conditions. The outcome of the pretest was significant modification of the questionnaires to shorten the length of interviews, some of which had taken well over two hours in the pretest.

Appendices One (women) and Two (men) show the English versions of the questionnaire forms, or instruments, which were adopted for the field study following the pretest. Appendix Three contains a modification introduced after the review during the middle of the fieldwork. The modification was aimed at discovering more precisely whether people who said that they were using condoms were using them exclusively.

Husbands and wives were interviewed separately and the instruments were different, although some questions were the same. The instruments were designed for use by two people in each interviewing team. One person (the interviewer) asked the respondent the questions. The other person (the notetaker) recorded answers to in-depth questions. This was to allow the interviewer to concentrate on asking questions and to conduct a normal conversation with the respondent. For female respondents, the interviewer and notetaker were both women, and for male respondents both were men. Field staff were assigned a fixed role either as a notetaker or an interviewer and trained accordingly. Their preference for this specialist approach was determined following the pretest, our initial view having been that the roles should be switched regularly.

The two instruments each had four substantive sections: respondent's background; children and pregnancy; family planning; religiosity. There were six main types of questions:

1) single-choice precoded questions;

2) uncoded questions requiring numeric answers;

3) multiple-choice precoded questions;

4) in-depth questions ('topics');

5) interviewer observations; and

6) filters/instructions.

Of these, nearly all can be found in standard survey instruments. However, the in-depth questions, or 'topics', were of quite a different style. The following example shows how they appear in the survey instruments. This type of question is easily recognizable, because no question is shown in the survey form, and there are no response/coding categories. Instead, the form describes a 'topic' for discussion, and there may be a list of sub-topics. The interviewer discussed the topic in depth with the respondent, choosing his or her own words to introduce the topic and judgment about how to proceed with the discussion. Meanwhile, the notetaker would record the discussion on a specially-designed notepad, concentrating on the responses of the respondent. 

PARTS OF THE MONTHLY CYCLE

Other innovatory approaches were used in this field survey. For instance, a look-up table was used to calculate the ages of young children, in months counting backwards from SeptemberOctober 1996 when the study was in the field. The interview teams reported that this approach was easy to use and saved considerable time, and of course it simultaneously averted the possibility of calculation errors. The table, with both Bengali and English components, is reproduced below. In the actual survey instrument, it was in Bengali script.

\begin{tabular}{|c|c|c|c|c|c|c|c|c|c|c|c|c|}
\hline & January & February & March & April & May & June & July & August & $\begin{array}{l}\text { Sept- } \\
\text { ember }\end{array}$ & October & $\begin{array}{l}\text { Nov- } \\
\text { ember }\end{array}$ & $\begin{array}{l}\text { Dec- } \\
\text { ember }\end{array}$ \\
\hline 1993 & 44 & 43 & 42 & 41 & 40 & 39 & 38 & 37 & 36 & 35 & 34 & 33 \\
\hline 1994 & 32 & 31 & 30 & 29 & 28 & 27 & 26 & 25 & 24 & 23 & 22 & 21 \\
\hline 1995 & 20 & 19 & 18 & 17 & 16 & 15 & 14 & 13 & 12 & 11 & 10 & 9 \\
\hline 1996 & 8 & 7 & 6 & 5 & 4 & 3 & 2 & 1 & 0 & & & \\
\hline & Baishak & Jaistha & Ashar & Sraban & Badhra & Ashwin & Kartik & $\begin{array}{l}\text { Agra- } \\
\text { hayan }\end{array}$ & Poush & Magh & Falgun & Choitra \\
\hline 1400 & 41 & 40 & 39 & 38 & 37 & 36 & 35 & 34 & 33 & 32 & 31 & 30 \\
\hline 1401 & 29 & 28 & 27 & 26 & 25 & 24 & 23 & 22 & 21 & 20 & 19 & 18 \\
\hline 1402 & 17 & 16 & 15 & 14 & 13 & 12 & 11 & 10 & 9 & 8 & 7 & 6 \\
\hline 1403 & 5 & 4 & 3 & 2 & 1 & 0 & & & & & & \\
\hline
\end{tabular}

Because of the importance given in the study to finding out what respondents knew about the method of periodic abstinence, special effort was put into investigating this, using the following question design. The scale of 28 days represented the menstrual cycle, from the first day of menstruation. This was to help the interviewer record stages of the menstrual cycle that the respondent said were 'safe' or 'dangerous' parts of the cycle. This innovation ensured that the summarized answer to the question could be interpreted correctly.

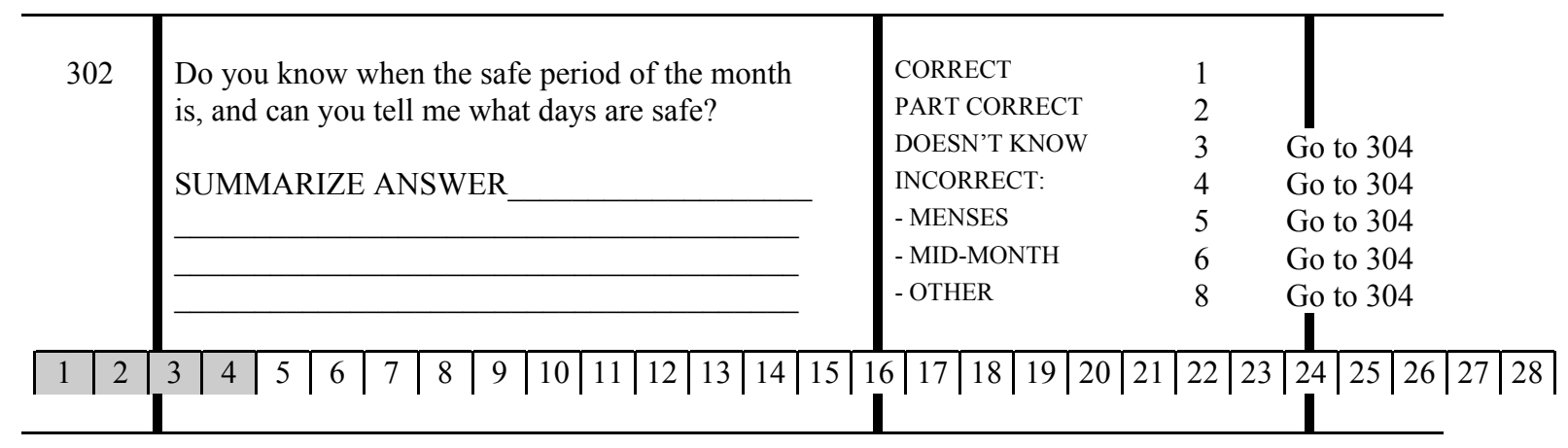


Training of the interview teams was conducted over two weeks from 9 September 1996 to 19 September 1996. There were four interview teams each consisting of interviewer and notetaker, plus a woman and a man to work as field supervision staff. Immediately after the training was completed, the field study was begun in Kesabpur thana, and continued throughout October and into November 1996.

The study aimed to interview 150 couples split evenly between the six categories of respondent, with 38 couples from Kesabpur thana, 74 from Bagerphara thana and 38 from Satkania thana. Most of the respondents were located in difficult-to-access rural locations, and there were frequent difficulties in locating both woman and man for interview. Interviews with men, in particular, were often difficult to arrange because their daily routines often took them away from their homes. Where it proved impractical to locate the men, substitutes were interviewed using the same sample lists, which had been compiled to include extra cases if needed.

The final sample included 150 women $^{2}$ and 141 men, from whom there were 128 matched couples. While there were meant to be equal numbers among the six categories of respondents, there were also certain difficulties in obtaining this result. While scrupulous attention was given to ensuring that the correct balance was being achieved according to the sample listings, the first difficulty was that these listings reflected contraceptive method use in July 1996, at least two months before the study went into the field, and as a result recent changes in method use altered the categories to which respondents were allocated. The second difficulty was that the correspondence between the Sample Registration System's (SRS) record of contraceptive method, and what was actually found by the interview teams, was approximate at best. Since the six categories were defined in terms of the final two family planning methods used by respondents, output categories differed quite markedly from the input categories derived from the SRS. There were also differences between categories assigned as a result of interviewing women and categories assigned as a result of interviewing men, for reasons which will be discussed extensively in this report.

An integral part of the study design was to maintain close contact with the field teams and to hold frequent evening discussion sessions to discuss cases which had been encountered, patterns of response and difficulties which were being experienced. The notes from these meetings form part of the evidence from which this report has been compiled. Also as an integral part of the study design, the interview teams returned to Dhaka mid-way through the field work to have a thorough review of progress and to decide whether it was necessary to focus more on particular topics.

There were two main outcomes of the mid-study review. The first, discussed earlier, was a modification of the survey instruments to investigate further whether respondents who said they were using condoms and nothing else were actually using them in combination with any other method. As already mentioned, the modification is shown in Appendix Three. The second outcome was to permit interviewers to move away more quickly from topics which had proved to be unexpectedly sensitive with some respondents. The main instance was discussion of the use of family planning methods between marriage and first birth, which encountered lack of understanding among a few respondents, mainly men. (This is discussed in detail in Chapter 6.)

Translation into English of the in-depth interview material, recorded in Bangla, was a major undertaking and was not completed until March 1997. Translation was begun while the interview teams were still in the field.

\footnotetext{
${ }^{2}$ Excluding one case where the interview with the woman was abandoned when it was found that she was out of scope for the study.
} 


\section{Taxonomy of family planning methods}

For reasons which will become increasingly clear in this report, we find the usual distinction between 'traditional' and 'modern' methods of family planning to be misleading, and prefer instead to distinguish what we call 'direct' methods of family planning, including condoms, withdrawal and periodic abstinence, from 'indirect' methods. Here, the term 'direct' refers to the fact that use of some methods of family planning makes sense only with reference to the occurrence of sexual intercourse (or absence of occurrence). We will argue that, in the way they are used in Bangladesh, the direct methods of family planning are used in combination so often that they are largely indistinguishable. In this section, we set out the background to the various ways in which methods of family planning are usually classified.

The method of withdrawal, including coitus interruptus and coitus reservatus ${ }^{3}$, is also widely known by the Arabic term azal in Islamic societies including Bangladesh, and the term will be used throughout this report. Successful use of the method of azal involves avoidance of discharge of semen inside the vagina by withdrawal of the erect penis before orgasm occurs, and to be effective it requires care and control to be exercised by the man. While it is often supposed that pre-ejaculatory fluid emission jeopardizes successful use of azal, Potts (1985) has questioned the validity of the belief.

The method of periodic abstinence requires avoidance of vaginal intercourse during the days of the woman's menstrual cycle in which she is most likely to be at risk of pregnancy. These at-risk days are in the middle of the menstrual cycle. Various terms are in use for variants of this method, including the terms 'safe period method', 'rhythm method', 'calendar method' and 'counting days'. The terms 'counting days' and 'safe period' are quite widely understood in Bangladesh and we will use 'safe period' except when variants are under discussion, such as those variants promoted by the advocates of 'natural' family planning, with their own specific terms.

Use of any variant of the safe period method requires a degree of knowledge of the physiological process of conception and the stages of the ovulatory/menstrual cycle. Some variants involve measuring physical changes in the woman's body, including temperature and cervical mucus, to detect when ovulation occurs. These variants require specific knowledge which can only be gained by instruction, and they may require the use of equipment such as a thermometer and charts, as for example in use of the symptothermal method promoted in Mauritius (Kambic et al., 1991), in which changes in both temperature and cervical mucus are noted. The temperature change associated with ovulation is a rise of 0.6 degrees Celsius, and if it occurs regularly on the same day of each cycle the at-risk period is identified as beginning four days before and ending three days after the day on which the increase in temperature occurs (Peel and Potts, 1969: 80-88). Cervical mucus becomes 'profuse and slippery', in practical terms receptive to the passage of sperm, on the at-risk days (Carne et al., 1974).

\footnotetext{
${ }^{3}$ In coitus reservatus, no ejaculation occurs either inside or outside the vagina.
} 
Other variants involve collection of information on the length of menstrual cycles over a long period, usually twelve months. For example, the days when there is risk of pregnancy are sometimes calculated to begin at the eighteenth day before the end of the woman's shortest menstrual cycle over a twelve-month period, and to end at the eleventh day before the end of her longest cycle (Peel and Potts, 1969: 83). Here the first day of the cycle is the day when menstruation begins. If every cycle were exactly 28 days, the at-risk period calculated in this way would be from the tenth to the seventeenth day of the monthly cycle; but if a woman had more variable cycles, with the shortest 26 days and the longest 31 days in the previous twelve months, her at-risk period would be estimated to be from the eighth to the twentieth day of the monthly cycle. Specific instruction is necessary before a person can adopt this version of the safe period method, and successful use will require the ability to use a calendar, keep records and do the necessary calculations.

A simpler variant involves identifying a fixed period in the middle of each menstrual cycle, for example the eighth to the twentieth day, or less conservatively the tenth to the twentieth day of the cycle, as the at-risk period. Other simplified versions exist. To be effective the simpler variants need to identify a somewhat longer at-risk period than the more complex variants. While ovulation occurs generally in the middle of the cycle, it can also occur a day before or after. The ovum might take three days to travel down the fallopian tubes, and motile sperm can still be present in the woman's reproductive tract for about two days after intercourse. For these reasons, the at-risk period must be taken to be at least one week.

If 'traditional' means 'dating from the 1930s' then the safe period method is a traditional method. Until researchers Knaus in Austria, and Ogino working independently in Japan, proposed in 1929 that ovulation occurred in the middle of the menstrual cycle, it was mostly thought that it coincided in some way with menstruation, and the period in the middle of the cycle thought to be most safe was in reality the least safe period (Peel and Potts, 1969: 80-81). Popularization of the method in Europe and North America was rapid during the 1930s because of endorsement by the Roman Catholic church.

Distinct from the periodic abstinence required by the safe period method is the adoption of permanent abstinence from sexual intercourse, which may occur towards the end of a woman's reproductive life for various reasons in different societies. This is also usually classified as a 'traditional' method. Other methods usually considered as 'traditional' are those requiring use of herbal preparations, which might or might not be effective.

At this point it is already possible to see that the term 'traditional' covers a multiplicity of approaches and behaviours. Use of the word 'traditional' implies an expectation that users of methods which come under its ambit represent a group of people who want to limit their families or space their children apart but who for one reason or another do not have access to 'modern' methods, or perhaps even that they are bound by cultural values to shun modern methods. This expectation has been modified by studies in another south Asian country, Sri Lanka (Caldwell et al., 1987; DeGraff and de Silva, 1991), where it was found that far from being used because no modern methods were available or accessible, methods such as safe period and azal were the family planning methods of choice for many couples. Caldwell and his co-authors (1987: 12-13) point out that what is called a 'traditional' method in the family planning literature refers to any type of contraception that was 'practised prior to the availability of the pill and the IUD in the 1960s [or] that do not depend on supplies or material objects'. This definition should be modified to allow the inclusion of traditional herbal preparations where these are used.

Turkey is another country where the 'traditional' methods are commonly used, with a little over half of all users of family planning using them, particularly azal, which is used by a quarter of all currently-married women, almost double the proportion using the next most 
favoured method, according to the Turkish Population and Health Survey, 1988 (cited by Goldberg and Toros, 1994: 123).

The 'traditional' methods, with substantial contribution from the use of condoms, other barrier methods and abortion, drove all of the major fertility declines that occurred before the advent of the main modern program methods in the 1960s (Wrigley, 1969; Potts, 1985). ${ }^{4}$ Most of these declines were in the industrialized countries. Condoms are only considered modern because they have been adopted as family planning program methods, and abortion is also considered modern if carried out under clinically safe conditions using modern technology, for example in menstrual regulation programs.

While abortion and menstrual regulation can be used as primary methods of family planning, in most countries their use is secondary, to deal with cases of unwanted pregnancy caused by primary contraceptive failure. It remains unclear whether menstrual regulation, which is widely available in Bangladesh as a preventive resort against the possibility of septic nonclinical abortion following contraceptive failure, is also used in a primary role. In this paper we regard it as a secondary method of dealing with contraceptive failure rather than a primary family planning method, but recognize that this treatment might not be universally valid given the extent of the practice.

Our purpose in exposing the view that the phrase 'traditional family planning' has little to do with tradition in the cultural sense, is that many people have been misled to expect the use of 'traditional' methods to have a cultural context. There is a cultural context, of course, but it is the same context as for 'modern' methods. The terminology might have more to do with the implication of superior potential efficacy of 'modern' methods. ${ }^{5}$ Yet as we and others have stressed, the 'traditional' methods have proved themselves to be efficacious in causing fertility decline, at least at population level.

A notable feature of the family planning methods described as 'traditional', and also of the use of condoms for family planning, is that they require male involvement in their use, unlike hormonal methods and IUDs which are in a sense divorced from sexual practice and behaviour, because they can be used without sexual intercourse actually occurring. It makes no sense at all to discuss azal and use of condoms without reference to the occurrence of sexual intercourse, and very little sense to refer to use of the safe period method except in terms of restricting sexual intercourse to what are perceived to be the safe periods of the monthly cycle. These three 'direct' methods are directly related to the occurrence of sexual intercourse and to sexual behaviour. Among other direct methods is the use of spermicidal foam tablets, which are little favoured or used in Bangladesh nowadays, but had a substantial role in the past, and the use of diaphragms, which does not require male involvement for use. Diaphragms are seemingly not used in Bangladesh at all.

An important distinguishing feature of direct methods is that they can sensibly be used in combination with each other. For example, it would make perfect sense for a couple to use a combination of azal, safe period, condoms and foam, with azal being used in what are identified to be the safe periods of the cycle, and condoms with foam being used in the at-risk days. It makes little sense to use an indirect method in combination with other methods, unless the user is unsure of the effectiveness of the method. Most of the literature on family planning ignores this distinguishing feature and makes the assumption that couples use no more than one method of family planning, or if more than one then one primary method with a supplementary method. There is also an assumption that it is possible, meaningfully, to contrast users of 'traditional' methods with users of 'modern' methods without overlap.

\footnotetext{
${ }^{4}$ The safe period method, if it contributed at all, could have done so only from the 1930s onwards.

5 'Efficacy' comprises the various concepts of theoretical levels of failure rates, effectiveness of use by users, and effects at population level as distinct from individual level.
} 
Some 'traditional' methods can also be considered as indirect methods, for example the use of a herbal preparation supplied by a kabiraj (traditional practitioner/supplier) and advertised as equivalent to a hormonal pill.

The contrast of 'traditional' methods with 'modern' methods tends to blur this more useful distinction between methods that have direct and indirect relationships to sexual intercourse and sexual behaviour. Of course, among the modern methods there are also subgroups, of which the main ones are barrier methods (condom, diaphragm), hormonal methods (pill, injection, implant), intra-uterine devices or IUDs, and sterilization (tubal ligation, vasectomy). These can be also divided meaningfully into temporary and permanent methods, although some temporary methods have long effect, making them semi-permanent. By contrast, the 'traditional' methods are mainly temporary.

In Bangladesh, which has a strong nationally coordinated family planning program, it is also reasonable to make a distinction between program methods, meaning those offered by the program, and all other methods. The main program methods are: oral pills and condoms, which are delivered to a client's doorstep by the Government's Family Welfare Assistants (FWAs) or field workers (FWs) of non-governmental organizations; intra-uterine devices and injections, which are offered at the level of Government Family Welfare Centres (FWCs) or NGO clinics; and male and female sterilizations, also delivered by referral. The program does not promote 'traditional' methods in any form, because of the perception that they have unacceptably high failure rates.

While this report is ostensibly about the 'traditional' methods (contrasted with 'modern'), the two taxonomies that are most useful in practice are the 'direct'/'indirect' contrast and the 'program'/‘non-program' contrast.

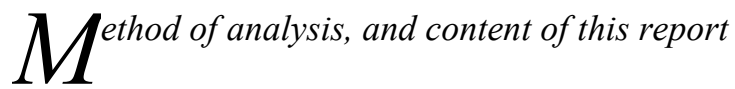

This study collected both quantitative and qualitative information, but the main emphasis in this report is on presenting the qualitative information from the in-depth interviews. There are important qualifications that need to be placed on the interpretation of this information. These qualifications arise from the process by which information was collected and processed into the (various) forms contained in the following chapters.

The information was collected by note-takers. Inevitably, note-takers cannot record every word that is said by respondents, nor can they record the tone in which a remark was made or the body language and gestures which accompany it. Sometimes this context can be inferred by recording key words, such as when a statement is preceded by 'Look! ...' By focusing on recording correctly an important or striking statement, even the best note-taker can miss the content of supplementary remarks. Note-takers can fall somewhat behind the interviewer. Interviewers in the study learned to assist the note-takers by slowing down the progression to new topics when they noticed that note-takers were significantly behind. Interviewer and note-taker subsequently discussed each interview to ensure that the note-taker's record of what was said on a topic was correct. Nevertheless, a proportion of the content of the interview will not be recorded in the notes, no matter how expertly taken.

On the other hand, notes have advantages over the main alternative of tape-recording and transcribing interviews, which is not only notoriously time-consuming but has the potential for introducing other types of loss of information. In the first place, tape-recorders unsettle respondents and make them less cooperative. Spoken language has only an approximate

\footnotetext{
6 Some traditional practitioners supply preparations which are intended to sterilize or provide longterm protection against conception to the user.
} 
correspondence to written language, since everyday speech contains many false starts and garbled sentence constructions, which make transcription an art form in itself to make statements read as if they might have been spoken. Notes by-pass this difficulty because they are taken in the written form of language by automatic adjustment on the part of the writer, even if the written form is abbreviated.

The ideal person to translate interview notes taken in one language into another language would be the person who took the notes, but this is rarely practicable and was not considered for this study because it was considered far more important to use expert interview teams. Translation is also very time-consuming, and it has the potential to introduce errors of misinterpretation on the part of the most expert of translators. Sometimes such errors can easily be identified by their context, as when in translating a woman's interview the translator renders the recorded 'wife', intended to mean 'the wife' (in a general sense), as 'my wife'. More often, slight errors which change meaning will not be noticed, such as when the important word 'not' is inadvertently omitted from the translation or at the time the translated interview is typed; in this study the translations were done long-hand. Emphasis can easily be lost in translation, and it can also be introduced inadvertently. The text of the translations given here is not always as produced by the translators. Usually the changes made by us are minor improvements to the English, retaining the flavour of the translation, but in some cases emphasis has been removed if it is not apparent that the emphasis was present in the original statement. In key cases discussed in this report, the translation rendered here has been compared again with the notes to ensure that the translation reflects the meaning intended.

Not quite finally, the person analysing the information and writing the results in these pages can introduce other errors of interpretation, by misunderstanding the context of a statement, by misunderstanding what the translator intended, by misunderstanding the culture-specific content of the statement and by misunderstanding the style of discourse which is being reported. Finally, the reader can as easily misinterpret statements.

What is presented in this report must, therefore, be regarded as a reflection of reality. We have attempted to maintain the integrity of the translated interviews by using abridgments from individual interviews to maintain both the style of discourse and the context of what was said. In other parts of the report, we use the structure of the interviews to excerpt statements made on individual sub-topics of the discussion. In yet other parts of the report, we simply collate brief statements on topics made in different parts of interviews. These are particularly subject to misinterpretation, because the absence of similar statements in the interviews of other respondents is no indication that they disagree with what has been said.

An example of the use of abridgment is also a good way to introduce the style of discourse which is commonly used by respondents:

F085 (19 years old, 1 child ever born): - (Advantages/disadvantages of safe period) ... I do not want to know anything more [about the safe period method]. What I know I will do. I have followed [the safe period method] as I have understood it and I did not become pregnant. ... Births can be prevented by using the safe period method, like injections and pills. If followed properly birth can be prevented as long as wanted.... (Reasons for method choice) Pills stop births, like injections. Birth will be prevented as long as I take the pills regularly. ... I did not have any problem when I was taking injections. To take injections one has to go to the hospital. So I have stopped doing that and I am taking pills, because the pill is delivered at home. I feel a vomiting tendency when I am taking the pill. But my husband asked me not to go to the hospital, so I am taking pills. ... They used to come to a neighbouring house to give injections before. They do not come anymore. I have to go far away to get injections. So I get the pills from those who come for door to door delivery of pills [FWA]... I 
told her, who comes to deliver pills, about the problem I have in taking pills. Instead of giving me any medicine for the vomiting tendency she asked me to accept a CT [IUD]. That is why I am dissatisfied with her. ... To get injections one has to go to the hospital or another person's house. The pill is delivered door to door, that is why I am taking pills. There is no problem in getting the pill. ... The ladies [FWA] come once in three months and give me three strips of pills. ... I did not have any problem with injections. Now I am taking pills, so I feel a vomiting tendency. For the last three to four days I have stopped taking the pills. I have not stopped taking the pill for ever. When the vomiting tendency has decreased I will start taking pills again in one or two days. ... (Extent of discussion with husband) ... I used to take injections. At that time they would come to my home to give injections. Now they don't come to my home any more. For injections one has to go to the hospital. I asked my husband, 'What shall I do now? I cannot take pills.' He told me 'If you can't take pills, don't take them. I do not know anything [you can do].' He does not want to use any method. So I decided to take pills. ... My opinion is more important [than my husband's]. If I don't want to take pills my husband can't make me take pills. ... I used to take injections. The ladies used to come to a neighbouring house to give injections before. They do not come now. I have to go to the hospital if I want to take injections. My husband asked me not to go far away to take injections. They come to my home to give the pills, so I am taking pills. My husband does not want to use any method.... To take injections I have to go far away. I can't tolerate pills. The lady who gives me pills asks me to use a CT. I discussed this with my husband. He [also] asked me to use a CT. But I was scared to accept a CT. I also feel shy to use a CT. ... My husband does not say anything about taking any method. He says 'Take whichever method is suitable.'

Here, the woman is identified by a serial number and the letter ' $F$ ' (' $M$ ' in the case of interviews of men), so that mention of the same household in different parts of this report can be cross-referenced. The structure of this account is a very good example of a narrative style found often in the study. In this style of discourse, seemingly endless repetition of the same facts is accompanied by subtle changes or extra details which make a luminous record of the person's experience. While the level of redundancy in this abridged excerpt is extremely high, if the redundancy is edited out then the tone of the account is lost. Patience is needed to obtain the full story from the respondent, and patience is needed to understand the import of what she has said.

There is a certain amount of statistical analysis of the field study data in the report. Much of this is not intended to be generalized in any way, but in Chapter 6 there is a statistical model which is meant to have more general application than the sample, or at least to be generalizable to the entire populations of the study areas. Although the sample for this study was a purposive sample, so that descriptive statistics based on the data will not represent the population of the study areas accurately, a statistical model can be constructed which is generalizable. If a theoretical model is valid, it will be valid for all individuals in the population and all samples, not just representative samples.

Because the data from this study will be available for others to use after the release of this report, we should also mention that there are other ways of performing valid statistical analyses from data of this type. A simple way to make comparisons is to use case-control estimates of relative risks, for example, although we have not adopted this approach in any of the analysis in this report.

In the next chapter, we examine data from the 1993-94 Demographic and Health Survey to derive a somewhat different interpretation than is usual about family planning method failure. The remaining chapters are all based on the field data from this study, and deal with the 
interpretation of lack of correspondence in reported method use by women and men, the sources of information and correctness of knowledge of 'traditional' methods among the survey respondents, use of family planning methods between marriage and first birth, and the influence of religiosity on family planning. The concluding chapter summarizes the results and draws implications for reproductive health policy in Bangladesh. 


\title{
Chapter 2. Contraceptive Careers in Bangladesh
}

\author{
Survey evidence of use of 'traditional' methods in Bangladesh
}

In the demographic surveys of every country, reporting of use of traditional methods is inconsistent and probably incomplete (Caldwell, 1985). This is mainly because the surveys concentrate more on accurate measurement of the prevalence of family planning program methods. However, there are other factors affecting reporting. One is that if the survey instruments do acknowledge that a couple might use more than one method, they usually allow only for a primary method and one secondary method, and the results are still generally reported only for the primary method. Another factor is the possibility that some respondents are reluctant to admit to using methods that have a direct relation to sexual behaviour, or even to acknowledge the existence of such methods. A further factor can be confusion among respondents who have been accustomed, and encouraged, to think that 'methods of family planning' refers only to program methods. Such confusion is possibly wide-spread in Bangladesh.

As an instance of the level of doubt about the prevalence of use of 'traditional' methods, it is instructive to compare the estimates given at the beginning of Chapter One, of 38 million users of withdrawal worldwide, and 30 to 35 million users of the safe period method (Rogow and Horowitz, 1993: 140) with other estimates. For instance, Gallen et al. (1986, cited in Faisel and Ahmed, 1996), suggested that the number of users of withdrawal was 35 million couples, similar to the more recent estimates, but that the number of users of the safe period method was only 17 million, about half the more recent estimates.

As will be demonstrated shortly, there is also abundant evidence of misreporting in Bangladesh, yet with reported ever-use of 'traditional' methods being as high as 30 per cent of ever-married women aged 10-49 in the Contraceptive Prevalence Survey of 1991 (Mitra et al., 1993: 52), it is clear that it forms a significant part of fertility control in the country. In the 1993-94 Bangladesh Demographic and Health Survey (Mitra et al., 1994: 44) a lower proportion of ever-married women, namely 24 per cent, reported having ever used a 'traditional' method. The inconsistency illustrates the reporting problems.

Figure 1 shows ever-use of 'traditional' and 'modern' family planning methods by evermarried women, according to a number of surveys. Since it is inconceivable that the fluctuations in the proportion of ever-married women who have used 'traditional' methods could be genuine, when the surveys are only two years apart in the cases of the three major fluctuations shown in the figure, it is wise to adopt the view that care should be taken in interpreting the information from any one survey.

The inconsistencies are less visible if current contraceptive prevalence among currentlymarried women aged 10-49 is considered. For this purpose we have accepted, perforce, the treatment adopted by survey reports, of classifying family planning users according to a single method. Figure 2 illustrates that both 'traditional' methods and 'modern' methods have been increasing in prevalence over time in Bangladesh, with the prevalence of 'modern' methods increasing more quickly. This does not support any notion that 'traditional' methods have been disappearing as modern methods have become more widely available. Instead, it implies that as couples in Bangladesh have come to accept the need to limit their family size, and the means to do so have become more widely available, a proportion of couples choose the 'traditional' methods in preference to the program methods. 

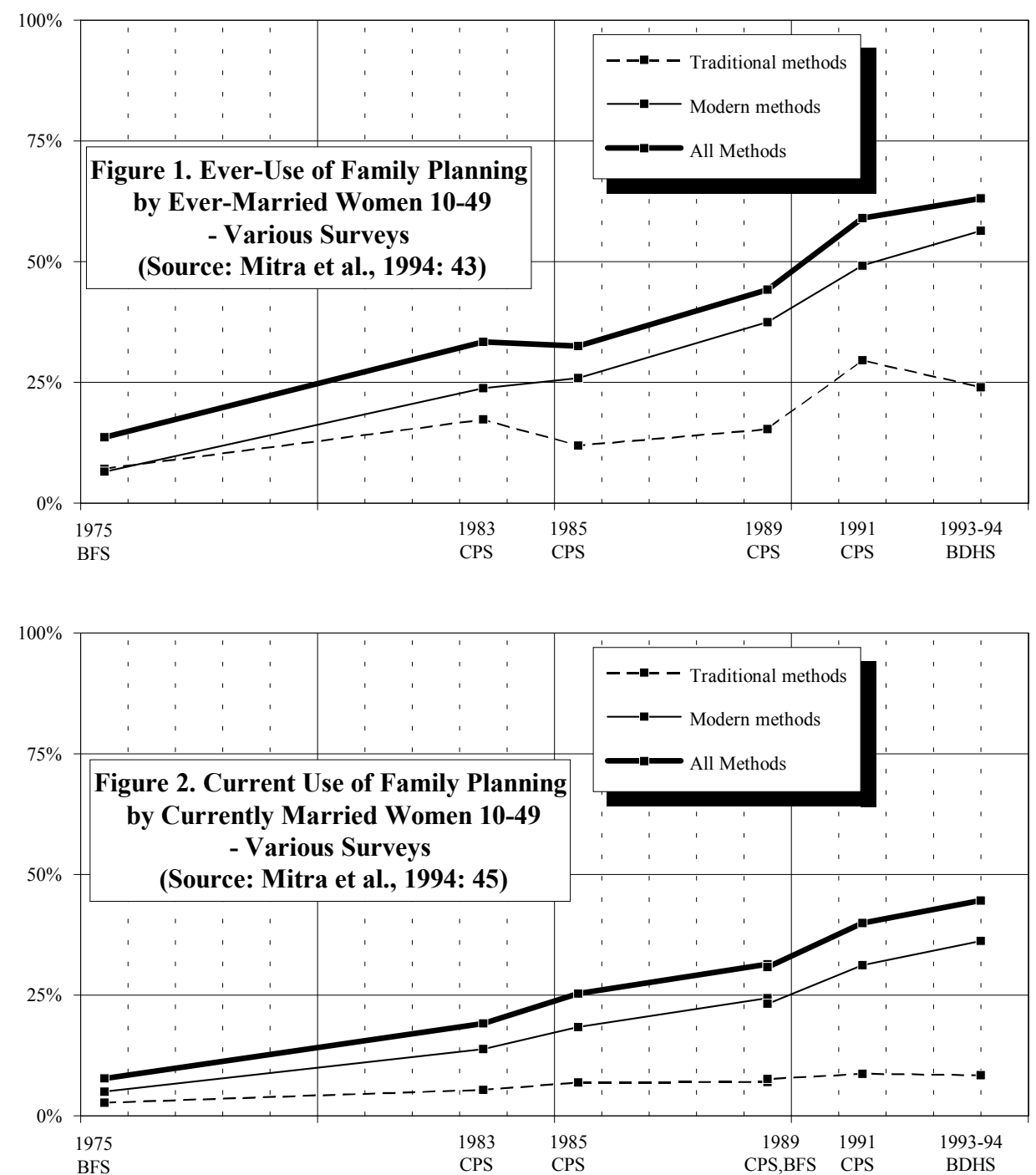

However, important qualifications should be placed on this interpretation. The first qualification is obviously that inconsistency in recording ever-use of 'traditional' methods almost certainly implies the existence of concurrent problems in the recording of current use. The second qualification, more subtle, is that it could be misleading to consider the choice of a method at a point in time as representing the only choice that couples will make during their reproductive careers. More specifically, a couple might choose 'traditional' methods at some stages of the family life cycle and 'modern' methods at other stages.

The strong evidence that use of family planning methods, and among them use of 'traditional' methods, are conditioned by the stage of the family life cycle is contained in Table 2.1, derived from data from the 1993-94 Bangladesh Demographic and Health Survey.

The patterns in Table 2.1 are very clear. The proportion of currently married women using any method increases with age group, except for the last age group, while the percentage of users who are using 'traditional' methods is high for the youngest age group, declines, then is again high in the oldest age group. However, when the number of children ever born is also considered, it can be seen that those with no children are the least likely to use any method, but if they do use a method then a rather large proportion use a 'traditional' method. 
Table 2.1. Current Use of Family Planning \& 'Traditional' Methods by CurrentlyMarried Women, According to Age and Number of Children Ever Born, Demographic and Health Survey, 1993-94

\begin{tabular}{|c|c|c|c|}
\hline $\begin{array}{c}\text { Age \& Number of } \\
\text { Children Ever Born }\end{array}$ & $\begin{array}{c}\text { Percentage of } \\
\text { Currently-Married } \\
\text { Women Using } \\
\text { Family Planning }\end{array}$ & $\begin{array}{c}\text { Percentage of Users } \\
\text { Using 'Traditional' } \\
\text { Methods }\end{array}$ & $\begin{array}{c}\text { Number of } \\
\text { Currently-Married } \\
\text { Women }\end{array}$ \\
\hline Less than 20: & $16 \%$ & $39 \%$ & 675 \\
\hline no children & $32 \%$ & $18 \%$ & 526 \\
\hline 1 child & $34 \%$ & $14 \%$ & 152 \\
\hline $2+$ children & $\mathbf{2 4 \%}$ & $\mathbf{2 4 \%}$ & $\mathbf{1 , 3 5 3}$ \\
\hline Sub-Total & & & 285 \\
\hline $\mathbf{2 0 - 2 9 :}$ & $15 \%$ & $16 \%$ & 769 \\
\hline no children & $36 \%$ & $14 \%$ & 1,110 \\
\hline 1 child & $50 \%$ & $\mathbf{1 4 \%}$ & $\mathbf{3 , 6 0 3}$ \\
\hline 2 children & $48 \%$ & $\mathbf{2 0 \%}$ & $\mathbf{2 , 4 3 2}$ \\
\hline $3+$ children & $\mathbf{4 6 \%}$ & $\mathbf{2 7 \%}$ & $\mathbf{1 , 3 0 8}$ \\
\hline Sub-Total & $\mathbf{5 8 \%}$ & $\mathbf{1 9 \%}$ & $\mathbf{8 , 9 8 0}$ \\
\hline $\mathbf{3 0 - 3 9}$ & $\mathbf{4 3 \%}$ & & \\
\hline $\mathbf{4 0 - 4 9}$ & & & \\
\hline Total 10-49 & & & \\
\hline
\end{tabular}

These observations suggest two distinct types of use of the 'traditional' methods. The first type is an increased level of use of 'traditional' methods before a couple has any children, among couples who use a method at all at this stage of the family life cycle. The second type is an increased level of use of 'traditional' methods at older ages. In summary, 'traditional' methods find favour at the beginning and at the end of the procreative phase of the family life cycle. This implies that there must be a considerable amount of switching between 'traditional' and modern methods during the years between marriage and menopause, and this topic will be investigated further in the next section of this chapter.

Investigations using data from the Contraceptive Prevalence Survey 1991 and the Demographic and Health Survey 1993-94 also reveal that use of the 'traditional' methods is most prevalent among people with higher educational levels and higher socio-economic status. It is not necessary to include the details here. This finding is replicated in data from Indonesia (Hull, forthcoming).

The neighbouring Indian state of West Bengal is predominantly Hindu while Bangladesh is predominantly Muslim, but otherwise shares cultural characteristics including language. Contraceptive prevalence among currently-married women (at 57 per cent) is higher than in Bangladesh, and the share taken by use of the 'traditional' methods is considerably higher than in Bangladesh, with 35 per cent of family planning users using 'traditional' methods, 
mainly safe period (International Institute for Population Sciences, 1995: 12). While the comparison is useful, it must be interpreted carefully against the very different method mix offered by the family planning program in India compared with Bangladesh. In India, the main program methods offered are permanent methods.

\section{Problems in the interpretation of survey data}

As we have already stressed, there are strong reasons to doubt the level of reporting of use of 'traditional' methods in surveys in Bangladesh, and there are also objections to the practice of reporting survey results in the form of use of a single method of family planning, either at a point in time or in a form which could imply that there is not much switching between methods. Both of these objections apply to the statistical results represented in Figures 1 and 2, and to the data in Table 2.1.

Recent surveys have indeed identified the use of methods in combination, and it is worthwhile to examine relevant data from the Contraceptive Prevalence Survey of 1991 and the Demographic and Health Survey of 1993-94, as shown in Table 2.2.

\section{Table 2.2. Current Use of Family Planning Methods by Currently-Married Women, Primary Users and All Users, Contraceptive Prevalence Survey 1991 \& Demographic and Health Survey, 1993-94}

\begin{tabular}{|l|r|r|r|r|}
\hline \multirow{2}{*}{$\begin{array}{c}\text { Method of } \\
\text { of family } \\
\text { planning }\end{array}$} & \multicolumn{2}{|c|}{$\begin{array}{c}\text { Contraceptive Prevalence Survey } \\
\text { 1991 }\end{array}$} & $\begin{array}{c}\text { Demographic and Health Survey } \\
1993-94\end{array}$ \\
\cline { 2 - 5 } & Primary users & All users & Primary users & All users \\
\hline Pill & 1,613 & 1,618 & 1,560 & 1,564 \\
\hline Condom & 328 & 359 & 269 & 298 \\
\hline Injection & 285 & 285 & 404 & 404 \\
\hline IUD & 210 & 211 & 196 & 196 \\
\hline Tubal ligation & 991 & 1,010 & 724 & 724 \\
\hline Vasectomy & 131 & 150 & 98 & 987 \\
\hline Safe period & 531 & 616 & 434 & 304 \\
\hline Azal & 229 & 337 & 220 & 96 \\
\hline Other & 223 & 243 & 96 & \\
\hline \multirow{2}{*}{ Total } & $\mathbf{4 , 5 4 1}$ & & 4,001 & \\
\hline
\end{tabular}

In the Contraceptive Prevalence Survey, special efforts were made to identify couples consisting of a husband and a wife who had both been sterilized, and 19 such couples were identified. Apart from this feature of the data in the table, it is evident that consideration of combinations of methods considerably increases the numbers of users of only three methods: azal, safe period, and condoms. Moreover, although not shown explicitly, the combinations of methods are mostly combinations of a selection of these three, in accordance with expectations based on the previous discussion in this chapter. 
Based on this evidence, the prevalence of use of azal should be 47 per cent higher than reported for the 1991 survey and 38 per cent higher than reported for the 1993-94 survey. The under-reporting is not as dramatic for the prevalences of safe period and condoms.

These limitations on the standard of reporting use of only one method could be circumvented by constructing a somewhat different classification of methods, which would permit the combination of methods that have a direct relationship with sexual intercourse. Use of the safe period method in combination with use of condoms or azal would recognize that the safe period method is the main method in use, since this is the logical explanation for these combinations. Less evidently, one logical explanation for use of condoms in combination with azal alone is also, in fact, that this is the safe period method! Used with the 1993-94 Demographic and Health Survey, a reclassification in these terms would, for currentlymarried women aged 10-49, decrease the prevalence of condoms from 3.0 per cent to 2.6 per cent, decrease the prevalence of azal from 2.5 per cent to 2.2 per cent, and increase the prevalence of the safe period method from 4.8 to 5.5 per cent. These are marginal changes, and would not change the position of the safe period method as the second most prevalent temporary method of family planning, after the pill.

\section{Contraceptive careers}

Contraceptive careers in Bangladesh can be taken to begin at marriage. There are only ten cases of female respondents in the 1993-94 Demographic Health Survey who were using family planning methods (recorded in the calendar data) before the date of their first unions, and one case of a woman who was recorded as pregnant. The calendar data for this survey consisted of three columns of information for every month from Baishak 1395 (April 1988) until the date of the survey, mainly from Agrahayan to Choitra 1400 (November 1993 to March 1994). The first column recorded method of family planning in use each month, if any, and also births, pregnancies and terminations. The second column recorded reason for discontinuation of a method of family planning, for each month in which a change was recorded in the first column. The third column recorded whether the woman was married or not in each month.

The calendar data can be split into segments which can be analysed as intervals of use or nonuse of methods of family planning, using various methods described and used by Mitra and Sabir (1996). Modelling approaches have also been recommended for examination of the determinants of contraceptive duration (see, for example, Steele et al., 1996), but for descriptive purposes attrition tables are satisfactory, and revealing. As an example, Table 2.3 represents the transitions over a five-year period experienced by women from the date of their first union, with possible outcomes being the adoption of a method of family planning or pregnancy. ${ }^{8}$ It shows the outcomes per 1,000 first unions, based on the probabilities of events as calculated from the recorded data. Eleven cases of women using family planning or pregnant before first union have been excluded from the analysis, and a further 56 cases which occurred in the first month of the calendar period have also been excluded because in these cases it is not possible to verify from the calendar data whether the respondents were using family planning previously.

\footnotetext{
${ }^{7}$ Another explanation is that when condom users runs out of supplies, they use azal.

${ }^{8}$ Table 2.3 is a cause-deleted multiple-decrement life table based on the analysis of all prospective intervals (open and closed) beginning with a first union which occurred during the period since Baishak 1395 until the date of the survey. The deleted cause is censoring, in the case of open intervals. The table is abridged from a single-month analysis over a period of five years from the beginning of each segment.
} 
The table requires only a little explanation. From the first line, it can be seen that of 1,000 women entering first unions, 53 would adopt a 'traditional' method of family planning in the first month, 123 would adopt a modern method in the first month, and 27 would become pregnant immediately. This leaves 797 women at the beginning of the second month, and in the second month 7 of these adopt a 'traditional method', 18 adopt a modern method and 24 become pregnant. Each line of the table represents the way in which women leave the status of being a just-married non-pregnant non-user of family planning. There are summaries for the first three months, the first six months and the first year, for comparison with the second three months, the second six months, and years two to five.

\begin{tabular}{|c|c|c|c|c|}
\hline \multicolumn{5}{|c|}{$\begin{array}{l}\text { Table 2.3. Attrition Table Describing Progression to } \\
\text { Use of Family Planning or Pregnancy After First Union, } \\
\text { Demographic and Health Survey, 1993-94 (Calendar Data) }\end{array}$} \\
\hline \multirow{2}{*}{$\begin{array}{l}\text { Time from } \\
\text { first union }\end{array}$} & \multirow{2}{*}{$\begin{array}{l}\text { Number } \\
\text { entering } \\
\text { interval }\end{array}$} & \multicolumn{2}{|c|}{ Number adopting: } & \multirow{2}{*}{$\begin{array}{l}\text { Number } \\
\text { becoming } \\
\text { pregnant }\end{array}$} \\
\hline & & $\begin{array}{c}\text { 'Traditional' } \\
\text { family } \\
\text { planning }\end{array}$ & $\begin{array}{c}\text { Other family } \\
\text { planning }\end{array}$ & \\
\hline First month & 1,000 & 53 & 123 & 27 \\
\hline Second month & 797 & 7 & 18 & 24 \\
\hline Third month & 748 & 4 & 10 & 30 \\
\hline First three months & 1,000 & 64 & 151 & 82 \\
\hline Second three months & 704 & 6 & 15 & 96 \\
\hline First six months & 1,000 & 70 & 166 & 178 \\
\hline Second six months & 586 & 3 & 16 & 128 \\
\hline First year & 1,000 & 74 & 182 & 306 \\
\hline Second year & 439 & 3 & 8 & 209 \\
\hline Third year & 219 & 1 & 2 & 80 \\
\hline Fourth year & 136 & 5 & 1 & 44 \\
\hline Fifth year & 85 & 0 & 0 & 22 \\
\hline Number of events & & 82 & 193 & 662 \\
\hline
\end{tabular}

The most evident feature of the table is that almost two-thirds of the women will have become pregnant within five years before adopting any method of family planning. This is the hard evidence of the cultural norm by which couples do not adopt any method of family planning before having any children. Conversely, the table also illustrates that in the five or six years before the 1993-94 survey, the normative behaviour had already been modified to the extent that approximately 28 per cent of women had adopted a method of family planning within five years of their first union before pregnancy had occurred. Most of the women who adopted family planning methods in this way did so in the very first month of their unions. Finally, just on thirty per cent of the women who adopted a method of family planning within five years of marriage used a 'traditional' method ( 82 from 275). In the fifth year of the marriage, 22 of the 85 remaining women become pregnant, leaving 63 women who have not yet used a method of family planning and have not become pregnant. This includes cases where the first union has dissolved, or the husband is absent for some other reason, and should not be interpreted as the level of primary sterility. 
All analysis of survival is affected by the possibility of undue weight being given to certain types of cases, although this is less likely when an event can occur only once in a lifetime, such as in the case of the analysis in Table 2.3 describing adoption of family planning or progression to pregnancy after first union. The possible biases need to be set out explicitly for every survival analysis. In the case of Table 2.3 , it is obvious that the only segments which are described are those which began during the survey's calendar period, including the segments which had not yet ended by the time of the survey (for calculation of exposure to risk). Cases of women whose first union occurred before the beginning of the calendar period, and who had not progressed to pregnancy or use of family planning until within the period, are not included in the analysis but no strong bias could result as a period of five years is sufficiently long to describe the end of approximately 94 per cent of segments beginning with first unions. The main possibility for mistaken conclusion is if there was marked change in the behaviour of newly-married couples during the six years of the calendar period, for example progressively greater probability of adopting a method of family planning at the time of marriage. Table 2.4 investigates this possibility.

Table 2.4. Proportion of Women using Family Planning from Date of First Union, Demographic and Health Survey, 1993-94 (Calendar Data)

\begin{tabular}{|c|c|c|}
\hline $\begin{array}{c}\text { Year } \\
\text { (Bengali Calendar) }\end{array}$ & $\begin{array}{c}\text { Proportion of women using } \\
\text { family planning from date } \\
\text { of first union }\end{array}$ & $\begin{array}{c}\text { Number of first unions } \\
\text { recorded }\end{array}$ \\
\hline 1395 & $14.6 \%$ & 308 \\
\hline 1396 & $18.7 \%$ & 316 \\
\hline 1397 & $13.2 \%$ & 357 \\
\hline 1398 & $18.1 \%$ & 288 \\
\hline 1399 & $17.9 \%$ & 374 \\
\hline 1400 & $23.7 \%$ & 291 \\
\hline Total & $\mathbf{1 7 . 5 \%}$ & $\mathbf{1 , 9 3 4}$ \\
\hline Kendall's $?_{\mathrm{b}}=0.052, \mathrm{p}=0.012$ & \multicolumn{2}{|}{} \\
\hline
\end{tabular}

While it can be verified that the appearance of slow and uneven increase in the proportion of women using family planning right from the time of first union is statistically significant at the 5 per cent level, as assessed using the ordinal statistic ? , the increase is certainly not one which would lead to substantially mistaken conclusions from the analysis in Table 2.3. Rather, Table 2.4 provides evidence that it has become increasingly unacceptable to ignore the use of family planning periods in the interval before first birth in Bangladesh. Nevertheless it is clear that almost three quarters of women do not adopt family planning before the first birth. The next logical step in following the contraceptive careers of women is to use the same technique to examine progression to adoption of family planning or further pregnancy after a first birth has occurred.

Besides an analysis for first live births, Table 2.5 shows the results for second and subsequent live births as well. The contrast between the analysis for first births and subsequent births is not as striking as might have been expected, given that most women in Bangladesh progress to at least one more birth after a first birth. Indeed, the major evident difference in the two analyses is that a somewhat larger proportion of women progress directly to another 
pregnancy, in the cases of first births. There are more subtle differences between the two panels in the timing of progression to either family planning use or pregnancy, more rapid in the case of first births, but eventual adoption of family planning methods is very similar for both panels of the table.

As would be expected, not much occurs in the first few months after a birth, so this table does not show the first three months separately. The results show that the most likely outcome after a birth is the adoption of some method of family planning rather than a pregnancy, but the type of family planning method adopted is much less likely to be a 'traditional method' than was the case in Table 2.3. Only 15 per cent of those who adopt a method of family planning within five years adopt a 'traditional' method, in the case of first births, and the number is even lower in the case of subsequent births, at 13 per cent. The table also illustrates that the peak periods for adoption of a method of family planning are quite early in the post-partum period, with the largest proportion in the first year, for both first births and subsequent births.

This way of presenting the data does not reveal, directly, that the highest probability of adopting a modern method is actually in the second year, in the case of second and subsequent births, while the highest probability for adopting a 'traditional' method is in the first year post-partum. After first births, the highest probability of adopting a modern method is also in the first year. The different timing in the case of subsequent births might signal greater acceptability of 'traditional' methods over modern methods during the period that a woman is still breast-feeding, but any effect is clearly not substantial on this evidence.

While the main reason for analysing first births separately from subsequent births is the unfulfilled expectation that there could have been substantial differences, a further reason is that there are substantial possibilities of selection bias in grouping births of different order. These possibilities arise from the fact that women who have short intervals between births are over-represented in the calendar data, because they are likely to have had several births during the calendar period. There were 8,342 live births used for the analysis in Table 2.5, to 5,577 individual women, of whom 3,228 had only one birth recorded, 1,953 had two births, 376 had three births and 20 had four births during the calendar period. 


\begin{tabular}{|c|c|c|c|c|}
\hline \multicolumn{5}{|c|}{$\begin{array}{l}\text { Table 2.5. Attrition Table Describing Progression to } \\
\text { Use of Family Planning or Pregnancy After a Live Birth, } \\
\text { Demographic and Health Survey, 1993-94 (Calendar Data) }\end{array}$} \\
\hline \multirow{2}{*}{$\begin{array}{l}\text { Time from } \\
\text { live birth }\end{array}$} & \multirow{2}{*}{$\begin{array}{l}\text { Number } \\
\text { entering } \\
\text { interval }\end{array}$} & \multicolumn{2}{|c|}{ Number adopting: } & \multirow{2}{*}{$\begin{array}{l}\text { Number } \\
\text { becoming } \\
\text { pregnant }\end{array}$} \\
\hline & & $\begin{array}{l}\text { 'Traditional' } \\
\text { family } \\
\text { planning }\end{array}$ & $\begin{array}{l}\text { Other family } \\
\text { planning }\end{array}$ & \\
\hline \multicolumn{5}{|c|}{ A: FIRST LIVE BIRTHS } \\
\hline First three months & 1,000 & 20 & 93 & 10 \\
\hline Second three months & 877 & 17 & 71 & 31 \\
\hline First six months & 1,000 & 37 & 163 & 42 \\
\hline Second six months & 758 & 18 & 113 & 60 \\
\hline First year & 1,000 & 55 & 277 & 102 \\
\hline Second year & 567 & 20 & 122 & 157 \\
\hline Third year & 269 & 3 & 28 & 106 \\
\hline Fourth year & 132 & 1 & 9 & 48 \\
\hline Fifth year & 74 & 0 & 1 & 29 \\
\hline Number of events & & 79 & 437 & 442 \\
\hline \multicolumn{5}{|c|}{ B: SECOND \& SUBSEQUENT LIVE BIRTHS } \\
\hline First three months & 1,000 & 18 & 80 & 7 \\
\hline Second three months & 895 & 10 & 60 & 23 \\
\hline First six months & 1,000 & 27 & 141 & 30 \\
\hline Second six months & 802 & 13 & 90 & 43 \\
\hline First year & 1,000 & 40 & 231 & 73 \\
\hline Second year & 656 & 20 & 161 & 160 \\
\hline Third year & 316 & 9 & 57 & 98 \\
\hline Fourth year & 153 & 2 & 15 & 43 \\
\hline Fifth year & 93 & 1 & 5 & 17 \\
\hline Number of events & & 72 & 469 & 392 \\
\hline \multicolumn{2}{|c|}{$\begin{array}{ll}\text { first births } & 2,037 \text { (right-censored 497) } \\
\text { second \& subsequent births } & 6,305 \text { (right-censored 1,604) }\end{array}$} & $\begin{array}{l}\text { analysis: } \\
\text { 2,037 (right-ce } \\
\text { 6,305 (right-ce }\end{array}$ & $\begin{array}{l}\text { nsored } 497) \\
\text { nsored } 1,604)\end{array}$ & \\
\hline \multicolumn{5}{|c|}{$\begin{array}{l}\text { The table excludes } 74 \text { segments where the birth occurred in the final month of the } \\
\text { calendar. }\end{array}$} \\
\hline
\end{tabular}

Because first births are events which can only occur once, this source of selection bias does not affect panel 'A' of Table 2.5, but panel 'B' is certainly affected to some extent because it groups together second and subsequent births, some of which occurred more than once to individual women. The number of second and subsequent births recorded in the analysis was 6,305 , to 4,320 individual women, of whom 2,633 or 61 per cent had only one birth recorded, 1,404 had two births, 268 had three births and 15 had four births during the calendar period. After controlling for right-censored cases, the median interval until pregnancy or adoption of a family planning method is 17.1 months for the most recent birth recorded, 16.9 months for the second most recent birth, 12.2 months for the third most recent birth, and 8.5 months for 
the fourth most recent. These results suggest that selection bias is quite strong in the cases of women with more than two births recorded for the calendar period, but since these women account for only 6.5 per cent of the women whose experience is analysed in panel ' $\mathrm{B}$ ' of Table 2.5, it can be inferred that the bias is small.

While we have taken the trouble to explain the way in which the selection bias occurs, it is important to note that it would not jeopardize the analysis in Table 2.5 even if it were a substantial bias, because the table does not deal with the characteristics of women and so undue weight to over-represented characteristics of women who have short birth intervals is not an issue. The table accurately describes intervals after births which occurred in the calendar period. It should be noted that the biases cannot be removed by restriction of the cases to a shorter part of the calendar. The women with shortest intervals would still be overrepresented, but less visibly.

Given that the most common outcome after a birth is adoption of some method of family planning, it is now logical to examine the outcomes of segments describing use of different methods. Instead of presenting separate tables of results for each different method, Table 2.6 shows the last line of tables on the same principle as Tables 2.3 and 2.5. In this case, the possible outcomes are switching to another method, method failure and method discontinuation (for various reasons) without adopting another method. Each line of the table shows how many such events would occur within five years to 1,000 women adopting each method, and a calculation of the number remaining at the end of the period.

Reading from the first line of the table, for example, from 1,000 women who began to use the pill, after five years 325 would have switched to a different method, 30 would have experienced method failure, 167 would have discontinued use (without adopting another method) because they wanted to become pregnant, 217 would have discontinued use (of any method) because of side effects or health concerns, and 143 would have discontinued use (of any method) for other reasons, leaving 117 continuing users.

There are many important results from this analysis, which can be appreciated best by examining the columns of the table. From the first column, it can be seen that all methods modern and 'traditional' have a substantial amount of attrition due to method-switching, but also that method-switching is at higher intensity for use of IUDs, injections and condoms. It is lowest for users of 'traditional' methods.

The next column of Table 2.6 shows that attrition due to method failure, meaning pregnancy, is highest for the 'traditional' methods. ${ }^{9}$ The results in this column lend support to the notion that higher failure from these methods is to be expected than for modern methods.

There are outstanding differences in two of the next three columns, showing the numbers of events representing discontinuation of method use without adopting another method. First, it is obvious that users of the safe period method are the most likely to discontinue because they want to become pregnant, no doubt reflecting the relatively high use of 'traditional' methods by women who have not yet experienced a birth. The next highest number of these events is for users of condoms, followed by users of the oral pill then users of azal. Users of IUDs and injectables are much less likely to discontinue use for this reason, reflecting the use of these methods for long-term contraception.

\footnotetext{
${ }^{9}$ It is not possible to calculate method failure rates easily from the data presented here, because of competing risks of attrition represented in the table. In particular, the relative numbers of failures in this column of Table 5 cannot be interpreted as the relativities of failure rates.
} 
Table 2.6. Summary of Attrition Tables Describing Progression to

Adoption of Another Method, Method Failure, or Discontinuation

- Outcomes after 5 Years for 1,000 Users of Each Method,

Demographic and Health Survey, 1993-94 (Calendar Data)

\begin{tabular}{|c|c|c|c|c|c|c|}
\hline \multirow{2}{*}{$\begin{array}{l}\text { Method of } \\
\text { Family } \\
\text { Planning }\end{array}$} & \multirow{2}{*}{$\begin{array}{c}\text { Switched } \\
\text { to Another } \\
\text { Method }\end{array}$} & \multirow{2}{*}{$\begin{array}{c}\text { Method } \\
\text { Failed }\end{array}$} & \multicolumn{3}{|c|}{$\begin{array}{l}\text { Reason for Discontinuation } \\
\text { (Without Adopting Another } \\
\text { Method) }\end{array}$} & \multirow{2}{*}{$\begin{array}{c}\text { Remaining } \\
\text { after } 5 \\
\text { Years } \\
\text { (from } \\
\text { 1,000) }\end{array}$} \\
\hline & & & $\begin{array}{c}\text { Wanted } \\
\text { Pregnancy }\end{array}$ & $\begin{array}{c}\text { Side } \\
\text { Effects/ } \\
\text { Health } \\
\text { Concerns }\end{array}$ & Other & \\
\hline Pill & 325 & 30 & 167 & 217 & 143 & 117 \\
\hline IUD & 424 & 11 & 82 & 252 & 138 & 92 \\
\hline Injection & 456 & 15 & 72 & 289 & 141 & 27 \\
\hline Condom & 424 & 79 & 235 & 58 & 162 & 43 \\
\hline Safe period & 277 & 159 & 284 & 6 & 101 & 172 \\
\hline Azal & 307 & 158 & 175 & 19 & 176 & 164 \\
\hline $\begin{array}{l}\text { Number of seg } \\
\text { Pill } \\
\text { IUD } \\
\text { Injectable } \\
\text { Condom } \\
\text { Safe period } \\
\text { Azal } \\
\text { Total }\end{array}$ & $\begin{array}{r}\text { gments of cont } \\
3, \\
4 \\
92 \\
98 \\
9 \\
4 \\
7,\end{array}$ & $\begin{array}{ll}\text { aceptive use } \\
354 & \text { (right- } \\
6 & \text { (right- } \\
9 & \text { (right- } \\
5 & \text { (right- } \\
6 & \text { (right- } \\
5 & \text { (right- } \\
605 & \text { (right- }\end{array}$ & $\begin{array}{lr}\text { included in ana } \\
\text { censored 1,945) } \\
\text { censored } 209 \text { ) } \\
\text { censored } & 443 \text { ) } \\
\text { censored } & 408) \\
\text { censored } & 533) \\
\text { censored } & 256) \\
\text { censored 3,794) }\end{array}$ & lysis: & & \\
\hline
\end{tabular}

Very high numbers of discontinuations, without adopting other methods, are said by respondents to be due to side effects or health concerns, in the case of users of the oral pill, IUDs and injectables. For IUDs and injectables, at least one in four segments of use results in discontinuation for these reasons without switching to another method, and the proportion is only slightly lower, one in five, for episodes of pill use. The proportion for condom users is very much lower, at about one in seventeen episodes of use, and the proportions for users of 'traditional' methods are negligible.

By contrast, the number of events representing discontinuation of the method without adopting another method, for reasons other than wanting to become pregnant or side effects and health concerns, varies little for the different methods. The most frequently cited reason in these other cases was classified under the rubric 'infrequent sex/husband away' (36 per cent), followed by 'husband disapproved' (17 per cent) and 'access/availability' (10 per cent) but there were also many cases classified as 'other reason' ( 25 per cent) besides small numbers whose reasons were classified as 'wanted a more effective method', 'inconvenient to use', 'cost', 'fatalistic', 'difficult to get pregnant/menopausal', 'marital dissolution/separation' and 'does not know' (all less than 5 per cent, and together amounting to 12 per cent of the cases). 
Little weight should be given to the net result of these sources of attrition as shown in the last column of the table, showing the number of persons who would be left after five years from 1,000 women who began to use each method. This number, which is by definition (Jejeebhoy, 1990, cited in Steele et al, 1996: 12) the continuation rate at five years, per thousand episodes of method use, is highest for the two 'traditional' methods, despite the occurrence of relatively high numbers of failures with these methods. Further examination, given in Table 2.7 , shows that continuation rates at shorter periods of use are highest for IUDs.

Table 2.7. Continuation Rates for Methods of Family Planning, per 1,000 Episodes of Method Use Demographic and Health Survey, 1993-94 (Calendar Data)

\begin{tabular}{|c|c|r|r|r|r|r|}
\hline \multirow{2}{*}{$\begin{array}{c}\text { Period of } \\
\text { use } \\
\text { (months) }\end{array}$} & \multicolumn{6}{|l|}{ Pamily planning method: } \\
\cline { 2 - 7 } & Pill & IUD & Injectable & Condom & Safe period & Azal \\
\hline 0 & 1,000 & 1,000 & 1,000 & 1,000 & 1,000 & 1,000 \\
\hline 12 & 552 & 615 & 435 & 295 & 560 & 444 \\
\hline 24 & 390 & 447 & 307 & 189 & 367 & 301 \\
\hline 36 & 276 & 315 & 198 & 137 & 234 & 239 \\
\hline 48 & 194 & 204 & 131 & 100 & 184 & 221 \\
\hline 60 & 119 & 94 & 30 & 45 & 174 & 166 \\
\hline
\end{tabular}

Nevertheless, the more detailed analysis shows that continuation with the safe period method is at a comparable level with continuation with the contraceptive pill at all interval lengths, and clearly higher than continuation of use of injectables. At all intervals of less than five years, IUD use has the highest continuation rate. While the IUD in sole use by the Bangladesh family planning program (CuT380a) was approved for use for eight years, most clients did not know this, and service providers also lacked specific knowledge about the method (Ahmed et al., 1992: 27,56). This may account for premature removal in some cases. Azal has the unusual pattern of low continuation rates at one and two years but high continuation, relative to other methods, by four years of use.

Considered as a representation of episodes of contraceptive use, and not as representations of the experience of individual users (some of whom would be grossly over-represented because their multiple episodes of use are short), the analysis in Tables 2.6 and 2.7 remains affected by selection bias. Very long periods of use are under-represented, because only those which began within the calendar period are contained in the analysis. This mainly affects cases of sterilization methods, in that 71 per cent of current users of tubal ligation, and 76 per cent of vasectomy users began their use of these methods before the beginning of the calendar period. However, long episodes of use of methods directly related to sexual intercourse are also under-represented. For users of the safe period method at the time of the survey, fully 19 per cent had begun use before the beginning of the calendar period, and for azal it was 14 per cent, condoms 10 per cent, and 'other' methods 16 per cent. Considerably smaller proportions of users of the pill ( 7 per cent), IUD ( 5 per cent) and injectables ( 1 per cent) had begun use before the beginning of the calendar period. To some extent these observations support the notion, expressed tentatively on the evidence of Tables 2.6 and 2.7, that long-term continuation of the direct methods is stronger than with the main program methods. The exception to this observation is that on the evidence of Table 2.7 condom use has very rapid attrition, but note that most of this attrition occurs very quickly, with just over 70 per cent of 
new users discontinuing for one reason or another within twelve months. There is a suggestion here that while most users use the method for very short episodes only, some find it a very satisfactory method for long-term use.

An evident question to ask is what then happens to women who discontinue a program method because of side effects or health concerns, and who do not adopt another method of family planning. Table 2.8 is an attrition table describing their return to family planning use or commencement of pregnancy.

\begin{tabular}{|c|c|c|c|c|}
\hline \multicolumn{5}{|c|}{$\begin{array}{l}\text { Table 2.8. Attrition Table Describing Progression to } \\
\text { Use of Family Planning or Pregnancy after Discontinuation of a Program } \\
\text { Method (a), } \\
\text { Demographic and Health Survey, 1993-94 (Calendar Data) }\end{array}$} \\
\hline \multirow{2}{*}{$\begin{array}{l}\text { Time from } \\
\text { discontinuation } \\
\text { of program method } \\
\text { (a) }\end{array}$} & \multirow{2}{*}{$\begin{array}{l}\text { Number } \\
\text { entering } \\
\text { interval }\end{array}$} & \multicolumn{2}{|c|}{ Number adopting: } & \multirow{2}{*}{$\begin{array}{l}\text { Number } \\
\text { becoming } \\
\text { pregnant }\end{array}$} \\
\hline & & $\begin{array}{c}\text { 'Traditional' } \\
\text { family } \\
\text { planning }\end{array}$ & $\begin{array}{l}\text { Other family } \\
\text { planning }\end{array}$ & \\
\hline First month & 1,000 & 0 & 0 & 51 \\
\hline Second month & 949 & 19 & 74 & 121 \\
\hline Third month & 735 & 5 & 44 & 67 \\
\hline First three months & 1,000 & 24 & 118 & 239 \\
\hline Second three months & 620 & 5 & 60 & 105 \\
\hline First six months & 1,000 & 30 & 177 & 344 \\
\hline Second six months & 449 & 8 & 43 & 86 \\
\hline First year & 1,000 & 38 & 220 & 430 \\
\hline Second year & 312 & 0 & 51 & 113 \\
\hline Third year & 149 & 3 & 10 & 41 \\
\hline Fourth year & 95 & 2 & 4 & 11 \\
\hline Fifth year & 77 & 0 & 0 & 0 \\
\hline Number of events & & 43 & 286 & 595 \\
\hline
\end{tabular}

The important outcome of this analysis is that the majority (60 per cent) of these women become pregnant, and that most of the women who become pregnant do so within twelve months - more than half of these within three months. These considerations lend an entirely different perspective to any comprehensive analysis of method failure, because it is reasonable to argue that it is a failure of the family planning program if side effects and health concerns leading to discontinuation of use of any method of family planning result in a large number of pregnancies. Recall that women who wanted to become pregnant were listed separately, so that concern about side-effects should have resulted in switching to other methods if the family planning program was delivering sound advice to clients. On the basis of approximately one quarter of users of pills, IUDs and injectables discontinuing use of any method because of concerns about side effects or their health, and one quarter of these becoming pregnant within three months, the program-attributable failure of these methods should be assessed as being of the order of five per cent or more, additional to the much lower levels of method failure recorded in Table 2.6. 
Method switching is noted in the previous analysis, but without any detail of the method changes involved when one episode of use ceases and another begins. As would be expected, for each non-permanent method of family planning there are as many varieties of method changes as there are methods to choose, and the exhaustive detail of a cross-tabulation is not very revealing. Instead, in Table 2.9 method changes are grouped into three categories, as switches to permanent methods, changes to higher-order methods, meaning those which provide lower failure rates or have longer-lasting effect, and other method changes.

\begin{tabular}{|l|c|c|c|c|}
\hline \multicolumn{5}{|c|}{$\begin{array}{c}\text { Table 2.9. Changes of Family Planning Method, } \\
\text { Demographic and Health Survey, 1993-94 (Calendar Data) }\end{array}$} \\
\hline Previous & New method: & $\begin{array}{c}\text { Higher order } \\
\text { method (a) }\end{array}$ & $\begin{array}{c}\text { Other } \\
\text { method changes }\end{array}$ \\
\hline method & Permanent & $39.7 \%$ & $59.3 \%$ & 972 \\
\hline Pill & $1.0 \%$ & $0.0 \%$ & $98.9 \%$ & 183 \\
\hline IUD & $1.1 \%$ & $6.5 \%$ & $93.2 \%$ & 263 \\
\hline Injectable & $0.4 \%$ & $71.4 \%$ & $28.1 \%$ & 222 \\
\hline Condom & $0.5 \%$ & $63.5 \%$ & $36.5 \%$ & 122 \\
\hline Safe period & $0.0 \%$ & $63.1 \%$ & $36.1 \%$ & 2,143 \\
\hline Azal & $0.8 \%$ & $57.1 \%$ & $42.1 \%$ & IUD, injection \\
\hline Total & $0.7 \%$ & $\begin{array}{l}\text { IUD } \\
\text { Pill, IUD, injection }\end{array}$ \\
\hline (a) Higher order method means: & $\begin{array}{l}\text { For pill } \\
\text { For IUD } \\
\text { For injectable } \\
\text { For condom, safe period \& azal }\end{array}$ \\
\hline
\end{tabular}

Changes to permanent methods during the calendar period were evidently rare outcomes of any episodes of contraceptive use, although more common among pill and IUD users than other methods. Choice of higher-order methods was prominent among changes from methods directly related to sexual intercourse (condom, safe period and azal) and to some extent from pill use, but from the higher-order methods of IUD and injectable change was overwhelmingly to methods of lower order. This pattern is to some extent dictated by the classification of methods by order, but the table also serves as an accurate assessment of the scale of method-switching, and particularly of the key role played by use of the oral pill in redistributing users of other methods into use of the various modern methods. Changes from pill use account for 45 per cent of all method-switching, and while it is not shown directly in this table, from all other methods changes to pill use account for 62 per cent of methodswitching.

\section{$D^{\text {sesasion }}$}

Most of the analysis in this chapter has drawn on the calendar data from the 1993-1994 Demographic and Health Survey to illustrate how contraceptive careers develop in Bangladesh, on the basis of episodes of non-use and use of family planning methods according to the stages of family formation from first union through to the first pregnancy and 
birth and then subsequent pregnancies and birth. While based on the same data source, the analysis goes much further than analysis of contraceptive use dynamics by Mitra and Sabir (1996), in that we draw specific attention to the consequences of discontinuation of method use.

For reasons which are both logical and based on the evidence from the survey, we have emphasized that it is unsatisfactory to view contraceptive prevalence at a point in time as representing anything except a cross-section from the multitude of contraceptive careers which are at their various stages. We have also argued that in the case of the direct methods, those which are directly related to sexual intercourse and which include the main 'traditional' methods, it is also illogical to regard use of one method as exclusive, although the presentation of survey data and consequently of much of the foregoing analysis forces suspension of disbelief in this false logic.

The volatile nature of the contraceptive careers that have been discussed is evident, but there are key characteristics which deserve to be emphasized again. One of these is the important role played by the 'traditional' methods and another direct method of family planning, use of condoms, in the period immediately after first union. Slightly more than one in six first unions which occurred during the six years before the 1993-94 Demographic and Health Survey were characterized by use of family planning from the time of the union, and this proportion was increasing at a gradual and inconsistent but statistically significant rate, even if there was no use of family planning before pregnancy for the majority of first unions. Among 339 cases of immediate use of a method from the time of the first union in the calendar data from this survey, just over 60 per cent were using condoms, safe period or azal, although the most popular single method was the pill. Direct methods, including the main 'traditional' methods, seem to play an important role at the end of contraceptive careers in Bangladesh, as well as at the very beginning.

The reason for use of 'traditional' methods can be examined to a certain extent using data from answers to a question in the 1993-1994 Demographic and Health Survey asking respondents to nominate the main reason they decided to use their current contraceptive method rather than any other method. The most frequent response among all female respondents was classified as 'side effects of other methods', and this was particularly prominent among users of condoms, safe period and azal, who gave this reason in over 50 per cent of current users of each of these methods. This reason was nominated by a minority of users of each of the other methods. By inference, it is likely to be the perception of the existence of side-effects rather than experience that dictates this response, but the serious implications of the occurrence or perception of side-effects among users of the main program methods has been given strong emphasis in the discussion in this chapter, because it so often leads to discontinuation and pregnancy.

Current users of family planning methods are not necessarily the best placed people to report on the occurrence of side-effects of the methods they are currently using, because in many cases they have actually only recently switched to a method because of side-effects of other methods, or for some other reason they retain some emotional investment in the method they are using. If they had had serious side-effects, why had they not yet stopped using the method? It is all the more notable that according to the Demographic and Health Survey of 1993-1994, more than a third of users of all the main program methods in Bangladesh, except condoms and vasectomy, say that they have health problems which they attribute to the family planning method, while almost no users of safe period or azal give this response (Mitra et al., 1994: 51).

Whether actual or perceptual, side-effects and health concerns result in 20 to 30 per cent of users of the main indirect temporary program methods (pill, IUD and injection) discontinuing 
use within five years of commencement, and almost one quarter of these are pregnant within three months. It is not obvious that pregnancy would be the main outcome of method discontinuation for reasons related to side-effects and health concerns, so it is extremely worrying that the one-quarter pregnant within three months eventually increases to almost 60 per cent of these women, and only about one in four discontinuations for these reasons result in use of another method of family planning within twelve months.

The main implication of these findings is that 'failure' of methods defined in terms of progression to pregnancy while using a method is a blinkered perspective. Failure of the family planning program to deal with actual or perceived side-effects of the main program methods effectively results in far more unwanted pregnancies than method failure itself. Yet, a woman who can use a hormonal method or an IUD without problems will evidently have greater protection against unwanted pregnancy than a user of direct methods. The dilemma for the family planning program involves dealing with health concerns of users as against supporting methods that are more failure-prone but actually result in comparable and eventually higher levels of continuation.

The next chapter of this report deals with cases of method failure (in the limited sense of pregnancy occurrence during method use) detected in the field study which we conducted. In view of what has been set out in this chapter, we would expect that most of these cases will be due to use of 'traditional' methods. Indeed they are, but investigation of the circumstances of the cases reveals surprisingly high potential for reduction of failure rates on the simple basis of better information and advice to users. 


\section{Chapter 3. Family Planning Method Failure}

\section{7 he nature of the field study evidence}

While 'traditional' methods of family planning have many failures compared with other methods, in Chapter 2 it was seen that when failure is put into a somewhat broader context than is usual the 'traditional' methods compare well with theoretically safer methods. We will now present information from the field study to illustrate particular cases of method failure. Women were asked whether they had ever become pregnant while using a method of family planning, then whether they had had the baby or terminated the pregnancy, and finally what their perceptions were about the causes of their unwanted pregnancies.

Excluding women who had never given birth or never used family planning, 19 out of 113 (17 per cent) reported that they had become pregnant while using family planning. At least two of the women had more than one case of method failure. There were four reported cases of menstrual regulation or other methods of abortion following method failure. The suggestion that method failure contributes significantly to the occurrence of unwanted pregnancies and consequently to the use of menstrual regulation and less safe abortion practices is inescapable.

All but four of the cases of method failure involved 'traditional' methods of family planning. The relatively high count of 'traditional' method failures here does not reflect population relativity, since the sample included a disproportionately high number of users of traditional methods. It is a high enough number to investigate what the in-depth interviews reveal about the reasons for method failure, and a small enough number to perform the investigation on a case-by-case basis. We begin with an examination of the five cases of reported failure of the safe period method, using selective abridgments of the translated interview transcriptions to describe the cases.

\section{Cases of safe period method failure}

The following woman's experience has been classified as a failure of the safe period method, but a thorough reading of the abridged interview report illustrates the difficulty of assigning an accurate classification:

F015 (35 years old, 2 children ever born) (How the safe period method works) ... The age of my youngest child is 13 years. So long, no baby has been born due to the use of this method [i.e. after learning more correct use - see below]. ... (Reasons for using more than one method) We would practice azal while following counting of days method before, because husbands can't have patience for 21 days. When menstruation starts, if we meet any day from the beginning of menstruation to the 21 st day, we use condom. Then there is no apprehension of pregnancy. At present we are not practicing azal. We use condoms for the fear of having a baby. At present my husband is using condoms without practicing azal. Practicing of azal was difficult for my husband. ... (Advantages/ disadvantages of $\boldsymbol{a z a l}$ ) ... We should use this method after the birth of one or two children. Babies have to be taken first lest no baby is born afterwards. ... There is nothing to keep concealed. If anybody asks me, I say that we follow counting of days method. ... This is the safest method because two seeds from the male and the female do not meet together. No baby will be born if two seeds do not meet at one place. I can't tolerate pills. ... (Advantages/disadvantages of safe 
period) ... This method should be taken after the birth of babies. It will be better to follow counting of days method then. It is better to have babies at a matured age. If the pill is taken it creates delivery problems. ... I want to know, if I follow the counting of days method, will it cause any problem to me? I would listen to whatever you say. I could know it privately. I could, therefore, remember it. ... This counting of days method is good for us. The use of this method prevents birth. If pill is taken, it creates an uneasy feeling in the body. (Use of family planning before having children)... Fertility is lost if the pill is taken [immediately] after marriage. Fertility is not lost if the counting of days or the azal method is followed. ... [The safe period method] may be used after the birth of one baby. It is necessary to take a method even if no children are born. There exists peace in the family if method is taken after marriage. If children are taken quickly, bondage between husband and wife become loose. The family harmony goes astray. ... If counting of days or azal method is practiced and then given up, babies are born. If this method is adopted after marriage there is no problem during delivery. ... (Causes of unwanted pregnancies) I didn't forget to use the method. We were following 17 days' gap [since beginning of last menstrual period] and by this time I conceived. ... We thought that [a gap of] 17 days had to be followed. We came to know later on that it was not correct. Afterwards, I heard that from the first day of menstruation to the 21 st day I should avoid meeting my husband. ... If [a gap of] 21 days may be avoided properly, no baby will be born. ... Since then [since learning more correct method] we avoid sexual intercourse within 21 days. We use condom if I meet my husband during that period. ... I would follow 17 days before. Now I follow 21 days. The method remains the same.

It appears that the woman and her husband had never relied on only one method of family planning. At the time of the unwanted pregnancy they were using an incorrect version of the safe period method, intruding into the at-risk period, in combination with azal After obtaining more correct, but still incomplete, information about the safe period method, they were at the time of the survey using it in combination with condoms. The method failure occurred when they were using the incorrect version of the safe period method (with azal during the perceived at-risk period). Notice that this woman says that if anybody asks her, she says that she is following the safe period method, and does not mention the condoms which her husband buys and uses during the at-risk period. Her husband was classified as a condom user from the same sequence of questions about method use.

It is difficult to be sure whether the failure was due to the incorrect use of the safe period method, or to a primary failure of azal. This woman has since persisted successfully with use of a less dangerous version of the safe period method, in combination with condoms, for thirteen years, which means since age 22 . Her strong preference for traditional methods is obvious from the interview.

The following interview refers to two unwanted pregnancies, but only one of them was a method failure:

F033 (36 years old, 6 children ever born): - (How the safe period method works) ... I have followed [the safe period method]. But while following the method, a baby came to the belly. So, I believe that baby comes to the belly if this methods is followed. ... (Advantages/ disadvantages of $\boldsymbol{a z a l}$ ) ... Taking of pills causes a health hazard. It causes dizziness and vomiting. ... If pill is taken for 3 years it dries up the innards, no baby is born.... After marriage if the parents-in-law know about it [use of family planning], there will be a problem. The mother-in-law becomes angry if she knows about the use of pills. As pills cause dizziness, she scolds.... (Advantages/disadvantages of safe period) ... This method may be used any time during the married life if one can follow it. It is better for some to use it 
[immediately] after marriage. For some, it is better to use a method after the birth of a baby. My sister-in-law has used it and she has no problem. If properly followed, it may be used any time. ... They [FWA] do not say anything. I came to know about it from my sister-in-law. ... It would be better if I can know about this method well. It would be better if the women [FWA] tell us like you. It would be better if it is told by those who serve in family planning. ... A baby may come in the belly if it is used. Once I followed it for 15 days. So, a baby came to my belly due to the use of this method. My sister would follow this method. She didn't have any problem. Suppose I have no supply of pills now. I shall have to go to a [village] doctor. But there would not be any problem if the safe period method is followed. If properly used it would prevent birth. ... (Extent of discussion with husband) ... There was a baby in my belly. My husband told me to abort the baby. I didn't do that. ... I told my husband about the use of a method. Many children will cause problems in the family. So, I decided to take pills. ... I told my husband about my taking of pills. Once I conceived while following the counting of days method. So, both of us took the decision together to use pills. ... (Reasons for not using family planning) I take pills. Those who supply pills don't come regularly. I am ready to buy, money is not a factor. I have no pills for the last 15 days. So, I can't take pills. Now I shall go [out] and bring pills. The women [FWA] don't supply pills regularly. They come at an interval of two to three months. I conceived one more time because of not getting the supply of pills in a timely way. This time again, I am unable to take pills for the last 15 days. ... Another time I conceived because of not getting supply. Those women do not supply regularly. I dropped the method because of not getting supply, and then I conceived. My husband asked me to abort the baby, I did not do so. Now, [although] I pay for the pills still they are not supplied regularly. ... My husband tells me to take pills. My husband is also angry with the woman [FWA]. ... (Causes of unwanted pregnancies) I didn't make any mistake in using a method. ... I used to follow the counting of days method. Fifteen days after the clearing of menstruation I would not have sex with my husband. I think, I forgot to count 15 days and as I stayed with my husband, a baby came to my belly. ... A baby doesn't come if the counting of days method is properly followed. With use of this method, one can prevent birth as long as one wishes. ... I made a mistake in counting days. I can't count days properly (I don't remember). So, I took pills. ... I used to follow the counting of days method. But once I conceived. So, I started using pills after that. At present I can't take pills because of non-availability. ... Now I do not follow the counting of days method. As I forget, I started taking pills.

The first of the unwanted pregnancies, in her opinion, occurred because although she used an approximation to the safe period method in which she did not have intercourse for fifteen days after the end of her last menstrual period, she was not always able to remember to count the days accurately. She then switched to use of oral contraceptive pills, about the use of which she remained very ambivalent. The other unwanted pregnancy resulted, in her narration, from irregular pill supply but no doubt her ambivalence about pill use contributed, because she was well aware of other sources of supply. At the time of interview, she was once more without a supply of pills and was considering getting them from a village doctor. Notice that the FWA was not only irregular in her visits but also charged for a service which is meant to be free of charge.

The following case illustrates how a woman not only had a method failure with a tenuous version of the safe period method, but gave the same version to other women with the result that they also became pregnant:

F042 (35 years of age, 3 children ever born) (How the safe period method works) ... I adopted it. While following the method of safe period, I became pregnant. I thought 
it prevented pregnancy. I also advised a few others to follow the method of safe period but they also had babies. That's why I don't consider it safe. ... To me the last part of the month seems to be safe. I think there is a sexual feeling in the first part of the month. If one has a sexual feeling, one will be pregnant. But in the last part of the month, there is no sexual feeling; hence, there is less possibility of being pregnant at that time. ... (Advantages/disadvantages of $\boldsymbol{a z a l}$ ) ... Many suffer from side-effects from taking pills. Therefore, this method [azal] is good for them. At first, it is necessary to have a baby. Those who have no babies, should not follow this method. It is painful for newly-married persons to adopt this method. During this time they like to enjoy [sexual life] and be happy. At that time, it is difficult to follow this method. It does not harm health. So, I followed this method though it was painful. ... Azal is more effective in preventing pregnancy. One may be pregnant if one follows the method of safe period. Azal is safer then 'safe period'. Other methods are harmful. No problem arises from the use of azal and birth can be prevented as long as desired. ... (Advantages/ disadvantages of safe period) ... It is better to use it after one or two children are born. All use it after the birth of a baby. But those who want to have $\mathrm{a}$ [nother] baby later, follow it. Those who want to have the first baby later [delay the first baby] may not have a baby at all [if they follow a family planning method]. Therefore the safe period method should be adopted after the birth of a baby. ... One may conceive even after following the method of safe period. I myself became pregnant once while I followed this method. So I think this method is not safe to prevent birth. Many became pregnant while they followed this method. (Reasons for method choice) My menstruation is not regular every month. Many say pills regularize menstruation. That's why I am taking pills instead of [continuing to use] azal. I am taking pills to prevent pregnancy and regularize menstruation. ... (Reasons for switching from traditional method) My menstruation was not regular. I had it after one or two months. When it began, I bled too much. When I did not have menstruation, I remained in doubt whether I had conceived or not. Pills make my menstruation regular. ... That's why I am taking pills. Pills will regularize my menstruation and prevent pregnancy. (Causes of unwanted pregnancies) I thought that during the first 11 days after my menstruation [commenced], I could sleep with my husband. Accordingly I slept with him during this period and became pregnant. Now I understand that what I heard so long [the first week after menstruation stops is safe] is not correct. If it were correct, I would have not been pregnant. ... I used it as I heard it. But I can't say why I became pregnant. ... Now I think that the method of safe period does not prevent pregnancy. While I followed it, I became pregnant. Many others have also told that they became pregnant while following this method.... After that, I took up azal. During the time when I followed azal my menstruation stopped for a month or two. That's why I am now taking pills. Pills make menstruation regular and prevent pregnancy. ... Both pills and azal prevent pregnancy but to regularize menstruation I am taking pills.

Apparently, the version of the method that she was using stated that the first eleven days after the commencement of menstruation constituted the safe period, and she interpreted this to mean the first week after the cessation of bleeding. For a woman who (at least later) had irregular menstrual cycles sometimes with heavy bleeding, this version of the method could easily have intruded into the at-risk period. Nowhere was she specific about when the at-risk period ended, although she also believed that the last part of the menstrual cycle was safe because she felt less sexual desire then. After the method failure, which can only be attributed to tenuous understanding, she switched to the other main traditional method (azal) and only abandoned that in favour of pill use to regulate her menstruation. She believed that azal and the pill were equally effective. 
The consequences of incorrect understanding about the safe period method could not be more clearly illustrated than in the experience of the following woman, whose story is a startling reminder that it is lack of information that disempowers women.

F068(34 years of age, 6 children ever born): - (Advantages/disadvantages of azal) My husband sustains anguish if he drops his semen outside. I haven't heard what the religion says about it. It is rumoured that one may go off one's head when using withdrawal. ... It is better to use this method after the birth of two or three children. This method may be used at any time. However, my husband suffers discomfort in following this method. If the husband takes the pain of following this method, it may be taken at any moment for preventing birth. ... My husband is a Mullah-type person. If people come to know [that he is using family planning], they will say, 'How come a Huzur [religious leader] has done it? So, he has started to use this method [azal]. People will come to know if other methods are used. ... I have been using it for one year. It prevents birth and it is safe. I shall take pills when I recover a little, because my husband suffers from agony while dropping his semen outside. I shall take pills for this reason. ... (Advantages/disadvantages of safe period) This method may be used at any time if one wishes. But the husbands suffer from mental agony if this method is used. It may be used at any time if one can take the pains of following it. The husband suffers from mental pain while following the counting of days method. ... I don't consider it as a method because a baby came into the belly when I used this method. There is no necessity of using this method. It doesn't prevent birth. ... I came to know about it from my grandmother. I haven't heard about it from those who supply pills. ... While following the counting of days method, a baby came into my belly. So, I can't believe that this method prevents birth. I followed the method exactly as I heard about it. Even after that I conceived. ... (Extent of discussion with husband) I told my husband at first, 'I won't take too many children, I shall take pills.' I can discuss with my husband. There is no problem. ... I can tell my husband everything. I face no problem. If I need to tell anything to my husband, I can tell. ... As I would not take any more baby, I have taken this method. I am weak. It will be a problem to have many children. I will not be able to feed them and it is difficult to rear them up. For this reason I told my husband about the use of family planning. ... I took pills on my own initiative. I told my husband but he didn't agree. He said, 'If people come to know about it, they will say that the wife of a huzur has adopted a method.' As my husband forbade me, I brought the pills home without telling him. He no longer forbade me after I had brought the pills home. At present I am weak due to my illness. So, my husband told me that he has a method to use. Now he drops his semen outside. ... I suffered from paratyphoid for three months. At that time I couldn't take pills. As I am weak my husband drops matter outside. I told him that I am not taking any more pills. Then he told me that he has a method. Now he is using withdrawal. ... I have discussed about injection, pill, counting of days method, dropping semen outside and so on. My husband said, that people will come to know if injections or pills are taken. They will say, 'The wife of a huzur uses those things.' People will speak ill of us. ... My husband didn't give his consent for my using pills. I brought pills secretly. He didn't tell me anything after I had brought pills. Now, my husband adopts azal himself. ... (Causes of unwanted pregnancies) I heard my grandmother saying that on the ninth day counting from the stoppage of menstruation one can't 'meet' [have intercourse] with the husband. And when it reaches the twentyfirst day, one can't meet with the husband. If one meets on those two days babies will come into the belly. And one can meet on all the rest of the days. I met with my husband accordingly. Still a baby came into my belly I followed the method as I had heard about its use. ... I have no faith in this method for preventing birth. I conceived while following the counting of days method. Because of this I don't believe this method. None can say when a baby will come [when conception will take place]. ... A 
baby came into my belly while I was following the counting of days method. So, I took pills for some days. I have given up taking pills because of fever. Now my husband drops his seed outside so that no baby will come into the belly again. ... Since then [unwanted pregnancy] I used to take pills. I am weak due to fever. So, my husband drops his semen outside currently.

The interview notes and the translation are an accurate record of what this woman told the interview team, who discussed this case with us after the interview. While this version of the safe period method is astonishing, it is easy to see how it came into being as a result of two transformations from a version which is widespread in Bangladesh. The original version would have specified the ninth to the twenty-first day from the beginning of menstruation as the at-risk period. After being recounted and passed on, possibly many times, the "ninth to the twenty-first day had been transformed into the 'ninth and the twenty-first day' while 'beginning of menstruation' was transformed into 'end of menstruation'. By chance, the ninth day from the end of menstruation is either the day of ovulation or very close to it in a regular twenty-eight day cycle, but avoidance of only one day carries extremely high risk. The woman says she heard of the safe-period method from her grandmother.

An interesting aspect of this interview is the effect of being the husband of a religious leader on the choices which this woman felt that she could make. Even after being expressly forbidden by her husband, she had secretly brought oral contraceptives into the house, although clearly she had not then tried to conceal their use from her husband. Current use of azal was seen as a short-term measure while she was recovering from serious illness. Her husband was not interviewed so it was not possible to examine his perceptions.

Lack of information about the safe period method, and a failure with its use, did not deter another woman from reverting to its use after perceived unsatisfactory experience with other methods:

F131 (40 years of age, 3 children ever born): - (Advantages/disadvantages of safe period) ... The safe period method seems to be more safe. But pills are also safe. The safe period method, that is to have sex on specific days before menstruation returns, is safe. It has no side effects. ... (Extent of discussion with husband) I used a Copper$\mathrm{T}$ after my daughter was born. But I had a lot of bleeding; then I began to follow safe period. But I conceived my younger son. After this, I took pills but I was allergic to them. So I decided to follow the safe period method [again]. ... After discussing the use of Copper-T, I got it inserted. But it didn't suit me. We had discussion about condoms and pills. I hate condoms; my husband also doesn't like them. ... (Reasons for switching from program method) The safe period method is as effective as pills. ... I didn't have any problem in taking pills. But I had rashes after I took it. Now I follow the safe period method and face no problem. ... After my second child, I wore a Copper-T but I began to bleed profusely. Next, I took pills but I had rashes. Now I follow the safe period method. ... My husband doesn't like condoms. I am allergic to pills. These also we cannot like. My husband will not allow ligation. Therefore, we are practicing safe period. ... (Causes of unwanted pregnancies) I couldn't practise it [the safe period method] correctly. I made a mistake in counting days for the safe period. So, I became pregnant. Earlier, I used to abstain from sex during 21 days from the beginning of menstruation. Even then I became pregnant. I understood I became pregnant after 21 days. So, now I observe the first 15 days and the last 4 days [of the menstrual cycle]. ... If days are correctly counted and observed there's nothing to be afraid of. I became pregnant because I couldn't understand the method in the beginning. But now, I have been practising it for the last ten years and pregnancy is prevented. ... Yes, now I follow the safe period method in a different way. ... Yes, I have correct knowledge about the safe period and follow it in that way. 
... In the past, I followed the safe period method in a manner as a result of which I became pregnant. Now I observe it in another way. I think this is correct. I have been following it [this way] during the last 10 years. (Any other matters?) I want to know matters relating to the safe period. I want to know what days are safe.

There are several notable features in this account. One is that the method currently used by the woman appears to be a less safe version than she was using at the time of the method failure, because her current practice would definitely intrude into the first part of the at-risk period unless she regularly had very long cycles. Although she expresses confidence in her version, she appears to have arrived at it more by reasoning from incomplete knowledge than from reliable information. At the end of the interview she requested factual information. Another notable feature of the account is the appearance of contradiction in the reasons given for the method failure. At first she stated that she had made a mistake in counting the days, but then she seemed to express some certainty that the conception had taken place after the 21st day of the menstrual cycle. It is probable that this certainty should be discounted, since almost every statement made in the interview is expressed with a conviction that seems misplaced. In particular, her persistence with a method that failed and about which she remained basically uncertain is striking.

\section{$A^{\text {zal failure }}$}

In contrast with cases of failure using the safe period method, failures of azal mostly have simple explanations. There were seven reported cases of pregnancy occurring during use of the method of withdrawal ( $a z a l$ ). The first case illustrates a positive attitude towards azal even though it caused a method failure for this woman. The failure is attributed to her husband. The woman has a highly negative attitude towards the use of the injectable contraceptive which she adopted after the failure with azal.

F012 (38 years old, 4 children ever born): - (Advantages/disadvantages of azal) ... It will be better if two children are born soon after marriage and then a method is used. But it is much better to practice this method at first [i.e. after two children]. However, this may be practiced in the beginning or after the birth of two children. If oral pill is taken before the birth of a baby it creates problems at the time of delivery. ... It is good to practice azal. If azal is practiced properly, no baby is born. It doesn't create any physical illnesses. It is far better to use this method. Use of pills may cause illnesses. ... (Advantages/disadvantages of safe period) ... It is very safe. If followed properly, it prevents birth. But azal is safer because if matter doesn't go inside, no baby will be born. On the other hand, while following days, conception may take place within 20 days [interpretation: the first 20 days after commencement of menstruation constitute the at-risk period]. ... (Reasons for method choice) I mistakenly conceived before while practicing azal. For this reason, I am taking injection. No baby will be born because of its use. ... I face problem in getting injections. Twice or thrice I had to come back [from the THC] without injection. Besides, menstruation stops if injection is taken. ... It is available in the hospital. ... Twice or thrice I didn't get injection. I feel very bad if I don't get injection at the time I go. ... The supply is exhausted [stock shortage at the supply point]. Twice or thrice I had to come back without injection. Also we have to sit waiting all day long. ... Occasionally my menstruation stops because of the use of injection. Beside this, there is no other problem. ... (Use of family planning before having children) Many people say that no baby is ever born if methods are taken before the birth of a baby. It is also my conviction is that no baby will be born if the pill is taken soon after marriage. However, if azal is practiced, babies will be born afterwards. Maya Bori (oral pill) causes illnesses. ... No-one needs to know if azal is used as a method. Even if any baby is born, the pregnancy will have been delayed. ... Methods may be used 
after the birth of two children and if birth is stopped after that it doesn't matter. There will be no problem. ... If azal is practiced, there will not be any problem to take a baby later on. After marriage, azal may be practiced without taking any baby. ... (Causes of unwanted pregnancies) While practicing azal, my husband dropped matter [ejaculated] inside [the vagina]. He forgot to drop outside. So, I conceived. ... No. Azal was not practiced properly. The matter has to be dropped outside but my husband dropped inside. We gave up azal later on. ... If properly used, no baby is born. During intercourse with the husband matter has to be dropped outside. If that can be done, no conception will take place. ... I am taking injection so that we do not commit any mistake again. ... We are not going to do azal anymore. After my conception through our mistake I aborted the pregnancy with the help of kabiraji medicine. Since two months after the abortion I have been using injection. ... I have changed the method itself. I did not use the method azal [properly].

Unlike most of the cases of failures with the safe period method, failure of azal is often due to a simple mistake remembered as a single occasion. The mistake could in fact have occurred repeatedly, and a useful component of advice given about this method would be that if mistakes ever occur, in which partial or full ejaculation occurs inside the womb, the couple should be advised to use another method or to use condoms in the at-risk part of the month. In the case just described, the woman has reacted to azal method failure by resorting to the theoretically safe method of injectables, but experiences serious supply problems and irregular menstruation from their use.

The failure resulted in resort to an indigenous abortion given by a kabiraji. This type of abortion usually involves insertion of an abortifacient bark or root into the reproductive tract, a practice which can produce dire consequences for the mother as well as the fetus.

The next case also involved a radical method switch after a failure of azal:

F017 (40 years old, 5 children ever born): - (Advantages/disadvantages of azal) ... One's health breaks down if azal is used. It is better to use azal after the birth of one or two children. ... I learnt about if from a lady. That lady comes to our area sometimes. She tells us about azal. She is a Muslim woman of our neighbouring village. ... If azal is done, there is no apprehension of pregnancy. However, all the methods are alike. Every method prevents birth. ... (Reasons for method choice) [In the past] I would consider it [vasectomy] to be a good method. Now I see that it is bad. Because the health of my husband has broken down. But the advantage is that it prevents birth. ... My husband's health is breaking down day by day. It is another disadvantage. Besides I do not get satisfaction remaining with my husband. ... My husband got himself operated from the Keshabpur hospital. ... This [sterilization] is sinful. No one will get any place from God. This is sinful because once it is used, no more baby can be taken. ... (Extent of discussion with husband) ... My husband has used [sterilization] method according to his sweet will. My husband has cut his abdomen alone without informing me. He informed me after his return. ... My husband has undergone operation with the intention that if many children are born that might affect the health of the children and their mother. Children can't be educated if they are too many in number. ... We have had discussion on pill, azal, condom, injection, Copper-T. ... Sometimes he holds same opinion with me. My husband has had his abdomen cut without telling me. What can I do now? I have accepted the thing. ... (Causes of unwanted pregnancies) At the right moment he forgot to drop matter [ejaculate] outside. ... The method [azal] was not used properly. My husband forgetfully dropped matter inside my body. ... If it is used properly, it prevents birth. For this reason, the method has to be used carefully. ... So that no such mistake is committed in future, my husband got himself sterilized five months after 
my last conception. ... My husband was using azal and from that method he switched over to operation [sterilization]. ... We were careful.

In this case, the description again appears to refer to a single remembered occasion of 'forgetfulness' on the part of the husband. It is impossible to know if the plaintive 'we were careful' is accurate or not. There was no consultation between the husband and wife over his vasectomy, and she is clearly unhappy about this method now, although it should be noted that she said that before the perceived deterioration in her husband's health she had regarded vasectomy as an acceptable method.

In the next case of azal failure, the method is reported to have been followed rigorously:

F043 (37 years of age, 4 children ever born): - (Advantages/disadvantages of azal) ... I became pregnant while using azal. My husband followed it properly; even then I became pregnant. Hence, I do not trust this method. ... (Reasons for method choice) To me both pill and condom are of the same kind. Both prevent pregnancy. ... I have gastritis. Pills cause trouble. For this reason, we use condoms, I find no problem in using them. ... My husband brings pills and condoms. We have no difficulty in getting them. ... I buy pills. Hence, I have no contact with those who supply pills. I buy more expensive pills because I need pills of good quality. ... We have our own drug store. My husband brings pills and condoms from this store. I have no difficulty in getting pills. But I have gastritis, hence we use condoms. ... Pills make my head and body dizzy. I feel weak and become thin. ... (Causes of unwanted pregnancies) My husband observed it ( $a z a l$ ) correctly; still I think it was not followed properly. So I became pregnant. But my husband said be could not have made a mistake and wondered for two or three months how I became pregnant. ... My husband observed it rightly; even then I became pregnant. Hence this method for preventing pregnancy is not safe. ... I first began to take pills for preventing pregnancy. But pills cause discomfort. For this reason, my husband uses condoms.

The husband of this woman surmised that: 'Azal is not safe. An accident may occur at any time. At the time of having sex, one may not act according to intention. There may be a miss.' This comment indicates that he might have been aware that a 'miss' did indeed occur, but his wife was apparently unaware of this.

The next case of azal failure resulted in an abortion by menstrual regulation:

F050 (36 years old, 4 children ever born) ... (Advantages/disadvantages of azal) ... It is better to use this method soon after marriage. Due to azal, no damage is done to health. Use of pills causes scarring in the baby-tube [uterus] and women become fat. So, in many cases, a baby doesn't come into the belly. If azal is done, one can have a baby as and when the method is given up. ... While using this method, once I conceived. So, I think that a baby may come into the belly if this method is not followed properly. They can prevent birth as long as they wish if they can follow the method properly and if the husband can drop [ejaculate] outside properly. ... (Reasons for method choice) Azal cannot be followed properly. Many a times, while practicing azal, semen may go inside and at that time, there is every chance of conception. For this reason I don't consider this method to be a safe method. But those who can follow properly, it is safe for them. ... Pill is safe. But I have [gastritis]. So, I suffer from the burning sensation in the chest and in the belly, if I take pills. If I follow azal and if any mistake is done, I can't realise that [cannot be sure what caused it]. But if there is any mistake in taking pills, it can be detected/understood. For this reason, I have taken pills. ... (Use of family planning before having children) ... It is better to use azal [immediately] after marriage. Many people say that no baby will be 
born if the pill is taken. The baby-tube dries up. There is no apprehension of not having babies if azal and safe-period method is used. ... (Extent of discussion with husband) ... While practicing azal, a baby came into the belly. So that no other baby could come into the belly we decided to take pills. ... My husband and I took the decision together. ... I discussed about injection, that one menstruates continuously if injection is taken. On the other hand, it causes scarring in the tube and bleeding if copper-T is taken. When my husband told me to be operated on, I told him to be operated on. I didn't agree to be operated on as I am scared of it. I did not discuss any other thing. ... My husband holds the same opinion as me. For example, when I disagreed to be operated on, both of us then decided that I would take pills. ... (Causes of unwanted pregnancies) I believe that my husband could not drop [ejaculate] semen outside properly. So, a baby came into the belly. ... No baby comes into the belly if it is properly followed. If semen doesn't enter into the womb, there is no chance of conception. ... To ensure that no more baby is born, I am taking pills and giving up azal. ... When the baby came into my belly, I got MR done. And after that I switched over to pills. ... Since the performance of the MR my husband doesn't practice azal.

In this case there is again no single remembered occurrence of failure of azal. It seems more in accordance with the narration that the husband was unable to perform azal properly on more than one occasion. As has already been noted, a component of advice to couples who use this method should be that repeated mishaps should result in consideration of method change. After the pregnancy was aborted, this couple seems to have given thoughtful consideration to the choice of the contraceptive pill, which they subsequently used.

The following case is similar, in that repeated failure to control ejaculation seems to have led eventually to a pregnancy:

F069 (32 years of age, 5 children ever born): - (Reasons for using more than one method) We used to do azal before. Now I take pills along with azal. As we did azal before and as we became used to it and it has become a habit, so even if I take pills now, my husband ejaculates outside. Once while practicing azal, a baby was born, I take pills for fear of this happening again. But azal has become a habit of my husband. For this reason we use two methods at the same time. ... (Advantages/ disadvantages of $\boldsymbol{a z a l}$ ) ... Babies may be born if seed is dropped outside. For this reason I am taking pills. My husband dropped seed outside, still I conceived. The use of pills prevents birth. ... (Reasons for method choice) No baby will be born if the pill is taken. I am taking pills for this reason. While adopting azal I conceived. So, to be more sure I am taking pills. ... If I take pills, I don't face any problem. The advantage is that it prevents birth. ... [Name of FWA] comes and supplies pills. ... [She] tells me to take pills regularly. She comes regularly and supplies me pills. I have no other problem. ... [She] comes to my house at an interval of 3 months. ... I have no problem in taking pills. I had doubt in the previous method. As babies may be born, I am taking pills. ... (Reasons for switching from traditional method) As there remains the possibility of having babies if semen is dropped outside, I am taking pills. No baby will be born if pill is taken. ... The pill is better as it prevents birth. If semen is dropped outside, there is the fear of having babies. ... I told my husband that I would take the pill. My husband told me to take pills. My husband would do azal before and he does it still now. My husband thinks that a baby may be born if semen is dropped inside. ... The worker told me about the use of pills. I didn't tell her about my use of azal. Then they told me to take a method so that no baby is born and for this they gave me pills. ... (Causes of unwanted pregnancies) The method (azal) was not taken properly. My husband could not follow azal properly. I believe that for this reason the baby came into my belly. ... It will be better if husbands can follow 
this method properly. If it is not followed properly, a baby comes into the belly. ... I am taking pills so that no baby is born in future if discharged semen goes inside. ... At present I am taking pills and also using azal. In the past, I conceived while dropping semen outside. ... Now I am taking pills because I conceived while following the method of dropping of semen outside.

This interview reveals at least one valid reason, habit, for the otherwise difficult-to-explain phenomenon of use of withdrawal in combination with the contraceptive pill.

Two method failures, one from azal and the other from condom use, were reported in the following interview:

F099 (39 years of age, 6 children ever born): - (Advantages/disadvantages of azal) ... I think this method does not prevent birth. Because when the ejaculation will be cannot be foretold. ... During intercourse suddenly it [semen] can come out. If it goes inside [the womb], there will be baby. ... (Extent of discussion with husband) ... I had an ulcer in my womb due to use of CT [IUD], so I asked my husband what I can take. ... Injections cause physical stress. I had an ulcer in my womb due to use of CT. I also had an ulcer in my womb due to condom rupture. There was headache [when I took the] pill. My body became weak. I took homeopathic medicine for gastric. When I went there I found another lady taking medicine for birth control. Seeing this I asked my husband to take homeopathic medicine and he agreed. ... I don't want another baby. We don't have much property. Already we have had so many babies. If we have more babies what we will feed them? I can't tolerate any other method so I am taking homeopathic medicine. ... There was discussion about CT, injections, pills and condoms with my husband. I took them one by one and when I had a problem I discussed about a better method. At last after discussion with my husband I have taken homeopathic medicine. ... (Causes of unwanted pregnancies) Once my husband practiced withdrawal. My husband ejaculated perfectly [outside] so I don't know how I could become pregnant. I think a small portion went inside and caused the pregnancy. ... If a condom is used it protects from pregnancy. But I became pregnant by condom rupture. ... I changed the method. At first a baby came as withdrawal failed so I started using condoms. Again, I became pregnant because of condom rupture so I took CT.

This couple had problems with all the methods they tried, although the ulcerations which are mentioned might be attributable to other causes, such as reproductive tract infections. Finally the woman learned by chance that homeopathic medicine suppliers also distribute what are purported to be contraceptive medicines. ${ }^{10}$ This woman's youngest child was aged only seven months, so the potential for another method failure and the birth of a seventh child through use of an ineffective method was clearly present.

In another case (household 150) an azal method failure and subsequent abortion is recorded but no details are discussed in the in-depth interview.

\footnotetext{
${ }^{10}$ The interviewers were told of these medicines by respondents in both geographical Divisions of Bangladesh in which this study was carried out, and we obtained a package with one remaining pill from one woman. The package was a small factory-produced plastic jar with professionally-produced labelling and instructions. Each package was meant for one month of use, with the instruction to take three pills after each occurrence of intercourse. We have not had the pill analysed. Homeopathic practitioners are found throughout Bangladesh and in other parts of south Asia, using a form of medical practice derived from the tradition developed in Europe in the nineteenth century. It is likely that at least some of the contraceptive pills supplied in this way in Bangladesh are hormonal preparations, but because of their source they are perceived by their users not to have the side-effects which are widely reported for pills supplied under the family planning program.
} 


\section{$K^{\text {abiraji method failure }}$}

As has already been seen, alternative medicinal practice relating to contraception exists in Bangladesh. Besides homeopathic suppliers and practitioners, there are also 'village doctors', who are self-taught practitioners of all types of medicine including allopathic methods. There is another type of supplier called a kabiraj, who makes traditional herbal preparations using plants and their bark, roots and seeds. Some make preparations which they claim will prevent pregnancy, and a number of cases of failure of this type of method were narrated to us. The first case was not complicated:

F053 (34 years of age, 3 children ever born): (Causes of unwanted pregnancies) It cannot be relied that this kabiraji medicine prevents birth. The kabiraj provides kabiraji medicine to earn money. ... I have started taking pill after delivery of the child so that there is no further mistake in the future. ... Yes, I have not taken kabiraji medicine any more. Soon after the baby was born I have changed the method and started taking medicine [effective medication]. ... Now from the pill I have switched over to [using] the safe period method.

Although this woman now perceives the use of kabiraji preparations to have been fraudulent, it was not a case of a once-only experimentation that failed. At the time of the first use of a kabiraji method she had one child, and had not used a method previously. Besides the pill, she had at one time used injectables. Since it was the third child which resulted from method failure, according to the narrative, it seems that the second child was planned and there had been no failure during her first use of the kabiraji preparation.

The case of this woman is far more interesting from another aspect. It will be noted that she subsequently gave up modern methods in favour of what she calls here the 'safe period method', but which is actually use of the safe period in combination with use of condoms and azal. Further discussion of such cases is in Chapter 4.

The following abridged interview report refers to two method failures, one with the safe period method and one with a kabiraji preparation (referred to as 'indigenous medicine'). The passing reference to a safe period method failure, near the start of the in-depth questions, was not followed up in the later part of the interview, where the failure with indigenous medicine is discussed.

F063 (29 years of age, 3 children ever born): - (How the safe period method works) ... To me it is not reliable. Only the oral pill suits me. The methods like safe period and azal did not suit me. Conception must take place. I have observed that conception takes place during the safe period also. I followed the safe period method and I got pregnant. ... (Advantages/ disadvantages of safe period) ... It can be adopted in old age. It is beneficial at that stage. During youth, the husband does not agree to practice safe-period method. ... I don't believe that this is a safe method. Does the safe period method ever prevent birth? No, it doesn't. ... (Reasons for method choice) While using injectables, I used to have ache in my waist. Indigenous medicine doesn't prevent birth. But pill prevents birth. Other problems are not caused. ... Due to pill use, I am menstruating regularly. There is no ache in the waist. Pregnancy is prevented. ... (Reasons for switching from traditional method) After the use of indigenous medicine for nine months I conceived. For this reason, I have no faith in the indigenous medicine. So, with a view to preventing birth, I have been using the government method [oral pill]. This will prevent birth. ... Pill use will prevent birth. No method suits my health. But as I have to prevent birth I am taking oral pills. ... My husband doesn't believe in kabiraji medicine. For this reason both of us unitedly 
decided that the oral pill would be better for us. ... When I started to use indigenous medicine, the field worker told me that indigenous medicine would not prevent birth. But I did not pay any need to her words. Later on, I conceived and had it washed [MR]. Now I am taking oral pill. ... I conceived while I was using indigenous medicine. ... (Causes of unwanted pregnancies) Indigenous medicine can not be relied upon. Government methods are the best. ... I gave up using indigenous medicine and at present I am taking pills. ... I will never use indigenous medicine again in my life time.

It is unfortunate that the mention of a safe period method failure was not followed up later in the interview, because as the cases discussed earlier demonstrate, it is difficult to know whether a failure attributed to use of the safe period method is because of incorrect knowledge about the method or a conception during the at-risk period. This woman's knowledge about the safe period method was classified as only partly correct, and her husband's knowledge as incorrect, so a failure due to misinformation seems likely.

This woman had cast around for a suitable method to use, and eventually settled on the oral pill as the least of the available evils. Her use of a kabiraji method (in the face of opposition from her husband and the FWA) resulted in her having menstrual regulation.

Another woman who had a kabiraji method failure was currently pregnant after abandoning family planning method use. This case illustrates the broader sense of method failure in which perceived method side-effects lead to the abandonment of family planning method use and lapse into unwanted pregnancy.

F142 (36 years of age, 7 children ever born): - (Extent of discussion with husband) I don't talk to my husband about any method [of family planning], because my husband is not ready to listen to anything about family planning. ... I can talk to my husband about all things. I will not feel shy. But I don't discuss family planning as my husband doesn't like to listen to anything about family planning. ... Those who supply pills [FWAs], they tell me to use a method. At first I took kabiraji medicine. While using it, I conceived. For this reason, [since then] I used injections, but they caused a burning sensation in my body. So, then I took pills. But use of pills caused dizziness. So, I have given up using pills after four years. I am pregnant at present. I wanted to use a copper-T. But the doctor at the hospital told me after examination that a copper$\mathrm{T}$ can't be given to me. ... I have taken these decisions myself. That is because my husband is not ready to listen to anything about family planning. He says that the strength of the family will increase if many children are born. Even now I don't find any strength in my body. ... No discussion was held with my husband on the use of any method. My husband does not like to discuss it. ... My husband does not hold the same opinion as me. My husband wants to have as many children as may be born. ... (Causes of unwanted pregnancies) I used to use kabiraji medicine, I used to take tablets made of indigenous herbs on empty stomach twice a week on Tuesday and Saturday. While I was taking kabiraji medicine, I conceived. For this reason I think that kabiraji medicine doesn't prevent birth. ... After the birth of that baby I had been to the hospital and took injections at first. As that didn't suit my health, I used pills. Pills also don't suit me. What else could I do? I went to the hospital and the doctor [FWV] examined my leg and said that I wouldn't be able to use a Copper-T, because I have varicose veins. As a result of not using any method, I have become pregnant again. ... Since then [when I became pregnant] I gave up using the pills made of herbs and started taking pills and injection. ... Since then I don't take herbal pills any more.

There was nothing complicated about the failure of the kabiraji method. The interesting aspects of this woman's story relate to her subsequent attempts to find an effective method of 
family planning suitable for her. There is every indication that her attempts were committed and with urgent intent, given the large number of children she had already had. The refusal of the family planning program to give her an IUD on the basis of a spurious contra-indication has no independent verification from the FWV responsible, and it is possible that some other contra-indication was the reason.

Because the role of this woman's husband is reported in a very negative light, we should take the effort to report his side of the story:

M142: - (Discussion about number of children) Who says discussion is not held? Both of us discussed [use of family planning] two years ago and started to use a method so that no more babies are born. But because of not taking the medicine [pills] properly, my wife has become pregnant now. ... The FWAs/FWVs do not come at all. So, what will they say? During the last year, they came twice only. But they don't say anything and they don't give any medicine. ... (Male involvement in family planning) The husband should also participate. In order to prevent birth both of us talked together and we used a family planning method. ... In the past we used a method after discussion. She used to take pills, she also took homeopathy medicine. But as pills were not available, she discontinued their use for some days and now my wife has become pregnant.

He shows a higher level of concern about his family's situation than the woman's story would have led us to expect, but nevertheless the man's report of discussion about use of a method 'two years ago' tends to confirm rather than refute the woman's assertion that it is difficult for her to discuss family planning with him. He has no apparent knowledge of the woman's use of injectables as well as pills, nor of her unsuccessful attempt to obtain an IUD. His perception that the woman became pregnant because of pill supply problems, rather than discontinuation because of side-effects, should possibly be discounted in view of his low level of knowledge about other things. Whatever is the truth about the main reason for discontinuation, there is still a failure of the family planning program to assist a woman in urgent need.

If the man had given more support his wife's attempts to limit the number of children, could it have made a difference? There are very many ways in which greater involvement by him could have assisted the woman. For example, if pill supply was a problem, he could have bought pills from the market or pharmacy. If his wife could not obtain a method that was suitable for her, then he could have considered use of a 'male' method, condoms or vasectomy, or a 'traditional' method. He could also have given support to her to obtain sterilization, if they both agreed on that course. While it is invidious to give gratuitous advice in the absence of a more detailed knowledge of the particular circumstances of this man and woman, there can be little doubt that greater involvement by this man could have assisted them to achieve a better outcome.

\section{$\boldsymbol{B}^{\text {ursting condoms }}$}

One case of failure with use of condoms, attributed to rupture, has already been discussed. In that case, the woman had also had an azal failure (F099). The following account also attributes pregnancy to an instance of condom rupture:

F078 (44 years of age, 7 children ever born): - (Reasons for method choice) ... I had small children. In case another conception occurred, my husband had secretly undergone operation [sterilization]. Sometimes conception may occur if the condom bursts. One day a condom did burst and I conceived. So, he had undergone operation. ... After the operation now my husband has irritation in his penis. During intercourse 
my husband sometimes has erection failure. I do not get proper satisfaction. ... My husband used to buy condoms from the market. Now-a-days, pills and condoms are distributed to households. But in the past was there any system like this? Now-a-days, this system of distribution is in practice but in the past was it in practice? My husband had undergone operation at the Khulna Sadar Hospital. ... The house of the person who supplies pill is nearby. I meet her always. My husband had undergone the operation long time ago, so now she does not come to me about any methods. ... Now-a-days injection is available but in our time it was not. At that time women also did not visit households. ... The worker comes monthly. ... I was about to die after taking the pill. I could not eat, I used to have dizziness. I conceived as a result of a condom bursting. So, my husband underwent the operation. ... (Extent of discussion with husband) ... My husband did not inform me about his operation. I have already had too many children. Every year I was giving birth. My health did not permit. Then without informing me my husband underwent operation and then told me. ... Every year I was having a baby and it died. My physical condition was getting worse. That is why husband adopted the method. Besides it is difficult to educate and feed them. We will not take any more children, that is why my husband had undergone operation. ... Without informing me my husband had undergone the operation but later on told me. I also agree with this. ... (Causes of unwanted pregnancies) I think the conception occurred as a result of a condom that burst. ... I used to think the condom to be safe but now I do not think it safe anymore. ... After that we have become careful. My husband himself underwent the operation after our youngest son was born. ... My husband underwent the operation and stopped using condoms. ... Now condoms are not used anymore, since my husband had the operation.

Notice the reference to side-effects of the oral pill, which apparently resulted in use of condoms instead. After the method failure produced the seventh child of this couple, the husband had a vasectomy, according to the woman's report. The interesting thing is that he said no such thing. He said he took kabiraji medicine which was supposed to have a sterilizing effect.

The next example also involves a burst condom. This woman and man had had long experience with effective use of family planning, beginning with use of an IUD to space their first and second children, and again the second and third children. Due to what is undoubtedly a genuine side-effect, profuse bleeding, she eventually gave up IUD use after at least two episodes of use, and tried other methods. At the time of the survey she and her husband were using a version of azal in which they used condoms on some occasions to ensure that no accidental ejaculation occurred in effecting withdrawal.

F140 (28 years of age, 4 children ever born): - (Reasons for using more than one method) When my husband feels unwell, he uses a condom on that day. But while using the condom, we still use azal. The skin of his penis gets bruised due to the use of condom. For this reason my husband doesn't use condoms throughout the whole month. We use the method azal during the whole month. But if my husband feels a problem ... in doing azal, we use a condom at that time. ... (Advantages/disadvantages of $\mathbf{a z a l}$ ) ... There is apprehension in the practice of azal on many occasions, if the husband cannot control himself properly. But there is fear in the use of condom also. Azal is a safe method if it is followed properly. ... (Extent of discussion with husband) I can initiate discussion about the methods of family planning. I said to my husband, 'My health has broken down because of using pills. Now you should use condoms.' ... I can discuss about all the methods. There can't be any shyness in discussing with the husband. ... After the birth of the first baby, I used a Copper-T. After the removal of the CT, another baby was born. Then I used a CT again. After the removal of this CT, I had another baby. Then I used pills, which 
caused me dizziness. Then I asked my husband to do azal. And it caused a problem. Now I am also using condom. ... The opinion of both is needed. Over and above [his opinion], my opinion is more important. ... We discussed adopting condoms and azal together. We also discussed about tubal ligation, but he can't hear about ligation. ... My husband holds the same opinion as me. Whatever method I take, I take it by discussing with my husband. ... (Reasons for switching from program method) There was nothing to be scared of in the use of CT. We had the confidence that it would prevent birth. The pill also gave similar confidence. But now I am scared of using azal and condoms. What if a baby is born [conception takes place] suddenly? Because sometimes my husband can't control himself. ... My husband has a problem in practicing azal. On the other hand, the skin of his penis gets bruised if a condom is used. The use of a Copper-T didn't cause any problem to my husband. But I used to bleed profusely. I had dizziness after I had used pills. For all these reasons, we are compelled to use azal. ... The use of pills used to cause dizziness to me. There was a burning sensation in my body. The doctor said that I had an ulcer. No, the condom burst and a baby was born. I used a CT and that would cause me profuse bleeding. In spite of that I continued to use the CT for some time. ... The doctor said that injections could not be taken as my health was weak. [Another] CT also could not be used due to this weakness. I have a condition of the cervix. That's why we're forced to use azal. ... I have told my husband, 'I can't tolerate any government method. You can use azal.' So, my husband is practicing azal. He also wants to avoid having many babies. ... (Causes of unwanted pregnancies) ... A condom burst and a baby came into the womb. Use of condoms is dangerous. Condoms may burst out at any time.

The woman seems well justified in being apprehensive about another method failure, because she has apparently already had a condom failure and her husband could not always avoid ejaculation while using azal. Their contraceptive history has the hallmarks of conscientious attempts on the part of both to avoid having too many children, yet she is still less than 30 years old and they clearly remain at risk of having more than four children.

Reference to 'burst' condoms, also translated as 'ruptured' condoms, was recorded in twelve of the interviews with women and eight of the interviews with men in this study. There was not a single case where both the man and the woman from one household mentioned this phenomenon, including the three households $(078,099$ and 140) where 'burst condoms' were said to have caused pregnancy. So what did these men say? All three said they had used condoms, one said he had also used the safe period method and kabiraji methods, one said he had also used the safe period method and azal, and the third said he had previously used azal. All three said they had also used the oral pill and two said they had used injections, but no other modern methods were mentioned except menstrual regulation in one case and IUD use in another. Of the three men, one said that he was still using condoms. (This is in agreement with his wife's report, although she added that he also practised azal.) This is what he said:

M140: - (Discussion about number of children) I don't want any more babies. Both of us have decided together that the three sons which Allah has given us are enough. Both of us decided that we would use a method of family planning. I have been using a method for the last five years since the birth of my youngest son. ... (Male involvement in family planning) After the birth of our youngest son, we decided that we would use a method. At first I used to practise azal. Then she used a coil [IUD]. But the coil created a problem for her and she then started to take pills. But pills also didn't suit her health. Since then, I have been using condoms for the last four years. ... (Reasons for method choice) The use of condoms prevents birth. No problem is caused. I have been using it for the last four years. No problem of any sort was created. ... There is no problem in its use. Her health started to be reduced due to the use of pills. So, she gave up use of pills and I started to use condoms. Condoms 
cause less problem. ... My wife goes to the hospital [FWC] and brings condoms. They [FWAs] come after two or three months. When they come, they supply them. ... If [name of FWA] fails to supply, my wife goes to the hospital and brings condoms.

If this hardly sounds like the account of a person who has had a condom method failure, then that is precisely the point that we want to make. There is little disagreement with his wife's account, except for her claim that they had a condom method failure due to rupture. We should consider the similarity between breakage of a condom and azal failure. Both have the same effect, namely unwanted release of semen inside the woman's reproductive tract. Nothing is said about use of condoms in the other two male interviews, but neither man had recently used them. In Chapter 4, we discuss the possibility that 'conventional accounts' are sometimes given to explain events which in some way confront social conventions. Without doubting that condoms sometimes burst, we leave open the possibility that accounts of rupture might sometimes be a cover for something else.

\section{Qther method failures}

While modern method use does carry with it the risk of failure, the following instance of conception after use of the oral pill can hardly be called a failure of the method:

F054 (21 years of age, 2 children ever born): - (Reasons for method choice) I am comfortable with Copper-T [IUD]. I can be anxiety-free for 10 years. I have no physical problem as well. Like the other methods, this method is free from apprehension. It prevents birth and there is no chance of conception. ... I took the Copper-T from a clinic. ... [Name of FWA] doesn't come to my house now. She doesn't take care of me any more. She used to come before. She used to come at an interval of 3 months. But she hasn't come to my house for the last 5 or 6 months. ... When I used to take injections, I would feel pain in my body and in my waist. I would vomit. It was unbearable. Use of the pill would cause dizziness. Now I am fine. ... (Reasons for not using family planning during amenorrhoea) During the first month there was no menstruation and so I didn't use any method. I met with my husband. Then I had menstruation and during the first month I thought that no baby would be born. So, during that month I met with my husband. For one month I didn't stay with my husband. After the baby was born, my husband was not at home. ... No. After the birth of a baby no baby will be born if there is no menstruation. I dared to think that there will be no be conception within one month after the birth of a baby. For this reason, I didn't use any method for about a month after menstruation. ... (Causes of unwanted pregnancies) Occasionally I would discontinue the use of pills willingly. ... I didn't follow [pill use] properly. Because I would suffer from dizziness. I would take the pill on the night I met my husband. ... One may remain free from anxiety for 10 years if Copper-T is used. There is every chance of conception if other methods are used. This method is safe. But if pill is taken properly it prevents birth. ... I have used another method (Copper-T) so that nothing like this happens in the future. ... I have ... given up pills. ... I did change my habit. Later on [after the failure], I took pills regularly.

Notice that both children of this young woman were apparently born after risk-taking behaviour, but after their births she has taken more stringent steps to avoid further pregnancies. A lackadaisical approach to contraception can be adopted by a young woman for the simple reason that she wants to have children at some time and so it does not necessarily matter to her if they come in a less planned manner. This woman's account is a very good example of progression to stricter use after the birth of children.

One case of failure with use of an IUD was reported: 
F087 (27 years of age, 2 children ever born): - (Reasons for using more than one method) ... When menstruation ends, there is the apprehension of conception if one meets with the husband after twelve or thirteen days so, if we need to meet during these twelve or thirteen days, we use condoms. There is no apprehension of having any baby during the rest of the days. So, we don't use any condom during the period even if we meet. My body remains unholy for 7 days starting from the day of menstruation. I don't have intercourse during that period. ... As husbands don't agree to wait for 21 days, we use condoms if we meet during this period. If condom is not used at that time, conception will occur. ... (Reasons for method choice) The use of pills and injections fattens the body. But I don't face any problem with condoms. I conceived even after the use of Copper-T [IUD]. There is no fear in the use of condoms. So, my husband is using it. ... [Name of FWA] supplies it [condoms] every month. My husband buys it from the shops. ... The use of pills fattened my body and I had dizziness. Use of injections also fattened my body. A baby came into my womb while there was a Copper-T in my womb. ... (Extent of discussion with husband) At first my husband said that he would use condoms. I did not understand anything about it in the beginning. When I menstruated, my husband told me that I would face problem if I had conceived then. So, we used condoms. Then I used Copper-T. But I conceived after the use of Copper-T. Finally I took pills and injections. But my hands and legs swelled and I had dizziness and felt weakness. Since then we have been following the counting of days method along with condoms after discussing with my husband. ... I had discussion [with my husband] about condoms. My husband brought pills for me. My husband told me about the Copper-T. He said, 'I have heard that the Copper-T is safe.' So, I used the Copper-T. My husband talked to a doctor and then after discussion we decided to use injections. We also had discussion about the operation [sterilization]. But my husband said, 'We'll never do all that.' A baby came into my womb and when a doctor advised us that the baby may be crippled if medicine was used, we both discussed and then aborted the baby. ... (Causes of unwanted pregnancies) In the hospital they [FWV] told me that the Copper-T might have not been inserted properly. Maybe it went to a corner of the womb. Had it been inserted properly, it wouldn't have created problems. A baby wouldn't have come into my womb. Birth is actually prevented if the Copper-T is used. I think the insertion of my IUD was not done properly. ... At present we are using condoms. But I think that for the conception, the Copper-T was not responsible. I conceived due to the wrong insertion of Copper-T. ... I may again use a Copper-T in future.

As in so many of the cases that have been discussed in this chapter, there are several notable features in this Hindu woman's description of her experience. After what appears to have been a simple case of IUD failure, she is now using the safe period method and condoms if she has intercourse during the first 21 days of the menstrual cycle. The progression from a method that is theoretically highly effective, but failed, to hormonal methods which she says caused side-effects, and then to a variant of the safe period method was not the result of disregard for the effectiveness of IUD use. It was based on rational choices, by the woman and her partner, about suitable contraceptive methods. She was considering using an IUD again.

$D$

iscussion

Accounts of method failure given during the field study enable an assessment of how failures occur. The five narratives about failure of the safe period method, for example, reveal two aspects which deserve further attention. 
The first is that the users of the method who experienced failure had at best a tenuous grip on the details of the method, and in one case the woman's understanding was so amiss that it would be comical if the consequences had been less serious. In Chapter 5, we will examine the general level of understanding of the safe period method found among respondents to the study. Anticipating the results presented there, it is possible to state in advance that for most couples who have even partly correct knowledge about it, the versions of the safe period method which they employ would almost force them to use the method in combination with some other method. There is no doubt that this often occurs. This leads to the second observation, which is that when the safe period method is used in combination with other methods (and it must be used in combination much more often than is reported), it is difficult to know to which method a failure should be attributed.

It is lack of information which is at the base of these problems, and we will return to this point several times in this report.

By contrast with safe period method failures, failures of azal are less difficult to interpret. There were seven accounts, and they can be divided into two basic groups. In the first group are cases where a single remembered occurrence of failure resulted in pregnancy. In the second group are cases where repeated failure to control ejaculation seems to have characterized use of the method by the couple. As noted earlier, people who use this method should be advised that if they have difficulty using it properly they should discontinue use.

Failures of kabiraji methods were also reported. Without knowing the pharmacological properties of preparations given by traditional practitioners in Bangladesh, it is difficult to be judgmental about their efficacy, but some of the women who had experienced failures were not hesitant to make their own judgments.

Condom failures were all attributed to rupture. While it is certainly possible that rupture is the explanation in all cases, we have raised the possibility that in some cases this is a conventional account of another type of event (namely azal failure). The concept of conventional accounts is discussed in greater detail in the next chapter of this report. It refers to explanations which do not confront social norms as much as the truth does.

There were two other cases of modern method failure, one with the oral contraceptive pill and the other with an IUD. The IUD failure was apparently one of the rare genuine cases, but the failure of oral pill use could hardly be attributed to the method.

Doubts have been raised in this chapter about what people report their current method of family planning to be. These doubts are serious enough to warrant an investigation in the next chapter to resolve the conflicting stories given by men and women. 


\section{Chapter 4. Reported Family Planning Method Use}

\section{' What method of family planning are you using?'}

A premise of the entire program of Demographic and Health Surveys (DHS), before them Contraceptive Prevalence Surveys (CPS) and before them World Fertility Surveys (WFS) carried out in most developing countries at intervals during and since the 1970s, has been that a universally-applicable set of questions can be asked to women to get an accurate answer to this question. The questions have been asked with little variation from a basic formula derived for the WFS. Women were asked first which methods of family planning they had heard of, prompted for any that they omitted to mention, then asked which of the methods they had heard of that they had ever used and finally which methods they were using at the time of the interview. ${ }^{11}$

The list of methods used for prompting and to determine which methods have ever been used, is also given in a fixed order. Modern methods beginning with the oral contraceptive pill are at the top of the list and 'traditional' methods at the end. For instance, in the DHS survey conducted in Bangladesh in 1993/1994 (Mitra et al., 1994), the following order was used: ${ }^{12}$

1. Oral contraceptive pill

2. Intra-uterine device

3. Injectable contraceptive

4. Condom

5. Female sterilization (tubal ligation)

6. Male sterilization (vasectomy)

7. Periodic abstinence

8. Withdrawal

9. Other (to be specified)

A current survey in Bangladesh, the 1996/1997 DHS, uses the same list of methods with 'Implant, Norplant' added before condom and 'Menstrual regulation' added before 'Periodic abstinence'.

There can be little doubt that this approach produces consistency between countries and between different surveys conducted in a single country. Whether the approach produces accuracy or not is quite a different question. ${ }^{13}$ For example, it was noted in the report of the 1993/94 Bangladesh survey (Mitra et al., op. cit.: 124) that the same sequence of questions asked to a sub-sample of husbands produced answers that were markedly inconsistent with their wives' answers. There is no need to reproduce the details here since an extremely similar pattern of inconsistency was also obtained in the 'traditional' family planning study, and is discussed extensively in this chapter.

The paradigm is so well-established that almost no criticism can be found. In an assessment of data quality in the DHS surveys (Arnold, 1991), the questions on method use are not even mentioned. We took quite a different approach to the questions, in which respondents were given descriptions of the 'traditional' methods before being asked if they had ever heard of

\footnotetext{
${ }^{11}$ The original version is set out in the core documentation for the World Fertility Survey (1975).

${ }^{12}$ This corresponds to the order prescribed in DHS-II Basic Documentation Number 1 (IRD/Macro, 1990: 24-25) except that it omits the item 'diaphragm, foam, jelly' :

${ }^{13}$ Originally the approach was not expected to produce accuracy. As noted in the core documentation for the World Fertility Survey (1975: 14), 'the data collected here will be of primarily descriptive rather than analytic utility, because both the "ever heard of" and the "ever use" questions are imprecise'.
} 
them, and we did not seek to obtain so-called unprompted responses about whether respondents had ever heard of any methods. If a respondent had not heard of some method, again descriptions were given to make sure. Moreover, since we felt that the relegation of the 'traditional' methods to the end of the list of methods was one factor contributing to underreporting of their use, we elevated them to the beginning of the list. We also encouraged respondents to reveal if they were using a combination of methods. Both men and women were asked the same questions (question numbers 301 to 315 in Appendix One and Appendix Two).

There were many instances in the survey where there was fundamental disagreement between man and woman over which method of family planning they were using, even with the modified approach. Most of these disagreements involved the direct methods. Excluding 35 interviews where either the husband or the wife was not interviewed and 4 cases where the woman was pregnant, there were 124 matched interviews. In 71 cases (57 per cent), the man and the woman either agreed that they were not using any method of family planning (19 instances) or else they agreed on the method or methods that they were using (52 instances). There were another 15 cases (12 per cent) where there was agreement on at least one method but other methods in current use were mentioned by at least one of the partners. This leaves 38 cases ( 31 per cent) of apparently fundamental disagreement between the man and the woman about whether they were using any method at all (17 instances) or where the woman said she was using one method and the man said he was using a different method (21 instances). Even if we had been expecting that there would be some disagreement, its extent is large and requires investigation before the information can be used.

While the survey was being conducted, it was common to find the male and female interviewing teams reporting quite different stories from each of the marriage partners. It was sometimes obvious that something had been held back by at least one of the partners. To take one example, after the conclusion of his interview before his wife's had concluded, one male respondent intruded into his wife's interview, asked her what she had told the interviewers about method use, then came back to the male interview team and said that 'sometimes' he also used condoms.

We must stress that the degree of care taken in determining method used was at least as great as in other surveys and greater than in most. If subsequent in-depth discussion about method use resulted in the discovery of error in the earlier responses to questions, the errors were corrected wherever possible. Apart from a few cases where the man's responses could not possibly be reconciled with those of the woman, it is possible to determine how most of the discrepancies could have occurred, and in this chapter we will investigate individual cases in detail to show this. We will conclude that the usual survey approach used to determine method of family planning is fundamentally flawed in the case of users of direct methods (safe period, azal and condoms).

It is useful to examine first the cases where there was complete agreement between the man and the woman about whether they were using a method or not, and which method they were using, before examining the cases where there was only partial agreement or no agreement at all.

\section{Statements about family planning methods: complete agreement between man and woman Sabout method(s) in use}

As discussed earlier in this volume, the term 'direct methods' refers to family planning methods which have a direct relationship to the occurrence of sexual intercourse. Other methods, including all program methods except condom use, are called 'indirect methods'. 
Most of the users of indirect methods agreed about which method they were using, and most of the users of direct methods did not, as shown in Table 4.1.

Table 4.1. Methods of family planning used, according to female and male respondents

\begin{tabular}{|l|c|c|c|}
\hline Method & $\begin{array}{c}\text { Both woman and } \\
\text { man report use }\end{array}$ & $\begin{array}{c}\text { Only woman } \\
\text { reports use }\end{array}$ & $\begin{array}{c}\text { Only man reports } \\
\text { use }\end{array}$ \\
\hline Safe period & 6 & 19 & 25 \\
\hline Azal & 9 & 28 & 18 \\
\hline Kabiraji method & 3 & 7 & 26 \\
\hline Oral pill & 15 & 21 & 3 \\
\hline IUD & 2 & 2 & 13 \\
\hline Injection & 12 & 12 & 2 \\
\hline Condom & 7 & 16 & - \\
\hline Tubal ligation & 2 & 2 & 1 \\
\hline Vasectomy & - & 2 & 21 \\
\hline Other & - & 31 & 2 \\
\hline No method & 19 & 2 & .
\end{tabular}

Note: Multiple responses are recorded where more than one method of family planning was reported.

There were no current users of Norplant or MR.

This pattern is extremely similar to that reported by Mitra and his co-authors (op. cit.: 124) for the 1993-1994 DHS. They drew particular attention to the large discrepancies in reported use of the oral pill, mainly because in the population at large pill users are a much higher proportion than they are in this study, so the effect of the discrepancy is to cast doubt on the size of the major component of contraceptive prevalence. However, it can be seen that in the case of users of pills, IUDs and injections, which are the main indirect methods in use by the family planning program, a majority of both female and male users agree with their partners about their use of these methods. This is not so in the cases of users of any of the direct methods, including condoms. The disproportions are just as great in the DHS data.

A preliminary conclusion from this is that neither of the devices used in the study to enhance response by users of 'traditional' methods (placing them at the top of the list of methods, and giving respondents information about them) achieved the goal of enhancing response compared with other survey approaches. While the approach used did have other objectives, it seems that the reasons for discrepancies between women and men in reporting family planning methods have explanations other than the explanations we presumed.

Where both woman and man agreed on the methods of family planning that they were using, only four reported use of more than one method. All of these said that they used the safe period method in combination with azal. Another two couples reported use of the safe period method alone, and four more reported use of azal alone.

The statements of women and men are in solid agreement in each of the four cases where the safe period method is combined with use of azal:

F019 (38 years old, 7 children ever born): - (Reasons for using more than one method) Why do we do that? While following the counting of days method, if I 'meet' my husband [have intercourse], conception may occur. For this reason we drop [the semen] outside. 
M019 (46 years old): - (Reasons for using more than one method) I follow the counting of days method. Together with that, we practise azal when we feel extreme desire [for sexual intercourse during the danger period].

F039 (34 years old, 3 children ever born): - (Reasons for using more than one method) My husband doesn't [always] want to follow the counting of days method. So, when my husband comes to me at that time [the danger period] my husband drops [the semen] outside.

M039 (39 years old): - (Reasons for using more than one method) I follow the safe-period method. The days when there is every chance of conception if we meet, if I feel like 'meeting' during those days, I practise withdrawal. But enough satisfaction can't be had from this.

F102 (42 years old, 7 children ever born): - (Reasons for using more than one method) I follow [a safe period of] ten days from the beginning of menstruation. After that my husband thinks that there may be pregnancy so he ejaculates outside.

M102 (63 years old): - (Reasons for using more than one method) For the convenience of intercourse, to follow the safe period I practice azal on some days. So that there remains no problem to have intercourse any time and the safe period is also followed I check and do azal.

F103 (29 years old, 2 children ever born): - (Reasons for using more than one method) I maintain the days [use the safe period] because I don't want to have babies. If I have sex while maintaining days, then I do azal. The last three days of the month are safe, but if I have sex during the other 25 days, then I use azal.

M103 (35 years old): - (Reasons for using more than one method) The reason is that people are always willing to know how they can have physical relationship at any time. If these two methods [safe period and withdrawal] are followed at the same time then there is no restriction to have physical relationship during married life. Health is maintained. It [this method] does not need to be eaten like the pill or used like a condom, there is no problem in it. For all these reasons I use these two methods at the same time.

It is clear from these accounts that one very good reason for the use of these two methods in combination is incomplete understanding of the at-risk period, and consequently a need to use some way of avoiding pregnancy during very long periods of the menstrual cycle perceived to constitute the 'danger period'. None of the four women was classified as having more than partly correct knowledge of the safe period, although two of the husbands (039 and 103) were classified as having correct knowledge, defined as recognizing the existence of an at-risk period of reasonable duration in the middle of the cycle.

Of the two couples who said they were using the safe period method and nothing else, in one household (number 024) the man had no correct knowledge about it and the woman's version (first sixteen days unsafe) was marginal at best. This couple is possibly not fully committed to avoiding further pregnancy:

M024 (35 years old): - (Reasons for switching from program method) ... But sometimes she says that she wants to have one more child and will not use any method. I say, 'There is no need for another child.'

In the other case where only the safe period was used, the woman's understanding of it seems at first reading to be puzzling, while the man has a frequently-found pattern of incomplete knowledge: 
F081 (41 years old, 4 children ever born): - (How the safe period method works) There's no physical change in me. But ten days after menstruation has ended there is white discharge and I don't conceive then. I have white discharge ten days after menstruation [The woman's menstruation lasts four days.] On the fourteenth day after the start of menstruation the matter which causes conception comes out. After that if [a woman] has sex with her husband, she doesn't conceive.

M081 (75 years old): - (Advantages/disadvantages of safe period) ... This is completely safe. Following this method will prevent birth. Paddy is grown as we plough the land, this is similar. If one abstains from having sex at these time birth will be prevented. The few days after the twentieth day [from the start] of menstruation are safe.

The woman's account seems to be the only one in the entire study where any mention of a physical change at the time of ovulation is mentioned. The reference to 'white discharge' occurring every cycle at around the fourteenth day is almost certainly a reference to the changes in the cervical mucus at that time. Even if she is wrong about what its function is, her ability to observe it would certainly be helpful in identifying the end of the at-risk period. The excerpt from the man's account evidently refers to use of the safe period method without any other methods. The man is elderly.

Among the cases where azal is reported to be used without any other method, the first case refers to a young couple who have not yet had children:

F016 (17 years old, no children): - (Advantages/disadvantages of azal) ... Azal prevents birth. It is better to do it now. For young people ['at a tender age'] it is better to delay child birth by using this method. It prevents birth.

M016 (26 years old): - (Advantages/disadvantages of $\boldsymbol{a z a l}$ ) ... There is no need to take pills. It $[a z a l]$ is convenient. Moreover, birth is being prevented by its use. I am using it and I am not having any baby. Others who have married at the same time as me have had babies but as I am using azal I am not having any baby.

As noted elsewhere in this volume, one of the 'traditional' methods can be used before the birth of any children without any apprehension of risk about method failure, because even though they may wish to delay having any children the occurrence of a pregnancy will be a joyous event.

There were two cases of apparent use of withdrawal over a long period of time without any mention of concurrent use of other methods, and one case of very temporary use because of illness:

M062 (48 years old): - (Advantages/disadvantages of $\boldsymbol{a z a l}$ ) ... Why should we use this method if it is not safe? This method prevents birth. Semen does not enter the womb. I have been using this method for the last eight years.

F065 (34 years old): - (Advantages/disadvantages of $\boldsymbol{a z a l}$ ) ... If a person practices a method, that method is safe for that person. I practice azal, it is safe to me. I have not had any babies for the last fourteen years by practicing this method.

F089 (22 years old): - (Advantages/disadvantages of azal) ... Withdrawal also is not safe. A problem may be created if it is not followed correctly. Pregnancy may occur. I am following the method of withdrawal for some time. I'm not well [so I am] not taking pills. I shall take them [again] after a few days. 
The final case of use of azal without concurrent use of any other method turns out to be not what it seems to be. The key statement is in the man's interview, hidden amongst the rest of his responses to in-depth questions, and in this case did not result in correction of the recorded answers on method use. This was possibly because both the man and the woman were referring to their use of coitus reservatus, rather than the more usual form of azal ('dropping semen outside'). They are Hindus.

M090 (40 years old): - (Male involvement in family planning) ... She alerts me about the dangerous time [unsafe period] and I restrain myself at that time. Moreover during the peak period of excitement, she co-operates with me and I become able to practise withdrawal [coitus reservatus]. It would not be possible without her cooperation.

This man and woman were actually using the safe period method in combination with azal. Neither of them said so in answer to the questions about method use, but there are actually other references in both the woman's interview and the man's interview to their practice of the safe period method, without clear indication that they were practising it currently. For example, in discussing how the safe period method works, the woman had said 'I adopted this method. It prevents pregnancy.'

This example is the first of many that will be discussed in this chapter, of men and women using a combination of direct methods of family planning but who do not necessarily say so at first, or they do not necessarily mention the same combination of methods, as in the cases discussed in the next section.

Statements about family planning methods: agreement between man and woman about method $\mathcal{S}_{\text {in }}$ use, but additional method(s) mentioned by at least one

There were fifteen instances in the interviews where the man and the woman were in basic agreement about one or more methods of family planning that they were using, but where additional methods were also mentioned by either the man or the woman. In marked contrast to the cases in the previous section of this chapter, all of the cases presently under consideration involved use of 'traditional' methods, and the most frequently found combinations were various permutations of use of the safe period method, azal and condoms. In three cases, all three of these methods were mentioned by one of the respondents as being in current use. Table 4.2 sets out the fifteen cases, with agreed methods in bold type.

There are good reasons to use direct methods of family planning in combination, and the extent of use of such combinations in the study areas will by now be increasingly clear. In this section, it seems preferable to concentrate attention on the more unusual combinations, and then select and discuss examples of reasons for using more than one method. 
Table 4.2. Cases of agreement between man and woman about method in use, but additional method(s) mentioned by at least one

\begin{tabular}{|c|l|l|}
\hline \multirow{2}{*}{$\begin{array}{c}\text { Case } \\
\text { number }\end{array}$} & Methods in use according to: \\
\cline { 2 - 3 } & Woman & Man \\
\hline 10 & Azal; condom & Safe period; azal \\
\hline 14 & Safe period; azal & Azal; condom \\
\hline 15 & Safe period; condom & Condom \\
\hline 20 & Oral pill & Azal; oral pill \\
\hline 21 & Azal; kabiraji method & Azal \\
\hline 27 & Safe period; azal & Safe period \\
\hline 35 & Safe period; azal & Safe period; condom \\
\hline 53 & Safe period; azal; condom & Safe period \\
\hline 67 & Safe period; azal; condom & Condom \\
\hline 85 & Oral pill & Safe period; oral pill \\
\hline 87 & Safe period; condom & Condom \\
\hline 96 & Azal; oral pill & Oral pill \\
\hline 104 & Safe period; condom & Safe period \\
\hline 140 & Azal; condom & Condom \\
\hline 148 & Azal; condom & Safe period; azal; condom \\
\hline
\end{tabular}

There are four unusual combinations (numbers 020, 021, 085 and 096). The first of these, where the man mentions using azal as well as oral pills, could not be easier to explain:

M020 (33 years old): - (Reasons for using more than one method) Suppose, I go to watch television after the call for night prayer $[$ Azan]. So, I cannot see whether she takes her pill or not. So, I drop [the semen] outside lest a baby is born.

This man is basically using azal on occasions because he distrusts his wife's ability or willingness to take the pill without his supervision. It is understandable that the woman would omit to mention his predilection in her interview.

The next case, where the woman mentions using a kabiraji preparation in addition to practising azal, is also uncomplicated:

F021 (27 years old, 6 children ever born): - (Reasons for using more than one method) I have taken kabiraji medicine. The kabiraj told me that I will not have another baby if I take the medicine. I am afraid that I might [nevertheless] conceive again. So, I am adopting this method $[a z a l]$.... (Advantages/disadvantages of $\boldsymbol{a z a l}$ ) ... A baby will not come into my belly if this $[a z a l]$ is used. Birth may be prevented as long as one wishes. The pill creates problems [for me]. I have no faith in the kabiraji medicine.

Is this woman correct to say that she is a current user of the kabiraji method, if she has no faith in its efficacy, and if she is using another method as well? If this criterion was employed, there would be many cases of method use excluded from the data, including instances in which the method excluded would undoubtedly be the most effective. It is, however, understandable that the man would simply have omitted to mention the use of the kabiraji preparation as irrelevant. 
The next case refers to the very unusual combination of safe period, mentioned by the man, with the oral pill, the use of which both woman and man acknowledge.

M085 (24 years old): - (How the safe period method works) ... It is fully safe. The pill is [also] safe. I also give her pills. I often have confusion about the counting of days. I might be wrong, so I give her pills also. ... (Reasons for using more than one method) We use two methods together. Calculating the dates may be wrong sometimes, so I give her pills. It keeps her healthy. We become sick if we have intercourse after working all day for days at a time; therefore, we avoid some days.

The account is confusing, but it appears that the use of pills is under the man's control, and not consistent. The woman's interview is given as an example in Chapter 1 (page 12). She also reveals use of the safe period method, and she does not seem to say it has stopped, but neither does she explicitly say she is still using it. Responding to questions on current method use, she referred only to the pill. The rigour of her use of pills appeared to be very tenuous, because of side-effects. It seems reasonable to conclude that the man and woman are primarily pill users, but not rigorous and consistent because of real or perceived side-effects. It also appears that the man's story of using the safe period method as well is plausible, but in using it he admits the possibility of error in counting the days. He regards the last seven days of the menstrual cycle as safe (not shown in the excerpt).

In the last of these four cases, the woman says that they use azal as well as the pill to which both admit. The reason for also using azal is straightforward.

F096 (28 years old, 3 children ever born): - (Reasons for using more than one method) I don't take the pill every day. I take it on alternate days. And the day when I 'meet' [have intercourse] with my husband, he drops the semen outside. That semen may suddenly go inside; with this fear in mind, I take pills. Again, as we practice azal, I don't take pills every day. Actually I feel distaste if the seed is dropped inside. For this reason, I never tell my husband to drop semen inside.

From this account, the primary method being used is azal, with pills being used improperly as a back-up.

We now turn to examples of reasons for using more than one direct method. The object of the investigation is to determine whether, if one of the three direct methods (safe period method, azal and condoms) is mentioned by the woman, and another of the three direct methods is mentioned by the man, and they agree on at least one method in use, then they are probably a combination of all the direct methods that they mention. We begin with the three cases where a respondent has admitted to using all three direct methods in combination:

F053 (34 years old, 3 children ever born): - (Reasons for using more than one method) I follow the safe period method. During the at-risk period if I wish to have a physical relationship with my husband, then we use condoms. Also, for mental peace sometimes azal is practiced [mental satisfaction is not fulfilled if the husband wears a condom].

F067 (35 years old, 2 children ever born): - (Reasons for using more than one method) My husband follows the safe period method. In my opinion, from the beginning of menstruation up to the fourteenth day there is every possibility of conception if couples copulate. There is the least possibility of conception in the rest of the days of the month. There is nothing to be scared of while using condoms. So, if my husband needs to copulate any day within the first fourteen days of my menstruation, he uses a condom. As the rest of the days are less apprehensive, we 
adopt azal. I am also scared of the method azal. I have a scar in the womb and as a result we do not use condoms throughout the whole month. A doctor [village doctor] has advised us not to use condoms.

F148 (40 years old, 7 children ever born): - (Reasons for using more than one method) My husband does not always want to ejaculate outside. This is why my husband often uses condoms.

M148 (39 years old): - (Reasons for using more than one method) I use condoms from the seventh day to the twenty-second day of the menstrual cycle.

In the first of these three cases (053) the man had admitted only to using the safe period method, and in the second (067) the man only mentioned condoms. Note the incorrect understanding of the at-risk days on the part of the woman, in the second case. In the third case (148) the man did not fully explain what he did, although it was he who said that he used all three methods. The woman (who had no knowledge of the safe period method) filled in the details.

There are three other cases in Table 4.2 where all three direct methods are mentioned, but not by either the man or the woman alone. These cases might also be genuine combinations of the three direct methods, but they are all somewhat more complicated than the previous three cases and are consequently treated separately here. In the first of the three, it seems that the man has a very poor understanding of the safe period, although he says he uses it:

F010 (38 years old, 6 children ever born): - (Reasons for using more than one method) [We use] condoms and azal. Sometimes no condom is available at hand and at that time my husband ejaculates outside. This happens almost every month.

M010 (47 years old): - (Reasons for using more than one method) It is not certain what will happen and when it may happen. It will be safe if it [azal] is done after seven or eight days of [from the start of] menstruation.

The meaning of the man's statement is admittedly obscure, but nowhere else in the interview does it become any clearer. The woman claimed no knowledge of the safe period method.

In the second case the man and woman disagree about when they use azal and if they use condoms at all,

F014 (26 years old, 3 children ever born): - (Reasons for using more than one method) While following the counting of days method I practice azal. The period when there is the greater chance of conception, if I copulate with my husband at that time, I practice $a z a l$, failing which conception will take place.

M014 (32 years old): - (Reasons for using more than one method) From the ninth to the nineteenth day of menstruation I use condoms. During the remaining periods, I practice azal, because I am afraid, lest pregnancy occurs.

This man said he did not use the safe period method! In fact, from his statement this is again a clear case of use of all three direct methods of family planning, whatever his perception might be. However, the woman and the man differ about the time of the menstrual cycle when they use $a z a l$, and there is no mention of condoms on her part.

In the third case the woman says she uses azal in disagreement with the man's claim to use condoms, although they agree that they use the safe period method:

F035 (23 years old, 3 children ever born): - (Reasons for using more than one method) I observe the safe period and my husband throws semen outside. My 
husband often fails to observe the safe period. He says 'I have married you. Shall I allow you to eat for nothing in return?' [Note: she regards the fifteen days from the start of menstruation as the at-risk period]

M035 (25 years old): - (Reasons for using more than one method) I observe the safe period. But where there is a possibility of my wife getting pregnant, and I feel sexual desire to 'mix' [have intercourse] with her, but if we sleep without a condom, it is sure she will be pregnant. Therefore, we observe the safe period and also use condoms.

What can be the cause of these differences, which are so characteristic of accounts given about use of direct methods? To understand this, it is necessary to consider the questions that these respondents have been asked to answer. These are:

- Are you or your husband/wife currently using any method so that you will not get pregnant?

- Which methods are you using?

While there are instructions to the interviewers to explain if necessary that the question refers to the current menstrual cycle, there are problems for respondents who use direct methods. If they have not yet had sexual intercourse in the current cycle, then they can only have an intention to use a method or methods, and the same observation applies if they use a combination of methods but they have not yet reached the stage of the cycle when they would normally switch over to another method. If they are not necessarily referring to the current cycle, then they must be referring to their usual or recent practice; but if they are using a combination of methods, the method mix might change slightly from month to month, and the man and woman might have different memory or perceptions of what they have done recently.

The examples in the following sections, of apparently fundamental disagreement between the woman and the man about which method they are using, point unequivocally to a need for a more thorough approach in determining use of traditional methods.

Statements about family planning methods: disagreement between man and woman about Whether any method is in use

There were seventeen cases where either the man or the woman said that they were using a method of family planning but the other did not. We have placed the accounts given by these men and women in Appendix Four, because they are long.

It is possible in most of the cases to explain the differences between the men's and women's stories, with only two cases of total incompatibility between the man's account and the woman's. A summary of the cases is given in Table 4.3. 


\begin{tabular}{|c|c|c|c|}
\hline \multicolumn{4}{|c|}{$\begin{array}{l}\text { Table 4.3. Statements about family planning methods: disagreement between man } \\
\text { and woman about whether any method is in use }\end{array}$} \\
\hline \multirow{2}{*}{$\begin{array}{l}\text { Case } \\
\text { no. }\end{array}$} & \multicolumn{2}{|c|}{ Method reported by: } & \multirow[t]{2}{*}{ Explanation } \\
\hline & Woman & Man & \\
\hline 033 & - & Oral pill & No supply in current moth \\
\hline 034 & Azal & - & $\begin{array}{l}\text { The man interprets 'method' as meaning } \\
\text { program methods only }\end{array}$ \\
\hline 046 & - & Safe period & $\begin{array}{l}\text { The woman is still amenorrheic after the birth of } \\
\text { a child, so use of the safe period can refer only } \\
\text { to intention to resume }\end{array}$ \\
\hline 048 & - & Azal & $\begin{array}{l}\text { The woman wants another child but the man } \\
\text { does not }\end{array}$ \\
\hline 049 & - & Safe period & $\begin{array}{l}\text { Both say they want another child, but the man is } \\
\text { adamant that he is still using the safe period } \\
\text { method, for no clear reason }\end{array}$ \\
\hline 055 & - & Safe period & $\begin{array}{l}\text { The man counts the days (controls the method), } \\
\text { but sexual intercourse is either rare or absent }\end{array}$ \\
\hline 056 & - & $\begin{array}{l}\text { Ayurvedic } \\
\text { pill; azal; } \\
\text { safe period }\end{array}$ & $\begin{array}{l}\text { The woman states that she has never used a } \\
\text { method but her husband has! }\end{array}$ \\
\hline 061 & - & Oral pill & Pill supply does not guarantee pill use \\
\hline 066 & - & Azal & $\begin{array}{l}\text { The woman does not regard azal as reliable, but } \\
\text { indicates that they have used it. They have } \\
\text { avoided pregnancy for } 19 \text { months since } \\
\text { marriage. }\end{array}$ \\
\hline 079 & - & Safe period & $\begin{array}{l}\text { The woman distrusts the safe period method, but } \\
\text { indicates that they use it. }\end{array}$ \\
\hline 080 & $\begin{array}{l}\text { Kabiraji } \\
\text { preparation }\end{array}$ & - & $\begin{array}{l}\text { The man wants another child, but the woman } \\
\text { took a kabiraji preparation on the advice of her } \\
\text { aunt after many infant deaths }\end{array}$ \\
\hline 100 & - & Safe period & $\begin{array}{l}\text { The man is an ascetic, and sexual intercourse is } \\
\text { very rare. He might have followed the safe } \\
\text { period method in the past and still regards it as } \\
\text { the method he uses }\end{array}$ \\
\hline 125 & - & Azal & [Accounts not compatible] \\
\hline 128 & - & Injectable & [Accounts not compatible] \\
\hline 134 & - & Safe period & $\begin{array}{l}\text { The woman is close to menopause with rare } \\
\text { menstruation and use of the safe period method } \\
\text { refers to past practice }\end{array}$ \\
\hline 136 & - & $\begin{array}{l}\text { Safe period; } \\
\text { condoms }\end{array}$ & $\begin{array}{l}\text { The woman is still amenorrheic after birth of a } \\
\text { child, and the man's account refers to past and } \\
\text { intended practice }\end{array}$ \\
\hline 151 & - & Condoms & Intercourse is very rare \\
\hline
\end{tabular}

Evidently, men in this sample are somewhat more likely than women to report use of a method, in particular a direct method, when the partner says that no method is in use. There were only two cases where the woman reported use of a method when the man did not. In one of these cases (034), the man's interpretation of the term 'family planning method' was restricted to program methods. He evidently did not consider azal (or any other method that did not involve 'medicine' from a doctor) to have a bearing on family planning. Because of 
the family planning program's constant emphasis on 'modern' methods, it is possible that there is a widespread misunderstanding in Bangladesh that the term 'family planning methods' refers only to modern methods. The design of the sequence of questions in this study was aimed at reducing the misunderstanding, but from the evidence of this interview it was not completely successful.

The other case (082) involved use of a kabiraji preparation by the woman, on the advice of her aunt, after she had borne ten children of whom only four were still living (three daughters and a son). The man wanted another son, but in desperation the woman took a kabiraji preparation which is supposed to prevent any further births. The man said they were not using any method of family planning, and claimed he did not know why they were not having any more children. The lack of births since ingesting the kabiraji medicine can in theory be attributed to successful use of the kabiraji preparation. Without making any judgment about whether this particular preparation or any other kabiraji preparation has or does not have any contraceptive properties, it is possible that his wife was pre-menopausal at the time she took the medicine. All methods 'prevent' further births in some cases, on the same principle that almost any 'medicine' will cure the common cold, in that its symptoms disappear after a few days. The appearance of success helps to ensure that kabiraji methods continue to be used.

This large cluster of deaths among the children in a single family provides a very instructive insight into one aspect of the multi-faceted relationship between fertility and infant mortality, because the man makes it reasonably clear that he would have been satisfied with one more surviving son. So while his wife bore him ten children, and only four survived, it is possible that they might have stopped at five births, or even fewer, if two sons had managed to survive.

Of the cases where it was the man who reported use of a method when the woman did not, there are several groups of cases. The first of these is 'use' of a direct method when intercourse is rare or absent (case numbers 55, 100, 151). There is a related group $(046,134$, 136) where reference is made to past or intended use of a direct method. In the previous section of this chapter we pointed out that answering questions about method use is more difficult for users of combinations of direct methods than for users of indirect methods, because the mix of direct methods is not necessarily the same from month to month. The current cases reflect other aspects of this. One example is that where intercourse is rare a direct method can at best be used occasionally. Another is that where amenorrhea occurs use of the safe period method is logically impossible but reported use can refer to firm intention or past practice.

There are two cases where the man says that the woman is taking oral contraceptive pills, but the woman herself does not say so. In one of these cases (033), her non-use is because she has no supply in the current month. The man also complained about irregular supply but was not as specific and was classified as a current user. In the other case (061), the man goes out of his way to praise the work of FWAs: "We followed what they advised. But all their instructions cannot be followed. They say, "Don't take more than two children." We use the methods they tell us to use. However, they tell us good things. ... They come to every households and supply pills. We also benefit from it.' The woman, on the other hand, says that she once used pills only to regulate her menstruation. We feel that they probably do take pills from the FWAs, but pill supply does not necessarily imply use.

Other cases involve non-reporting of a method that the woman thinks is ineffective (066, $079)$, or of methods that are under the control of the man $(055,056)$, or of methods that go against the woman's wish to have another child $(048,049)$. 
In summary, there can be no clear preference for the woman's or the man's version in these cases. Sometimes the evidence points to no effective use of a method, in favour of the woman's account, especially where direct methods are involved but intercourse is rare or there is lactational amenorrhea. In other cases, the evidence indicates that the man is correct.

Statements about family planning methods: disagreement between man and woman about Whether any method is in use

There were 21 cases where the man and woman agreed that they were using a method, but did not agree on which method. While these cases are in some respects the least tractable, there were only three where no explanation for the discrepancy can be offered. A detailed discussion of the individual cases is given in Appendix Four, and the cases are summarized in Table 4.4. As might have been expected from previous discussion in this chapter, the most common reason for the inconsistency is reporting of different aspects of use of a combination of direct methods. This accounts for seven of the cases shown in Table $4.4(031,040,072$, $074,101,131,150)$.

There were two cases $(017,078)$ where the woman said that her husband had had a vasectomy but the man said that his wife had received kabiraji treatment which had sterilizing effect. We believe it is very likely that the men are using a conventional account of vasectomy:

F017 (40 years old, 5 children ever born): - (Reasons for method choice) I used to consider it [vasectomy] to be a good method. Now I see that it is bad. Because the health of my husband has broken down. But the advantage is that it prevents birth. ... My husband's health is breaking down day by. It is another disadvantage. Besides I do not get satisfaction remaining with my husband. ... My husband got himself operated from the Keshabpur hospital.

M017 (46 years old): - (Discussion about number of children) My wife told me that we can't have another baby. Ours is a poverty-stricken family. Our poverty will increase with the increase of the number of children. So, she has had medicine from a kabiraj. ... I didn't discuss [it with her]. My wife went to India and took pills. After coming back she told me that as we don't need any baby, she has prevented birth for ever by taking pills. ... (Male involvement in family planning) My wife has come back from India after eating tablets. She told it to me afterwards. We are very poor people. She has done the right thing. We will have no more children. 


\begin{tabular}{|c|c|c|c|}
\hline \multirow{2}{*}{$\begin{array}{l}\text { Case } \\
\text { no. }\end{array}$} & \multicolumn{2}{|c|}{ Method reported by: } & \multirow[t]{2}{*}{ Explanation } \\
\hline & Woman & Man & \\
\hline 009 & $\begin{array}{l}\text { Kabiraji } \\
\text { treatment }\end{array}$ & Oral pill & $\begin{array}{l}\text { The woman's menstruation has only recently } \\
\text { returned after lactational amenorrhea; she says } \\
\text { she then took a kabiraji treatment. The man is } \\
\text { referring to past use of oral contraceptives }\end{array}$ \\
\hline 017 & Vasectomy & $\begin{array}{l}\text { Kabiraji } \\
\text { sterilization } \\
\text { of woman }\end{array}$ & Conventional account of vasectomy - see text \\
\hline 025 & $\begin{array}{l}\text { Safe period; } \\
\text { azal }\end{array}$ & Oral pill & $\begin{array}{l}\text { The man appears to be stating a preference } \\
\text { rather than describing actual practice }\end{array}$ \\
\hline 028 & Safe period & Abstinence & $\begin{array}{l}\text { No sexual relations; if there were they would use } \\
\text { the safe period method }\end{array}$ \\
\hline 031 & Azal & Safe period & Both methods used \\
\hline 040 & Azal & Safe period & Both methods used \\
\hline 045 & Safe period & Oral pill & $\begin{array}{l}\text { The man's claim that they switched to oral pill } \\
\text { use might reflect a desire to answer questions in } \\
\text { the way he thought was wanted }\end{array}$ \\
\hline 051 & $\begin{array}{l}\text { Oral pills - } \\
\text { homeopathic }\end{array}$ & Oral pill & The man makes no distinction \\
\hline 072 & Azal; oral pill & Safe period & $\begin{array}{l}\text { Habitual use of safe period with azal, and } \\
\text { recently including use of oral pills also }\end{array}$ \\
\hline 074 & Azal & Safe period & Both methods used \\
\hline 078 & Vasectomy & $\begin{array}{l}\text { Kabiraji } \\
\text { sterilization } \\
\text { of woman }\end{array}$ & Conventional account of vasectomy - see text \\
\hline 088 & Azal & Condom & Conventional account of $a z a l$ - see text \\
\hline 093 & Oral pill & $\begin{array}{l}\text { Azal; } \\
\text { condoms }\end{array}$ & $\begin{array}{l}\text { The man is unaware that his wife has resumed } \\
\text { use of pills after suspension due to side effects }\end{array}$ \\
\hline 094 & Condoms & Safe period & [Accounts not compatible] \\
\hline 095 & $\begin{array}{l}\text { Safe period; } \\
\text { azal }\end{array}$ & IUD & [Accounts not compatible] \\
\hline 099 & $\begin{array}{l}\text { Oral pills - } \\
\text { homeopathic }\end{array}$ & Oral pills & $\begin{array}{l}\text { The man did not mention that the oral pills are } \\
\text { from a homeopathic practitioner }\end{array}$ \\
\hline 101 & $\begin{array}{l}\text { Kabiraji } \\
\text { treatment }\end{array}$ & Safe period & $\begin{array}{l}\text { Both methods probably used; the woman has not } \\
\text { heard of the safe period method }\end{array}$ \\
\hline 131 & Safe period & Condoms & Both methods used \\
\hline 135 & Oral pills & Condoms & Irregular pill supply \\
\hline 146 & Azal & Oral pill & [Accounts not compatible] \\
\hline 150 & Azal & Safe period & Both methods used \\
\hline
\end{tabular}


F078 (44 years old, 7 children ever born): - (Reasons for method choice) ... I had small children. In case another conception occurred, my husband had secretly undergone operation [sterilization]. Sometimes conception may occur if the condom bursts. One day a condom did burst and I conceived. So, he had undergone operation. ... After the operation now my husband has irritation in his penis. During intercourse my husband sometimes has erection failure. I do not get proper satisfaction. ... My husband had undergone operation at the Khulna Sadar Hospital. ... My husband had undergone the operation long time ago, so now she [FWA] does not come to me about any methods. ... I conceived as a result of a condom bursting. So, my husband underwent the operation.

M078 (55 years old): - (Discussion about number of children) What is the use of increasing family size? I will not have more children. The age of my youngest son is 14 years. It was decided earlier that we will not have any more children. So now it is not needed to discuss about the number of children. ... Now we do not need to discuss about having children. Because sterilization was done thirteen years back through kabiraji treatment. ... (Male involvement in family planning) Yes, of course, the husband should participate. ... Because if we have many children our health will not remain good. So, both of us have to agree. A wife cannot adopt any method without the consent of the husband. So to adopt a family planning method the husband must cooperate with the wife. ... Both of us discussed it and decided that we will not take any more children. So I brought medicine from a shalsha [kabiraj] and she took them. This has prevented birth.

The case of household 017 has also been discussed in Chapter 3, with reference to an azal method failure. That episode does not appear to be in question, from sections of the man's interview not quoted here, but there are complicating circumstances in deciphering the evidence. What is in question is what they did after the unwanted pregnancy. Each says that the other did something without the knowledge of both partners. The woman says her husband had a vasectomy without her knowledge. The man says that his wife went to India and had kabiraji treatment to avoid more births, then told him about it later. If they are both right, it is an object lesson in the consequences of failure to communicate and cooperate. It is not our opinion that this is what actually occurred, that is, the man had a vasectomy and his wife took the kabiraji medicine, despite the fact that both interviews have the flavour of openness and veracity.

These details are replicated almost exactly in the case of household 078. The woman is classified as using vasectomy of her husband, the man is classified as using kabiraji treatment, and the woman reported a previous method failure, in this case a burst condom rather than an azal failure. As in the previous case, the man says that the kabiraji treatment was to sterilize his wife. It has apparently been successful, in that no more children have been born for thirteen years - another exemplary success to ensure that kabiraji treatments will continue to be used.

In a rural and largely illiterate society, the evidence of what people actually did in a given set of circumstances can be contaminated by conventional accounts, that is socially acceptable ways of describing events which confront social convention. Such conventional accounts can be adopted by a person as the explanation of his or her particular circumstances. As convenient explanations of things which it might otherwise be inconvenient to explain, these conventional accounts have high utility and can be adopted widely by individuals to explain what happened to them. If two instances of an unusual combination of reported family planning method use are reported independently by two different couples, then intrusion of a conventional account is to be suspected. 
On the evidence of these two cases, it cannot be ruled out as being extremely likely that a conventional men's account of vasectomy is that it was not them but their wives who were sterilized, using some kabiraji treatment. It is much less likely, because much less socially acceptable, that a conventional women's account of using sterilizing kabiraji treatment is that their husbands were sterilized. Secret execution of the sterilization features in the accounts both from the woman's side and the man's side. The attribute of secrecy for the actions of another person might also indicate that a conventional account is being given.

The second of these two cases (078) has also been mentioned in Chapter 3 as representing a possible case of another conventional account, namely reference to bursting condoms as an explanation of azal failure. There is another instance in Table 4.4 (case number 088) where the most likely explanation of the woman's reference to azal and the man's reference to use of condoms is that they are using azal, not condoms. The man refers to bursting of condoms as a disadvantage in its use 'if people are not careful'. Care in use is the precaution most frequently mentioned in the case of azal, and is stipulated by the woman in this case. In response to a question about whether there was any restriction from his religion to the use of condoms, he mentioned a condition from the Islamic tradition for the use of azal, namely that it can be used only by agreement between wife and husband.

The remaining explicable cases in Table 4.4 generally have reasonably simple explanations, such as failure to mention that the oral pills being used are from homeopathic practitioners, or reference (usually by the man) to methods that they have used in the past or which they intend to use again or which one of them thinks they should use.

\section{$D^{\text {iscussion }}$}

Disagreement between men and women about the methods of family planning that they are using, especially affecting the 'traditional' methods and users of condoms, has been noted in data from other surveys in Bangladesh and prompted the use of special measures in our field study to overcome the problems. Since the pattern of disagreement that was found was almost identical to that found in other surveys, it must be reported that these approaches (which had other aims) were not successful in reducing disparity between men's and women's accounts.

With the exception of users of the direct methods of family planning (safe period, azal and condoms) men and women usually agree about which methods they are using. The few cases of disagreement are also explicable quite easily in most cases. It is where any of the direct methods are mentioned by either the man or the woman that the problems of interpretation begin. The easiest of these to explain are those where some other method is mentioned by one or other partner in addition to a method mentioned by both. In most cases it appears that they are using methods in combination but do not mention all of them. We found a number of cases where all three direct methods were usually used in combination, and suspect that this practice is more widespread. The reason for such combinations, as we have already discussed in Chapter 3, is that respondents' understanding of the safe period method is often so limited that if it was used alone the opportunities for conducting a normal sexual relationship would be severely curtailed. In this chapter, we have also noted that where direct methods are used in combination the method mix might change somewhat from month to month and different aspects of their normal sexual practice could be reported by women and men as a result.

Reconciliation of differences becomes more difficult when one partner reports use of a method and the other does not, and the degree of difficulty of interpretation increases again in considering the cases where both man and woman agree that they are using some method but nominate different methods. However, there are only five cases where we conclude that the accounts are totally incompatible and that either the woman or the man is not being honest. 
In some cases, for example, it is clear that one partner, usually the man, is referring to intent rather than current practice, for example when his wife is still amenorrheic following a birth and he says that he is using the safe period method, which he cannot actually do until her menstruation returns. In other cases, the sexual activity of the couple might have been suspended. When indirect methods of family planning are in use, there is never any question about whether sexual relations are continuing; if a woman has an IUD in place then she is an IUD user no matter whether she ever has sex. There are also many other explanations for different accounts for individual cases.

The occurrence of parallel cases of highly unusual cases of disagreement raised the possibility of use of 'conventional accounts' of events which might otherwise confront social conventions. For instance, we regard it as likely that a conventional account by men of vasectomy is that the man's wife has had treatment from a kabiraj which sterilized her. There was further support for the idea that narratives mentioning burst condoms could be conventional accounts of failure to use azal properly.

However, it does seem that the most likely explanation, whenever there is disagreement between woman and man over the family planning method they are using, is that both accounts are correct, or at least reflections of the truth. The main implication of these findings is that it is clearly much more difficult to identify what methods of family planning are being used by an individual than is commonly recognized, and this is particularly true for direct methods.

There was an unstated motive in the program of this chapter, which has resulted in the exposure of considerable information about most of the individual cases of use of 'traditional' methods, including information about switching between 'traditional' methods and program methods. It will be very clear that the reasons for this method-switching are exactly in line with the findings of other surveys, that switching to the direct methods is very often because of the side-effects of program methods, while switching away from them is because of concerns about effectiveness. The many stories told here about side-effects of hormonal methods provide strong support for efforts to improve quality of care and advice to individual users. 


\section{Chapter 5.}

\section{Source of Information and Correctness of Knowledge about the Safe Period Method}

\section{$K^{2}$}

As we have seen, poor information about the safe period method is a significant contributor to failure with its use. Misinformation and incomplete factual information characterizes the accounts given in Chapter 3 on this topic. It can be argued that lack of access to accurate information about the safe period method is no less than a denial to women of information about how their bodies work, apart from its contribution to unwanted pregnancies.

If it is possible to deliver clear descriptions of the features of the ovulatory cycle to women and men, with the at-risk periods identified, then this would not amount to official encouragement of the use of non-program methods. It would merely recognize that these methods are already in use by a considerable proportion of the population, and allow women and men to use the 'traditional' methods properly, thereby reducing the occurrence of unwanted pregnancies in Bangladesh. Information about basic reproductive physiology would also be useful to users of other methods of family planning, in a situation where supplies are not always regular or method problems occur.

If they had heard of the safe period method, the source and correctness of men's and women's information about the method was assessed. In the in-depth part of the interview, there were additional questions about the source of their information, about azal as well as the safe period method, and questions about whether they thought more information should be available through public media or other arrangements.

Correct knowledge about the safe period method was very low among the respondents to the survey, even though the sample was selected to include quite a high proportion of current and former users of the 'traditional' methods, and a quite liberal definition of the concept of 'correct' knowledge was used. The interviewer instructions were as follows:

Question 302 is designed to evaluate the extent of knowledge. A 'correct' answer to this question is one which refers to the middle part of the menstrual cycle as unsafe. There are various versions of a 'correct' answer. You should accept as 'correct' variations on any of the following versions:

1) 'The first seven days after the start of the period are safe, the next fourteen days are unsafe, then the last seven days are safe';

2) 'The first ten days after the start of the period are safe, the next ten days are unsafe, then the remaining days until the next period are safe';

3) 'Three or four days after the end of the period are safe, and the last week before the next period is safe, but the middle of the month is not safe'.

The safe period is actually quite variable between individuals, but it can be determined somewhat more accurately than these versions. If you hear any version which refers to changes in temperature, or changes in cervical mucus, or keeping records of the length of menstrual cycles over a long period of time, you can assume that the respondent is referring to one of these more accurate versions, and record the answer as correct. Note down what is said so it can be checked for accuracy later.

Any explanation that includes the middle part of the menstrual cycle as unsafe can be regarded as 'partly correct'. An example might be where a woman counts fifteen days 
after the end of her period before having sexual relations with her husband. (This version was found in the pre-test.) It is reasonable if the woman does not have very short periods. While strictly accurate, a version which says that only the days of menstruation are safe should be regarded as 'incorrect', and so should any version which refers to the middle part of the cycle as safe. Versions which refer to lunar cycles or anything else not connected with menstrual cycles are incorrect.

Table 5.1 shows that even with this liberal definition, only 7 per cent of women who had heard of the safe period method, and 25 per cent of men, were able to give a 'correct' definition in these terms. Most of the 'partly correct' answers referred to the last week or so of the menstrual cycle as being the only safe time for sexual intercourse.

Table 5.1. Correctness of knowledge about the safe period method

\begin{tabular}{|l|r|r|r|c|}
\hline \multirow{2}{*}{ Assessed knowledge } & \multicolumn{2}{|c|}{ Woman } & \multicolumn{2}{c|}{ Man } \\
& 6 & $7 \%$ & 26 & $25 \%$ \\
\hline Correct & 47 & $55 \%$ & 33 & $32 \%$ \\
\hline Partly correct & 32 & $38 \%$ & 43 & $42 \%$ \\
\hline Incorrect & $\mathbf{8 5}$ & $\mathbf{1 0 0 \%}$ & $\mathbf{1 0 2}$ & $\mathbf{1 0 0 \%}$ \\
\hline Heard of method & 65 & & 39 & \\
\hline Not heard of method & $\mathbf{1 5 0}$ & & $\mathbf{1 4 1}$ & \\
\hline Total & & & & \\
\hline
\end{tabular}

This lack of accurate knowledge is even worse when the combination of a woman's and a man's knowledge is analysed. From 128 instances where both the man and woman were interviewed, in 64 cases both the woman and the man had heard of the safe period method. In the case of only one out of these 64 couples did both the man and the woman have correct knowledge of the method; in a further 27 cases they both had knowledge that was at least partly correct; in 11 cases the man's knowledge was at least partly correct but the woman's was incorrect; in 16 other cases the woman's knowledge was at least partly correct but the man's was incorrect; and in the remaining 9 cases the knowledge of both partners was incorrect.

This would not matter so much if the level of knowledge was higher among those couples claiming to use the method, but it is actually not much higher. Of 34 cases where either the man or the woman said they were current users of the method (this includes instances where one partner had never heard of the method), there was one case where both the man and the woman had correct knowledge, fourteen more cases where they both had knowledge that was at least partly correct, twelve cases where only the man's knowledge was at least partly correct, five cases where only the woman's knowledge was at least partly correct, and in two cases neither had even partly correct knowledge. While this means that in a majority of cases of current use of the safe period method, at least one partner did not have knowledge of it which was even partly correct, there were only two cases of current use where neither partner had partly correct knowledge or better.

This dismal lack of correct knowledge is more prevalent among women than men, and some flavour of that situation has been seen in the discussion of individual cases in Chapter 3 .

Lack of correct knowledge is often attributable to the source from which knowledge was obtained. As Table 5.2 shows, incorrect knowledge about the safe period method is passed on 
by friends, relatives and neighbours more than any other source, and especially is this true in the case of women, who are also more likely to receive information in this way.

Table 5.2. Correctness of knowledge according to sources of information

\begin{tabular}{|l|c|c|c|c|}
\hline & \multicolumn{2}{|c|}{ Woman: } & \multicolumn{2}{c|}{ Man: } \\
\hline Source of information & $\begin{array}{c}\text { Received } \\
\text { information } \\
\text { from this } \\
\text { source }\end{array}$ & $\begin{array}{c}\text { Knowledge } \\
\text { incorrect }\end{array}$ & $\begin{array}{c}\text { Received } \\
\text { information } \\
\text { from this } \\
\text { source }\end{array}$ & $\begin{array}{c}\text { Knowledge } \\
\text { incorrect }\end{array}$ \\
\hline Husband/wife & 9 & 1 & 20 & 8 \\
\hline Friend, relative, neighbour & 58 & 29 & 39 & 22 \\
\hline FWA/FWV & 14 & 2 & 11 & 2 \\
\hline Book & 10 & 1 & 11 & 7 \\
\hline Village practitioner & 5 & 1 & 8 & 2 \\
\hline Other & 6 & - & 14 & 2 \\
\hline All sources & 85 & 32 & 102 & 43 \\
\hline
\end{tabular}

It is not necessarily possible to identify the source of the incorrect information for individual cases, because multiple sources were recorded where mentioned. The 85 women described in the table had on average 1.2 sources of information, while only one of 102 men had more than a single source recorded. However, the women were more likely to have obtained their information from the most unreliable source, that is from friends, relatives or neighbours.

Since the table refers to all respondents who had heard of the safe period method, it does not accurately reflect the case of current users of the method. Of the six women who had heard of the method, were current users (or whose husbands were current users) and had incorrect knowledge of the method, all six had obtained information from friends, relatives or neighbours.

We turn now to what respondents say about the sources of knowledge which they have used. There were ten women who said they had received information from books, and in two cases these were named books nominated as sources by two women each:

F010 (38 years old, 6 children ever born): - I have learnt [about the safe period method] from books and from neighbours. I have learnt it from the book. Shami Istrir Milan Katha [Sex between husband and wife]. The [family planning] workers do not say anything. ... I haven't used this method myself. Only I have read in books that this method prevents birth. [The same book was named by F045, 20 years old, 1 child ever born.]

F028 (39 years old, 3 children ever born): - The women [FWAs] don't say anything. I asked the worker myself and she told me that I could follow this method. I have learnt about this method from the book, Namaj Shikhya [Guide to Prayer]. [The same book was named by F114, 42 years old, 5 children ever born; this woman also nominated her husband as a source.]

In all four cases, their knowledge of the safe period method was classified as partly correct, so it cannot be certain that either book gives much information. 
A family planning worker (it is not specified whether FWA or FWV) who had obtained information from a training course as well as books also had only partly correct knowledge:

F036 (21 years old, 1 child ever born): - I think that the last ten days are more safe. I took training at Kakrail, Dhaka. ... They [FWAs] do not say anything to the women about it. Before taking training, I knew it from a book. ... I read in the book that if this method is used, birth remains controlled

There were two women who had undergone teacher training courses and had received some information about the safe period method from books which were used in the course:

F131 (40 years old, 3 children ever born): - They [FWAs] say nothing about the safe period method. I have heard about it from my husband. I saw it mentioned in the book on Child Psychology in the P.I.T. training course. [Similar story told by F130, 34 years old, 4 children ever born.]

The first of these two women was classified as having incorrect knowledge, the second as having partly correct knowledge.

Of the remaining three women who said they had received information from books, none mentioned the title of the book or where they obtained it:

F006 (38 years old, 5 children ever born): - I have read it from books. I have heard about it from the neighbours. I don't know if any other sources are there.

F134 (40 years old, 4 children ever born): - I heard about the safe period from those who distribute pills. Again, I got it from books. Neighbours also talk about it and I heard from them.

F146 (43 years old, 10 children ever born): - Those who supply the pill, they do not say anything. I have known about the safe period method from a book.

Only the last of these women was classified as having correct knowledge, in the limited sense used here, and she had given birth ten times. It is to this extent evident that the limited references available to women in the study areas do not provide much useful information about the safe period method.

There were only six women altogether who had correct knowledge, and only one of these obtained the information from a book. Where did the others obtain their information? It was actually from a wide variety of sources:

F104 (45 years old, 7 children ever born): - Those who distribute pills [FWA] say nothing. I've heard from my neighbours.

F105 (27 years old, 1 child ever born): - They [FWAs] won't even discuss it. But my friend who works in the family planning office has told me about it. I have heard of it from her.

F140 (28 years old, 4 children ever born): - [Information from unspecified relatives, neighbours, friends.] Those who supply pills from door to door, nothing can be learnt from them in this regard. They only talk about pills and condoms.

F147 (29 years old, 7 children ever born): - [Information from village practitioner.] They do not tell anything about selection of days. They [Sample Registration System workers] want to know what methods we are adopting and nothing else. The Government workers [FWAs] do not come to our homes.

F161 (41 years old, 9 children ever born): - Every month a man and a woman visit here [Sample Registration System workers]. I have heard about the safe period 
method from them. The FWAs don't visit my house. When they paid a visit here they didn't talk about the safe period method.

Husbands have already been mentioned as one of the sources of information for two women (households 114 and 131), one with partly correct knowledge and one with incorrect knowledge. All of the remaining women who had obtained information from their husbands had partly correct knowledge of the safe period method. This makes husbands one of the most reliable sources.

F014 (26 years old, 3 children ever born): - It can be learnt from my husband. Those who supply pills, they also tell us. We ask about it.

F039 (34 years old, 3 children ever born): - They [FWAs] don't say anything. I can't say where my husband heard about it.

F041 (16 years old, no children): - It can be learnt from my husband. It may be known from no other sources.

F093 (29 years old, 2 children ever born): - Those who supply the pill at home, they don't tell anything about this. I have heard this from my husband and I have told it to many people.

F103 (29 years old, 2 children ever born): - [Information from husband] They [FWAs] don't tell anything about this method. They tell about pills and condoms.

F132 (33 years old, 2 children ever born): - I didn't hear these things from them [FWA]. She [FWA] is an aunt of ours. I didn't hear it from her. I heard from my husband about the safe period method.

F144 (26 years old, 7 children ever born): - I have not heard about the use of counting of days method from the FWAs. They don't come to my house. My husband learnt about it from a doctor [village doctor] and he told me about it.

The least reliable sources, as observed in Table 5.2, are friends, relatives and neighbours. It is possible to be much more specific than that about which of the types of friends, relatives and neighbours are less reliable than others. We may start with women who obtained their information from various types of relatives, beginning with sisters-in-law:

F011 (23 years old, 2 children ever born): - I have learnt it from my sister-in-law. Those who supply the oral pill at every house do not say anything about it.

F033 (36 years old, 6 children ever born): - They [FWA] do not say anything. I came to know about it from my sister-in-law.

F048 (21 years old, 1 child ever born): - The wife of my brother used to visit the hospital. She learnt of it from there and told me about it. She said, 'Observe the safe period [specifically "sex before menstruation returns"]. If you desire not to have a baby, you will not get one.'

F074 (28 years old, 4 children ever born): - They [FWA/FWV] say nothing. I have heard from my sister-in-law who lives nearby [wife of a neighbour who is regarded as a brother by the husband].

F079 (34 years old, 6 children ever born): - No, they [FWA] do not talk about this [safe period]. I heard from my sister-in-law.

F115 (43 years old, 8 children ever born): - They [FWA] don't say anything. I have heard about it from my sister-in-laws. Birth is prevented if the counting of days method is followed. Those who supply pills at the door step, they advise us to use pills, injection, copper-T, etc.

F152 (28 years old, 4 children ever born): - I have heard about it from my sister-inlaw, who is my neighbour. Those who supply pills [FWA], don't say anything.

Only two of these women, from households 033 and 115, had knowledge that was even partly correct. Not surprisingly, aunts and aunts-in-law were not much more reliable: 
F005 (26 years old, 2 children ever born): - I heard of this method from my aunty. It is not possible for me to learn from any other people.

F023 (21 years old, 2 children ever born): - The FWV gives my maternal aunty pills. They have told her about this method. I heard this from my maternal aunty.

F027 (18 years old, no children): - The workers [FWA] do not say anything. I have heard it from my second aunt. It can be known from doctors if anyone desires.

F066 (16 years old, no children): - I have learnt about this method from my mother's sister. I don't know whether I can know it from any other source.

F085 (19 years old, 1 child ever born): - Those who come to give pill, they do not say anything. I have known things from a aunt who lives nearby.

F110 (30 years old, 3 children ever born): - I heard from my aunt-in-law [father-inlaw's brother's wife]. The workers do not say anything about the safe period. They tell us to take pills.

F113 (28 years old, 4 children ever born): - I have not heard about the safe period method from those who supply pills at the doorstep. I heard from my aunt-in-law.

Four of these had incorrect knowledge and three had partly correct knowledge (households 023, 027 and 085). There were six other instances of named types of relatives from whom information had been obtained, and of these three women had partly correct information (households 012, 024 and 081).

F012 (38 years old, 4 children ever born): - I came to know from my sister. It can't be learnt from any other sources.

F024 (31 years old, 4 children ever born): - The workers do not talk about this while they visit house to house. I have never heard it from them. I heard it from my sister's husband. Hearing from him I told my husband. He came to know from the [village] doctor that if the safe period is maintained, birth can be controlled.

F051 (22 years old, 2 children ever born): - They [FWAs] don't say anything. I have learnt about this method from my grandmother who lives nearby.

F062 (36 years old, 3 children ever born): - Those who supply pills, did not say anything. I heard about it from my sister but meanwhile I have forgotten and don't remember how to practice it. I have never used this method myself.

F068 (34 years old, 6 children ever born): - I came to know about it from my grandmother. I haven't heard about it from those who supply pills.

F081 (41 years old, 4 children ever born): - They [FWA] say nothing. I have heard of it from the husband of one of my sisters.

Two of the informants who supplied partly correct information were men, which might have been expected given that husbands were much better informants than other types of relatives. The analysis for named types of relatives has been given to illustrate the fact that it is female relatives who are the most likely to have given incorrect information about the safe period method.

Without listing all the cases in the same amount of detail, the women who nominated neighbours and friends as their informants had a somewhat higher proportion with information at least partly correct (14 out of 28), and there were two cases with correct knowledge as defined here. Those two cases have been mentioned earlier. For women who obtained their information from named female relatives, the proportion was 5 out of 17 . The tally of cases that have been dealt with here does not include instances where information was also obtained from some other source; these cases are discussed below.

While a large majority of women said that no information was available from family planning workers, there were a number of instances found where information about the safe period 
method had been given by workers in the family planning system. However, no such case was reported from the study area in Satkania. One case of a woman who had correct knowledge of the safe period method has already been discussed (household 105). The remaining statements about obtaining information from the family planning service are listed below:

F019 (38 years old, 7 children ever born): - I have heard about safe-period method from a [village] doctor. The doctor is my brother-in-law [younger brother of my husband]. Beside that, the family planning worker told about it. ... We live in a village. We can discuss things sitting with my sisters-in-law. The field worker supplies the pill but I cannot take it. Then that Apa [field worker] said, 'Sisters-in-law [Bhabi], you can follow this safe-period method.'

F025 (22 years old, 2 children ever born): - It can be heard from them [FWAs].

F032 (36 years old, 2 children ever born): - I have come to know from those who come to our house to supply pills. If it is known from other places, then I don't know that.

F035 (23 years old, 3 children ever born): - I heard about it from [name of FWA] and [name of neighbour]. They say if we observe days I shall not be pregnant.

F040 (25 years old, 2 children ever born): - [Name of FWA] said that if some days of the month are avoided, no baby will be born. I have also heard it from those who use it.

F042 (35 years old, 3 children ever born): - I heard about it from the female workers of family planning. Again, I have heard from my sister that the adoption of 'safe period' prevents pregnancy.

F050 (36 years old, 4 children ever born): - Once an FWV told me that no baby is born if the safe-period method is followed. I don't remember how she told me to follow the method.

F067 (35 years old, 2 children ever born): - [Name of FWA] has said to me 'If you do not have sex with your husband within seven days after the stoppage of your menstruation, no child will be born.'

F096 (28 years old, 3 children ever born): - The people from the hospital [FWV] come and they tell us about the counting of days method. On the other hand I have heard from the neighbours.

F097 (30 years old, 2 children ever born): - [Name of FWA] told me about the safe period. I asked her what sort of practice can prevent birth then she told me about following the safe period method.

Of these ten cases, three women (households 050, 067 and 096) had incorrect knowledge of the safe period method and the rest had partly correct knowledge. This seems to indicate that, at best, the primary knowledge imparted by workers within the family planning service is incomplete. Since their primary knowledge is incomplete, it can hardly be expected that the second-hand knowledge gained from neighbours and relatives could be any more complete. There is no intention to generalize from these observations. They clearly apply only to the study areas, where the names of particular FWAs recur repeatedly in interviews. Moreover, the conclusion is modified very substantially by evidence from the interviews of men.

Among the remaining cases where knowledge of the safe period method was obtained from other sources, there were two who obtained information from nurses, two who learned about it from their Hindu religious leaders, two whose source of information was a village doctor, and three who obtained information from the workers of the Sample Registration System (SRS). In most of these cases, the knowledge of the respondent was classified as partly correct. There were two cases of correct knowledge, using the definition employed here, and one case of incorrect knowledge. 
While we have been treating the source of the information as the determinant of correctness of knowledge, it is important to recognize that the capacity of recipients of information to absorb it correctly is at least as important as the source. This is illustrated in the case of the three women who received information about the safe period method from SRS staff. One had knowledge classified as correct, another as partly correct and the third as incorrect. Individual variations in capacity to absorb and remember information might affect the analysis of sources of information in another way, namely that choice of a source of information, or access to it, could be influenced by precisely the same personal characteristics that affect capacity to absorb the information correctly. For these reasons, the analysis of sources of information in the previous few pages should be regarded cautiously.

This analysis has essentially aimed to expand the summary information in Table 5.2, by exposing what individuals actually said, and also to split up the amorphous 'friends, relatives and neighbours' and 'other' categories of the table into more meaningful sub-groups. It is not necessary to go through exactly the same process for the interviews with male respondents. Instead, it is better to focus on what is different about the sources of information available to men and why they have a larger proportion with incorrect information in most of the source categories shown in Table 5.2.

It is, perhaps, surprising that almost as many men as women (11 men and 14 women) said that they had received information from family planning workers, since these workers concentrate their attention on women. Indeed, approximately one quarter of the male respondents (26 out of 102) stated in various ways that they did not know what the family planning workers said to their partners. In examining the responses of men to questions about their sources of information, we actually found more references to FWAs and FWVs than are recorded in Table 5.2. Some of these references were to having obtained information indirectly, through their wives:

M059 (39 years old): - From them [FWA/FWV] my wife has got some information. She then spoke to me. They are our relations. That's why they give her [my wife] a lot of information and advice.

M095 (38 years old): - The FWAs tell my wife and my wife tells me that this method prevents birth.

M098 (30 years old): - My wife has heard about it from her [FWA]. I have heard from her [my wife].

M099 (40 years old): - The FWA tells it to my wife. My wife has told me that there will be no baby if intercourse is delayed until after 16 or 17 days after menstruation has ended.

M133 (36 years old): - Yes, they advised my wife about it. She reported it to me.

M148 (39 years old): - Yes, information is obtained. The family planning worker has told my wife. My wife has told me about this.

There is no overlap here with the cases reported above, where women said they had obtained information from family planning workers. Also, there are two cases from Satkania, where no women reported having received advice from FWAs. These observations indicate that availability of information from this source could be somewhat more widespread than examination of the women's accounts alone would lead us to believe. Five of these six men were classified as having correct knowledge of the safe period method, and one (household 098) as incorrect knowledge, but note that the account given by M099 indicates that the information from the FWA was only partly correct.

There are also cases where men apparently obtained information more directly from workers in the family planning service delivery system: 
M019 (46 years old): - I learnt about it by hearing from the family planning workers and then by reading the religious books. The MBBS doctors [medical graduates] also tell about it, if asked. The aged males and females, who have stopped having babies, also talk about it.

M061 (31 years old): - They told us about this method. However, she [FWA] is my relative. So, I went to her house and by the by I asked her and learnt about it. But they don't tell everybody about this method.

M092 (60 years old): - Yes, I have heard from the family planning workers [FWA/FWV]. They came from Bagherpara. A man and a woman came and talked to me [NGO workers?]. He was a resident of Comilla. He has been transferred.

M097 (34 years old): - First, I knew about this method from my sister-in-law. Later on while she was breastfeeding, the Doctor Apa [FWV] from the hospital [FWC] told me about this method and she advised me to follow this method.

M118 (25 years old): - Yes, the FWA says that the best method is to follow the safe period.

M121 (36 years old): - They have told me that those who say their prayers can follow this counting of days method.

M131 (46 years old): - Yes, I heard about it from them [FWA/FWV]. I also knew from the training courses for health assistants.

The last three of these men were classified as having correct knowledge of the safe period method, and the second man was classified as having incorrect knowledge. The others had partly correct knowledge. There are two features of these accounts that should be noted. One is that in three cases the respondents report going after more information. The other is that in at least three cases (households 097, 121 and 131) the FWA or FWV was not the primary source of information, and in the case of M121 it appears that the FWA was trying to dissuade the man from using the safe period method.

There is some doubt that one respondent (household 092) was talking about the Government's family planning workers. Another man, whose knowledge was not correct, reported receiving information from people who were probably not Government workers:

M066 (21 years old): - Once a male and female worker came to our area, held a group meeting and explained about this method. They didn't give their identity [whether FWAs/FWVs or not].

Almost no women reported receiving information from any media other than books. Two women referred to having heard something about the safe period method on the radio, one quite recently. (F096, 28 years old, 3 children ever born: 'I have heard about the counting of days methods on the radio. I heard about it a few days ago.') While most men were in agreement with women that no information was ever broadcast about 'traditional' methods, several men were aware not only of information that was broadcast on the radio, but of other information in the public media:

M005 (35 years old): - Information on the safe period method is sometimes discussed in the family planning radio programs.

M008 (37 years old): - In the radio program on family planning, if somebody asks about this method, then a reply is given.

M015 (43 years old): - In the Shukhi Paribar (Happy Family) program on the radio one can learn about it. When we meet with our friends, we discuss and learn about it. I have learnt it by reading books.

M019 (46 years old): - It is found in the magazines (Monthly Madina). It is discussed in the radio programs about family planning. It can also be learnt from discussion, and by questioning the papers and magazines sometimes we can learn about it. 
M053 (38 years old): - Sometimes it can be known from an acquaintance through tactful discussion. The radio also provides information, but I have not heard it.

M093 (38 years old): - TV and Radio give the message, that if one does not 'go in touch' for ten to fifteen days with his wife after her menstruation, birth can be prevented.

M122 (49 years old): - No, many of them [FWAs] are my students. So, they never thought of telling me about it. They did not tell about it to my wife either. I have been to India and learnt about it from here and there. On many occasions, in the question and answer session on the radio, we learn about it. ... In the question and answer session of the radio, publicity is made about this method. No information is received through any other media.

M130 (46 years old): - No, no information can be obtained. But now and then information about it may be got from magazines and booklets.

M134 (43 years old): - I came to know of it from my books on homeopathy. ... But information about it may be had from magazines.

Surprisingly, only three of these men had even partly correct knowledge of the safe period method (households 19, 53 and 134). The man (household 093) who referred to (nonexistent?) messages on TV as well as radio, gave a different, incorrect, version to the interview team. None of the three with partly correct knowledge had relied on the radio program, although one seems to have heard it. There is perhaps some indication here that the radio is not a suitable medium for transmitting information about the safe period method, although the program apparently has a policy of answering questions rather than giving direct information about the method. Only one of the two women who referred to information from the radio had partly correct knowledge of the safe period method, and the one who had incorrect information was the one who heard about it on the radio only 'a few days ago'.

If the radio program to which these respondents refer follows a policy of not giving direct information about the safe period method, but does provide answers to questions, then it seems that this policy should be reviewed. The safe period is more difficult to learn, even in rudimentary form, than program methods. A proper understanding requires information about what ovulation is, when it occurs and the consequential rationale for avoiding the days surrounding ovulation. On the evidence that we have obtained, a policy of doing no more than answering questions could have adverse results and certainly does not have positive results.

Few men who refer to having obtained information from books had even partly correct knowledge about the safe period method, according to Table 5.2. The reason is that in contrast to women who referred to books, men's acquaintance with knowledge from this source was much more casual:

M014 (32 years old): - I have learnt about it from a book. The book is written by Moulana Abbas. I learnt about it from a training course also.

M023 (24 years old): - I heard it from other people by the by. But I learnt something about it from a book.

M039 (39 years old): - I have read about it in books. From four to five days after the menstruation until two weeks, if people 'meet' together, no baby comes. I haven't heard through any other media.

M045 (38 years old): - It can be learnt from various books. I haven't heard about it from any other media.

M060 (38 years old): - After marriage my wife brought a book named Biyer Age $O$ Pore (Before and After Marriage) from my father-in-law's house. My wife read the book and told me about it.

M089 (34 years old): - My friend read to me from a book. No information is obtained from them [FWA/FWV]. I can't give the name of the book. 
M100 (55 years old): - Radio and TV do not say anything about this subject but information is available in books.

M146 (60 years old): - No, no information is available through publicity media. A long time ago, I read about this method in a book of Hadith. I do not remember the name of the book.

[Other respondents who mentioned books as sources: nothing specific at all]

One man described his frustration at the lack of information about the safe period method in the following terms:

M064 (40 years old): - I could not hear about [the safe period method] as it is a secret matter. I am in a fix about whom to approach to learn about this method. ... My earnest desire is that I learn about this method well.

Among many of the men who had correct information about the safe period method, there is a hint of insider knowledge, obtained through family connections with knowledgeable people in the family planning service delivery system or other parts of the health service, and sometimes obtained from participation in training courses themselves. There are other cases of 'inside information' (M072, 31 years old: - 'I don't know if anybody gets any information. However, I didn't get any information from the family planning workers. But $\mathrm{Mr}$ [name], the health worker, told me about it personally.') The cases of three out of four men who mentioned training courses have already been mentioned here. The fourth, who had knowledge classified as correct, gave the following account to the interviewers:

M065 (39 years old): - I learnt about the safe period method from a training program organized by SMC [the Social Marketing Company, which sells oral pills and condoms]. In 1990, SMC organized training for the village doctors at Bagherpara. This was a two-day training program. Along with the other modern methods, the safe period method was discussed. They supplied us a pamphlet. That is still with me. There, in the training, they told us that if it is a 28-day menstrual cycle, then days nine to twenty-one are the danger period. If there is copulation during that period, there is every possibility of conception. Before or after this period, there is no possibility of having any conception. However, they also said that the days after the twenty-first day of menstruation are less safe than the early safe days. They also said that the scientists could not be unanimous on the issue as to on which day ovulation actually takes place. So, this method is not $100 \%$ reliable. On the whole it is $70 \%$ reliable.

Among the men, there were also some accounts of obtaining information about the safe period method from sources outside the local communities to which women were much more confined. The following is one example:

M151(45 years old): - They [FWAs] don't speak to me. Neither do they come to our house. I've heard about this method from a Russian doctor in the G.M. plant in Chittagong.

There can be no doubt that men have access to a wider range of primary sources of information about the safe period method than women, and this accounts both for the higher proportion who had heard of the method and for the wider spread of sources listed in Table 5.2. It also appears that some of these sources of primary information, no matter how wellintentioned, have had the effect of introducing misinformation, or at least they have not succeeded in creating correct knowledge. 


\section{Disseminating knowledge about the safe period method}

Both men and women were asked whether information about the safe period method should be disseminated publicly, and if so through what media. The responses to these questions differed considerably in the cases of women compared with men, due apparently to cultural reasons.

All of the women who answered the question in the negative answered by saying 'I do not want to know', rather than that information should not be disseminated. Often this negative response was not elaborated:

F018 (27 years old, 5 children ever born) and ten others: - I don't want to know anything about it. [+ variants]

In other cases the women said they were using a different method, or no method, so they did not want to be informed:

F054 (21 years old, 2 children ever born): - I don't want to hear about the counting of days method. Because we don't follow the counting of days method. As we have used a Copper-T, there is no need to know about following the counting of days method. F065 (34 years old, 2 children ever born): - I practice azal. This method is good for me. I do not want to listen to you about the safe period method.

F076 (35 years old, 4 children ever born): - I don't want to know anything in this regard. Because I haven't used this method.

F078 (44 years old, 7 children ever born): - No, I do not need to know. I will not conceive any more children. My husband has undergone the operation.

F088 (33 years old, 2 children ever born): - I don't need to know. The method I am using is better.

F098 (21 years old, 2 children ever born): - I don't want to know as I have selected the pill.

F110 (30 years old, 3 children ever born): - I do not need to know any more. Because I have adopted another method.

F114 (42 years old, 5 children ever born): - I don't want to know. My need is not that great. I am quite aged now, I don't need to know who will do what. I shall not follow the counting of days method. I shall follow that which I am following now. Because of this I don't want to know.

In other cases women felt they already knew enough about the safe period method so it was not necessary to be informed further:

F019 (38 years old, 7 children ever born): - No. I don't want to know any more. Whatever we know, we go on using. No, I have no more desire to know, what ever I know is sufficient. Whatever I know is not bad for me. So, I don't want to know anymore.

F048 ( 21 years old, 1 child ever born): - My purpose is served by the little that I know of it. I don't want to know more. During the last five years I have been observing the safe period method I have not faced any problem.

F085 (19 years old, 1 child ever born): - I do not want to know anything more. What I know will do. I have followed [the method] as I have known it and I did not become pregnant.

F086 (41 years old, 5 children ever born): - No I have known [about it] from my gurudev. It would have been better if I could learn it before. I would not have had so many babies. I do not need to know from anybody else. 
F146 (43 years old, 10 children ever born): - I do not want to know anything more. I came to know myself from a book. Besides, I will never practise it [safe period].

F151 (31 years old, 5 children ever born): - I used to follow the safe period method. I don't want to know further about it. What I know is enough.

There were some other miscellaneous negative responses:

F011 (23 years old, 2 children ever born): - I have no necessity to know anything about this day-counting method. Can anybody follow the counting of days method? The way I am following is good. Husbands will not be willing to follow the counting of days method.

F079 (34 years old, 6 children ever born): - I do not like it so I do not need to know it. F094 (21 years old, 2 children ever born): - It is my belief that the safe period method cannot prevent birth. That is why I do not want to know.

Relatively few men responded in any of these ways, although there were some (12 instances out of 152, compared with 28 out of 85 women). This does not mean that relatively few men said that they themselves did not want to know. There was a large group of men who said that they personally did not want any information, but qualified their statements by referring to which media were most suitable if information was to be made available. Their views are valuable because they contain few negative statements about publicity for the safe period method:

M009 (46 years old): - No. I don't want to know now. It will be better if people can learn about it from them [FWA/FWV]. The radio will also be better.

M014 (32 years old): - It is better to inform people about it through the family planning workers. I know about it. It shouldn't be publicized through the public media [radio/T.V.].

M045 (38 years old): - Whether I use it or not, it is better to know. It will be better if it can be learnt through training. And the way you have asked questions and you have told us, it will be better to be like that. It is best if the government appoints people to inform [others]. I don't want to know it through the radio and T.V. However, if it is publicized through the radio and T.V., it will not be a problem.

M060 (38 years old): - I don't want to know. But if the government wants to inform [us], it would be better to inform through the T.V.

M071 (42 years old): - I don't want to be informed. If the government wants to publicize these things, it can be done through the family planning workers. If questions are asked from radio and TV, answers are not given quickly.

M072 (31 years old): - No, I don't require any more. Whatever I need to know, I have learnt that. People of the country should be informed through the radio and TV.

M073 (37 years old): - No, I don't want to know. If it is to be taught to all the people of the country, it is better to publicize through the radio and T.V., because we can't read papers and magazines.

M079 (43 years old): - I do not need to know. If the government wants to inform [us], then it can be done through radio and TV.

M080 (47 years old): - I think what I know is enough, I don't what to know more. Those who want to know should ask questions to the Government workers who visit houses.

M081 (75 years old): - It is not necessary to know. Those who feel the need to know may hear [should be told] on radio and TV. Those who are educated can learn from books.

M099 (40 years old): - No, what shall I know? If the government wants to inform us, it would be better if it could be through the FP workers. 
M116 (43 years old): - No, I don't want to know. But if the government want to make the people know about this, then people like you can say this by going personally from house to house. This will be good for the people.

M136 (31 years old): - I know. I don't need to know. If the government wants to inform [us], it is better to inform through the radio and TV.

Since none of the women responded in this way, the general lack of negative attitudes towards media publicity displayed by these respondents indicates that there would be little public opposition to dissemination of information about the safe period method through the electronic media or the print media. In fact, we have now covered all of the negative attitudes except for one case which will be discussed shortly.

Out of those who had heard of the safe period method, a majority of women (56 out of 85) and a majority of men ( 75 out of 102) said that they wanted information about the method to be disseminated, and nominated what they felt would be the appropriate methods of disseminating the information. Table 5.3 shows the pattern of response, which is totally different in the case of women from the case of men. 


\begin{tabular}{|l|c|c|}
\hline \multicolumn{3}{|c|}{ Table 5.3. Appropriate Source for Publicity of Safe Period Method, } \\
Respondents Wanting Information Publicized \\
\hline Publicity source & Women & Men \\
\hline & & \\
Electronic media: & & 38 \\
\hline Radio & 10 & 47 \\
\hline Television & 4 & \\
\hline Print media: & & 9 \\
\hline Newspapers, magazines & - & 2 \\
\hline Books, booklets & 1 & \\
\hline Personal contact: & & 17 \\
\hline FWA, FWV & & 5 \\
\hline 'You' [interviewers], people like you & 40 & 2 \\
\hline 'Doctor' & 18 & 2 \\
\hline Experienced people informing others & 1 & 1 \\
\hline Training of 'village doctors' to inform others & 1 & - \\
\hline Sample Registration System workers & - & - \\
\hline Relatives & 1 & 2 \\
\hline & & \\
\hline Any/all media & - & 75 \\
\hline Number of respondents (multiple responses recorded) & & \\
\hline
\end{tabular}

Men favour dissemination of information through the electronic media, particularly television, while women favour family planning workers. A significant minority of women told the interviewers that they (the interviewers) were appropriate, or at least 'people like you', meaning educated people who knew something about the topic. Some similar responses were recorded by the male interviewers, but the responses were less personal, that is in the form 'people like you'. There were a number of instances where women began by responding 'you' but qualified their answers as they realized that FWAs would be more likely to remain in the locality and remind them if they forgot the details.

As mentioned earlier, there was one case of a man who qualified his statement in favour of publicizing the safe period method:

M052 (40 years old): - I want to know [more]. It is better if it is done through the FP worker. There is a problem to publicize through radio or TV because it is shameful to discuss this in front of children. Besides, many people do not listen to radio or TV. 


\section{$D^{\text {iscussion }}$}

The extent of inaccurate knowledge about a method in such widespread use, as the safe period method is in Bangladesh, is appalling. Basically most respondents do not just have poor knowledge, they do not really know what the method is or the foundation of its use.

It is among the most basic of reproductive rights of women that they should have enough information about the workings of their own bodies to understand choices that they might make about family planning. Approximately forty per cent of both women and men who had heard of the safe period method gave 'incorrect' accounts of when the danger period was, meaning that they nominated a safe period which intruded into the danger period in the middle of the month. To give such a version, a person cannot be aware of when ovulation occurs.

Very few women or men described a version of the method which allowed a safe period for a few days after menstruation, so that the knowledge which they had restricted the safe period to the last week or so of the menstrual cycle before the commencement of the next cycle. To conduct a satisfactory sex life with this version of the method, couples are virtually forced to combine it with other methods, such as azal and condoms, with attendant risks.

The very clear implication of the analysis in the first part of this chapter is that whatever obstacles have existed in the past to dissemination of knowledge about the safe period method, it is important that women and men should receive appropriate information about basic reproductive physiology if they wish to use this method of family planning.

The analysis in the second part of the chapter demonstrates that there would be general acceptance for dissemination of knowledge about the safe period method, but there are radical differences between men and women about the appropriate way to do this. Men are in favour of dissemination through electronic media, but women would most definitely prefer to obtain information on a personal basis from sources such as FWAs. 


\title{
Chapter 6. Family Planning Before First Birth
}

\author{
The reproductive health context of family planning before first birth
}

Dealing with early onset of childbearing is a critical issue in reproductive health in Bangladesh. An early start to reproduction is associated with high fertility, but this is a limited view of the reproductive health context. There are substantial risks for immature bodies at the time of delivery, and for the babies born from immature bodies. There are risks to infants if they are to be nurtured by women who themselves are little more than children, and whose under-developed reproductive systems are accompanied by under-developed mental and physical capacities to nurture. There is also the associated issue of impeded educational and social development of young women as valuable human resources by ascribing only one role for them, namely to bear and raise children.

Ideally, early childbearing can be avoided by later marriage, with its benefits for human resource development. If early marriage occurs, early childbearing can also be avoided by using methods of family planning immediately after marriage until the young woman is considered mature enough to begin to have children.

In this chapter, some of the factors affecting attitudes towards use of family planning methods immediately after marriage are examined. Analysis of data from the 1993-94 DHS, cited in Chapter 2, shows that use of 'traditional' methods is high among young people and especially high for those who have not yet had any children, relative to the use of other methods of family planning by adolescents. Among possible reasons for this are lack of access to family planning services and preference for 'traditional' methods. The influence of family members from the young man's side could also have a bearing on the issue.

In the absence of any previous investigation of the matter, we formulated a working hypothesis that married adolescent women in Bangladesh do experience some problems in access to modern family planning methods, and resort to traditional methods instead, but the main reasons that they have low use of modern methods is that use of traditional methods does not challenge traditional or parental attitudes. This working hypothesis played down the role of preference factors, but of course it was set up to provide a framework for investigation. In the field study, the topic of use of family planning before having children was introduced among the structured in-depth interview questions. In this chapter we report the main features of replies by respondents and the contextual style of their replies, which is important for interpreting the patterns of response.

However innocuous the topic might seem as a subject of enquiry, there were considerable problems reported by the field teams. These problems related to the concept of 'family planning method', to ingrained resistance against the idea of use of 'methods' before the birth of a child, and also to whether a family planning method could be used for any purpose other than stopping childbearing. More than in any other part of the interviews, there was obvious confusion among respondents about whether anything except a 'government method' was actually a method of family planning. The effect of this confusion is considerable in the context of discussion of delaying first births after marriage, because as will be seen there is a high level of concern about the health effects of program methods. It will be recalled that in the earlier sections of the interviews, emphasis was placed on ensuring that respondents knew that direct methods of family planning were included in the definition of the term 'family planning method' that we were employing. Nevertheless, respondents who claimed to have no knowledge of methods such as the safe period method and azal might not have been primed 
sufficiently to the inclusiveness of the intended concept. For people who think of adopting a method as using contraception to stop childbearing, while anything done to delay or space births is nothing to do with family planning, it can be confusing and even shocking to be asked about the use of methods before the birth of any child has occurred. The field teams persisted patiently in explaining the intention of their questions, but in the interests of avoiding non-cooperation they would move on quickly if the topic was too difficult. The result of their efforts is a valuable set of information about attitudes to use of family planning methods in the interval between marriage and first birth in Bangladesh.

\section{$A^{\text {nalytical strategy }}$}

In this chapter the results of this investigation are presented by first examining what was said by respondents about the attitudes of parents-in-law. Second, there is an investigation of the views expressed by respondents about the effect of use of family planning methods on the ability to bear children. Third, an assessment is made of views on whether it is necessary for a woman to prove her reproductive capacity after marriage. Fourth, we present a discussion of access to family planning methods by young people. The answers given by respondents about how many children should be born before a method of family planning is adopted are then examined. Finally, a statistical model of determinants of use of family planning before first birth is discussed.

\section{$A^{\text {ttitudes of parents-in-law }}$}

Most marriages in rural Bangladesh involve the movement of a young woman into the household of her partner's parents, itself located within a contiguous group of households, called a bari, with other households formed from the patrilineal line. Often these women are not just young but extremely young. Tradition seeks to make their wills subservient to the wills of the families they have joined, and particularly to the wills of their respective mothersin-law, who have experienced the same process one generation before. Apart from the relationship they form with their husbands, they can hope to form friendly relationships with their sisters-in-law and so-called 'joking' relationships with brothers-in-law.

For our purposes, there are two types of parents-in-law:

F052 (32 years old, 5 children ever born): - There are two groups. Those who are illiterate, they ask to take children immediately after marriage. They want to have fun with their grand children. Those who are a little conscious ask to delay birth. They say their daughter-in-law will live at peace if childbirth is delayed.

Without necessarily acknowledging the 'illiteracy' of the first group, or the 'consciousness' of the second, it is certainly possible to classify the women in the study almost completely into three groups: those who said parents-in-law wanted grand-children as soon as possible, those who said there were two types of parents-in-law, as above, and those who said parentsin-law (their own) encouraged them to delay having their first children.

In the first group, referring to parents-in-law who wanted no delay in the birth of grandchildren, there were 93 female respondents. In the second group, acknowledging two types of parents-in-law, were 37 respondents. And just 17 women formed the third group, referring to parents-in-law who encouraged them to delay having children. (There were three respondents who were outside this classification system for individual reasons.)

The first group should be examined a little more closely, because it is less seamless than it appears from the description given by this one respondent. It contains one major sub-group, two minor sub-groups, and a group of other miscellaneous responses, with very little overlap. 
The major sub-group consists of those women who reported that the reason their parents-inlaw wanted grand-children was because of the pleasure they obtained from having them:

F115 (43 years old, 8 children ever born): - The parents-in-law want us to have babies early. They want to see the faces of their grand sons and grand daughters. They want to take their grand children in their lap and they want to fondle them.

There were 57 respondents who gave answers in this vein.

The first of the other, minor sub-group contains women who referred to the concerns of parents-in-law about the health risks associated with use of family planning methods, particularly about supposed effects on the ability to conceive, but also about effects on the ability of women to carry a baby through to term and deliver safely. A selection of statements illustrates the major concerns expressed:

F034 (15 years old, no children): - My mother-in-law forbids taking of pills. Pills are harmful to health. Many say pills prevent pregnancy [permanently]. That's why my mother-in-law does not like pills.

F055 (40 years old, 2 children ever born): - Parents-in-law say, 'Take a method after the birth of a baby.' If a method is used without having a baby, fat accumulates in the abdomen and it causes problem afterwards in having babies. For this reason, the mothers-in-law prohibit the use of methods.

F056 (19 years old, no children): - No, mothers-in-law are not in favour of any method. They have the idea that if methods are adopted before the birth of a baby, children will never be conceived afterwards.

F097 (30 years old, 2 children ever born): - Parents-in-law do not forbid the use of any method after two babies. But they prohibit use of a method immediately after marriage. They restrict the use of the pill because it accumulates fat in the womb. If fat accumulates in the womb, it can make it a problem to conceive.

F151 ( 31 years old, 5 children ever born): - The elders say that we should have babies first and then follow a method. If a method is used at the beginning we may not have a baby later. For this reason, they forbid us to use a method. If government medicine [contraceptive] is used, a woman may not be pregnant later.

It will be seen that the same concerns are often expressed by the respondents themselves, and not just by those who attribute these views to their parents-in-law, of whom there were 21 in this sub-group.

There were only three women who belonged to both of these groups, that is, who said that their parents-in-law wanted to see the faces of their grand-children and were concerned about health risks from the use of family planning methods. This lack of overlap indicates that these groups are quite distinct.

The same is true for the other minor sub-group, which had no overlap at all with the other two. This consisted of just eight women, who said that their parents-in-law opposed the use of any family planning methods because they were sinful.

There were a further ten women who gave various non-specific responses about the opposition of parents-in-law to the use of family planning methods, or in some cases highly specific responses which did not fall into the other three groups. The following are examples: 
F039 (34 years old, 3 children ever born): - If no baby is born after marriage, we ourselves feel bad. My parents-in-law do not say anything regarding this.

F064 (29 years old, 3 children ever born): - Fathers and mothers-in-law want grand children. After the birth of my first child my mother-in-law told me not to adopt any method. She said that a child might die afterwards [leaving her with none]. My father and mother-in-law prohibit me from using any method.

F156 (23 years old, 4 children ever born): - The parents-in-law tell us to use a method after the birth of four children. Does anybody use a method just after marriage? Why should people use a method before the birth of a baby?

The incredulousness of the last of these three women was repeated in the interview of another woman from the same area, in Satkania. It was apparently the first time that either of them had heard of using a method of family planning to delay the first birth, and beyond their comprehension. Naturally this made it difficult to discuss the topic with them.

We have already used an example from the rather large group of 37 women who referred to the existence of two type of parents-in-law. Their responses vary little in content, with perhaps the most representative one being the following:

F106 (30 years old, 1 child ever born): - Some mothers-in-law want children to be born early [after marriage]. They want that if babies are born early, they will be able to see the faces of their grand-children. Again, some say that the health of the daughter-in-law will remain good if childbirth is delayed.

Specific reference to maintaining the daughter-in-law's health occurs in more than half of the cases in this group, and most others refer to other developmental benefits for the daughters-inlaw, whom it should be remembered are often extremely young at the time they join the household. The main counter-factual case is the following, which refers to very different reasons for delaying the birth of the first child:

F004 (26 years old, 4 children ever born): - There are some fathers and mothers-inlaw who are pleased if a baby is born early. On the contrary, there are some ... who become displeased if a baby is born early. They will be annoyed and say, 'Our daughter-in-law has come from her parent's house along with a baby.' My sister-inlaw (the wife of the brother of my husband) has a daughter. Her mother-in-law advised her to abort her pregnancy. Her mother-in-law said to her, 'Why have you come to our house with a baby in your lap?' On the other hand some mothers-in-laws are there who want early births from their daughters-in-law with a view to seeing their grand children.

Among the seventeen women who refer to parents-in-law who approve of the use of family planning methods before the birth of children, there are also examples of this attitude:

F066 (16 years old, no children): - The mothers-in-law of remote villages advise their daughters-in-law to take the oral pill in order to avoid early conception. In case of early conception, they cut jokes that their daughter-in-law had brought a baby along with her. Then they consider that the daughter-in-law is too mature a woman.

Most of the women, however, refer to having parents-in-law who encourage them to delay childbirth for the sake of well-being, as in the following examples: 
F016 (17 years old, no children): - My parent-in-laws have asked me to delay having a baby. As I have been married young, so they have asked me to delay childbirth. My mother-in-law says that if I have a baby now, my health will break down.

F045 (20 years old, 1 child ever born): - My mother-in-law thinks that there should be a delay before having a baby. My mother-in-law pointed one woman out and said to me, 'Look, that woman waited three years before having a baby.' Instantly I understood that she was telling me to delay having a baby.

F146 (43 years old, 10 children ever born): - In-laws advise us not to have children at the beginning of our marriages. The health of the daughter-in-law will remain good. For this reason they advise us to delay having children. ... All other methods are prohibited, except withdrawal and safe period methods.

F160 (43 years old, 7 children ever born): - Now-a-days, mothers-in-law think that the health of their daughters-in-law will be safe if childbearing is delayed. No illness can arise. The son and daughter-in-law can enjoy life for some time if childbearing is delayed after marriage.

The last two examples come from Satkania, a conservative location in the conservative Chittagong division, and have been selected in order to illustrate that attitudes construed as 'progressive' can exist in any environment. Notice, however, that the methods said to be permissible for one of these two women do not include program methods, and that both women had many, many children. Parents-in-law who exhibit attitudes of this type are themselves well ahead of the family planning program's practices. While women without children are meant to be registered by family planning field staff, such women are rarely visited on the regular rounds of FWAs for supply of family planning methods because of an assumption that women without children do not need contraceptives.

Compared with the lucid and comprehensible responses given by women about this topic, the responses given by men are vague and often unformed. It is useful to quote a few examples of opaque responses given by the respondents:

M005 (35 years old): - I have not heard the parents forbidding it. In our area parents do not say anything like this to their sons and their daughters-in-law. After marriage, they want to see their grand children.

M011 (40 years old): - They [parents] become pleased if a method is taken after the birth of a son. But they don't tell us anything about it. Now-a-days everyone wants to keep the family-size small.

M024 (35 years old): - I cannot say exactly.

M043 (41 years old): - The father does not know about it since it is a confidential matter between the husband and the wife. My parents do not oppose much the visit of a worker to our house. If no child is born during a long time they think that the daughter-in-law may have some physical defects. So, they ask [her] to have medical treatment.

The reason for this is quite clear. It is that men usually do not know first-hand what advice or instructions are given to daughter-in-law by mother-in-law, and in many families it is not a topic for discussion between son and parents. We are not meaning to imply that such interaction never occurs, but its impact might not have the immediacy of the interaction between a young woman and her mother-in-law. 
It is evident from the statements made by women that the views of mothers-in-law are prominent in their thoughts about the use of family planning during the early stages of marriage. What remains to be seen is whether the influence projected by mothers-in-law has an impact on their sons' wives' views about the propriety of using family planning before the birth of first children.

\section{$E^{\text {ffect of family planning on the ability to bear children }}$}

As we have just seen, one of the factors fuelling parental opposition to delaying childbirth is concern about the health effects of contraceptive methods, and particularly about the possibility that family planning methods can affect the capacity to conceive babies, or deliver them without trouble. It is to be expected that similar concern will be expressed by respondents themselves.

Several types of concern are expressed. One of the most common is a belief that fat accumulates in the abdomen or even in the womb as a result of use of the oral contraceptive pill, and as a result conception becomes difficult or impossible. This belief is sometimes extended to other family planning methods. There are many statements about this in the women's interviews, with some of the variations included in the following examples:

F004 (26 years old, 4 children ever born): - Yes, I have heard that fertility is lost. Whatever method is used to prevent birth will cause accumulation of fat in the intestines. When a Copper-T [IUD] is used or the oral pill 'Maya' [brand name] is used, fat is accumulated in the intestines. I also believe it. ... However, fat does not accumulate if the pill is [only] used for two or three years. But if any method is taken for five years, fat accumulates in the intestines.

F032 (36 years old, 2 children ever born): - One can't use a method before having any baby. Fertility is lost if a method is used immediately after marriage. If azal and the method of counting of days are adopted, one may have a baby later on. But if the family planning pill is used, it accumulates fat in the belly. Then it creates problems at the time of delivery. [Note how this woman is confused over what is a method.]

F042 (35 years old, 3 children ever born): - Many women accumulate fat in the womb if they take steps to prevent pregnancy. Health improves if pregnancy is prevented. My health has improved because I have adopted a method. If one does not have babies for five years after marriage, no baby is born later. That's why methods should not be adopted before the birth of a baby.

F067 (35 years old, 2 children ever born): - It is better to adopt a method after the birth of a baby. If the oral pill is taken before the birth of a baby, it may cause accumulation of fat in the belly, which ultimately causes infertility. I do not believe it because after the birth of a child I took the oral pill for five years [without any problem].

F069 (32 years old, 5 children ever born): - If methods are taken immediately after marriage, it creates problems in having children later on. Fat accumulates in the womb. After marriage some women use methods and they have babies when they discontinue the method use. On the other hand, fat accumulates in the belly of some women due to method use, but they can have babies if they get their belly washed. ${ }^{14}$

\footnotetext{
${ }^{14}$ The term 'wash' in this context usually means menstrual regulation. Here she apparently means a curette procedure.
} 
Another frequently-mentioned health problem emanating mainly from pill use is said to be 'burning' or drying of the reproductive tract, and other specific conditions are also mentioned by some respondents:

F006 (38 years old, 5 children ever born): - One can not take pills soon after marriage. It causes damage to the womb. It is not proper to use any method before the birth of a child. Fertility is destroyed if any method is used. The womb and the fallopian tube become small. So, the wife cannot contain the discharged matter [semen]. But if azal or the safe period method is used, it will not cause any problem for conception.

F013 (31 years old, 1 child ever born): - Some people are affected [by use of a method] and cannot have any baby soon after their marriage and some are benefited. After their marriage some women take pills and suffer from dizziness and as a result suffer from problems at the time of the delivery. Fertility is not lost if the counting of days method is followed.

F027 (18 years old, no children): - It becomes difficult to have a child if pills are taken. Doctors and neighbours say there will be no children if pills are taken. If injections are is taken, the body, hands and legs burn, disease ${ }^{15}$ occur and there will be no child.

F062 (36 years old, 3 children ever born): - It is not good to take a baby soon after marriage. Use of pill burns the intestines in the stomach. If condoms are used, they cause scarring in the fallopian tube. For all these reasons, it is better not to use any method before a baby is born.

F089 (22 years old, 2 children ever born): - The ability to conceive is not ruined. [Note that she then changes her mind.] Some say that pills may burn the womb. I do think pills may cause problems in respect of pregnancy. Now, I take pills. I've two children, so, there will be no problem if no other child is born. But no problem is created in regard to conception if condoms, withdrawal and safe period are used.

F094 (21 years old, 2 children ever born): - I have heard that the womb dries up if the pill is taken. Injections are very powerful. If used, later on it causes a problem for conception. If methods such as condoms, safe period and withdrawal are adopted and later on the methods are dropped, then conception will occur.

F162 (35 years old, 3 children ever born): - The pill can't be taken. It can burn the birth tube, so one can't conceive. I have heard that injections prevent fertility. I don't know about the other methods. But condoms can be used.

Many other respondents, including some who said they did not believe it themselves, reported the existence of such a belief. Two examples are sufficient to show that there is very little difference between disbelief and belief, in such cases:

F011 (23 years old, 2 children ever born): - Everybody says that later on, method use will create problem during delivery. In our area, a woman took oral pills and later on her child producing intestine dried up. Hearing all these things, people say that no baby will be born if the pill is taken. I do not believe this. I used pills. Had my child producing intestine dried up, it would have been better for me, I wouldn't have

\footnotetext{
${ }^{15}$ Since no distinction is made in ordinary speech, the term translated here as 'disease' (meaning a specific condition) is often intended to mean what is simply called 'illness' in English.
} 
needed to take injections. But my child producing intestine has not dried up. This is why I don't believe it.

F058 (25 years old, 1 child ever born): - I have heard that if pills are taken before the birth of a baby, the womb may become fatty. Unless one has a baby, one should not take injections. I took a neighbouring woman to the hospital. There they said that injections could not be given to those who did not have a baby yet. Injections can be taken after a baby. All other methods may be adopted before the birth of a baby. By adopting a method a woman's fecundity is not destroyed. When the method is dropped one can conceive.

We have quoted enough cases to illustrate the ubiquity of beliefs that prolonged use of family planning methods has a permanent effect on the ability to conceive. The examples just quoted shows that belief (or disbelief) is often supported by mention of specific cases. Some other testimony to cases of infertility attributed to family planning methods is given by the following respondents:

F007 (33 years old, 3 children ever born): - Fertility is lost if the oral pill is taken soon after marriage. One of my sisters has faced this problem.

F054 (21 years old, 2 children ever born): - If a method is taken soon after marriage, one may not have any baby at all later on. I have seen this. But I think that one can take a method after marriage and can have a baby afterwards when one wants to take a baby.

F075 (28 years old, 3 children ever born): - I have heard that if pills are taken, the ability to conceive is destroyed. I have seen with my own eyes that in my neighbourhood a woman has lost the ability to conceive because of taking pills. That's why I believe that pills destroy one's capability to conceive.

F103 (29 years old, 2 children ever born): - A woman who is our neighbour cannot conceive. I think she has lost her power. One can lose the capability of being pregnant if she starts using pills soon after her marriage. But no problem occurs if the pill is taken after one baby is born.

F140 (28 years old, 4 children ever born): - Fertility will not be lost if condoms are used. But one of my nieces is not having any baby, due to the use of pills. I also think that no baby is being born due to the use of pills.

All of these statements are framed without specific mention of the cause of the supposed effect on reproductive capacity, and there are many other non-specific statements which do not contain references to actual cases. (Respondents were not asked if they knew of cases.)

Before attempting to summarize findings on this topic, it should be mentioned that there are counterfactual statements, though few in number. These are of two types. The first type of counterfactual statement is that discontinuing a method helps a woman to conceive, not just restores the ability to conceive. This view is found in varying degrees of intensity but is quite explicit in some statements, such as the following:

F093 (29 years old, 2 children ever born): - If a method is used [immediately] after marriage, there will be no problem later in bearing a child. As birth can be prevented if the pill is taken, so those who do not have any baby yet, if they take pills and then discontinue, they may conceive. As pills prevent the birth, they also help to give birth to a baby [if they are stopped]. 
The second type of counterfactual statement is that it is best for the health or welfare of the woman if she has babies as soon as possible, as for example in the following case:

F029 (22 years old, 2 children ever born): - Delivery at an older age causes hardship. It is better to use a method after the birth of one or two children. It is better to have babies at an early age.

Although some differences are discussed shortly, the views of men were quite similar to those of women. Table 6.1 summarizes the views of all respondents. It can be seen that the major difference between male and female respondents is that there was only one case of a man stating that he had heard that the ability to conceive or deliver babies could be affected by method use, but did not believe it himself. There was also a quality of greater vagueness about the responses from men, evidenced not only by the much larger number who said they did not know if there was an effect, or gave a non-specific response, but also by the way in which responses were given. The first example below was classified as 'does not know' and the second example was classified as an 'other response', although both answers could also be classified as stating that reproductive capacity can be impaired.

M003 (29 years old): - I do not know anything about all these things. I have been married only one year and three months. How can I learn so much in such a short span of time? I think that the womb may move upward because of the use of a method. I know no more about it.

M044 (30 years old): - This is not known to me. It has been six years, my friend has no children. Now they are not having any children but I do not know the reason for this. Doctors can say. But everybody suspects that this happened for taking pills. 
Table 6.1. Existence of Problems from Method Use Affecting Reproductive Capacity - Views of Women and Men

\begin{tabular}{|l|c|c|}
\hline Response category & Women & Men \\
\hline Reproductive capacity can be impaired & 48 & 38 \\
\hline Heard of problems, but disbelieves & 17 & 1 \\
\hline Reproductive capacity cannot be impaired & 75 & 73 \\
\hline Does not know & 7 & 21 \\
\hline Other response & 1 & 6 \\
\hline No response & 2 & 2 \\
\hline Interviewed & $\mathbf{1 5 0}$ & $\mathbf{1 4 1}$ \\
\hline
\end{tabular}

There were responses from men that were just like responses from women:

M077 (46 years old): - If the pill is taken, fat may accumulate in the womb. Most of the time no baby comes into the womb if a method is used before the birth of a child. Again it has been found that even if conception takes place it causes problem during delivery.

But in many other cases there was a 'practical' aspect to the way in which responses were given by men:

M036 (30 years old): - Fecundity is not lost. This [family planning methods] has been invented after research to stop child birth and not to destroy fecundity. So, it does not destroy fecundity.

M043 (41 years old): - No, it's not destroyed. These family-planning methods have been examined by competent researchers. So, if it is used, no harm is done to babies.

M065 (39 years old): - If anybody wants to use a method, she must consult a doctor or a field worker. She must learn from them whether they would lose their fertility for using any method.

The existence of this 'practical' quality suggests that an approach to male involvement in family planning which exploits it could be fruitful. There is evidence in these responses of respect for the authority of experts in these matters, but it is the way in which the validity of expertise is recognized that provides the hand-hold on which a successful male intervention could be built. Almost the same words used by these respondents could be employed.

There was also a cryptic quality to some responses, which it is possible to interpret in the light of the response pattern of women, but (standing alone) could easily be misinterpreted:

M071 (42 years old): - How can I say that? I don't know what method will be adopted and how long will it be continued. 
This man is apparently inviting more specific questions. If we asked him about specific methods used continuously over a period of years, how would he answer? We have seen that women often said that use of some methods in this way would impair reproductive capacity.

One aspect of the opinions expressed by both men and women that is highly relevant to the overall aim of this report is that not only do the respondents mention adverse effects of some program methods, especially the oral contraceptive pill, but they also occasionally refer to direct methods as safe. Since these opinions relate directly to whether people will approve of use of family planning methods before the birth of the first child to a marriage, we should expect that they will be instrumental in deciding such approval.

\section{Proof of reproductive capacity}

Apart from significant disincentives to the use of family planning methods before having children because of concerns about the effect of methods on reproductive capacity, it is possible that some respondents disapprove of the use of methods on the related grounds that a woman should prove her reproductive capacity as soon as possible. Again there are distinct differences in the patterns of response given by men and women, with women less inclined to agree that it is necessary to prove their reproductive capacity.

Among women who do agree that it is necessary to prove their ability to have children, there are two distinct patterns. The first pattern has some variants so it is useful to give a number of examples:

F019 (38 years old, 7 children ever born): - A baby should be had soon after marriage. Why should one take those pills first? After marriage, it is necessary to know whether a couple is fertile or not. For this reason we will say one must have a baby first. One should have a baby first and thereby prove her fertility.

F022 (25 years old, 3 children ever born): - It is necessary to have babies early. It is better to have babies just after marriage. If a baby is born soon after marriage, a husband cannot divorce his wife because of the baby's presence.

F036 (21 years old, 1 child ever born): - After marriage, without taking any method, it should be tested, whether conception occurs or not. It is better to take a method after knowing, but how would it be known to oneself whether one will have child or not? It is difficult for those who want to delay child birth to know. All families are not the same. In some families the mothers-in-law bring pills for their newly married daughters-in-law.

F075 (28 years old, 3 children ever born): - If I adopt a method before having babies, I may not have a baby at all. It is better to use a method after having one or two babies.

F102 (42 years old, 7 children ever born): - It is important to know. It should be seen without taking any method whether there would be any baby or not. Then a method should be taken. Many people are infertile, they need not to take any method.

F153 (38 years old, 3 children ever born): - It is necessary to know before a method is used. But how can one know whether babies would be born or not?

There are several different strands here. One is the trial by ordeal which many women feel they should endure to establish that they can bear children. Another strand (F075) is the fear that using a family planning method will impair fecundability before reproductive capacity 
has been proved. A counterfactual strand is evident in the observation (F102) that infertile women do not need to use methods, with the implication that unless fertility is established it might be unnecessary to use a family planning method. And puzzlement about how to establish reproductive capacity (F153) also occurs in a number of cases.

Similar statements are made by men, as in the following examples:

M015 (43 years old): - Certainly it is necessary to know. It is not necessary to know for the first two to four years of marriage. It may be known when a couple needs a baby. I can't say anything more.

M099 (40 years old): - It is important to know. The method may be harmful to her, things might be like that. Even there may be no baby at all. So it should be known first by having a baby.

M118 (25 years old): - One should know about it. To know whether she can conceive or not, a woman must be pregnant before following any method. To know about fertility she should conceive a baby before adopting any method.

M137 (29 years old): - It is necessary to know it. But I don't know how to know it.

M134 (43 years old): - It is certainly necessary to know. It can be known through experimentation.

The possibility of initial abstinence, that is delay of commencement of sexual relations after marriage, was not really recognized in the design of these structured questions, and it may be the basis for some of the difficulty which some men had with the topic (M015).

The second pattern of response among women and men who thought that reproductive capacity should be proved was to say that it should be done by medical examination. This pattern was very much less common among women than men, but the following examples include some statements from women:

M010 (47 years old): - The condition may be ascertained through medical check-up. That is a delicate matter. It will not be wise to make any comment.

M078 (55 years old): - Before having children it must be known if a woman is able to bear children. It has to be known by examining at the hospital.

F088 (33 years old, 2 children ever born): - It is necessary to know before the birth of a baby. Many women say that no baby is born if the pill is taken for two or three years consecutively. So, one must know from a doctor about her fertility before using a method. If it is learnt that the woman is infertile, there would be no need to use any method.

M098 (30 years old): - It is important to know. The lady doctors [FWA] who come in the village, their advice should be taken.

F130 (34 years old, 4 children ever born): - It is necessary to know whether one is capable of producing a child before adoption of a method. It's better to get oneself examined by a doctor and then to use a method. Why should they who cannot have a baby adopt a method? 
By 'hospital' these respondents generally mean the Family Welfare Centre, and the 'doctor' that they expect will establish reproductive capacity is the Family Welfare Visitor (FWV), who is not qualified to establish any such thing. In one case, a man nominated the FWAs who distribute pills and condoms as the appropriate people to decide whether a woman's reproductive capacity is sound. This pattern of response, largely confined to men, was met frequently in all areas in which the study was carried out, so it is not a local myth.

Again there is sensitivity expressed by one male respondent (M010).

Among both men and women, there were many who said that it was unnecessary to prove reproductive ability. We will cite only three examples, the first representing the typical pattern, and the second and third because of their explanatory interest on other matters:

F011 (23 years old, 2 children ever born): - I don't believe that after marriage a woman has to prove by taking a baby that she is fertile.

F014 (26 years old, 3 children ever born): - ... On meeting her husband after marriage, a woman can understand whether babies will be born or not. People adopt methods if they know that they will have babies. Nobody ever thinks that she will not have a baby.

M105 (31 years old): - No, why should it be proved? It is not good to take pills before the birth of babies, one gets fat in the belly.

The second example refers, only a little obliquely, to the reproductive capacity of the man as an important factor. The third example has been given because this man had said that the reproductive capacity of women was not affected by the use of family planning methods, yet only a few seconds later he was referring to one of the most common opinions expressed about effects of family planning methods on capacity to reproduce. This example is by no means isolated. It occurs because the order in which respondents choose to reveal beliefs, about which they have not been questioned directly, is in essence up to them. To identify the actual prevalence of any belief it would be necessary to ask direct questions, and all that we can do here is establish that they are present in the sample and they are often mentioned.

Many respondents, but especially men, had difficulty giving any meaningful response on this topic, as shown in Table 6.2 


\begin{tabular}{|l|c|c|}
\hline \multicolumn{2}{|c|}{ Table 6.2. Existence of Need to Prove Women's Reproductive Capacity - } \\
Views of Women and Men \\
\hline Response category & Women & Men \\
\hline Reproductive capacity should be proved - by trial & & 32 \\
\hline \multicolumn{1}{|c|}{ - by 'doctor' } & 43 & 38 \\
\hline No need to prove reproductive capacity & 7 & 33 \\
\hline Does not know, no opinion, unsure & 77 & 18 \\
\hline Other response & 7 & 7 \\
\hline No response & 7 & 13 \\
\hline Interviewed & $\mathbf{1 5 0}$ & $\mathbf{1 4 1}$ \\
\hline
\end{tabular}

While one third of the women and just under half of the men in the sample definitely stated that it was important to establish reproductive capacity, this does not necessarily establish that this opinion will translate directly into opposition to the use of a method of family planning before the birth of a child. It is no doubt likely to have some association.

\section{$A$ ccess to family planning by young people}

Nearly all respondents, both women and men, agreed that young married people had no problem with access to family planning methods. This consensus was based on the multiple avenues that existed to get hold of contraceptives. If we accepted this evidence, it would be directly counter to the working hypothesis stated at the beginning of this chapter. In this section, it is better to cover, briefly, what was said by the few young respondents themselves, as they are the ones most directly affected by the matter.

There were only thirteen cases in the sample where the woman was aged less than twenty years. They are listed in Table 6.3. The very large age differences between women and their husbands are not unusual in Bangladesh.

Of these, only F027, F030, F044 and F085 have ever used methods other than 'traditional' methods. Their statements do include some minor references to problems of access:

F027: - The new wife can go to the hospital, there is no problem in it. Methods can also be taken from those who come to give pills.

M027: - The older generation do not like to allow the workers [to come] because taking pills is not good at this age. It will affect health.

F030: - Husbands can bring them. There is no problem in getting the supplies. M030: - No problem is caused. It may be purchased from the market.

F044: - If the mother-in-law forbids [contraceptive use], then the husband will secretly bring pills and condoms. Sometimes sisters-in-law can also bring them. There is no problem.

M044: - No, there is no restriction. It is available in the shops, clinics and with the family planning workers. 
F085: - If they want they can take any method. They can take pill from those who come to give it. The husband can also bring it.

M085: - There is no problem and no barrier.

Table 6.3. Adolescents in the Sample

\begin{tabular}{|c|c|c|c|}
\hline Case number & Woman's age & Man's age & Children ever born \\
\hline F003 & 15 & 29 & 0 \\
\hline F016 & 17 & 26 & 0 \\
\hline F027 & 18 & 25 & 0 \\
\hline F030 & 19 & 33 & 2 \\
\hline F034 & 15 & 25 & 0 \\
\hline F041 & 16 & Not interviewed & 0 \\
\hline F044 & 16 & 30 & 0 \\
\hline F056 & 19 & 27 & 0 \\
\hline F057 & 16 & 29 & 0 \\
\hline F066 & 16 & 21 & 3 \\
\hline F070 & 19 & 42 & 24 \\
\hline F085 & 19 & 25 & 1 \\
\hline F139 & 18 & & \\
\hline
\end{tabular}

It is reasonable to conclude that minor problems which do occur are easily overcome. At least one partner from each of these four couples agrees with the consensus which appears to have been adopted by the population as a whole. This consensus, which seems like that of a group of observers, is very well represented by the views of the other nine young couples, none of whom have yet been in the position of using methods which must be obtained.

F003: - What problem? My husband will take supplies from those who supply pills from door to door. Why be ashamed of it? In case of shyness my husband will buy modern methods from the shops.

M003: - If the young couples want it they can get it from the FWA or buy it from the market. Now-a-days, pills, condoms etc. are not difficult to get.

F016: - No problem is there in getting methods after marriage. If the husband is told he can bring it.

M016: - No difficulty is faced. [Name of FWA] delivers things. If she doesn't give it, it may be bought from the shops.

F034: - No problem exists. One can buy it from the market and have it. The husband brings them from market.

M034: - [No response]

F041: - There is no problem is getting supplies. My husband can bring it from the doctors. It is available with those who supply pills at the doorsteps.

M041: [No interview] 
F056: - What's the difficulty? I may get pills from those who distribute them from house to house. I may have pills, sitting at home, I will not feel shy even in the presence of my mother-in-law.

M056: - No, there's no problem. Government workers supply them. Further, if one wants supply from them, they provide.

F057: - No problem will be caused. My husband will make arrangement. If I feel shy, my husband will fetch it.

M057: - I can't say.

F066: - I don't face any problem in getting contraceptives for the prevention of birth. If I tell my husband, he will bring it. Even my mother-in-law wants to bring contraceptives for me.

M066: - No. The field workers come and supply us. They provide us contraceptives on demand.

F070: - If one is willing, one can adopt a method. Those who supply pills can give what one requires. What's the difficulty?

M070: - I don't understand much of it. I'm not a fish for such deep water and I don't keep enough information.

F139: - They don't face any problem in getting supplies. Their husbands will bring [supplies] from the shops. Also they can receive supplies from those who supply pills. M139: - Those who want, they can get family planning methods. They don't face any problem in getting those methods. Family planning methods are available in the hospital and with the government women [FWAs].

In summary, if any problems of access to family planning methods are encountered, they are quite easily overcome.

How many children should be born before adopting family planning?

As we have seen, none of the items, that were discussed by the interviewers to investigate use of family planning before first birth, was as innocuous as it might appear. The number of children that should be born first was no different as an item. Because it was men who had the most difficulties with preceding items under the topic, we might expect that they would also have more difficulty than women with this one. They did find considerable difficulty.

Despite the limitations of the data, it is possible to classify most responses into one category, and when this is done in Table 6.4 the results are surprising indeed, after the discussion in earlier sections of this chapter. 
Table 6.4. Number of Children Needed Before Adoption of a Family Planning Method Views of Women and Men

\begin{tabular}{|l|r|c|}
\hline Response category & Women & Men \\
\hline None & 61 & 42 \\
\hline One & 16 & 26 \\
\hline One or two & 16 & 33 \\
\hline Two & 36 & 20 \\
\hline Two or three & 10 & 6 \\
\hline One son and one daughter & 2 & - \\
\hline Two to four & - & 3 \\
\hline Three & 3 & 3 \\
\hline Other number ${ }^{\mathrm{a}}$ & 3 & 1 \\
\hline Other response & 1 & 4 \\
\hline No response & 2 & 3 \\
\hline Number interviewed & $\mathbf{1 5 0}$ & $\mathbf{1 4 1}$ \\
\hline
\end{tabular}

a Includes one case of a man specifying 'one daughter and two sons', one case of a woman specifying 'three or four', one case of a woman specifying 'four' and one case of a woman specifying 'two sons and two daughters'

The first source of difficulty was lack of acceptance on the part of some men that a family planning method could ever be used, put succinctly in the answer of the following respondent:

M139 (25 years old): - Family planning methods should not be used before or after the birth of a baby.

This was the husband of one of the adolescent women mentioned in the previous section, aged 18 and already the mother of three children. There were other cases.

The second source of difficulty, found much more commonly and only among male respondents, was the need to place conditions on the response. Three different types of condition are included in the following responses:

M032 (43 years old): - It depends on the age [of the couple]. Very young couples can have a baby after using a method for a long time. And those who are older can have a baby first and then use a method.

M033 (39 years old): - Those who have inconsistency of age and income, and are financially insolvent, should delay having babies. Otherwise one or two children may be had after marriage and then a method should be used.

M105 (31 years old): - If it is necessary to use a method before babies are born, the safe period method may be observed. Before using any other methods, one or two children should be taken. 
There were other responses by men which allowed the possibility of more than one outcome, but without conditions:

M096 (35 years old): - It is better to use a method after the birth of one or two children. But if anybody wants to delay having a baby, he can use it - no problem will be there.

While these respondents were able to articulate the difficulties that they had with giving a single response, there are certainly many other cases where men gave a single answer but were not at ease with their answers. This observation applies to all cases where there was confusion about whether the term 'family planning method' included anything other than program methods.

In the introduction to this chapter, we referred to the related issue of whether it was proper to use a family planning method for any purpose other than stopping childbearing. Now that widespread fear about the possibility of permanent effect of some methods has been discussed in this chapter, the challenging nature of the suggestion that methods could be used before a woman has any children can be appreciated. The thought process which lies behind a particular response is illustrated in the following example, with the italicized section referring to the issue we are discussing:

M089 (34 years old): - ... The ability to conceive may be destroyed as a result of the use of modern methods. The womb may stop functioning. ... A method should be used after the birth of the number of babies one wants. ... [What method could be used before first birth?] No method should be used before the birth of children. ... No, they [young people] don't face any difficulty in getting a method. Government workers supply them. If one wants, one can buy them from a shop.

This man was only referring to program methods. He believed that these methods could cause sterility. He definitely could not countenance the use of any method before a birth had occurred. There is little hint of any of this context in the italicized statement.

Similar difficulties were experienced by female respondents, but were not nearly as apparent. Some examples, chosen for their interest, are the following:

F006 (38 years old, 5 children ever born): - A method should be used after the birth of a child. If the oral pill is taken after a birth has occurred the womb does not shrink. So, it helps the births of children.

F034 (15 years old, no children): - In my opinion, if one wants to take pills, one should take them after a baby is born. Because if one takes pills, one may not have a baby at all. What we do, can be done before one has a baby. There is no problem in our method, i.e. the method of throwing semen outside.

F056 (19 years old, no children): - Many are of the opinion that a method should be adopted after having one or two babies. If a method is followed in the very beginning, one may not be able to conceive. For this reason, a method should be adopted after the birth of one or two babies. But I think a method may also be adopted immediately after marriage.

F075 (28 years old, 3 children ever born): - A method should be adopted after the birth of two children. If a method is used earlier, then one may not have babies at all.

The first example extrapolates the belief that it is better to use the oral contraceptive pill after children have been born in two directions: one, that use of the pill can actually help 
conception (after it is stopped), and two, that possible loss of reproductive capacity from pill use only affects women who do not yet have children. The second example gives a conditional answer, dependent on type of method used. The other two examples limit the reference of the statements to program methods.

Despite the disincentives that we have discussed, 41 per cent of women and 30 per cent of men said that a method of family planning should be adopted before the birth of any children. We suspect that these proportions are considerably higher than would have been obtained with a more summary survey approach. We also suspect that approval of delaying the first birth could be even higher if respondents recognized that it was possible without jeopardizing reproductive capacity. For instance, out of the 86 women who said that at least one child should be born before a method was used, 28 mentioned concerns about loss of reproductive capacity as the reason, more than the number (24) who proffered any other reason.

\section{$A$ statistical model for approval of use of family planning before first birth}

The evidence accumulated in this chapter indicates a very strong role for fear of loss of the capacity to bear children from the use of modern methods, the need to prove reproductive capacity, and the views of mothers-in-law, as motive forces to have children before adopting a method of family planning. It is reasonable to discount any major role for access to family planning methods.

There are many other potential influences, such as socio-economic background, which should be taken into account in a more complete assessment. For this purpose, a multivariate analysis was carried out, using as dependent variable whether a woman said that family planning methods should be used before first birth or not. The explanatory variables included were:

\begin{tabular}{|c|c|c|c|}
\hline 1. & Religion & : & Muslim or Hindu \\
\hline 2. & Age of wife & & $<20,20-29,30-39,40+$ \\
\hline 3. & Age of husband & & $<30,30-39,40-49,50+$ \\
\hline 4. & Education of wife & & five ordinal categories \\
\hline 5. & Education of husband & & five ordinal categories \\
\hline 6. & Attitudes of parents-in-law & & eight categories as discussed this chapter \\
\hline 7. & $\begin{array}{l}\text { Effect on reproductive } \\
\text { capacity (women) }\end{array}$ & & first three categories of table 6.1 \\
\hline 8. & $\begin{array}{l}\text { Effect on reproductive } \\
\text { capacity (men) }\end{array}$ & & first three categories of table 6.1 \\
\hline 9. & $\begin{array}{l}\text { Need to prove reproductive } \\
\text { capacity (women) }\end{array}$ & & first three categories of table 6.2 \\
\hline 10. & $\begin{array}{c}\text { Need to prove reproductive } \\
\text { capacity (men) }\end{array}$ & & first three categories of table 6.2 \\
\hline 11. & Heard of safe period (women) & & no/yes \\
\hline 12. & Heard of safe period (men) & & no/yes \\
\hline 13. & Heard of azal & & no/yes \\
\hline 14. & Heard of azal & & no/yes \\
\hline 15. & Heard of condoms (women) & & no/yes \\
\hline 16. & Heard of condoms (men) & & no/yes \\
\hline
\end{tabular}

Only two of these variables (numbers 7 and 9) were significant in a stepwise logistic regression analysis. These were the variable describing women's beliefs about the effect of contraceptive methods on their reproductive capacity, and the variable describing women's beliefs about the need to prove their reproductive capacity. The statistical model is shown in Table 6.5, and the resultant classification table is shown in Table 6.6. The latter shows that the model satisfies desirable qualities of sensitivity and specificity. 


\section{Table 6.5. Model of Determinants of Whether a Woman Said that Family Planning Should be Used before First Birth}

\begin{tabular}{|c|c|c|c|}
\hline Explanatory Variable & Coefficient & $\begin{array}{l}\text { Standard } \\
\text { error }\end{array}$ & Odds ratio \\
\hline \multicolumn{4}{|l|}{$\begin{array}{l}\text { Belief about effect of family planning on } \\
\text { reproductive capacity: }\end{array}$} \\
\hline Reproductive capacity can be impaired & $($ base $=0)$ & & $(1.0000)$ \\
\hline Heard of problems, but disbelieves & 1.2662 & .9212 & 3.5472 \\
\hline Reproductive capacity cannot be impaired & 1.7932 & .6502 & 6.0086 \\
\hline \multicolumn{4}{|l|}{$\begin{array}{l}\text { Belief about need to prove reproductive } \\
\text { capacity: }\end{array}$} \\
\hline Capacity should be proved - by trial & (base $=0)$ & & $(1.0000)$ \\
\hline - by 'doctor' & 2.3396 & 1.2098 & 10.3774 \\
\hline No need to prove reproductive capacity & 1.7692 & .7638 & 5.8660 \\
\hline Constant & -2.4699 & .8122 & \\
\hline $\begin{array}{l}\text { LR}^{2} \text { - } \\
\text { Null } \\
\text { Model } \\
\text { Improvement }\end{array}$ & $\begin{array}{l}85.886 \\
\underline{69.237} \\
16.649\end{array}$ & d.f. $=4$ & $\mathrm{p}=0.0023$ \\
\hline
\end{tabular}

Table 6.6. Classification Table for Model of Table 6.5

\begin{tabular}{|l|l|c|c|c|}
\hline & & Model & & \\
\hline & & No & Yes & Correct \\
\hline Observed & No & 24 & 8 & $75 \%$ \\
\hline & Yes & 10 & 20 & $67 \%$ \\
\hline & Correct & $71 \%$ & $71 \%$ & $71 \%$ \\
\hline
\end{tabular}

To interpret the model, we first calculate the odds and probability of a woman saying that family planning should be used before first birth if she belongs to the base category, that is she believes that reproductive capacity can be impaired by the use of contraceptives and she also believes it is necessary to prove reproductive capacity by having a baby before using any method of family planning. The logodds for the base category is the constant of the model (2.4699 ) corresponding to odds of 0.084593 and a probability of agreeing that family planning can be used of 0.078 or about 8 per cent.

Ignoring the intermediate categories of the two explanatory variables (because they do not actually have coefficients significantly different from zero), the odds and probability of a woman saying that family planning should be used before first birth if she does not believe that reproductive capacity can be impaired and she does not think it is necessary to prove reproductive capacity are calculated from the odds for the base category multiplied by the odds ratios for the corresponding categories of the explanatory variables. The odds are 2.9816 $(0.084593 \times 6.0086 \times 5.8660)$, corresponding to a probability 0.749 or 75 per cent. 
The difference between 8 per cent and 75 per cent illustrates the extremely important role played by these self-reinforcing sets of beliefs in determining use of family planning before first birth in Bangladesh. It should be noted that this model is valid beyond the sample, which is itself not representative of the population of Bangladesh. This is because variables for knowledge of direct methods of family planning were included in the analysis, and were not significant. In this way, knowledge of traditional methods and consequently use of them has effectively been controlled in the model.

\section{$D^{i s c u s s i o n}$}

The analysis in this chapter was aimed partly at explaining the relatively high level of use of 'traditional' methods in the interval between marriage and first birth in Bangladesh. It was found that very significant numbers of respondents believed that use of program methods generally, and oral contraceptives in particular, had the potential to impair women's reproductive capacity permanently, especially if the methods were used before a woman had any children. It is little wonder that couples who do elect to use a method of family planning before the birth of a child often choose a traditional method. This choice is undoubtedly helped by lack of contact with family planning field workers.

Perhaps because of the nature of the sample, with relatively high numbers of users of the 'traditional' methods, it was nevertheless surprising to find that 40 per cent of women and 30 per cent of men were in favour of use of some method to delay the birth of a woman's first child after marriage. The family planning program still virtually ignores women who have not yet had a child. We even found that a significant minority of mothers-in-law were in favour of their sons' wives delaying the first birth.

There were two factors which we found in a statistical model had a significant impact on whether women favoured use of family planning before the birth of a child. One was whether or not they believed that family planning methods could impair reproductive capacity. The other was whether they believed that it was necessary for women to prove their reproductive capacity (by having a child) before they could adopt a method of family planning. This statistical model excluded, as non-significant, a wide range of background variables including some which identified the special characteristics of the purposive sample of the study. It is, therefore, a model which is valid for the whole population of the study areas and not just the sample.

Discussion of the topic of family planning before first birth confronted the widespread twin beliefs in the capacity of family planning methods to permanently impair fecundability, and in the need for women to prove their reproductive capacity after marriage. Future field research on the topic could benefit from awareness of the sensitivities that we found. Within the reproductive health context with which this topic was investigated, and which is set out at the beginning of the chapter, it is extremely important to come to a thorough understanding of issues that are discussed in this chapter. 


\section{Chapter 7. Religiosity and Method Choice}

Tntroduction

The extent to which families' choices about family planning are influenced by religious teaching is a difficult one to approach. Religious adherence is not easy to measure and the intensity of religious adherence is still more difficult. Without broaching the large amount of writing on this topic in the international literature, much of it culture-specific, we adopt a descriptive approach to exposing the situation in Bangladesh, within a logical framework.

The logical framework has two stages. If religious teaching is opposed to the use of family planning methods, then that teaching has the potential to influence the views of individuals about whether prevention of pregnancy and the various means to achieve it are sinful. The first stage is, therefore, to examine what respondents say about the influence of religious teaching on their beliefs, and what their beliefs are. Secondly, while commission of sin might be a disincentive, the second stage of the analysis is to examine the extent to which concepts of sinfulness are considered in the behaviour of women and men.

Bangladesh is an overwhelmingly Muslim but constitutionally secular state, with a large Hindu minority. The main attention in this chapter is on Muslims, not just because they are predominant in population terms but also because conflict between religious precepts and behaviour is most marked among Muslims, Evidence about Hindus is not excluded, but discussed in context. No religious affiliation other than Muslim and Hindu was detected in the sample, so that although there are both Christian and Buddhist minorities in the country, there is no data to discuss these groups.

A case study is a useful way to introduce the two stages of analysis which are employed in this chapter. It refers to a couple using an IUD:

F030 (19 years old, 2 children ever born): - (Reasons for method choice) I have used this method (IUD) for about one year. No problem is caused. Pregnancy is still prevented. ... My husband can't follow azal. So, I have used Copper-T. My husband faced problems in adopting azal. My husband doesn't get pleasure. Now I have begun to use a Copper-T. This doesn't cause any inconvenience to my husband. ... [Name of FWA] gave me the advice to use a Copper-T. It is about one year that I have used the Copper-T. ... I went to the hospital secretly to use it. Nobody knows. ... The field workers comes to our house at an interval of two months. They enquire about us. ... Babies are given by Allah. Allah says, 'I am giving you children, why do you prevent it?' It is a sin to disobey the orders of Allah. ... The Mollahs say that no jenaza [religious burial] will be given to a Copper-T user. This method causes sin. ... (Extent of discussion with husband) Everything can be discussed with my husband. I told my husband about the use of Copper-T, and he said, 'You can take it'. ... I have one baby. [Note: another baby died.] I want to take another baby later. My husband doesn't agree to follow the safe-period method properly. If he doesn't follow it properly, there may be conception and that will create problems. So, I told my husband about the use of the Copper-T. My husband agreed. ... Both of us were unanimous before taking this decision. ... I have discussed [with my husband] about the method which is followed by men. I have discussed about the Copper-T. I told my husband that one can prevent birth for a long time by using the Copper-T. ... My husband said, 'You can try it'. No more was said. ... (Influence of religion on use of family planning) I don't know what the religion says. I have never heard religion 
saying that there is no sin in method use. All the methods are sinful. But the operation [sterilization] and Copper-T cause greater sin. ... No burial will be given. Pills cause less sin. These things are told by the Mollahs. ... I feel shy in using the Copper-T. Cutting of the abdomen is also shameful. When people learn about it, they scold us. ... The Mollahs give a burial without following religious formalities. They don't read verses from the holy Quran. ... I shall not be able to give food and clothing if many children are born. People say, 'One mouth can be filled with gold. But ten mouths cannot be filled with ashes. ${ }^{16}$

M030 (33 years old): (Discussion about number of children) Yes, I say that we will not take another baby now. We have one at present. We feel it is difficult to maintain him. When this one grows up, we will take another one. Health also breaks down if babies are born in quick succession. ... They [FWAs] don't come to our house. ... I said that I shall take two babies consecutively. But my wife said that she would take another baby some time later. Because she faces problems in rearing up this baby.... (Male involvement in family planning) Yes, cooperation is there. My wife has come back after getting a coil [fitted] after both of us had discussed about it. ... (Reasons for method choice) Although the use of coil has prevented birth, my wife suffers from dizziness. She has become weak. She looks like an old woman. ... The pill is required to be taken daily, but once a coil is used, one may be free from problems for a long time. ... The family planning workers don't come to our house regularly. ... No method is sinful. Because I am not destroying babies. ... The Mollahs says that use of the coil is haram [illegal]. Whoever uses a coil, it is illegal to take food from her hands. I have got it done under extreme privacy. But I don't believe it [what the Mollahs say].... (Influence of religion on use of family planning) I don't think that there is any sin in it. Because I am not destroying the baby. ... No method is shameful. However, this is a rural village. If people know about the use of the coil, they will speak ill of us.

The man and the woman had reached a rational decision to use an IUD after discussion and consideration of the options. However, they both felt considerable reluctance to let anyone else know they were using it, because of social and religious disapproval. They both said that their religious leaders had railed against us of IUDs and threatened sanctions. The woman, but not the man, also felt that IUD use was sinful.

Some aspects of what they have said require explanation to avoid confusion on the part of the reader. There are at least two things to consider in assessing the influence of religious belief. The first concerns what Muslim respondents believe to be the views expressed by religious leaders on the sinfulness of family planning methods. There is not necessarily any correlation between what they report the Mollahs to say and the respondents' own expressed views about the sinfulness or otherwise of family planning or particular methods. This is because, in Islam, the concept of sin is based in the believers' own opinions about what is right and wrong, and their own interpretation of scriptural evidence. The second factor to consider is a certain level of disjuncture between this personal concept of sin and actual behaviour. These are the two stages of analysis which have been mentioned above.

The reference in this interview to refusal of religious leaders to perform the jenaza burial ritual is an extremely serious matter from the point of view of personal salvation and also in social terms. A recent case of refusal to perform burial rites for a man who had had a vasectomy was reported in more than one interview from one of the study areas. The refusal to take food from the hands of a person who is using an IUD is also a very serious matter from the social point of view, especially during the fasting month of Ramadhan when the

\footnotetext{
${ }^{16}$ This traditional saying is known throughout Bangladesh and was mentioned in several interviews. Its potential value in support of family planning activities, even encouragement to limit families to one child, is evident.
} 
evening meal of iftar after abstinence from food and drink during the daylight hours is an important social occasion. Among the statements collated in the next section of this chapter (some of them already included in examples discussed in previous parts of this report), there can be found respondents who told us that they themselves would not take food from a woman who had had a tubal ligation. Both refusal of religious burial and refusal of food are mentioned in very many of the interviews, more in reference to sterilization than IUD use.

hat the Mollahs say (according to respondents)

Most of the interviews conducted as part of our study contained at least one reference to vehement opposition on the part of religious leaders to use of any or particular methods of family planning.

There might or might not be a relationship between what the mollahs are reported to say and what respondents themselves believe are sinful. However, the statements in this section are reported without reference to individual interviews, and the evidence from some individuals appears in different places in what follows. This is because our aim is not to illustrate some direct connection between the statements of religious leaders and personal beliefs about sinfulness, but to set the general context of religious exhortation in which personal beliefs are held.

The terms mollah (or mullah, or molla), munshi and imam have been confounded in this section and all are represented as mollah. Statements about people called huzur (religious teacher) or moulavi or moulana have not been included unless they are also called mollah. The statements below are taken from the interviews of women, but similar statements occur in the interviews of men, with less frequency. While a majority of women do not have direct knowledge of what mollahs say, because women do not attend prayers in the mosques, it is their perception of what their religious leaders say that is important.

The following statements refer to opposition to all methods of family planning by Islamic religious leaders:

- The mollahs say that prevention of birth is a sin. The grave would not accept those who would use any method. All the methods are sinful to them.

- The mollahs say that these [methods] are sinful acts. Children are given by Allah. They say that before sending a baby to this earth, Allah allocates his food for twelve years in advance. For this reason, prevention of birth is a sin. If a child is born, Allah will feed it.

- The mollahs forbid birth prevention. They say that the grave will not accept those who are ligated. Besides that, they define abortion as 'killing of life' and say that those who abort babies will not be greeted by Allah.

- The mollahs say that use of methods for the prevention of birth is sinful. During their waj [religious lecture] they tell us not to use family planning methods. It is sinful.

- Mollahs talk about it, when they speak. They haven't told me anything [directly]. They say, stopping of birth is sinful. Whatever number of children is given by Allah, all should be taken. Stopping of birth itself is evil.

- What is that to me even if it is forbidden by religion? I will not have any more babies. So, I have got washed [had menstrual regulation]. The mollahs say that the use of any method is sinful. Do they provide us food?

- They say pregnancies must not be prevented. They say the more the followers of Rasul [The Prophet] the better. Mollahs say pills are not permissible.

- The mollahs say that prevention of birth is a sin. They say 'He, who has given mouths, will give food to eat.' They don't give a religious burial if the abdomen is cut [sterilization]. 
- The mollahs say that food can not be taken from the hands of those who prevent birth, they cannot be given funeral prayers. The grave will not accept those who have undergone the operation [sterilization]. Religious people say these things but I do not believe them.

- The mollahs say prevention of pregnancy is a sin. They say that those who prevent pregnancy will be put to hell-fire. I also believe that prevention of pregnancy is sinful.

- If a method is adopted before conception, it is not sinful. The mollahs say that a tree may bear fine fruits, if it is cut down, it is not good. In the same manner, a woman may have as many children as she can bear. To stop it is sinful.

- The mollahs say that birth should not be prevented. No medicine can be taken for the prevention of birth. But I believe this is not true. If we take too many children and fail to feed them, that would be sinful. To my opinion, the use of a method for the prevention of birth is ones legal right.

- The mollahs say all methods are sinful. Food cannot be accepted from those who have had the operation [sterilization] and also the grave will not accept their bodies. [They say] 'Religious activities first, then family.' Those who cover themselves with the veil, inside their mind is the devil's abode. We do not wear a veil but still we move in a conservative way. I do not adopt any method because it is sinful.

- Religious leaders (mollahs) say it is sinful to prevent birth. Their wives also take the pill and prevent birth. They say they will not take food from the hands of those who will undergo sterilization. Their funeral will not be held. Fearing this, I have not undergone the operation.

- The mollahs say that it is Allah who will stop the birth of babies and will give them. 'Allah provides for us. Why would you do these things by yourselves. Why should you be sinners?'

- I do not know what other mollahs say. My husband himself is an imam in the Mosque. He says it is sinful to adopt any method. But he used to say that it will be pious to have many children. I have shown him the book of Hadith where the rules of the safe period and withdrawal are mentioned.

- My husband is a hajji [one who has performed the pilgrimage to Mecca]'. My husband and the mollahs say that the prevention of birth is sinful. I am also of the opinion that it causes some sort of $\sin$ at least. However, it is my husband who tells me to use methods.

- I have had kabiraji medicine. My husband is more or less a mollah-type person. So, he considers the use of any method to be sinful. My elders told me that the use of kabiraji medicine also prevents birth. Then I got the kabiraji medicine brought by them and took it by putting it in banana for three consecutive days. My husband is yet to know about it.

- They forbid us to prevent birth. No transaction is held with the person who has had an abortion. It is sinful in the society to undergo the operation [sterilization], no one wants to have anything to do with them. The mollahs do not take food from their hands. However, this type of attitude has changed now-a-days. If anybody dies after undergoing operation, then the mollahs do not want to say the funeral prayer. They say that the grave will not accept the body.

This list of statements has been pruned down to include only those which mention different aspects of prohibition, but it should be enough to dispel any idea that opposition by Islamic religious leaders to the use of any family planning methods is insignificant. However, if there is opposition in general, there must be a veritable campaign against sterilization, because the number of statements which specifically mention the forbidden nature of sterilization, male or female, is far longer. Only a few examples are given here, mainly to bring out two aspects of what the mollahs are believed to say. These are, that the mollahs will not give a proper religious burial to a woman who has had a tubal ligation, and that they will not take food from her hands. 
- The mollahs say that ligation is sinful. [They say] 'She, who will undergo ligation, we will not bury her.'

- It will be sinful if one gets ligated or takes pill. Nobody is thinking about what will happen after death. They are only thinking about keeping the family small and passing days happily. People are keeping their family small and taking medicines [pills, injections]. All these are sinful. The mollahs say, cutting of the abdomen is najaez [illegal].

- If a person is operated upon, the mollahs do not bury them. If they conduct the burial, they just put the dead body on the ground. The earth, they say, does not accept them.

- The mollahs and munshis say that they will not recite the jenaza [last prayer after death] if the belly is cut [tubal ligation]. They say that if one dies with a CT[IUD] in place, one cannot be buried unless the $\mathrm{CT}$ is removed.

- Ligation is more sinful. The mollahs then refuse to conduct the funeral prayer. Other methods are less sinful. ... If one undergoes ligation, the mollahs will not conduct the funeral prayer of that person. Ligation makes it necessary for others to touch my body. They have to stitch [my body]. That's why I feel great shyness. Has Allah asked us to be operated upon?

- They say that to destroy a baby is sinful. If one gets her abdomen cut, food can't be taken from her hands. If a milad [religious congregation] is arranged and if she cooks, they don't eat that food. The mollahs say that she can't be touched .

- The mollahs say that cutting of the abdomen or use of a Copper-T is sinful. They say that none can take food from the hands of those who get their abdomen cut or use Copper-T. The mollahs call them 'women without veil and shame.' The mollahs don't like to take food from their hands and they don't say the funeral prayer for them.

- They say, those who have the operation are without purdah [veil]. Destroying babies is a great sin. In this, a life is taken. Having the operation means committing much sin. They [mollahs] do not want to take any food from them, they don't want to offer the jenaza for them.

- ... I had a wish to undergo the operation but I heard that the mollahs will not permit a [proper] funeral for those who undergo the operation. Because of this, I did not undergo the operation.

- The mollahs do not want to arrange the funeral for those who are operated upon. They will not take food from the hands of those people. They do not visit their houses. They will not come to help those people. They say the grave will not accept people who have been operated upon.

- There is religious restriction. People say that prevention of birth is sinful. The operation is highly sinful. If anyone is operated upon, the mollahs say that she or he will not be accepted by the grave. Destruction of a baby [abortion/MR] is also sinful. This is equal to the taking of a life. The value of my own life is equal to the life of the baby in my womb. I can take a life but can I create a life?

- The mollahs says that it would cause sin. If the abdomen is cut, mother Fatima will not recommend her on the day of resurrection. Prevention of birth or abortion/MR, both are acts against Allah.

There are statements about other methods, particularly abortion and use of IUDs, included in the list, and evidence for a scale of sinfulness, with use of an IUD, sterilization and abortion (including menstrual regulation) in that order at the high end of an increasing scale. At the low end are the 'traditional' methods, condoms and hormonal methods. One woman observed that she was not aware that the mollahs had placed any restrictions on the use of the pill:

- I think all methods are equally sinful. It is all the same if it prevents birth. The mollahs did not say anything about the pill. It seems to me that all methods are equally sinful, because all methods prevent childbirth. 
Observe that this woman's own judgment about the sinfulness of all methods of family planning was more severe than what she understood the mollahs to say. As we will see, this is less common than the opposite case, in which respondents do not accept that methods which the mollahs say are sinful are wrong.

Some respondents seem to place the mollahs' views about IUD use on the same level as restrictions on sterilization, both in the list above and in the following three cases:

- The mollahs says that the Copper-T and the operation are not legal. It will cause sin. No jenaza will be held if one undergoes the operation.

- One has to be a sinner before Allah if a Copper-T is used or the operation is done. No one can take any food from her hands. If they cook something and send it to the mosque, the mollahs will not eat it. They do not get a religious burial after death.

- The mollahs say that no jenaza will be given to a Copper-T user. This method causes sin.

Statements about the mollahs' views on abortion or menstrual regulation are rare, except as accompaniments to their reported views on permanent methods and IUDs, which have already been listed. This is basically because not only the mollahs but the respondents regard abortion as so obviously sinful that the mollahs do not need to remind people about it. When they are reported to have done so, the scale of the sin is easily assessed, as in the following cases:

- The mollahs say that abortion is a sin. Abortion is as sinful as killing a human being. The mollahs say that the grave will not accept a ligated client. They will not be buried according to religion.

- Abortion and ligation are greater sins. Other methods are less sinful because Allah may pardon these lapses - This is what mollahs say. ... They say abortion is a greater sin. The same is true of ligation. One mollah tells a story about a woman who underwent ligation. After her death, when her dead body was to be taken to the place of funeral prayer, people couldn't raise it on to the cot; it was so heavy. People narrate this story. I myself have not heard it from them. ... Mollahs say prevention of pregnancy is a sin. But if after producing children, we can't feed and cloth them can't make their life comfortable, Allah will impute greater sin to us. For this reason, I have had few children. To me family and religion are equally important.

- In my opinion, all the methods contain the same amount of sin. But the mollahs say that abortion and the operation are vicious sins. Allah will not forgive us if we adopt these methods. I believe this. ... The use of any method for the prevention of birth is sinful. But abortion/MR is more sinful as it is equal to the taking of a life. Birth is prevented for ever if one is operated upon. It is sinful for this reason. ... They say that abortion and operation are vicious sins. If I do it, Allah will never forgive me. According to them the use of any method which aims at the prevention of birth is sinful.

- There is a religious barrier against the destruction of a fetus. According to religion every method is sinful except the rhythm method. The mollahs say that the earth would not accept those who cut the abdomen or who destroy their babies in the womb.

The Bangla term translated in these excerpts as 'abortion' is the English word wash, which in Bangla refers exclusively to menstrual regulation. ${ }^{17}$ There is no perception of difference between menstrual regulation and abortion. 'Washing' is simply the means by which abortion is done. If some other method is meant, that will be clearly explained by the respondent.

Is the threat of withholding religious burial any more than just a threat? It would appear so from the following account:

\footnotetext{
${ }^{17}$ A case where the term wash was used to refer to what was apparently a curette of a non-pregnant woman has been mentioned in another part of this report. The analogy is evident.
} 
- The mollahs say that use of condoms is a sin. They would not bury the people who have had tubal ligations. Nobody can take food from her hands. A woman, who is my neighbour, underwent the operation. Nobody takes iftari food [evening meal during the fasting month] from her. I also do not take it. A man was operated upon. He was not buried by the people of the village. Then a moulavi from the neighbouring village Sagardari came and buried him. The moulavi said that if he [the man who was operated upon] had committed any sin by undergoing the operation, Allah will see to that. Why should we commit wrong?

Enquiries by the interview team to this respondent and others elicited the additional information that the event referred to had taken place within the previous two years.

A substantial number of women referred to the hypocrisy of religious leaders who exhorted other people not to use family planning methods but used methods themselves. Examples of such statements are:

- In the eyes of Allah and His Rasul [Prophet], prevention of birth is a sin. Being in danger, I have been operated upon. I haven't accepted it willingly. Now-a-days, the daughters of many mollahs prevent birth. Do they not commit sin? At the time of my last delivery, the doctor said that I would die if I conceived again. Because of this reason I got myself ligated.

- The mollahs say it's sin. But they are taking pills. The mollahs say ligation is a sin. They say nothing should be done. No method is permissible.

- People say that religious leaders mollahs say that it is sinful to prevent birth. But they also allow their wives to adopt these methods. But they did not tell us anything.

- Quite a number of mollahs themselves adopt methods for prevention of pregnancy. Again, many mollahs says that if a woman is ligated, her funeral prayer will not be offered.

- They say that use of methods is sinful. But their wives commit more sin. Sometimes the wives of many of the mollahs go to the hospital and use methods [from there]. Also their wives put watches on their hands and walk through the roads openly with bare faces, and these mollahs advise the other people that it is sinful for the women to go out of the house. I told a mollah, 'Your own wife used a method and she once had an abortion. Does that not cause any sin?' Then the mollah kept quiet and didn't say anything.

- The mollahs say that the use of any method is sinful. They are the people who use many methods.

- What can the mollahs say? It is the mollahs who prevents birth more. Most of the mollahs have [only] one or two babies.

- The mollahs don't say much about it nowadays. The mollahs themselves are preventing birth in great numbers. They are giving fatwa [religious injunctions] for others. They say that they would not give a religious burial after death if a woman got her abdomen cut.

There were, among the respondents, a number of men who were religious leaders themselves, and some of them were aware of such criticism. The wife of one said:

- ... My husband is a mollah-type person. If people come to know [about us using a method], they will say, 'How come a huzur has done it?' So, he [my husband] has taken this method [azal]. People will come to know if other methods are used.

Counter to the conventional wisdom of all these statements, some respondents refer to far less strict views of their religious leaders. Often these respondents are in close contact with the religious leaders whose views they report.

- My nandai [brother-in-law] is an Alem [person of religious learning] who says that prevention of birth is not sinful. But induced abortion is a sin. But the mollahs say that any 
method used to prevent birth is sinful. They say that those who will adopt methods will go to hell. My mother also says that it is sinful.

- I haven't heard anything from the mollahs. However, many people, including the neighbouring women, say that nothing edible can be taken from the hands of a ligated woman. They also say that oral pills stick to the intestines. Because, by competing with Allah one accrues sin.

- My husband is the mollah of a mosque. He has never told me that the use of methods is sinful. People say that it begets sin. I think that there is no sin in the use of methods like pills, condoms and injections.

The important thing is not what the mollahs actually say, but what people believe them to say. The views attributed to mollahs in this section are as perceived by women, who are least likely to have actually heard the mollahs say these things. Even if all of the religious leaders, in the areas in which the study was conducted, were convinced that use of family planning methods is permissible in Islam, it would have little effect on the common perceptions unless they took positive steps to speak out in favour of family planning methods and did it loudly enough and often enough for all members of the society to know what they were saying.

ersonal opinions about the sinfulness of family planning methods

Do people accept what they believe their religious leaders to say about family planning? We take a statistical approach to the issue by collating the number of references by respondents to their own beliefs in the sinfulness of all family planning methods or particular methods, deleting multiple references by individual respondents. Some of these references have appeared in statements already cited, so their nature does not need to be illustrated by further examples.

It should be emphasized that the summary information in Table 7.1 is based only on the existence of definite statements by respondents about their beliefs. If they did not choose to include a statement about the sinfulness or otherwise of particular methods, then we cannot draw any conclusion about what their beliefs are. For example, the fact that many fewer men than women were inclined to make statements about the sinfulness or otherwise of the methods mentioned in the table might indicate no more than cultural difference between women and men in their way of making statements.

The extent of personal belief, on the part of women, that family planning methods are sinful is nevertheless striking. Men were far less inclined to make such statements. Without questioning the conviction with which these beliefs are held, when the beliefs were compared with current method use variables to determine whether there was any relationship, none was found.

Table 7.1. Perceived sinfulness of family planning methods, women and men

\begin{tabular}{|l|r|r|}
\hline Belief & \multicolumn{1}{l|}{ Women } & \multicolumn{1}{l|}{ Men } \\
\hline All methods are sinful & 88 & 17 \\
\hline Abortion is sinful & 103 & 45 \\
\hline Sterilization is sinful & 89 & 38 \\
\hline IUD use is sinful & 24 & 10 \\
\hline Number of cases & $\mathbf{1 5 0}$ & $\mathbf{1 4 1}$ \\
\hline
\end{tabular}


In most of the excerpts from interviews that have been quoted so far in this chapter, there is no hint that the opinions of mollahs or even personal views about sinfulness have any direct effect on choice of family planning methods. While there exist some examples, they are rarely as clear as in the following case, and even here there is a strong indication that the choice is only coincidentally acceptable from a religious point of view:

- In religion, use of other methods are prohibited. The one I follow [safe period] is not restricted by religion. So, if anybody wants a small number of children this method can be adopted. It will not do if we listen to the religion. If many children are born, the mollahs will not provide food and clothing. Will they buy us saris? The mollahs give lectures saying prevention of birth is a sin. We can't live by listening to religion alone.

\section{$\boldsymbol{R}^{\text {eligious teaching and the needs of the family }}$}

Most of the information that has been discussed so far in this chapter came from discussion items where informants could choose for themselves whether they mentioned a particular matter or not. Other respondents might hold exactly the same view but have chosen not to reveal it. That is why the quotations have not been made specific to individuals. There was one issue which interviewers were asked to raise with respondents which was, by contrast, quite specific. This was whether the teachings of religion outweighed the needs of the family, in matters of family planning.

From the tabulation of responses in Table 7.2, we conclude that the use of family planning methods is not influenced by religion for most respondents, either men or women. We give some examples of different types of response, the first group being from those who judge that religious instruction outweighs their families' needs:

F014 (26 years old, 3 children ever born): - Both are great. But religion should be considered greater I do whatever the religion says. It is legal to do this.

M014 (32 years old): - Religions teaching is greater. In the Holy Quran it has been written that Allah is the giver of food. But in the Hadith, it has been said that those who possess less wealth, they should pray to Allah that he doesn't give them too many children. So, in case of using a family planning method religious instruction is greater. According to religion, family planning method use is supportable. [The man sees no incompatibility between religion and family.]

\begin{tabular}{|l|c|c|}
\hline \multicolumn{3}{|c|}{ Table 7.2. Religious teaching and the needs of the family } \\
\hline \multicolumn{1}{|c|}{ Category of response } & Women & Men \\
\hline Family's needs outweigh religious teaching & 116 & 75 \\
\hline Both family needs and religion are important & 5 & 10 \\
\hline Religious teaching outweighs family's needs & 11 & 13 \\
\hline No incompatibility between religion \& family's needs & - & 10 \\
\hline Nothing told by religion & 3 & 18 \\
\hline Other response & 12 & 10 \\
\hline No specific response & 3 & 2 \\
\hline No response & - & 3 \\
\hline Number of cases & $\mathbf{1 5 0}$ & $\mathbf{1 4 1}$ \\
\hline
\end{tabular}


F026 (27 years old, 2 children ever born): - Birth prevention is sinful. Allah will feed the excess children. The husband will feed them by doing labour. Birth cannot be prevented. It will be a sin.

M026 (50 years old): - I give importance to what religion has taught. The Huzurs say that using family planning methods is sinful. So I do not use any family planning method.

F057 (16 years old, no children): - To me religion is more important. What my husband asks me to do, I shall do that even if it is wrongful, because religion prescribes that the husband should be obeyed.

M057 (29 years old): - Our deeds must be consistent with our religion. I shall have to solve the family problems from the religious point of view. Religion and family are not different from each other.

F061 (32 years old, 3 children ever born): - Religion is greater to me. But religion can't be followed due to the [needs of the] family. For this reason, family benefits are given more importance.

M061 (31 years old): - Religion consists of family. There is no religion without family. Family benefit is important. But the religion is the greatest. The family has to be run through the religion. But I think that family interest is important.

F126 (41 years old, 9 children ever born): - Religion is more important to me. I have three adult daughters. I didn't allow them to go out to school for study. I got my daughters to learn Arabic at home. Going outside is prohibited by religion.

M126 (55 years old): - As there is no religious restriction/bar, I am of the opinion that family planning methods may be used for the benefit of self and of the country. The benefit of the country and my own benefit is important to me. [This case has been mentioned earlier in the report; the man's statements do not appear to reflect his real opinions.]

The anguish in the decisions made by respondents such as the man and woman of household 061 is evident. The woman in this case is classified in the opposite camp to her husband, since she believes that the family's needs outweigh the dictates of religion, but they have still never used any method of family planning to which she admits, although her youngest child is nearly five years old. Her husband says they are using the oral contraceptive pill, but for reasons discussed in Chapter 3, there must be some doubt about this. The quality of anguish is also present in many of the responses from those who judge that their family's needs outweigh religious teachings:

F029 (22 years old, 2 children ever born): - For peace and happiness I shall keep the family size small. Religious teachings in this regard can't be obeyed. If there are many children, how can I feed them? If I have five daughters, how can I feed them? If sons are born, they will earn for us. Shall I take five daughters to get one son? For the benefit of the family religious instructions cannot be obeyed.

M029 (32 years old): - Religious teachings are greater. However, those teachings cannot be supported in case of the adoption of family planning. In all other matters, religious teachings are greater.

F034 (15 years old, no children): - Methods for birth control are sinful. But if one does not adopt a method, many children will be born. That will cause unhappiness in the family. For the sake of family's happiness, it is not always possible to abide by religious instructions. Many adopt a method.

M034 (25 years old): - When I think of the expenses to be incurred for maintenance of the family, I feel reluctant to listen to the mollahs and munshis. Religion is more 
important, but if one faces any difficulty after having pills, then one should bear in mind that this is not allowed in religion; then what you say [safe period] should be followed.

F049 (30 years old, 2 children ever born): - My family is small. If I have many children from where will I feed them? According to religion it is sinful to control birth. If I listen to religion and take many children, the family will expand. That is why to me my family's well being is more important.

M049 (55 years old): - To do what Allah has forbidden to do is of course sinful. After death people have to answer to Allah. If I myself cannot survive with the family, then what else can happen? That is why advantage of the family is greater.

F062 (36 years old, 3 children ever born): - Religion prohibits prevention of birth. In spite of that we are preventing birth, because our property is too small. How shall we feed them if we have too many children? Although I know that prevention of birth is a sin, I have adopted a method considering the benefit of our family.

M062 (48 years old): - Family interest is greater, because if there are many children who will feed them? There will be poverty in the family. So, family benefit is greater than religious education.

F086 (41 years old, 5 children ever born): - Religion is important, the interest of the family is also important. But religion can't be properly followed if family interest is to be protected. Though I think it is a great sin to destroy pregnancy but there is no harm in doing a little sin for the interest of the family.

M086 (47 years old): - Family interest is more important. If there are more babies, land will be divided and it becomes a problem to afford food and education to all those children. So family planning should be adopted for the happiness and peace of the family. I adopted family planning for the advantages of my family. 
There is another group of respondents for whom this decision caused no troubled minds:

F018 (27 years old, 5 children ever born): - What is the use of religious restriction on the use of family planning methods? Who will bring them up when many children are born? What shall we do with these children if we can't feed and educate them properly? What shall we do with the children if we fail to get them treated during their illness? What is the use of taking many children?

M018 (32 years old): - We can't act as the Mollahs say. We will have to take care of ourselves. They say so many things.

F039 (34 years old, 3 children ever born): - What is that to me even if it is forbidden by religion? I will not have another baby. So, I have got washed [had MR]. The huzurs say that the use of any method is sinful. Do they provide us food?

M039 (39 years old): - One should obey religions teachings. Because religion will stay forever. So, it is necessary. But we can't follow it, because of family needs and family necessity. There are a lot of expenses in a family. For this reason, I consider the family benefit greater. [The man is more in the previous group.]

F040 (25 years old, 2 children ever born): - I can't feed and clothe them if I take many children. It is difficult to rear them up. So, for the benefit of my family, I have taken method to prevent birth.

M040 (34 years old): - So far as I know, after giving birth to a baby if I fail to feed the child, it is a sin. So, I think that family benefit is greater to me.

F050 (36 years old, 4 children ever born): - To me, the benefit of my family is more important. Although I know that abortion is sinful, still I have had an abortion for the benefit of the family. I shall not be able to rear them up properly if many children are born.

M050 (39 years old): - [No response recorded.]

F059 (30 years old, 4 children ever born): - I shall consider first the interest of the family. Because if there is peace and happiness in the family, attention may be given to provisions of religion. If there is unhappiness in the family, religion and its rites will have no appeal. I shall first pay attention to the welfare of the family, then I shall observe religious instructions.

M059 (39 years old): - The interest of the family is of great importance. It is of great importance. I don't use those methods which religion forbids. I use those methods which are permissible. Thus I abide by religion and also see to the interest of the family.

F100 (46 years old , 3 children ever born): - Only to give birth is no enough, they have to be reared up properly. Children are not offspring of foxes and dogs that once they are born they do not need any support. So, to me now the advantage of the family is more important.

M100 (55 years old): - The meaning of the world 'Islam' is peace. Whatever rules are there, are for the welfare of the people. Both family and religious advantage and disadvantage are followed if Islamic rules can be obeyed.

F132 (33 years old, 2 children ever born): - There are restrictions in the use of family planning methods in Islam. But in [our] Hindu religion, there is not such restriction in the use of these methods. I first consider the benefits of the family. It is stated in our religion that to consider the advantages of the family life is also a part of religion. 
M132 (42 years old): - It hardly needs to be emphasized that the advantages and disadvantages of the family in this respect are of greater importance. Since religion is not opposed to it, people use family planning methods for the advantages of the family.

\section{$D^{\text {iscussion }}$}

There was a welter of opinion from respondents that Islamic religious leaders were opposed to the use of family planning methods, and very particularly to the use of sterilization methods. These views were much stronger among women than men, who are in closer contact with their religious leaders through attendance at mosques for prayers and instruction. A majority of women also believed that all methods of family planning were sinful, and in particular that sterilization and abortion (including menstrual regulation) were extremely sinful. Again these views were put less explicitly by men. Although we have pointed out that in Islam the sinfulness of actions and behaviour is a personal judgment, it is still clear that most of our respondents believed that sin was attached to the use of any form of family planning..$^{18}$ There was, however, a scale of sinfulness, with the 'traditional' methods, condoms and pills at the low end, sterilization very high and abortion at the pinnacle (a 'vicious sin' in the words of one respondent).

For logical reasons as well as evidential reasons, it is unlikely that views about the sinfulness of family planning methods have any effect on the adoption of 'traditional' methods in preference to other methods of family planning. The logical reason is that most people adopt methods of family planning even though they regard them as being sinful, because they regarded their families' needs as outweighing the dictates of religion. Where they adopted a 'traditional' method, this choice seemed to have little to do with their opinions about sinfulness of family planning, although they would sometimes state that the methods they were using were acceptable from a religious standpoint. Rather, methods of family planning were adopted because of the dire necessity of limiting family size, over-riding any religious objections.

In considering this question, many respondents gave as the basis for their choice that it would be a greater sin (than using family planning) to bring children into the world if they could not be fed, clothed and educated properly, or if there was not enough land for them.

The main effect of religious restriction on method choice was avoidance of sterilization because of the harmful social consequences, encouraged by the perception of opposition by religious leaders in the study areas. We believe that it would be necessary to mobilize religious leaders in active support of family planning to overcome the perceptions of people in the sample areas.

\footnotetext{
${ }^{18}$ Among people who had ever heard of the method of azal, there was considerable knowledge of the prophet Muhammad's endorsement of this method, recorded in the hadith, although this has not been discussed in this chapter. These people, mainly men, mostly regarded azal as being free of sin.
} 


\title{
Chapter 8. Discussion and Implications for Reproductive Health Policy
}

\author{
The reproductive health context of the study
}

The 'traditional' methods of family planning hold some interest for family planning service delivery programs in Bangladesh, because use of 'traditional' methods has been seen as an impediment to achieving the aims of the national family planning program. The safe period method, and azal (withdrawal), have been considered to be markedly ineffective methods with high failure rates, and use of these methods has been officially discouraged.

Nevertheless, we have taken the trouble to point out that while apparent method failure is high with use of these methods, method continuation is in the long term as good as or better than method continuation with the main program methods. This is because many users of the main program methods in Bangladesh discontinue use because of side effects or health concerns, without immediately adopting another method. A large proportion of these women become pregnant in a very short space of time (within three months), so that while method failure strictly defined is low with use of the main program methods, ultimately their use has been no more effective in preventing pregnancy than use of the 'traditional' methods. The conclusion is that even in the limited context of programs to increase contraceptive prevalence, the use of 'traditional' methods has been considered incompletely.

There is a wider reproductive health context in which women and men choose 'traditional' methods of family planning. One fundamental aspect of this wider context is that discouragement of use of the 'traditional' methods, and in particular discouragement of the safe period method, amounts to denial to women of basic knowledge about the working of their own bodies. In the study, we found that most respondents do not just have poor knowledge of the menstrual cycle and the timing of ovulation, they do not really know enough to have any foundation for use of the safe period method. Yet still they try to use it. It is among the most basic of reproductive rights of women that they should have enough information about the workings of their own bodies to understand choices that they might make about family planning.

Use of the 'traditional' methods of family planning in Bangladesh has high prevalence among adolescents, particularly in the interval between marriage and first birth. Early onset of childbearing is a critical issue in reproductive health in Bangladesh, so that use of any methods of family planning by young couples without children is a matter of considerable policy interest. The substantial risks for immature bodies at the time of delivery, for the babies born from immature bodies, and for infants nurtured by women who themselves are little more than children are all matters of basic reproductive health interest. While early childbearing can be avoided by later marriage, with consequent benefits for education, employment and social development, it can also be avoided by using methods of family planning immediately after marriage until the young woman is mature enough to begin to have children. These methods are often the 'traditional' methods of azal and safe period, and are frequently used in combination with condoms, in practice.

The direct methods of family planning (including use of condoms as well as azal and the safe period method) are the only methods apart from vasectomy that require male involvement for their use. For this reason they are of some interest in any discussion of increasing the role of men as participators in family planning, unless this role is perceived to be no more than providing the means and support for choices to be made by women. 
In this report, we have concentrated on investigations relevant to these matters, but there are other aspects of the use of 'traditional' methods of family planning that should be mentioned in the context of reproductive health. The fact that the safe period method used alone has no positive impact on preventing transmission of sexually-transmitted diseases (STDs) and HIV/AIDS is evident. While the safe period method is used in combination with azal or condoms or both very often in Bangladesh, this is unlikely to provide significantly more protection. Given that exclusive use of condoms is a significant factor in protection against disease transmission, the implications for reproductive health policy of use of condoms in combination with other methods need to be considered.

\section{$\boldsymbol{F}^{\text {indings and policies }}$}

Higher use of 'traditional' methods and the other direct method, condoms, occurs both at the very start of the reproductive cycle and also at its end. Very often, use of the safe period method, azal and condoms is some combination of these methods, based on the safe period with azal and condoms used in the perceived at-risk period of the cycle. It is difficult to distinguish between these methods, which are no doubt used by individual women and men in different combinations from time to time. ${ }^{19}$

Use of any method of family planning before the birth of at least one child is basically ignored by the family planning program, and most young women are not visited by family planning field workers. However, about 28 per cent of women entering first unions in the five years before the 1993-1994 DHS would use some method of family planning before the first birth, and this proportion was gradually increasing over that period.

One of the main reasons for use of direct methods before the birth of any children is a widespread belief that use of hormonal methods, particularly the contraceptive pill, can destroy the ability to have children at all, or create delivery complications if conception does occur. One of the most common expressions of this concern is a belief that fat accumulates in the abdomen or in the womb as a result of use of the oral contraceptive pill, and as a result conception becomes difficult or impossible. Other respondents refer to drying up of the reproductive tract, or other effects. Overall, about one third of women (48 of 150) and one quarter of men ( 38 out of 141) in the sample for this study indicated that they themselves held the belief that reproductive capacity of the woman could be impaired. Many others mentioned the belief, and among these were respondents whose behaviour could also have been affected by it.

We also found that 33 per cent of women and 50 per cent of men, when asked, felt that the reproductive capacity of a woman should be proved before any family planning method is used. Many people with this belief also hold the view that reproductive capacity can be impaired by the use of hormonal methods. The combination of these two beliefs is a powerful disincentive to the use of program methods before the birth of a child. We found that the two beliefs over-rode other factors such as the attitudes of parents-in-law and background characteristics of respondents in determining whether people felt that family planning methods should be used before the birth of a child.

Of people in the sample, 41 per cent of women and 30 per cent of men said that no children were needed before a young couple adopted a method family planning. It is probable that these proportions are higher than would be found with a different survey approach, in which respondents did not appreciate that direct methods were included in the definition of 'family planning method'. Since there was still some confusion about this even among the

\footnotetext{
${ }^{19}$ The implication is that usual survey approaches to identifying method in use, allowing at best one main method and one supplementary method, are fundamentally flawed. This implication has been discussed in the body of the report.
} 
respondents to the field study, who had already been primed about the intended inclusiveness of the concept, the proportion of people who believed that something could be done to delay the first birth was probably even higher than we found. Many respondents approved of delaying births to very young women until they matured physically. It was even clear that a proportion of mothers-in-law encouraged delay of the first birth.

The policy implications of the findings about use of family planning methods before the birth of a child are of two kinds. Firstly, we regard attention to the reproductive health needs of married adolescents by the family planning program as long overdue, since societal attitudes in Bangladesh are progressing well beyond the idea that family planning should not be used before the birth of children. The reproductive health benefits of an appropriate change in policy will be substantial. Secondly, it must be considered imperative to overcome the widespread misconception that use of hormonal methods can permanently impair reproductive capacity. Among the interview evidence from the field study there was even mention that this belief was being promoted by family planning field workers themselves. The existence of this belief limits choices available to many couples to the use of family planning only to stop having children. Use of family planning methods to delay childbearing is a major avenue for fertility reduction and improving reproductive health in the future, so the limitation has serious policy ramifications.

While resort to direct methods of family planning by young couples wishing to delay first births is understandable under the circumstances, it is less evident that there would be a substantial change in this pattern of use if an effective attack was made on misconceptions about program methods. Unlike method failure at older ages, when on the evidence from the field study many couples are desperately trying to avoid any more births, method failure at the early stages of married life can be a joyful event. The choice of a method that is not entirely effective is in this sense rational.

A major concern about traditional methods is that they have unacceptably high failure rates. We analysed data from the 1993-1994 DHS from a different perspective. While the direct methods of family planning all have higher failure rates than indirect methods, 20 to 30 per cent of users of the main indirect temporary program methods (pill, IUD and injection) discontinue use within five years of commencement because of side-effects and health concerns, and almost one quarter of these become pregnant within three months of discontinuation.

The proportion of safe period method users continuing use at all durations up to five years is similar to continuation for the oral contraceptive pill, and by five years duration the continuation rate is higher for the safe period method.

The main implication of these findings is that 'failure' of methods defined in terms of progression to pregnancy while using a method is a blinkered perspective. Failure of the family planning program to deal with actual or perceived side-effects of the main program methods effectively results in far more unwanted pregnancies than method failure itself. Yet, a woman who can use a hormonal or anti-implantation method (IUD) without problems will evidently have greater protection against unwanted pregnancy than a user of direct methods. The dilemma for the family planning program involves dealing with health concerns of users as against supporting methods that are more failure-prone but actually result in comparable and eventually higher levels of continuation.

Accounts of method failure given during the field study enable an assessment of how failures occur for the direct methods. The narratives about failure of the safe period method reveal two aspects which deserve further attention. 
The first is that the users of the method who experienced failure had at best a tenuous grip on the details of the method. For most couples who have even partly correct knowledge about it, the versions of the safe period method which they employ would almost force them to use the method in combination with some other method. There is no doubt that this often occurs. This leads to the second observation, which is that when the safe period method is used in combination with other methods it is difficult to know to which method a failure should be attributed. It is lack of information for effective method use which is at the base of these problems.

It is lack of information for effective method use which is at the base of these problems. Denial of information about the safe period method endorses a self-fulfilling prophecy that users of the safe period method will have high rates of method failure. Of course they will, if approximately forty per cent of people who have heard of the method describe a 'safe period' which intrudes on the at-risk period of the cycle.

The policy questions concern how information on basic reproductive physiology, such as the structure of the menstrual cycle and the timing of ovulation, should be given to women and men who want to use the safe period method. Such information can also be beneficial for users of other methods. The evidence from the field study indicates that users of the safe period method in Bangladesh often combine it with azal and condoms and could in some cases continue to combine it with these methods even if they became aware that the at-risk period is only a few days in the middle of the month. This is because of the belief that the sexual needs of men cannot be denied.

The use of the safe period method in combination with either azal or condoms can result in problems. As will be discussed shortly, azal has a failure rate which is seemingly almost intrinsic. However, it is not desirable from the viewpoint of control of disease transmission to promote the use of condoms in conjunction with unprotected sexual intercourse (in the safe period of the cycle). It would therefore be more desirable to simply provide women and men information about the structure of the menstrual cycle and the timing of ovulation, if they want to use the safe period method.

Women expressed marked preference for one-on-one transmission of information. This is of considerable importance for any policy decisions on dissemination. While men expressed preference for transmission of information through radio and even television, it seemed that information obtained from existing radio programs was often repeated incorrectly. Yet because a woman cannot use the safe period method without her husband's involvement and cooperation, information should be received by men and woman at the same time. We believe that the solution is to develop clear diagrammatic material suitable to be given to women to share with their husbands.

By contrast with safe period method failures, failures of azal are less difficult to interpret. There are two basic groups. In the first group are cases where a single remembered occurrence of failure resulted in pregnancy. In the second group are cases where repeated failure to control ejaculation seems to have characterized use of the method by the couple. People who use this method should be advised that if they ever have difficulty using it properly they should discontinue use immediately and adopt a different method.

Condom failures were all attributed to rupture. While it is certainly possible that rupture is the explanation in all cases, we have raised the possibility that in some cases this is a conventional account of another type of event (namely azal failure). The term 'conventional account' refers to an explanation which does not confront social norms as much as the truth does. Another suspected conventional account was the story given by two men, whose wives 
said that they had been vasectomized, that it was not them who had been sterilized at all but rather it was their wives, who had received treatments from kabiraj that made women sterile.

A final matter investigated for its policy implications was the question of religiosity and method use. We found widespread belief that Islamic religious leaders opposed methods of family planning and that they campaigned actively against permanent methods of family planning. The policy question is how religious leaders can be mobilized to advocate use of family planning methods to overcome misconceptions among rural people.

In Islam as it is practised in Bangladesh, people use their own reason and interpretation of scripture to decide whether behaviour is sinful or not. While most women and a substantial minority of men held the view that all methods of family planning were sinful, and in particular that abortion and sterilization were sinful, we found that the majority of respondents felt that their families' needs outweighed religious teaching in the matter of family planning. This emphasized the need for continuing efforts to counsel and give support to choices made by women and men in these matters. A number of women and men interviewed during the study pointed out that it was a greater sin to bring children into the world if they could not be fed, clothed and educated properly. 


\section{Section 1. Respondent's background}

\begin{tabular}{|c|c|c|c|c|}
\hline NO. & QUESTIONS AND FILTERS & \multicolumn{2}{|c|}{ CODING CATEGORIES } & Skip \\
\hline 101 & \multirow[t]{2}{*}{ RECORD THE TIME } & \multirow{2}{*}{$\begin{array}{l}\text { HOUR } \\
\text { MINUTES }\end{array}$} & & \\
\hline & & & & \\
\hline \multirow[t]{2}{*}{102} & \multirow{2}{*}{$\begin{array}{l}\text { How long have you been living continuously in } \\
\text { (NAME OF PLACE OF RESIDENCE)? }\end{array}$} & YEARS & & \multirow{2}{*}{$\begin{array}{l}\text { Go to } 104 \\
\text { Go to } 104\end{array}$} \\
\hline & & ALWAYS & 95 & \\
\hline \multirow[t]{2}{*}{103} & \multirow{2}{*}{$\begin{array}{l}\text { Just before you moved here, did you live in a } \\
\text { city, in a town, or in the countryside? }\end{array}$} & CITY & 1 & \\
\hline & & TOWN & 2 & \\
\hline \multirow[t]{5}{*}{104} & \multirow{5}{*}{ What is your religion? } & ISLAM & 1 & \\
\hline & & CHRISTIANITY & 2 & \\
\hline & & HINDUISM & 3 & \\
\hline & & BUDDHISM & 4 & \\
\hline & & $\begin{array}{l}\text { OTHER } \\
\text { (SPECIFY) }\end{array}$ & 5 & \\
\hline 105 & How old are you? & \multicolumn{2}{|l|}{$\begin{array}{l}\text { YEARS } \\
\text { (COMPLETED) }\end{array}$} & \\
\hline \multirow[t]{5}{*}{106} & \multirow[t]{5}{*}{ Are you now married, widowed or divorced? } & \multirow{5}{*}{$\begin{array}{l}\text { MARRIED } \\
\text { NEVER MARRIED } \\
\text { WIDOWED } \\
\text { SEPARATED } \\
\text { DIVORCED }\end{array}$} & 1 & \\
\hline & & & 2 & Go to 502 \\
\hline & & & 3 & Go to 502 \\
\hline & & & 4 & Go to 502 \\
\hline & & & 5 & Go to 502 \\
\hline \multirow[t]{2}{*}{107} & \multirow{2}{*}{$\begin{array}{l}\text { Has your husband been living here with you } \\
\text { during the last three months? }\end{array}$} & \multirow{2}{*}{$\begin{array}{l}\text { YES } \\
\text { NO }\end{array}$} & 1 & \multirow{2}{*}{ Go to 502} \\
\hline & & & 2 & \\
\hline 108 & Have you ever attended school/madrasa? & $\begin{array}{l}\text { YES } \\
\text { NO }\end{array}$ & 1 & Go to 110 \\
\hline \multirow{2}{*}{109} & \multirow{2}{*}{ What is the highest class you completed? } & \multirow{2}{*}{$\begin{array}{l}\text { GOVT } \\
\text { MADRASA }\end{array}$} & & \\
\hline & & & & \\
\hline
\end{tabular}




\section{Section 1. Respondent's background (continued)}

\begin{tabular}{|c|c|c|c|c|}
\hline NO. & QUESTIONS AND FILTERS & \multicolumn{2}{|c|}{ CODING CATEGORIES } & Skip \\
\hline 110 & $\begin{array}{l}\text { Do you usually read a newspaper or magazine } \\
\text { at least once a week? }\end{array}$ & $\begin{array}{l}\text { YES } \\
\text { NO } \\
\text { CANNOT READ }\end{array}$ & $\begin{array}{l}1 \\
2 \\
3\end{array}$ & \\
\hline 111 & $\begin{array}{l}\text { Do you usually listen to the radio at least once } \\
\text { a week? }\end{array}$ & $\begin{array}{l}\text { YES } \\
\text { NO }\end{array}$ & $\begin{array}{l}1 \\
2\end{array}$ & \\
\hline 112 & $\begin{array}{l}\text { Do you usually watch television at least once } \\
\text { a week? }\end{array}$ & $\begin{array}{l}\text { YES } \\
\text { NO }\end{array}$ & $\begin{array}{l}1 \\
2\end{array}$ & \\
\hline 113 & Do you belong to any organizations? & $\begin{array}{l}\text { YES } \\
\text { NO }\end{array}$ & $\begin{array}{l}1 \\
2\end{array}$ & Go to 117 \\
\hline 114 & $\begin{array}{l}\text { Which organizations? } \\
\text { RECORD ALL MENTIONED }\end{array}$ & $\begin{array}{l}\text { GRAMEEN BANK } \\
\text { BRAC } \\
\text { BRD } \\
\text { ASHA } \\
\text { PROSHIKA } \\
\text { MOTHER'S CLUB } \\
\text { OTHER } \\
\quad \text { (SPECIFY) }\end{array}$ & $\begin{array}{l}\mathrm{A} \\
\mathrm{B} \\
\mathrm{C} \\
\mathrm{D} \\
\mathrm{E} \\
\mathrm{F} \\
\mathrm{G}\end{array}$ & \\
\hline 115 & $\begin{array}{l}\text { CHECK 114. IS 'YES' RECORDED FOR ANY } \\
\text { ITEM? }\end{array}$ & $\begin{array}{l}\text { YES } \\
\text { NO }\end{array}$ & $\begin{array}{l}1 \\
2\end{array}$ & Go to 117 \\
\hline 116 & $\begin{array}{l}\text { Are you involved in any income-generating } \\
\text { activities through these organizations? }\end{array}$ & $\begin{array}{l}\text { YES } \\
\mathrm{NO}\end{array}$ & $\begin{array}{l}1 \\
2\end{array}$ & \\
\hline 117 & $\begin{array}{l}\text { I would like to ask you some questions about } \\
\text { your household. } \\
\text { What is the source of water your household } \\
\text { uses for drinking? }\end{array}$ & $\begin{array}{l}\text { PIPED WATER } \\
\text { - INSIDE DWELLING } \\
\text { - OUTSIDE DWELLING } \\
\text { WELL WATER } \\
\text { - TUBEWELL } \\
\text { - OTHER WELL } \\
\text { SURFACE WATER } \\
\text { - POND/TANK/LAKE } \\
\text { - RIVER/STREAM } \\
\text { RAINWATER } \\
\text { OTHER } \\
\text { (SPECIFY) }\end{array}$ & $\begin{array}{l}11 \\
12 \\
21 \\
22 \\
31 \\
32 \\
41 \\
51\end{array}$ & \\
\hline
\end{tabular}


Section 1. Respondent's background (continued)

\begin{tabular}{|c|c|c|c|c|c|}
\hline NO. & QUESTIONS AND FILTERS & \multicolumn{3}{|c|}{ CODING CATEGORIES } & Skip \\
\hline 118 & $\begin{array}{l}\text { What is the source of water for bathing for } \\
\text { members of your household? } \\
\text { (RECORD ALL SOURCES MENTIONED) }\end{array}$ & \multicolumn{3}{|c|}{$\begin{array}{l}\text { PIPED WATER } \\
\text { - INSIDE DWELLING } \\
\text { - OUTSIDE DWELLING } \\
\text { WELL WATER } \\
\text { - TUBEWELL } \\
\text { - OTHER WELL } \\
\text { SURFACE WATER } \\
\text { - POND/TANK/LAKE } \\
\text { - RIVER/STREAM } \\
\text { RAINWATER } \\
\text { OTHER } \\
\text { (SPECIFY) } \\
\end{array}$} & \\
\hline 119 & Is there a toilet or latrine in your household? & \multicolumn{2}{|l|}{$\begin{array}{l}\text { YES } \\
\text { NO }\end{array}$} & $\begin{array}{l}1 \\
2\end{array}$ & to 121 \\
\hline 120 & $\begin{array}{l}\text { What type of toilet or latrine does your } \\
\text { household have? }\end{array}$ & \multicolumn{2}{|c|}{$\begin{array}{l}\text { SEPTIC TANK OR } \\
\text { MODERN TOILET } \\
\text { PIT TOILET/LATRINE } \\
\text { - WATER SEALED/SLAB } \\
\text { - PIT LATRINE } \\
\text { - OPEN LATRINE } \\
\text { - HANGING LATRINE } \\
\text { OTHER } \\
\text { (SPECIFY) }\end{array}$} & $\begin{array}{l}11 \\
21 \\
22 \\
23 \\
24 \\
51\end{array}$ & \\
\hline 121 & $\begin{array}{l}\text { Does your household have: } \\
\text { - Almirah? } \\
\text { - A table, chair or bench? } \\
\text { - A watch or clock that is working? } \\
\text { - A cot or bed? } \\
\text { - A radio that is working? } \\
\text { - A television that is working? } \\
\text { - A bicycle? } \\
\text { - A rickshaw van (country van)? } \\
\text { - A motorcycle or other vehicle? } \\
\text { - Agricultural land? }\end{array}$ & $\begin{array}{l}\text { YES } \\
1 \\
1 \\
1 \\
1 \\
1 \\
1 \\
1 \\
1 \\
1 \\
1\end{array}$ & $\begin{array}{l}\text { NO } \\
2 \\
2 \\
2 \\
2 \\
2 \\
2 \\
2 \\
2 \\
2 \\
2--\end{array}$ & & 123 \\
\hline 122 & $\begin{array}{l}\text { How many decimals of agricultural land does } \\
\text { your household own? }\end{array}$ & DECIMALS & & & \\
\hline
\end{tabular}


Section 1. Respondent's background (continued)

\begin{tabular}{|c|c|c|c|c|}
\hline NO. & QUESTIONS AND FILTERS & \multicolumn{2}{|c|}{ CODING CATEGORIES } & Skip \\
\hline 123 & $\begin{array}{l}\text { MAIN MATERIAL OF THE ROOF } \\
\text { (RECORD OBSERVATION) }\end{array}$ & 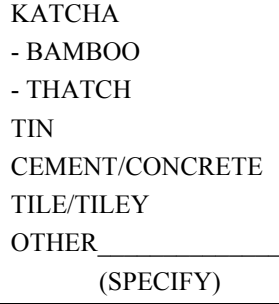 & $\begin{array}{l}11 \\
12 \\
21 \\
31 \\
32 \\
41\end{array}$ & \\
\hline 124 & $\begin{array}{l}\text { MAIN MATERIAL OF THE WALLS } \\
\text { (RECORD OBSERVATION) }\end{array}$ & $\begin{array}{l}\text { KATCHA } \\
\text { - JUTE } \\
\text { - BAMBOO } \\
\text { - MUD } \\
\text { WOOD } \\
\text { BRICK/CEMENT } \\
\text { TIN } \\
\text { OTHER } \\
\quad \text { (SPECIFY) }\end{array}$ & $\begin{array}{l}11 \\
12 \\
13 \\
21 \\
31 \\
32 \\
41\end{array}$ & \\
\hline 125 & $\begin{array}{l}\text { MAIN MATERIAL OF THE FLOOR } \\
\text { (RECORD OBSERVATION) }\end{array}$ & $\begin{array}{l}\text { KATCHA } \\
\text { - EARTH } \\
\text { - BAMBOO } \\
\text { WOOD } \\
\text { CEMENT/CONCRETE } \\
\text { OTHER } \\
\text { (SPECIFY) }\end{array}$ & $\begin{array}{l}11 \\
12 \\
21 \\
31 \\
41\end{array}$ & \\
\hline
\end{tabular}

END OF SECTION 1 


\section{Section 2. Children and pregnancy}

\begin{tabular}{|c|c|c|c|c|}
\hline NO. & QUESTIONS AND FILTERS & \multicolumn{2}{|c|}{ CODING CATEGORIES } & Skip \\
\hline 201 & $\begin{array}{l}\text { I would like to ask you some questions about } \\
\text { your family and children. Have you ever given } \\
\text { birth? }\end{array}$ & $\begin{array}{l}\text { YES } \\
\text { NO }\end{array}$ & $\begin{array}{l}1 \\
2\end{array}$ & Go to 206 \\
\hline 202 & $\begin{array}{l}\text { Do you have any sons or daughters to whom } \\
\text { you have given birth who are living with you } \\
\text { now? }\end{array}$ & $\begin{array}{l}\text { YES } \\
\text { NO }\end{array}$ & $\begin{array}{l}1 \\
2\end{array}$ & Go to 204 \\
\hline 203 & $\begin{array}{l}\text { How many sons live with you? } \\
\text { And how many daughters live with you? } \\
\text { IF NONE RECORD ' } 00 \text { ' }\end{array}$ & $\begin{array}{l}\text { SONS AT HOME } \\
\text { DAUGHTERS AT HOME }\end{array}$ & & \\
\hline 204 & $\begin{array}{l}\text { Do you have any sons or daughters to whom } \\
\text { you have given birth who are alive but do not } \\
\text { live with you? }\end{array}$ & $\begin{array}{l}\text { YES } \\
\text { NO }\end{array}$ & $\begin{array}{l}1 \\
2\end{array}$ & Go to 206 \\
\hline 205 & $\begin{array}{l}\text { How many of your living sons do not live with } \\
\text { you? } \\
\text { And how many of your living daughters do not } \\
\text { live with you? } \\
\text { IF NONE RECORD ' } 00 \text { ' }\end{array}$ & $\begin{array}{l}\text { SONS AWAY } \\
\text { DAUGHTERS AWAY }\end{array}$ & & \\
\hline 206 & $\begin{array}{l}\text { Have you ever given birth to a boy or girl who } \\
\text { was born alive but died later? } \\
\text { IF NO, PROBE: Any baby who cried or showed } \\
\text { any sign of life but only survived a few hours or } \\
\text { days? }\end{array}$ & $\begin{array}{l}\text { YES } \\
\text { NO }\end{array}$ & $\begin{array}{l}1 \\
2\end{array}$ & Go to 208 \\
\hline 207 & $\begin{array}{l}\text { In all, how many boys have died? } \\
\text { And how many girls have died? } \\
\text { IF NONE RECORD '00' }\end{array}$ & $\begin{array}{l}\text { BOYS DEAD } \\
\text { GIRLS DEAD }\end{array}$ & & \\
\hline 208 & $\begin{array}{l}\text { SUM ANSWERS TO 203, } 205 \text { AND } 207 \text { AND } \\
\text { ENTER TOTAL. IF NONE, RECORD ‘00’. }\end{array}$ & TOTAL & & \\
\hline 209 & $\begin{array}{l}\text { CHECK 208: } \\
\text { Just to make sure that I have this right, you have had } \\
\text { in total ..... births during your life so far. Is that } \\
\text { correct? } \\
\text { IF NO PROBE AND CORRECT } 201 \text { TO } 208\end{array}$ & & & \\
\hline
\end{tabular}

\section{Section 2. Children and pregnancy (continued)}




\begin{tabular}{|c|c|c|c|c|}
\hline NO. & QUESTIONS AND FILTERS & \multicolumn{2}{|c|}{ CODING CATEGORIES } & Skip \\
\hline 210 & Are you pregnant now? & $\begin{array}{l}\text { YES } \\
\text { NO } \\
\text { TUBAL LIG'N } \\
\text { VASECTOMY } \\
\text { UNSURE } \\
\text { UNABLE TO GET } \\
\text { PREGNANT }\end{array}$ & $\begin{array}{l}1 \\
2 \\
3 \\
4 \\
8 \\
9\end{array}$ & $\begin{array}{l}\text { Go to } 301 \\
\text { Go to } 215 \\
\text { Go to } 215 \\
\text { Go to } 215\end{array}$ \\
\hline 211 & In the future, do you want a(nother) child? & $\begin{array}{l}\text { HAVE A CHILD } \\
\text { NO MORE/NONE } \\
\text { TUBAL LIG'N } \\
\text { VASECTOMY } \\
\text { CAN'T GET PREGNANT } \\
\text { UNDECIDED }\end{array}$ & $\begin{array}{l}1 \\
2 \\
3 \\
4 \\
3 \\
8\end{array}$ & $\begin{array}{l}\text { Go to } 215 \\
\text { Go to } 215 \\
\text { Go to } 215 \\
\text { Go to } 215 \\
\text { Go to } 215\end{array}$ \\
\hline 212 & $\begin{array}{l}\text { Would you like to wait before having a(nother) } \\
\text { child or would you like to have a baby soon? }\end{array}$ & 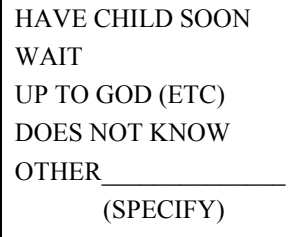 & $\begin{array}{l}1 \\
2 \\
7 \\
8 \\
9\end{array}$ & \\
\hline 213 & $\begin{array}{l}\text { How many (more) children would you like to } \\
\text { have? }\end{array}$ & $\begin{array}{l}\text { NUMBER } \\
\text { UP TO GOD (ETC) } \\
\text { UNDECIDED } \\
\text { DOES NOT KNOW }\end{array}$ & $\begin{array}{l} \\
95 \\
98 \\
99\end{array}$ & $\begin{array}{l}\text { Go to } 215 \\
\text { Go to } 215 \\
\text { Go to } 215\end{array}$ \\
\hline 214 & $\begin{array}{l}\text { How many of these would you like to be boys } \\
\text { and how many girls? }\end{array}$ & $\begin{array}{l}\text { BOYS } \\
\text { GIRLS } \\
\text { EITHER } \\
\text { UP TO GOD (ETC) } \\
\begin{array}{r}\text { OTHER } \\
\quad \text { (SPECIFY) }\end{array}\end{array}$ & $\begin{array}{l} \\
\\
\\
\\
95 \\
96\end{array}$ & \\
\hline 215 & $\begin{array}{l}\text { CHECK } 202 \text { AND 203. RECORD WHETHER } \\
\text { WOMAN HAS CHILDREN LIVING AT HOME }\end{array}$ & $\begin{array}{l}\text { CHILDREN AT HOME } \\
\text { NO CHILDREN AT } \\
\text { HOME }\end{array}$ & $\begin{array}{l}1 \\
2\end{array}$ & $\prod_{\text {Go to } 301}$ \\
\hline
\end{tabular}


Section 2. Children and pregnancy (continued)

\begin{tabular}{|c|c|c|c|c|}
\hline NO. & QUESTIONS AND FILTERS & \multicolumn{2}{|c|}{ CODING CATEGORIES } & Skip \\
\hline 216 & $\begin{array}{l}\text { How old is your youngest child who is living with } \\
\text { you?* }\end{array}$ & & & \\
\hline 217 & $\begin{array}{l}\text { RECORD WHETHER AGE IS IN YEARS OR } \\
\text { MONTHS. }\end{array}$ & $\begin{array}{l}\text { YEARS } \\
\text { MONTHS }\end{array}$ & $\begin{array}{l}1 \\
2\end{array}$ & \\
\hline 218 & $\begin{array}{l}\text { IS THE CHILD LESS THAN THREE YEARS } \\
\text { OLD? }\end{array}$ & $\begin{array}{l}\text { YES } \\
\text { NO }\end{array}$ & $\begin{array}{l}1 \\
2\end{array}$ & Go to 301 \\
\hline 219 & Are you breastfeeding this child? & $\begin{array}{l}\text { YES } \\
\text { NO }\end{array}$ & $\begin{array}{l}1 \\
1\end{array}$ & Go to 221 \\
\hline 220 & $\begin{array}{l}\text { For how long did you breastfeed this child? } \\
\text { RECORD COMPLETED MONTHS }\end{array}$ & $\begin{array}{l}\text { DOESN'T KNOW } \\
\text { OTHER } \\
\quad \text { (SPECIFY) }\end{array}$ & $\begin{array}{l} \\
97 \\
98\end{array}$ & \\
\hline 221 & $\begin{array}{l}\text { Has your period returned since this child was } \\
\text { born? }\end{array}$ & $\begin{array}{l}\text { YES } \\
\text { NO }\end{array}$ & $\begin{array}{l}1 \\
2\end{array}$ & Go to 301 \\
\hline 222 & $\begin{array}{l}\text { How many months was it until your period } \\
\text { returned? } \\
\text { RECORD COMPLETED MONTHS }\end{array}$ & $\begin{array}{l}\text { DOESN'T KNOW } \\
\text { OTHER } \\
\quad \text { (SPECIFY) }\end{array}$ & $\begin{array}{r}\frac{1}{97} \\
98\end{array}$ & \\
\hline
\end{tabular}

* FOR A CHILD WHO MAY BE LESS THAN THREE YEARS OLD, ESTIMATE THE MONTH AND YEAR OF BIRTH AND USE THE FOLLOWING TABLE TO CALCULATE AGE IN MONTHS:

\begin{tabular}{|c|c|c|c|c|c|c|c|c|c|c|c|c|}
\hline & January & February & March & April & May & June & July & August & $\begin{array}{l}\text { Sept- } \\
\text { ember }\end{array}$ & October & $\begin{array}{l}\text { Nov- } \\
\text { ember }\end{array}$ & $\begin{array}{l}\text { Dec- } \\
\text { ember }\end{array}$ \\
\hline 1993 & 44 & 43 & 42 & 41 & 40 & 39 & 38 & 37 & 36 & 35 & 34 & 33 \\
\hline 1994 & 32 & 31 & 30 & 29 & 28 & 27 & 26 & 25 & 24 & 23 & 22 & 21 \\
\hline 1995 & 20 & 19 & 18 & 17 & 16 & 15 & 14 & 13 & 12 & 11 & 10 & 9 \\
\hline 1996 & 8 & 7 & 6 & 5 & 4 & 3 & 2 & 1 & 0 & & & \\
\hline & Baishak & Jaistha & Ashar & Sraban & Badhra & Ashwin & Kartik & $\begin{array}{l}\text { Agra- } \\
\text { hayan }\end{array}$ & Poush & Magh & Falgun & Choitra \\
\hline 1400 & 41 & 40 & 39 & 38 & 37 & 36 & 35 & 34 & 33 & 32 & 31 & 30 \\
\hline 1401 & 29 & 28 & 27 & 26 & 25 & 24 & 23 & 22 & 21 & 20 & 19 & 18 \\
\hline 1402 & 17 & 16 & 15 & 14 & 13 & 12 & 11 & 10 & 9 & 8 & 7 & 6 \\
\hline 1403 & 5 & 4 & 3 & 2 & 1 & 0 & & & & & & 7 \\
\hline
\end{tabular}

END OF SECTION 2 


\section{Section 3. Family planning}

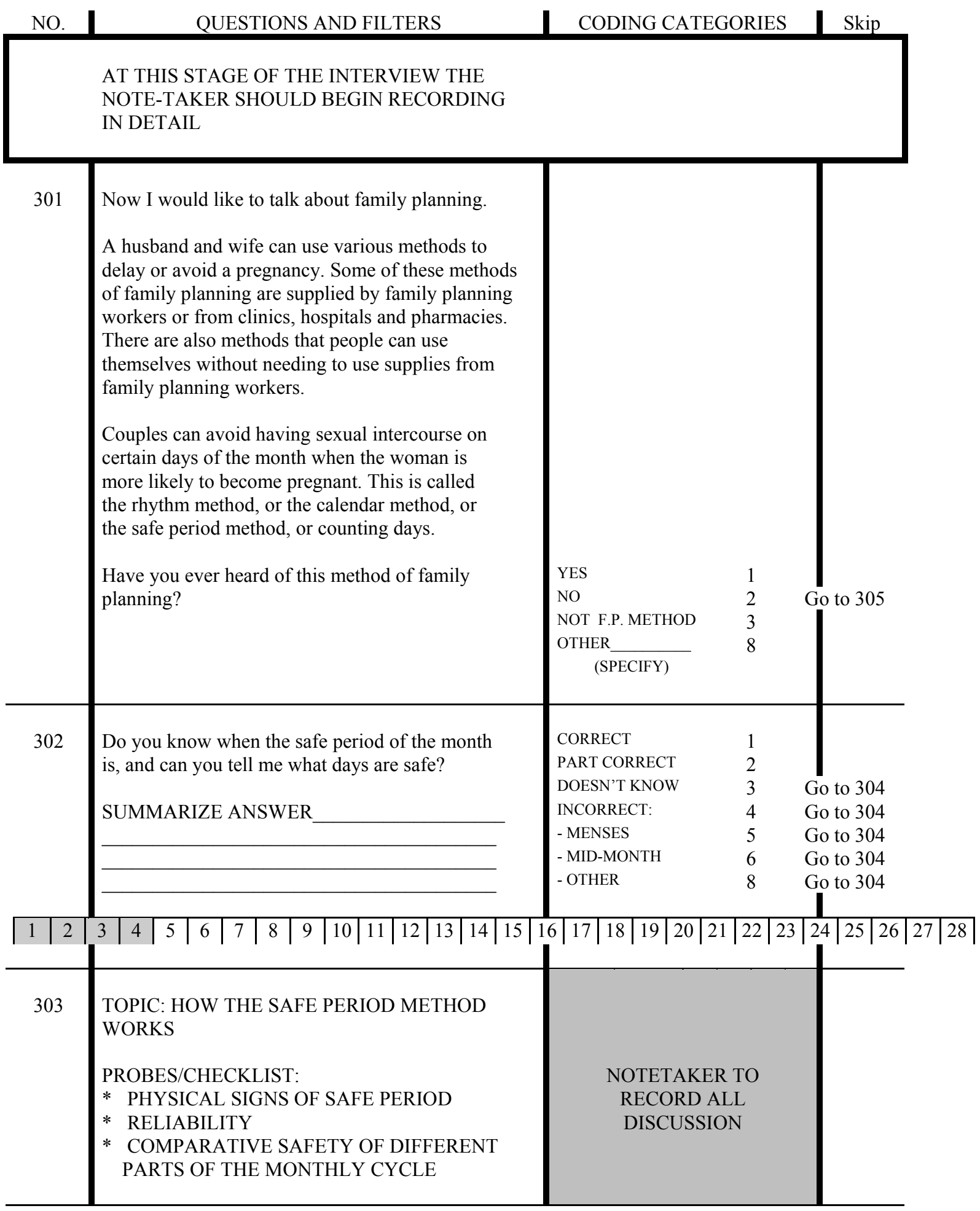


Section 3. Family planning (continued)

\begin{tabular}{|c|c|c|c|c|}
\hline NO. & QUESTIONS AND FILTERS & \multicolumn{2}{|c|}{ CODING CATEGORIES } & Skip \\
\hline 304 & $\begin{array}{l}\text { What was the source of your information about } \\
\text { the safe period method? }\end{array}$ & $\begin{array}{l}\text { HUSBAND } \\
\text { FRIEND/RELATIVE/ } \\
\text { NEIGHBOUR } \\
\text { FWA/FWV } \\
\text { BOOK } \\
\text { PAMPHLET } \\
\text { OTHER } \\
\quad \text { (SPECIFY) }\end{array}$ & $\begin{array}{l}1 \\
2 \\
3 \\
4 \\
5 \\
6\end{array}$ & \\
\hline 305 & $\begin{array}{l}\text { Another method of avoiding pregnancy is for men to } \\
\text { be careful and pull out before climax. } \\
\text { This is called azal. } \\
\text { Have you ever heard of this method of family } \\
\text { planning? }\end{array}$ & $\begin{array}{l}\text { YES } \\
\text { NO } \\
\text { NOT F.P. METHOD } \\
\text { OTHER } \\
\quad \text { (SPECIFY) }\end{array}$ & $\begin{array}{l}1 \\
2 \\
3 \\
8\end{array}$ & \\
\hline 306 & $\begin{array}{l}\text { Some women go to the kabiraj to get preparations to } \\
\text { avoid pregnancy. } \\
\text { Have you ever heard of this method of family } \\
\text { planning? } \\
\text { IF THE RESPONDENT ANSWERS 'NO', } \\
\text { PROBE: } \\
\text { - Are there any foods that people should eat } \\
\text { if they do not want to get pregnant? } \\
\text { - Are there any drinks they should take? }\end{array}$ & $\begin{array}{l}\text { YES } \\
\text { NO } \\
\text { NOT F.P. METHOD } \\
\text { OTHER } \\
\text { (SPECIFY) } \\
\text { NOTETA } \\
\text { TECORD } \\
\text { DISCUSS }\end{array}$ & $\begin{array}{l}1 \\
2 \\
3 \\
8\end{array}$ & \\
\hline
\end{tabular}


Section 3. Family planning (continued)

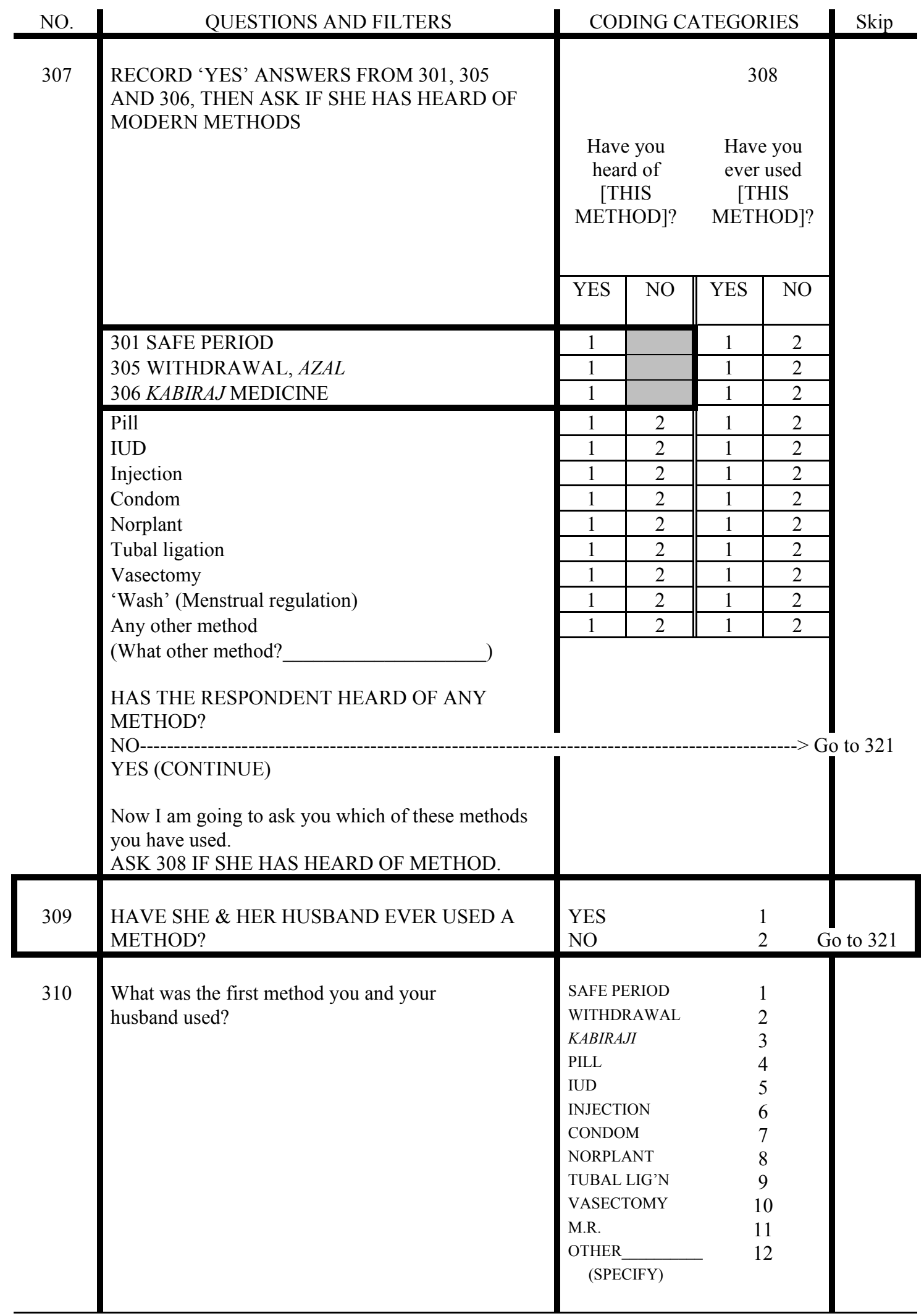




\section{Section 3. Family planning (continued)}

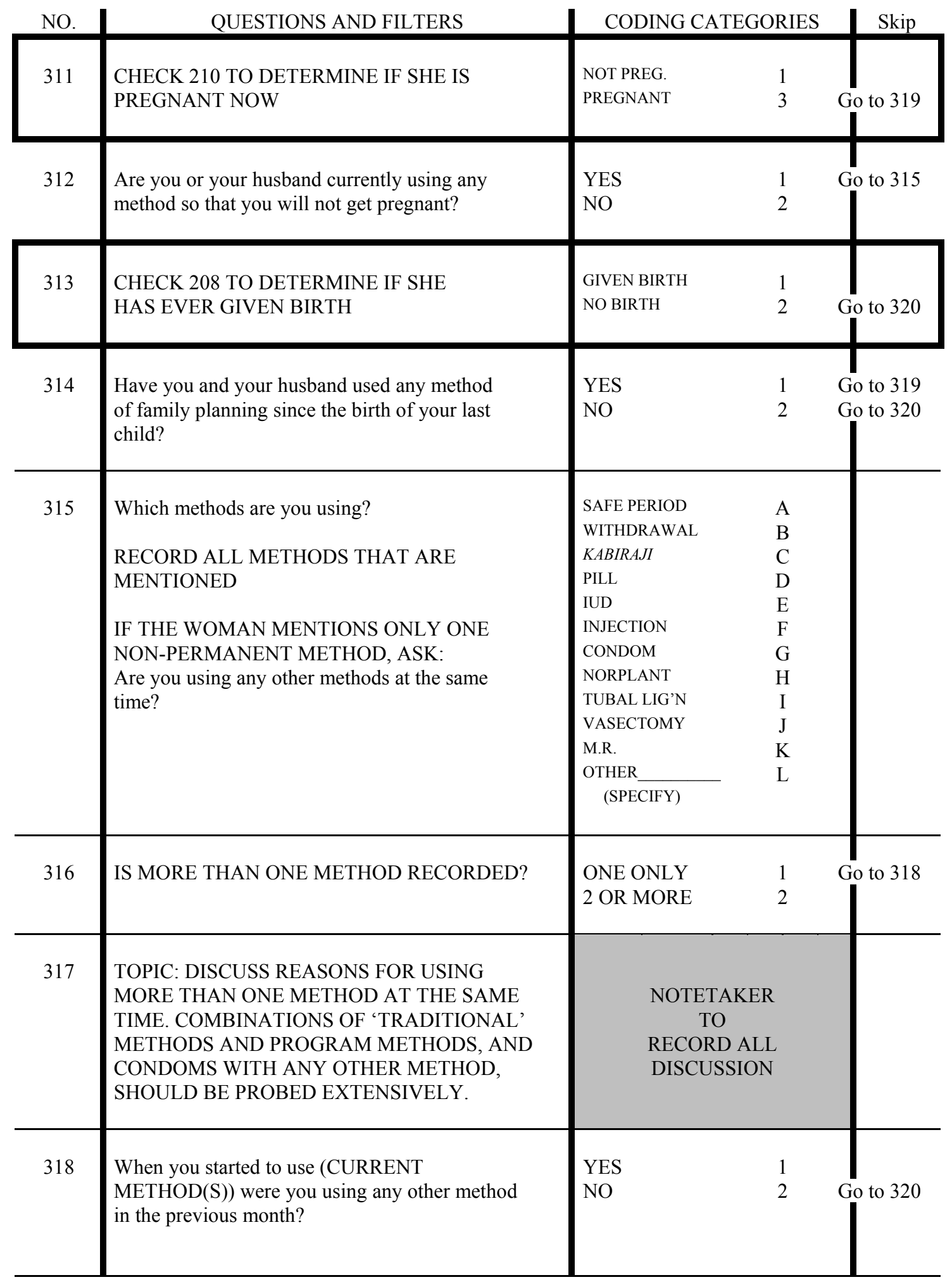




\section{Section 3. Family planning (continued)}

\begin{tabular}{|c|c|c|c|c|c|}
\hline NO. & \multicolumn{2}{|c|}{ QUESTIONS AND FILTERS } & \multicolumn{2}{|c|}{ CODING CATEGORIES } & Skip \\
\hline 319 & $\begin{array}{l}\text { IF SHE IS NOT CURR } \\
\text { METHOD, ASK: } \\
\text { Which methods of fami } \\
\text { using last? } \\
\text { IF SHE IS CURRENTL } \\
\text { ASK: } \\
\text { Which methods of fami } \\
\text { using previously? } \\
\text { RECORD ALL METHC } \\
\text { MENTIONED }\end{array}$ & $\begin{array}{l}\text { ГLY USING ANY } \\
\text { lanning were you } \\
\text { JSING A METHOD, } \\
\text { lanning were you } \\
\text { THAT ARE }\end{array}$ & \begin{tabular}{l} 
SAFE PERIOD \\
WITHDRAWAL \\
KABIRAJI \\
PILL \\
IUD \\
INJECTION \\
CONDOM \\
NORPLANT \\
TUBAL LIG'N \\
VASECTOMY \\
M.R. \\
OTHER \\
\multicolumn{1}{l}{ (SPECIFY) }
\end{tabular} & $\begin{array}{l}\mathrm{A} \\
\mathrm{B} \\
\mathrm{C} \\
\mathrm{D} \\
\mathrm{E} \\
\mathrm{F} \\
\mathrm{G} \\
\mathrm{H} \\
\mathrm{I} \\
\mathrm{J} \\
\mathrm{K} \\
\mathrm{L}\end{array}$ & \\
\hline 320 & \multicolumn{2}{|c|}{$\begin{array}{l}\text { How many living children did you have when } \\
\text { and your husband first used a family planning } \\
\text { method? (IF NONE RECORD ' } 00 \text { ') }\end{array}$} & & & \\
\hline \multirow[t]{4}{*}{321} & \multicolumn{2}{|c|}{$\begin{array}{l}\text { CHECK } 310,315 \& 319 \text { AND RECORD } \\
\text { LAST TWO FAMILY PLANNING METHODS } \\
\text { (SINCE LAST PREGNANCY) }\end{array}$} & & & \\
\hline & PREVIOUS METHOD & CURRENT METHOD & & & \\
\hline & $\begin{array}{l}\text { NEVER HEARD OF F } \\
\text { PREGNANT NOW } \\
\text { NO METHOD (SINCE } \\
\text { 'TRADITIONAL' MET } \\
\text { PROGRAM METHOD } \\
\text { PERMANENT METHC } \\
\text { NONE } \\
\text { NONE } \\
\text { NONE } \\
\text { 'TRADITIONAL' } \\
\text { 'TRADITIONAL' } \\
\text { 'TRADITIONAL' } \\
\text { PROGRAM } \\
\text { PROGRAM } \\
\text { PROGRAM }\end{array}$ & $\begin{array}{l}\text { ILY PLANNING } \\
\text { ST PREGNANT) } \\
\text { D(S) ONLY } \\
\text { ONLY } \\
\text { ONLY } \\
\text { 'TRADITIONAL' } \\
\text { PROGRAM } \\
\text { PERMANENT } \\
\text { NONE } \\
\text { PROGRAM } \\
\text { PERMANENT } \\
\text { NONE } \\
\text { 'TRADITIONAL' } \\
\text { PERMANENT } \\
\end{array}$ & & $\begin{array}{l}00 \\
98 \\
11 \\
22 \\
33 \\
44 \\
12 \\
13 \\
14 \\
21 \\
23 \\
24 \\
31 \\
32 \\
34\end{array}$ & to 401 \\
\hline & $\begin{array}{l}\text { 'TRADITIONAL' ME } \\
\text { WITHDRAWAL (AZA } \\
\text { PROGRAM MEANS } \\
\text { NORPLANT, CONDO } \\
\text { PERMANENT MEAN } \\
\text { STERILIZATION }\end{array}$ & $\begin{array}{l}\text { S SAFE PERIOD, } \\
\text { R KABIRAJI } \\
\text { IUD, INJECTION, } \\
\text { R M.R. } \\
\text { IALE OR FEMALE }\end{array}$ & \multicolumn{2}{|c|}{$\begin{array}{l}\text { RECORD CATEGORY ON } \\
\text { FOLLOWING PAGES }\end{array}$} & \\
\hline
\end{tabular}


Section 3. Family planning (continued)

\begin{tabular}{|c|c|c|c|c|}
\hline NO. & QUESTIONS AND FILTERS & \multicolumn{2}{|c|}{ CODING CATEGORIES } & Skip \\
\hline & RECORD CATEGORY FROM 321 & & & \\
\hline 322 & $\begin{array}{l}\text { CHECK } 305 \text {. HAS SHE HEARD OF } \\
\text { WITHDRAWAL }(A Z A L) ?\end{array}$ & $\begin{array}{l}\text { YES } \\
\text { NO } \\
\text { NOT F.P METHOD } \\
\text { OTHER }\end{array}$ & $\begin{array}{l}1 \\
2 \\
3 \\
8\end{array}$ & $\begin{array}{l}\text { Go to } 324 \\
\text { Go to } 324 \\
\text { Go to } 324\end{array}$ \\
\hline 323 & $\begin{array}{l}\text { TOPIC: ADVANTAGES/DISADVANTAGES OF } \\
\text { WITHDRAWAL AS A METHOD OF FAMILY } \\
\text { PLANNING } \\
\text { PROBES/CHECKLIST: } \\
\text { (PROBE ONLY IF RELEVANT) } \\
* \quad \text { WHAT RELIGION SAYS ABOUT IT } \\
* \\
\text { STAGES OF MARRIED LIFE WHEN IT } \\
\text { SHOULD/SHOULD NOT BE USED } \\
\text { * PRIVACY OF USE } \\
\text { AVAILABILITY OF INFORMATION FROM } \\
\text { FWA/FWV \& OTHER SOURCES } \\
\text { EFFECTIVENESS OF AZAL FOR F.P. } \\
\text { COMPARED WITH OTHER METHODS }\end{array}$ & $\begin{array}{r}\text { NOTET } \\
\text { TO } \\
\text { RECORI } \\
\text { DISCUS }\end{array}$ & & \\
\hline 324 & $\begin{array}{l}\text { CHECK } 301 \text {. HAS SHE HEARD OF } \\
\text { RHYTHM METHOD (CALENDAR, COUNTING } \\
\text { DAYS, SAFE PERIOD, ETC.)? }\end{array}$ & $\begin{array}{l}\text { YES } \\
\text { NO } \\
\text { NOT F.P METHOD } \\
\text { OTHER }\end{array}$ & $\begin{array}{l}1 \\
2 \\
3 \\
8\end{array}$ & $\begin{array}{l}\text { Go to } 326 \\
\text { Go to } 326 \\
\text { Go to } 326\end{array}$ \\
\hline 325 & $\begin{array}{l}\text { TOPIC: ADVANTAGES/DISADVANTAGES OF } \\
\text { RHYTHM (ETC.) AS A METHOD OF FAMILY } \\
\text { PLANNING } \\
\text { PROBES/CHECKLIST: } \\
\text { (PROBE ONLY IF RELEVANT) } \\
* \text { WHAT RELIGION SAYS ABOUT IT } \\
* \text { STAGES OF MARRIED LIFE WHEN IT } \\
\text { SHOULD/SHOULD NOT BE USED } \\
\text { * } \\
\text { PRIVACY OF USE } \\
\text { AVAILABILITY OF INFORMATION FROM } \\
\text { FWA/FWV } \\
\text { * AVAILABILITY OF INFORMATION IN } \\
\text { MEDIA (NEWSPAPERS, MAGAZINES, } \\
\text { RADIO, TELEVISION) } \\
\text { * } \text { WHETHER INFORMATION SHOULD BE } \\
\text { AVAILABLE AND SUITABLE SOURCE } \\
\text { EFFECTIVENESS OF RHYTHM (ETC.) } \\
\text { COMPARED WITH OTHER METHODS }\end{array}$ & $\begin{array}{r}\text { NOTET } \\
\text { TO } \\
\text { RECORI } \\
\text { DISCUS }\end{array}$ & & \\
\hline
\end{tabular}


Section 3. Family planning (continued)

\begin{tabular}{|c|c|c|c|}
\hline $\mathrm{NC}$ & QUESTIONS AND FILTERS & CODING CATEGORIES & Skip \\
\hline & RECORD CATEGORY FROM 321 & & \\
\hline 326 & 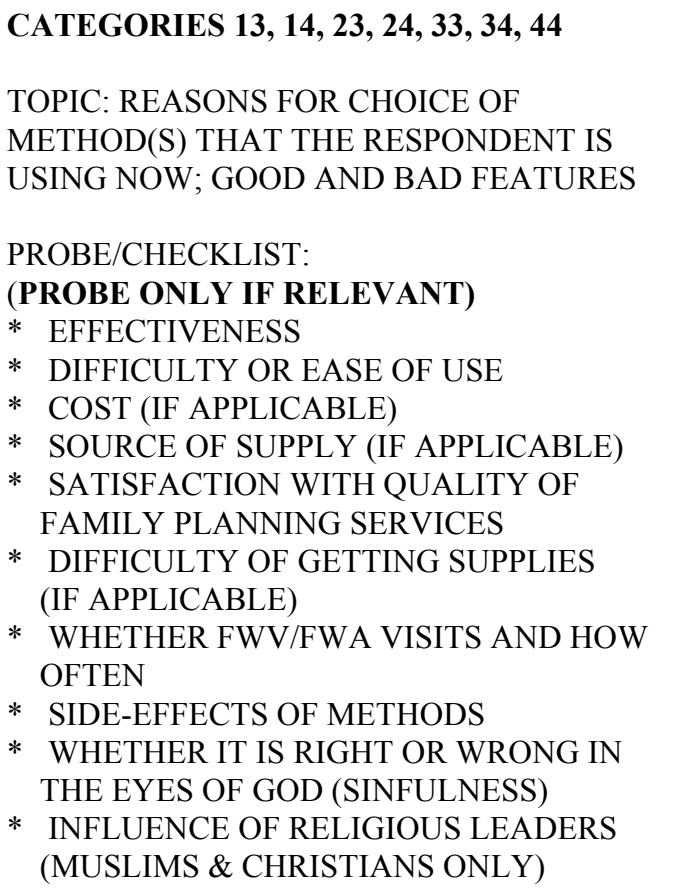 & $\begin{array}{c}\text { NOTETAKER } \\
\text { TO } \\
\text { RECORD ALL } \\
\text { DISCUSSION }\end{array}$ & \\
\hline 327 & $\begin{array}{l}\text { TOPIC: DISCUSS WHETHER A COUPLE } \\
\text { SHOULD USE ANY METHOD OF FAMILY } \\
\text { PLANNING BEFORE THEY HAVE CHILDREN. } \\
\\
\text { PROBES/CHECKLIST: } \\
\text { (PROBE ONLY IF RELEVANT) } \\
* \text { PARENTAL ATTITUDES } \\
* \text { ATTITUDE OF RELIGION } \\
* \text { EFFECT ON ABILITY TO HAVE CHILDREN } \\
* \text { PROOF OF ABILITY TO HAVE CHILD } \\
* \text { NUMBER OF CHILDREN NEEDED BEFORE } \\
\text { USE OF FAMILY PLANNING } \\
* \text { ACCEPTABLE METHODS, IF ANY } \\
* \text { ACCESS TO F.P. PROGRAM METHODS } \\
\text { FOR YOUNG PEOPLE }\end{array}$ & $\begin{array}{l}\text { NOTETAKER } \\
\text { TO } \\
\text { RECORD ALL } \\
\text { DISCUSSION }\end{array}$ & \\
\hline
\end{tabular}


Section 3. Family planning (continued)

\begin{tabular}{|c|c|c|c|}
\hline NO. & QUESTIONS AND FILTERS & CODING CATEGORIES & Skip \\
\hline & RECORD CATEGORY FROM 321 & & \\
\hline 328 & 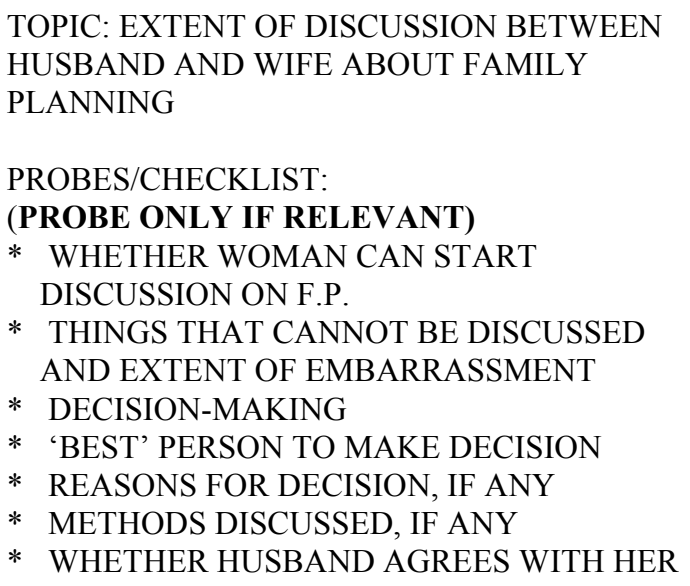 & $\begin{array}{c}\text { NOTETAKER } \\
\text { TO } \\
\text { RECORD ALL } \\
\text { DISCUSSION }\end{array}$ & \\
\hline 329 & 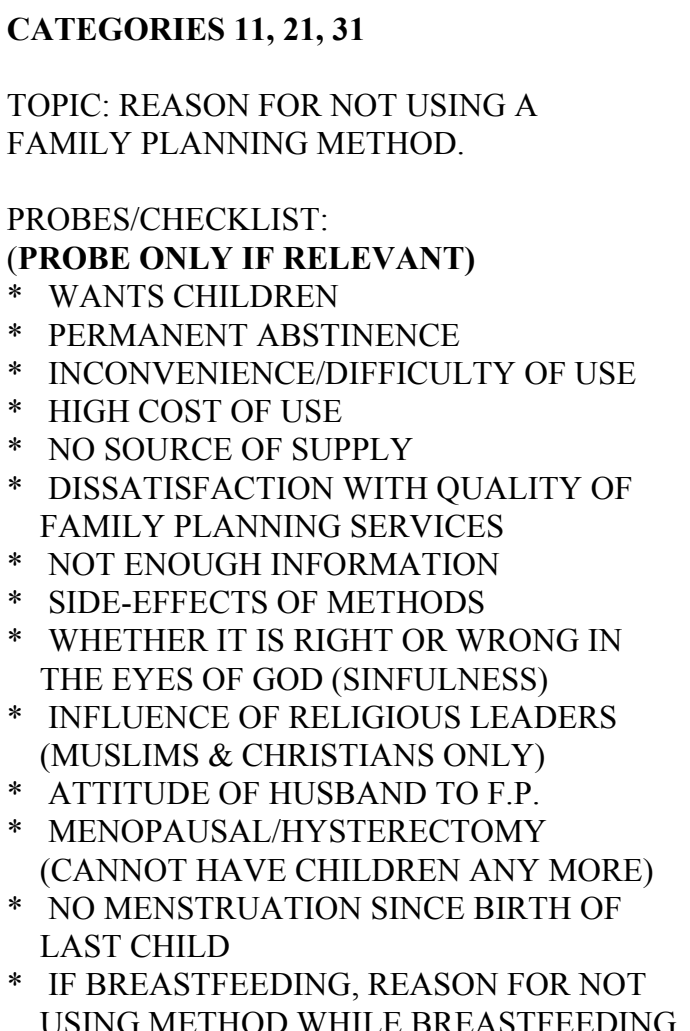 & $\begin{array}{l}\text { NOTETAKER } \\
\text { TO } \\
\text { RECORD ALL } \\
\text { DISCUSSION }\end{array}$ & \\
\hline
\end{tabular}


Section 3. Family planning (continued)

\begin{tabular}{|c|c|c|c|}
\hline NO. & QUESTIONS AND FILTERS & CODING CATEGORIES & Skip \\
\hline & RECORD CATEGORY FROM 321 & & \\
\hline 330 & $\begin{array}{l}\text { CATEGORIES 23, } \mathbf{2 4} \\
\text { TOPIC: REASON FOR STOPPING USING } \\
\text { 'TRADITIONAL' METHOD AND ADOPTING A } \\
\text { PROGRAM OR PERMANENT METHOD } \\
\\
\text { PROBES/CHECKLIST: } \\
\text { (PROBE ONLY IF RELEVANT) } \\
* \text { EFFECTIVENESS } \\
* \text { CONVENIENCE OF USE } \\
* \text { ATTITUDE OF HUSBAND TO METHOD } \\
* \text { MOTIVATED BY F.P. WORKER TO } \\
\text { ACCEPT PROGRAM METHOD OR } \\
\text { PERMANENT METHOD } \\
\text { P METHOD FAILED (M.R. NECESSARY) }\end{array}$ & $\begin{array}{c}\text { NOTETAKER } \\
\text { TO } \\
\text { RECORD ALL } \\
\text { DISCUSSION }\end{array}$ & \\
\hline 331 & 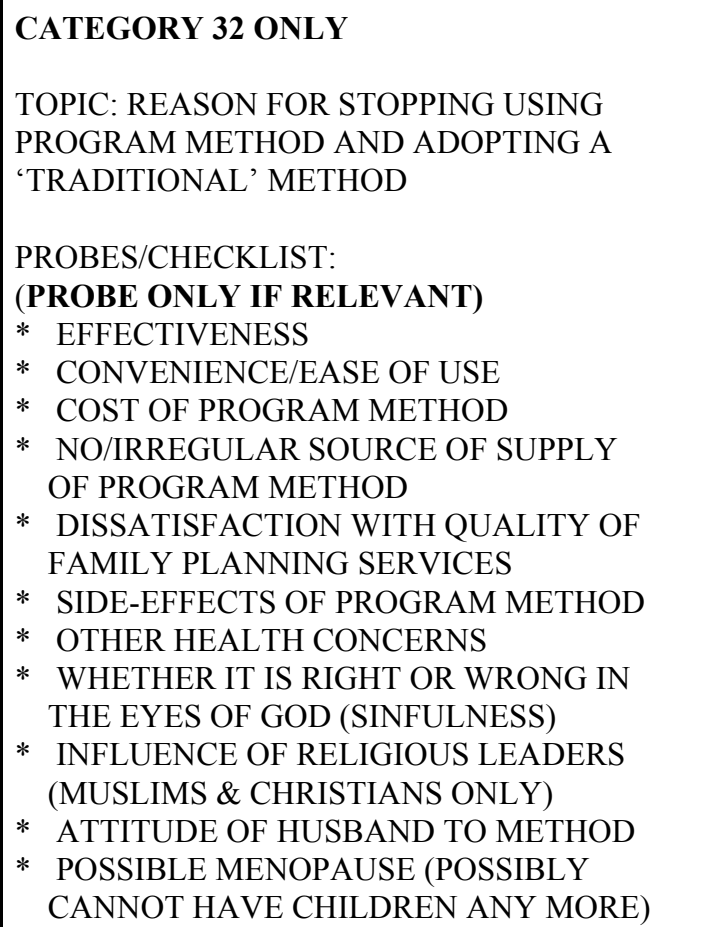 & $\begin{array}{c}\text { NOTETAKER } \\
\text { TO } \\
\text { RECORD ALL } \\
\text { DISCUSSION }\end{array}$ & \\
\hline
\end{tabular}


Section 3. Family planning (continued)

\begin{tabular}{|c|c|c|c|c|}
\hline NO. & QUESTIONS AND FILTERS & \multicolumn{2}{|c|}{ CODING CATEGORIES } & Skip \\
\hline & RECORD CATEGORY FROM 321 & & & \\
\hline 332 & $\begin{array}{l}\text { CHECK 218. DOES SHE HAVE A CHILD } \\
\text { LESS THAN } 3 \text { YEARS OLD? }\end{array}$ & $\begin{array}{l}\text { YES } \\
\text { NO }\end{array}$ & $\begin{array}{l}1 \\
2\end{array}$ & o to 343 \\
\hline 333 & IS SHE PREGNANT (CATEGORY 98)? & $\begin{array}{l}\text { YES } \\
\text { NO }\end{array}$ & $\begin{array}{l}1 \\
2\end{array}$ & 401 \\
\hline 334 & 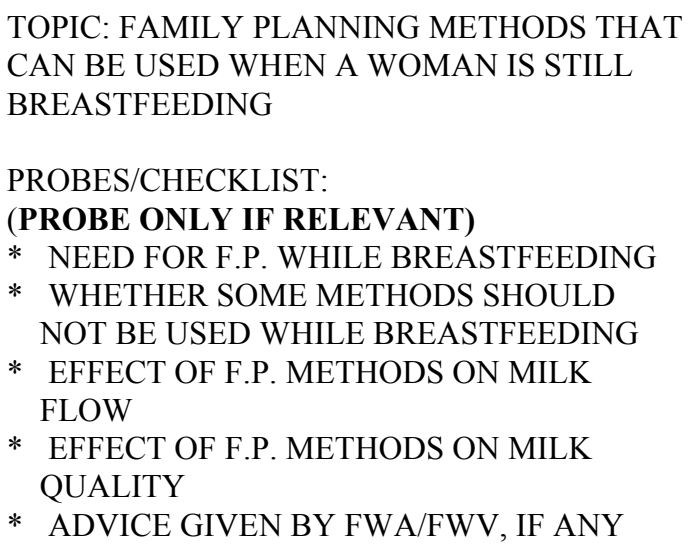 & $\begin{array}{l}\text { NOT } \\
\text { RECC } \\
\text { DISC }\end{array}$ & $\begin{array}{l}\text { ER } \\
\text { OLL } \\
\text { ON }\end{array}$ & \\
\hline 335 & IS SHE CATEGORY $11 ?$ & $\begin{array}{l}\text { YES } \\
\text { NO }\end{array}$ & $\begin{array}{l}1 \\
2\end{array}$ & to 401 \\
\hline 336 & CHECK 221. IS SHE STILL AMENORRHOEIC? & $\begin{array}{l}\text { YES } \\
\text { NO }\end{array}$ & $\begin{array}{l}1 \\
2\end{array}$ & to 339 \\
\hline 337 & $\begin{array}{l}\text { Did you use any method of family planning } \\
\text { before your period returned, after the birth of } \\
\text { your last child? }\end{array}$ & $\begin{array}{l}\text { YES } \\
\text { NO } \\
\text { DON'T KNOW }\end{array}$ & $\begin{array}{l}1 \\
2 \\
9\end{array}$ & o to 339 \\
\hline 338 & $\begin{array}{l}\text { TOPIC: REASONS FOR NOT USING FAMILY } \\
\text { PLANNING BEFORE PERIOD RETURNS } \\
\\
\text { PROBES/CHECKLIST: } \\
\text { (PROBE ONLY IF RELEVANT) } \\
* \quad \text { ABSTINENCE FROM SEXUAL RELATIONS } \\
* \quad \text { POSSIBILITY OF PREGNANCY BEFORE } \\
\text { PERIOD RETURNS } \\
\text { * WHETHER SOME METHODS SHOULD } \\
\text { NOT BE USED WHILE AMENORRHOEIC } \\
\text { * HEALTH CONCERNS }\end{array}$ & $\begin{array}{l}\text { NOT } \\
\text { RECC } \\
\text { DISC }\end{array}$ & $\begin{array}{l}\text { ER } \\
\text { OLL } \\
\text { ON }\end{array}$ & \\
\hline
\end{tabular}


Section 3. Family planning (continued)

\begin{tabular}{|c|c|c|c|c|}
\hline NO. & QUESTIONS AND FILTERS & \multicolumn{2}{|c|}{ CODING CATEGORIES } & Skip \\
\hline & RECORD CATEGORY FROM 321 & & & \\
\hline 339 & $\begin{array}{l}\text { CHECK 219. IS SHE STILL BREASTFEEDING } \\
\text { HER LAST CHILD? }\end{array}$ & $\begin{array}{l}\text { YES } \\
\text { NO }\end{array}$ & $\begin{array}{l}1 \\
2\end{array}$ & Go to 343 \\
\hline 340 & $\begin{array}{l}\text { Were you still breastfeeding when your period } \\
\text { returned? }\end{array}$ & $\begin{array}{l}\text { YES } \\
\text { NO }\end{array}$ & $\begin{array}{l}1 \\
2\end{array}$ & Go to 401 \\
\hline 341 & $\begin{array}{l}\text { Did you use any method of family planning } \\
\text { while you were still breastfeeding your last } \\
\text { child? }\end{array}$ & $\begin{array}{l}\text { YES } \\
\text { NO } \\
\text { DON'T KNOW }\end{array}$ & $\begin{array}{l}1 \\
2 \\
9\end{array}$ & \\
\hline 342 & $\begin{array}{l}\text { What was the first method(s) you used after } \\
\text { your last child? } \\
\text { RECORD ALL METHODS THAT ARE } \\
\text { MENTIONED }\end{array}$ & \begin{tabular}{l} 
SAFE PERIOD \\
WITHDRAWAL \\
KABIRAJI \\
PILL \\
IUD \\
INJECTION \\
CONDOM \\
NORPLANT \\
TUBAL LIG’N \\
VASECTOMY \\
M.R. \\
OTHER \\
\multicolumn{1}{c}{ (SPECIFY) }
\end{tabular} & $\begin{array}{c}\mathrm{A} \\
\mathrm{B} \\
\mathrm{C} \\
\mathrm{D} \\
\mathrm{E} \\
\mathrm{F} \\
\mathrm{G} \\
\mathrm{H} \\
\mathrm{I} \\
\mathrm{J} \\
\mathrm{K} \\
\mathrm{L}\end{array}$ & \\
\hline 343 & CHECK 208. HAS SHE EVER GIVEN BIRTH? & $\begin{array}{l}\text { YES } \\
\text { NO }\end{array}$ & $\begin{array}{l}1 \\
2\end{array}$ & Go to 401 \\
\hline 344 & $\begin{array}{l}\text { Have you ever become pregnant while you were } \\
\text { using any method of family planning? }\end{array}$ & $\begin{array}{l}\text { YES } \\
\text { NO }\end{array}$ & $\begin{array}{l}1 \\
2\end{array}$ & Go to 401 \\
\hline 345 & Did you have the baby? & $\begin{array}{l}\text { YES } \\
\text { NO } \\
\text { PREGNANT } \\
\text { WITH BABY }\end{array}$ & $\begin{array}{l}1 \\
2 \\
3\end{array}$ & \\
\hline
\end{tabular}


Section 3. Family planning (continued)

\begin{tabular}{|c|c|c|c|c|}
\hline NO. & QUESTIONS AND FILTERS & \multicolumn{2}{|c|}{ CODING CATEGORIES } & Skip \\
\hline & RECORD CATEGORY FROM 321 & & & \\
\hline 346 & $\begin{array}{l}\text { What method(s) were you using when you } \\
\text { became pregnant? } \\
\text { RECORD ALL METHODS THAT ARE } \\
\text { MENTIONED, FOR ANY PREGNANCY THAT } \\
\text { RESULTED }\end{array}$ & \begin{tabular}{l} 
SAFE PERIOD \\
WITHDRAWAL \\
KABIRAJI \\
PILL \\
IUD \\
INJECTION \\
CONDOM \\
NORPLANT \\
TUBAL LIG'N \\
VASECTOMY \\
M.R. \\
OTHER_- \\
\multicolumn{1}{l}{ (SPECIFY) }
\end{tabular} & $\begin{array}{l}\text { A } \\
\text { B } \\
\text { C } \\
\text { D } \\
\text { E } \\
\text { F } \\
\text { G } \\
\text { H } \\
\text { I } \\
\text { J } \\
\text { K } \\
\text { L }\end{array}$ & \\
\hline 347 & 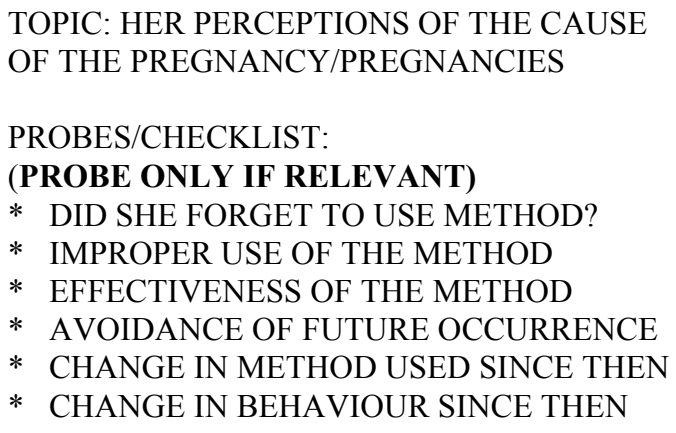 & $\begin{array}{l}\text { NOTE } \\
\text { RECO } \\
\text { DISCL }\end{array}$ & & \\
\hline
\end{tabular}

END OF SECTION 3 


\section{Section 4. Religiosity}

\begin{tabular}{|c|c|c|c|}
\hline NO. & QUESTIONS AND FILTERS & CODING CATEGORIES & Skip \\
\hline & RECORD CATEGORY FROM 321 & & \\
\hline 401 & $\begin{array}{l}\text { Often people's beliefs about family life are } \\
\text { influenced by the teachings of their religion and } \\
\text { religious leaders. } \\
\text { TOPIC: THE WAYS IN WHICH RELIGION } \\
\text { INFLUENCES FAMILY LIFE, AND HER } \\
\text { RELATIONSHIP WITH HER HUSBAND } \\
\text { PROBES/CHECKLIST: } \\
\text { (PROBE ONLY IF RELEVANT) } \\
* \text { MODESTY AND DRESS } \\
\text { * OBEDIENCE TO HUSBAND } \\
* \text { OBEDIENCE TO RELIGIOUS TEACHING } \\
\text { * RESTRICTIONS ON MOVEMENT OUTSIDE } \\
\text { THE BARI OR THE VILLAGE } \\
\text { * OBLIGATIONS (HUSBAND, PARENTS, } \\
\text { HUSBAND'S PARENTS, CHILDREN, } \\
\text { OTHER RELATIONS, OTHER PEOPLE) } \\
\text { * RELATIVE IMPORTANCE OF RELIGIOUS } \\
\text { TEACHING AND FAMILY'S NEEDS }\end{array}$ & $\begin{array}{c}\text { NOTETAKER } \\
\text { TO } \\
\text { RECORD ALL } \\
\text { DISCUSSION }\end{array}$ & \\
\hline 402 & $\begin{array}{l}\text { ALL CATEGORIES EXCEPT } 00 \\
\text { TOPIC: INFLUENCE OF RELIGION ON } \\
\text { USE OF FAMILY PLANNING } \\
\text { PROBES/CHECKLIST: } \\
\text { (PROBE ONLY IF RELEVANT) } \\
* \quad \text { METHODS THAT ARE PERMITTED OR } \\
\text { PROHIBITED BY RELIGION } \\
\text { * WHETHER SOME METHODS ARE LESS } \\
\text { SINFUL THAN OTHERS (IF ANY) } \\
* \text { SHAME TO USE SOME METHODS } \\
* \quad \text { TEACHINGS OF RELIGIOUS LEADERS } \\
* \text { RELATIVE IMPORTANCE OF RELIGIOUS } \\
\text { TEACHING AND FAMILY'S NEEDS }\end{array}$ & $\begin{array}{c}\text { NOTETAKER } \\
\text { TO } \\
\text { RECORD ALL } \\
\text { DISCUSSION }\end{array}$ & \\
\hline
\end{tabular}

END OF SECTION 4 


\section{Section 5. End of interview}

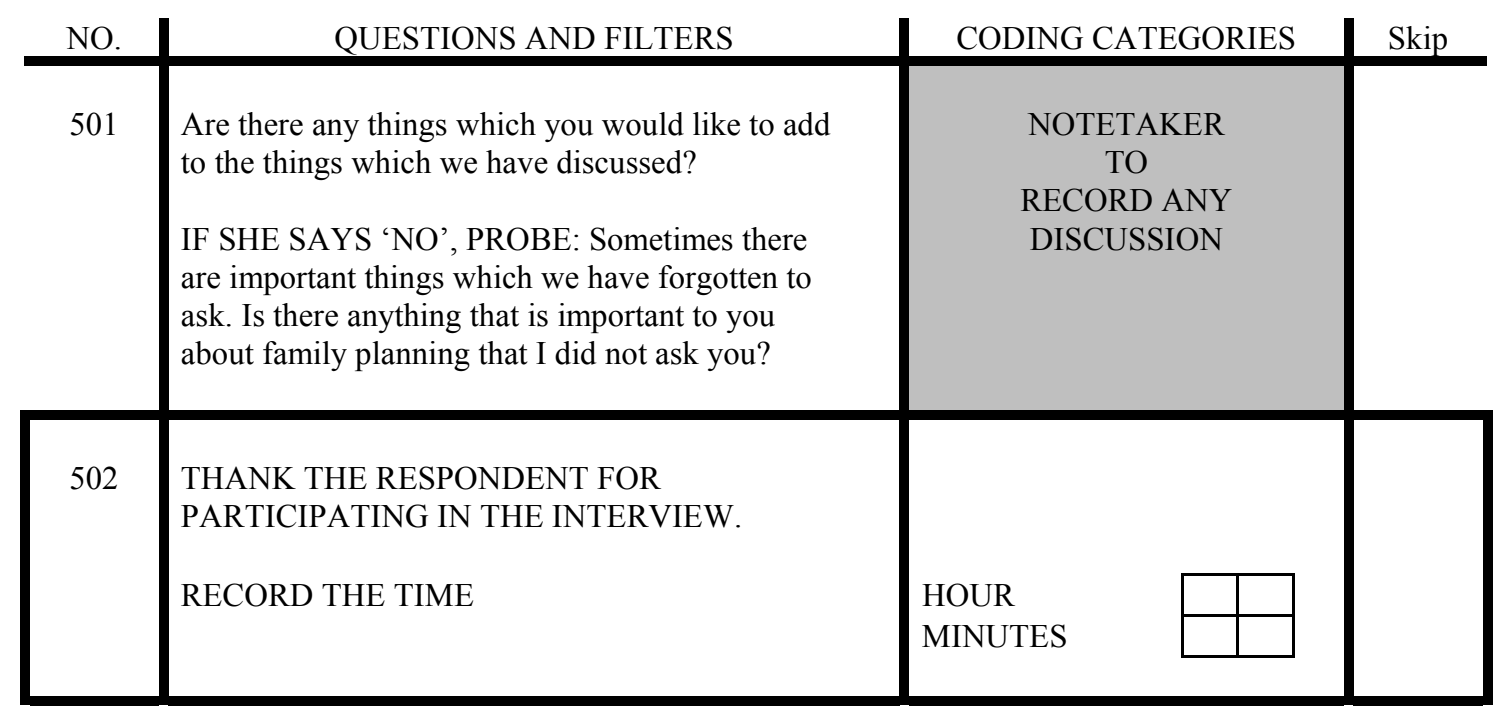

END OF INTERVIEW 


\section{Section 1. Respondent's background}

\begin{tabular}{|c|c|c|c|c|}
\hline NO. & QUESTIONS AND FILTERS & \multicolumn{2}{|c|}{ CODING CATEGORIES } & Skip \\
\hline \multirow[t]{2}{*}{101} & RECORD THE TIME & \multirow{2}{*}{$\begin{array}{l}\text { HOUR } \\
\text { MINUTES }\end{array}$} & & \\
\hline & & & & \\
\hline \multirow[t]{2}{*}{102} & How long have you been living continuously in & YEARS & & \multirow{2}{*}{$\begin{array}{l}\text { Go to } 104 \\
\text { Go to } 104\end{array}$} \\
\hline & (NAME OF PLACE OF RESIDENCE)? & ALWAYS & 95 & \\
\hline \multirow[t]{3}{*}{103} & \multirow{3}{*}{$\begin{array}{l}\text { Just before you moved here, did you live in a } \\
\text { city, in a town, or in the countryside? }\end{array}$} & CITY & 1 & \\
\hline & & TOWN & 2 & \\
\hline & & COUNTRYSIDE & 3 & \\
\hline \multirow[t]{5}{*}{104} & \multirow[t]{5}{*}{ What is your religion? } & ISLAM & 1 & \\
\hline & & CHRISTIANITY & 2 & \\
\hline & & HINDUISM & 3 & \\
\hline & & BUDDHISM & 4 & \\
\hline & & OTHER & 5 & \\
\hline 105 & How old are you? & YEARS & & \\
\hline 106 & Have you ever attended school/madrasa? & YES & 1 & Go to 108 \\
\hline 107 & What is the highest class you completed? & $\begin{array}{l}\text { GOVT } \\
\text { MADRASA }\end{array}$ & & \\
\hline \multirow[t]{3}{*}{108} & \multirow{3}{*}{$\begin{array}{l}\text { Do you usually read a newspaper or magazine } \\
\text { at least once a week? }\end{array}$} & YES & 1 & \\
\hline & & $\mathrm{NO}$ & 2 & \\
\hline & & CANNOT READ & 3 & \\
\hline \multirow[t]{2}{*}{109} & \multirow{2}{*}{$\begin{array}{l}\text { Do you usually listen to the radio at least once } \\
\text { a week? }\end{array}$} & YES & 1 & \\
\hline & & NO & 2 & \\
\hline \multirow[t]{2}{*}{110} & \multirow{2}{*}{$\begin{array}{l}\text { Do you usually watch television at least once } \\
\text { a week? }\end{array}$} & YES & 1 & \\
\hline & & NO & 2 & \\
\hline
\end{tabular}


Section 1. Respondent's background (continued)

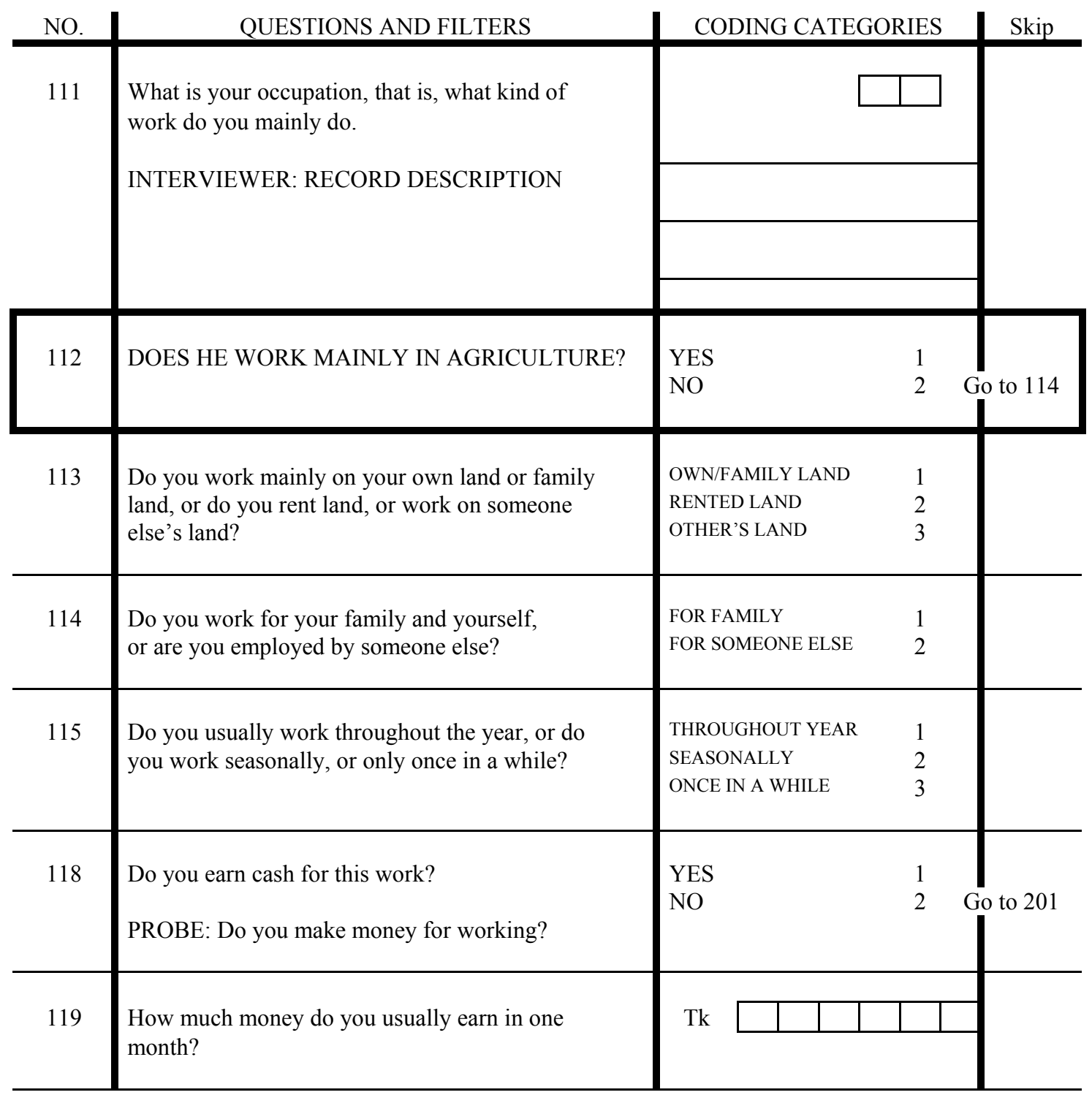

END OF SECTION 1 
Section 2. Children and pregnancy

\begin{tabular}{|c|c|c|c|c|}
\hline NO. & QUESTIONS AND FILTERS & \multicolumn{2}{|c|}{ CODING CATEGORIES } & Skip \\
\hline 201 & $\begin{array}{l}\text { I would like to ask you some questions about } \\
\text { your family and children. Has your wife ever } \\
\text { given birth? }\end{array}$ & $\begin{array}{l}\text { YES } \\
\text { NO }\end{array}$ & $\begin{array}{l}1 \\
2\end{array}$ & \\
\hline 202 & Is she pregnant now? & $\begin{array}{l}\text { YES } \\
\text { NO } \\
\text { TUBAL LIG'N } \\
\text { VASECTOMY } \\
\text { UNSURE } \\
\text { UNABLE TO GET } \\
\text { PREGNANT }\end{array}$ & $\begin{array}{l}1 \\
2 \\
3 \\
4 \\
8 \\
9\end{array}$ & $\begin{array}{l}\text { Go to } 207 \\
\text { Go to } 207 \\
\text { Go to } 207 \\
\text { Go to } 207\end{array}$ \\
\hline 203 & In the future, do you want a(nother) child? & $\begin{array}{l}\text { HAVE A CHILD } \\
\text { NO MORE/NONE } \\
\text { TUBAL LIG'N } \\
\text { VASECTOMY } \\
\text { CAN'T GET PREGNANT } \\
\text { UNDECIDED }\end{array}$ & $\begin{array}{l}1 \\
2 \\
3 \\
4 \\
3 \\
8\end{array}$ & $\begin{array}{l}\text { Go to } 207 \\
\text { Go to } 207 \\
\text { Go to } 207 \\
\text { Go to } 207 \\
\text { Go to } 207\end{array}$ \\
\hline 204 & $\begin{array}{l}\text { Would you like to wait before having a(nother) } \\
\text { child or would you like to have a baby soon? }\end{array}$ & $\begin{array}{l}\text { HAVE CHILD SOON } \\
\text { WAIT } \\
\text { UP TO GOD (ETC) } \\
\text { DOES NOT KNOW } \\
\text { OTHER } \\
\qquad \text { (SPECIFY) }\end{array}$ & $\begin{array}{l}1 \\
2 \\
7 \\
8 \\
9\end{array}$ & \\
\hline 205 & $\begin{array}{l}\text { How many (more) children would you like to } \\
\text { have? }\end{array}$ & $\begin{array}{l}\text { NUMBER } \\
\text { UP TO GOD (ETC) } \\
\text { UNDECIDED } \\
\text { DOES NOT KNOW }\end{array}$ & $\begin{array}{l}5 \\
8 \\
9\end{array}$ & $\begin{array}{l}\text { Go to } 207 \\
\text { Go to } 207 \\
\text { Go to } 207\end{array}$ \\
\hline 206 & $\begin{array}{l}\text { How many of these would you like to be boys } \\
\text { and how many girls? }\end{array}$ & $\begin{array}{l}\text { BOYS } \\
\text { GIRLS } \\
\text { EITHER } \\
\text { UP TO GOD (ETC) } \\
\text { OTHER } \\
\quad \text { (SPECIFY) }\end{array}$ & 6 & \\
\hline
\end{tabular}




\section{Section 2. Children and pregnancy (continued)}

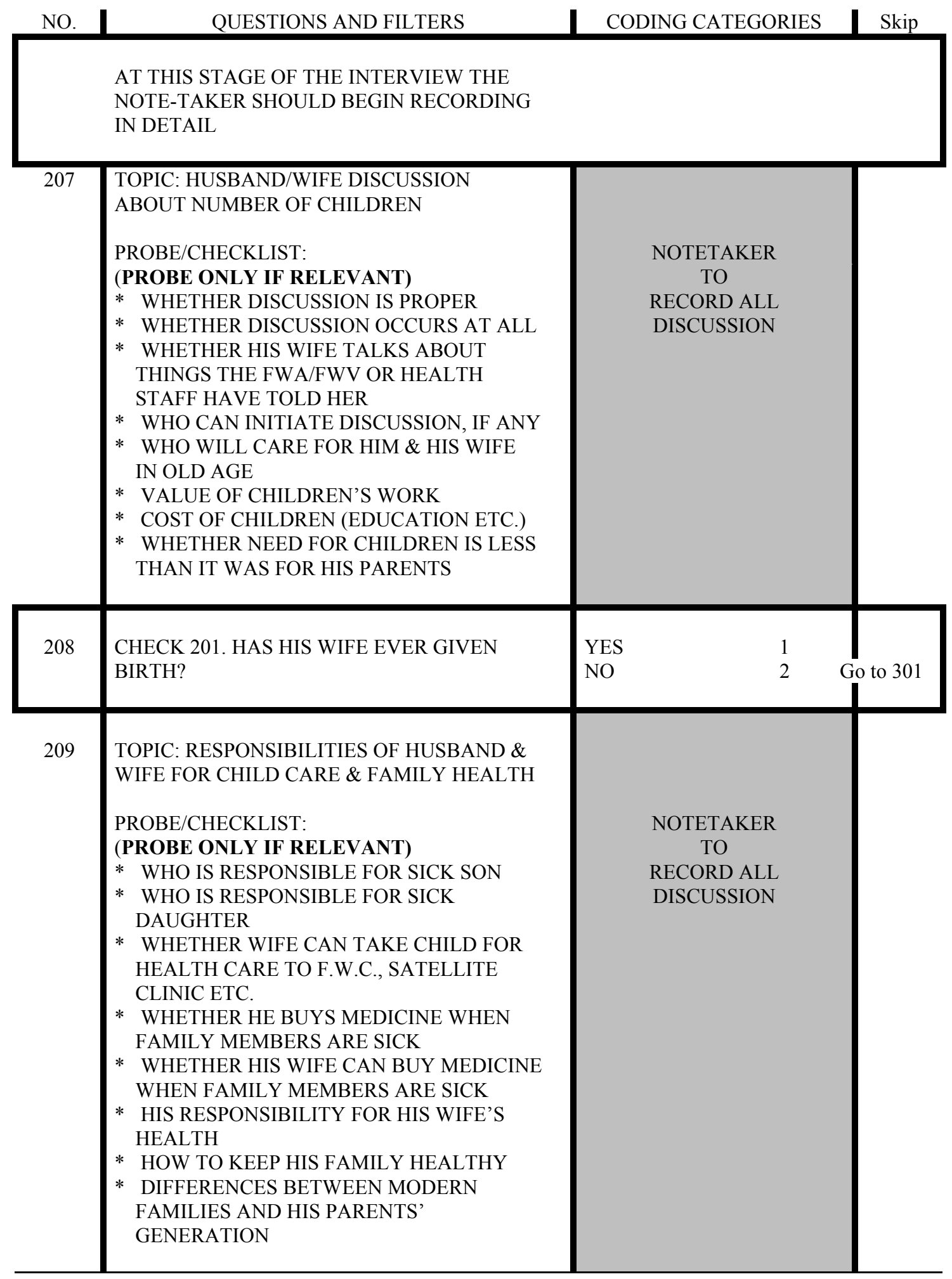

END OF SECTION 2 


\section{Section 3. Family planning}

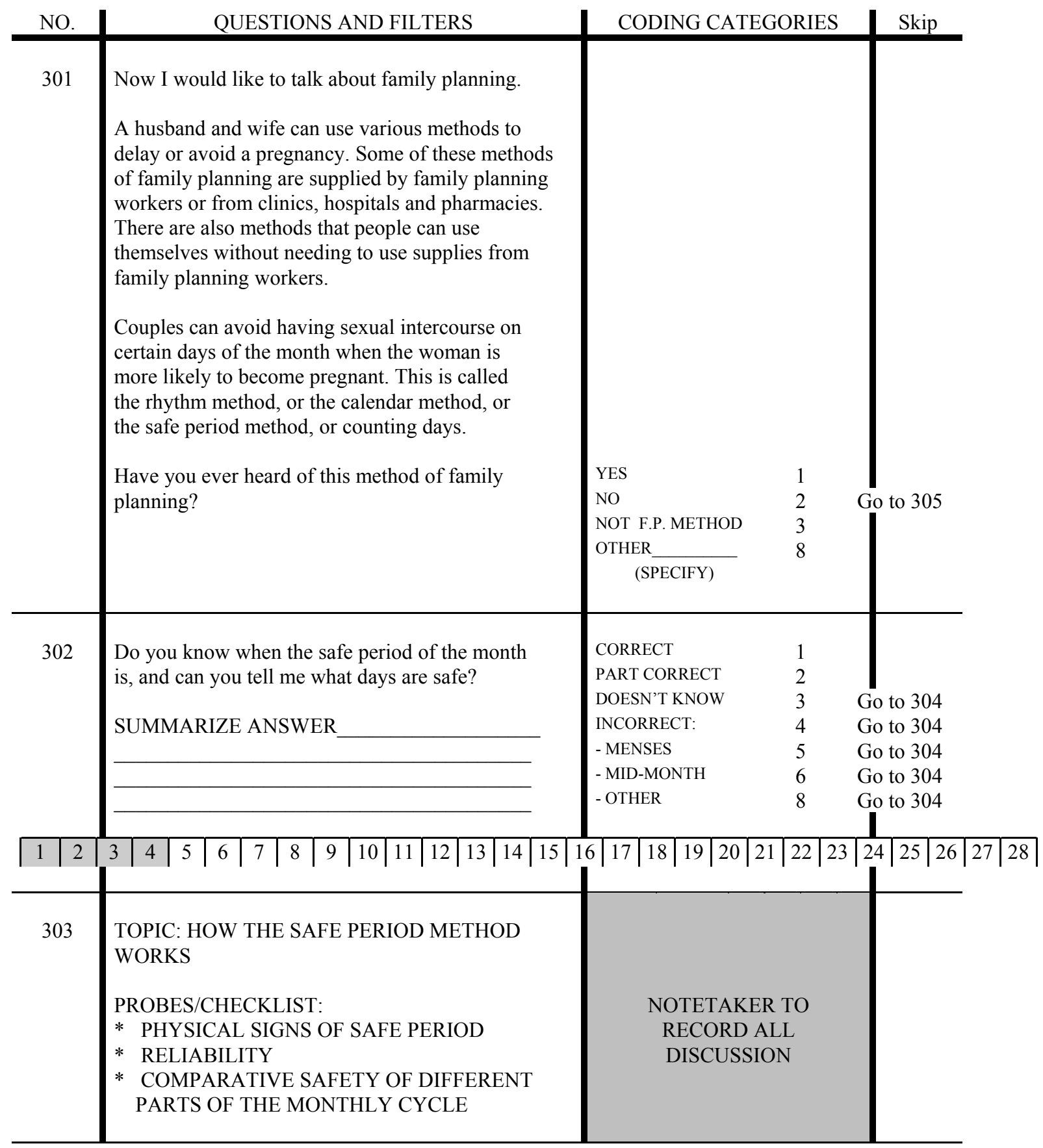


Section 3. Family planning (continued)

\begin{tabular}{|c|c|c|c|c|}
\hline NO. & QUESTIONS AND FILTERS & \multicolumn{2}{|c|}{ CODING CATEGORIES } & Skip \\
\hline 304 & $\begin{array}{l}\text { What was the source of your information about } \\
\text { the safe period method? }\end{array}$ & $\begin{array}{l}\text { WIFE } \\
\text { FRIEND/RELATIVE/ } \\
\text { NEIGHBOUR } \\
\text { FWA/FWV } \\
\text { BOOK } \\
\text { PAMPHLET } \\
\text { OTHER } \\
\quad \text { (SPECIFY) }\end{array}$ & $\begin{array}{l}1 \\
2 \\
3 \\
4 \\
5 \\
6\end{array}$ & \\
\hline 305 & $\begin{array}{l}\text { Another method of avoiding pregnancy is for men to } \\
\text { be careful and pull out before climax. } \\
\text { This is called azal. } \\
\text { Have you ever heard of this method of family } \\
\text { planning? }\end{array}$ & $\begin{array}{l}\text { YES } \\
\text { NO } \\
\text { NOT F.P. METHOD } \\
\text { OTHER } \\
\quad \text { (SPECIFY) }\end{array}$ & $\begin{array}{l}1 \\
2 \\
3 \\
8\end{array}$ & \\
\hline 306 & $\begin{array}{l}\text { Some people go to the kabiraj to get preparations to } \\
\text { avoid pregnancy. } \\
\text { Have you ever heard of this method of family } \\
\text { planning? } \\
\text { IF THE RESPONDENT ANSWERS 'NO', } \\
\text { PROBE: } \\
\text { - Are there any foods that people should eat } \\
\text { if they do not want to get pregnant? } \\
\text { - Are there any drinks they should take? }\end{array}$ & $\begin{array}{l}\text { YES } \\
\text { NO } \\
\text { NOT F.P. METHOD } \\
\text { OTHER } \\
\text { (SPECIFY) } \\
\text { NOTETA } \\
\text { TO } \\
\text { DISCORD }\end{array}$ & $\begin{array}{l}1 \\
2 \\
3 \\
8\end{array}$ & \\
\hline
\end{tabular}


Section 3. Family planning (continued)

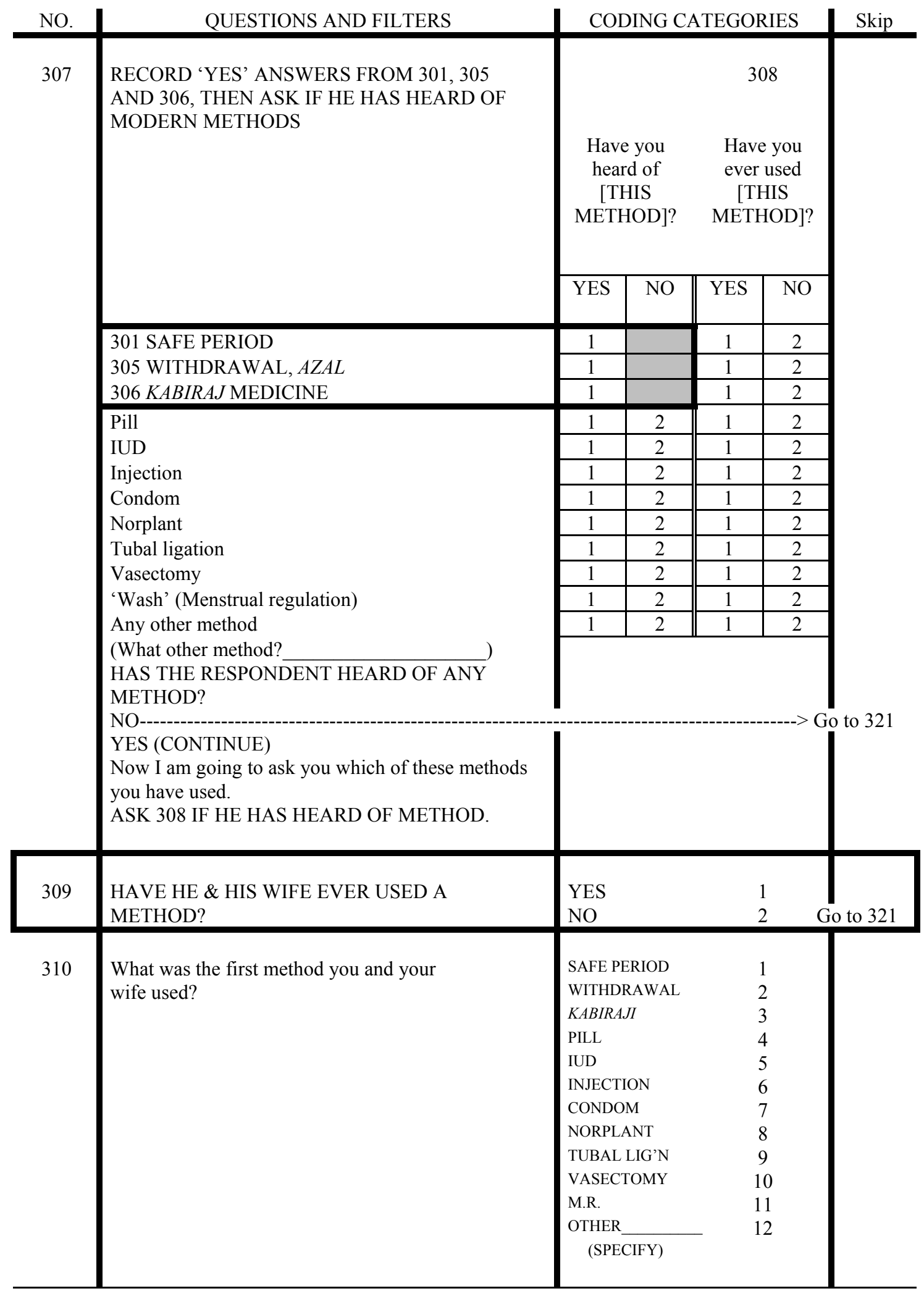

Section 3. Family planning (continued) 


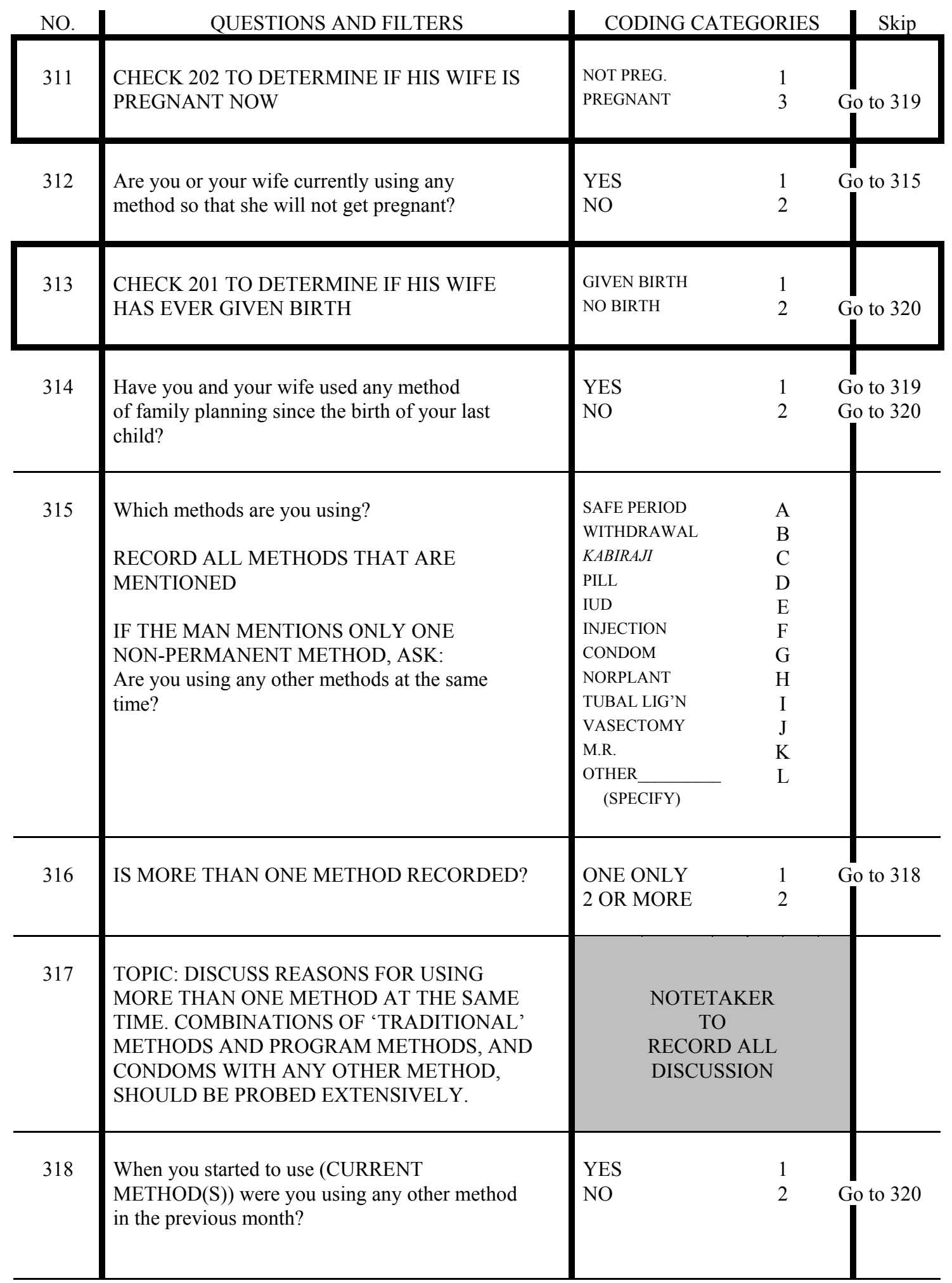


Section 3. Family planning (continued)

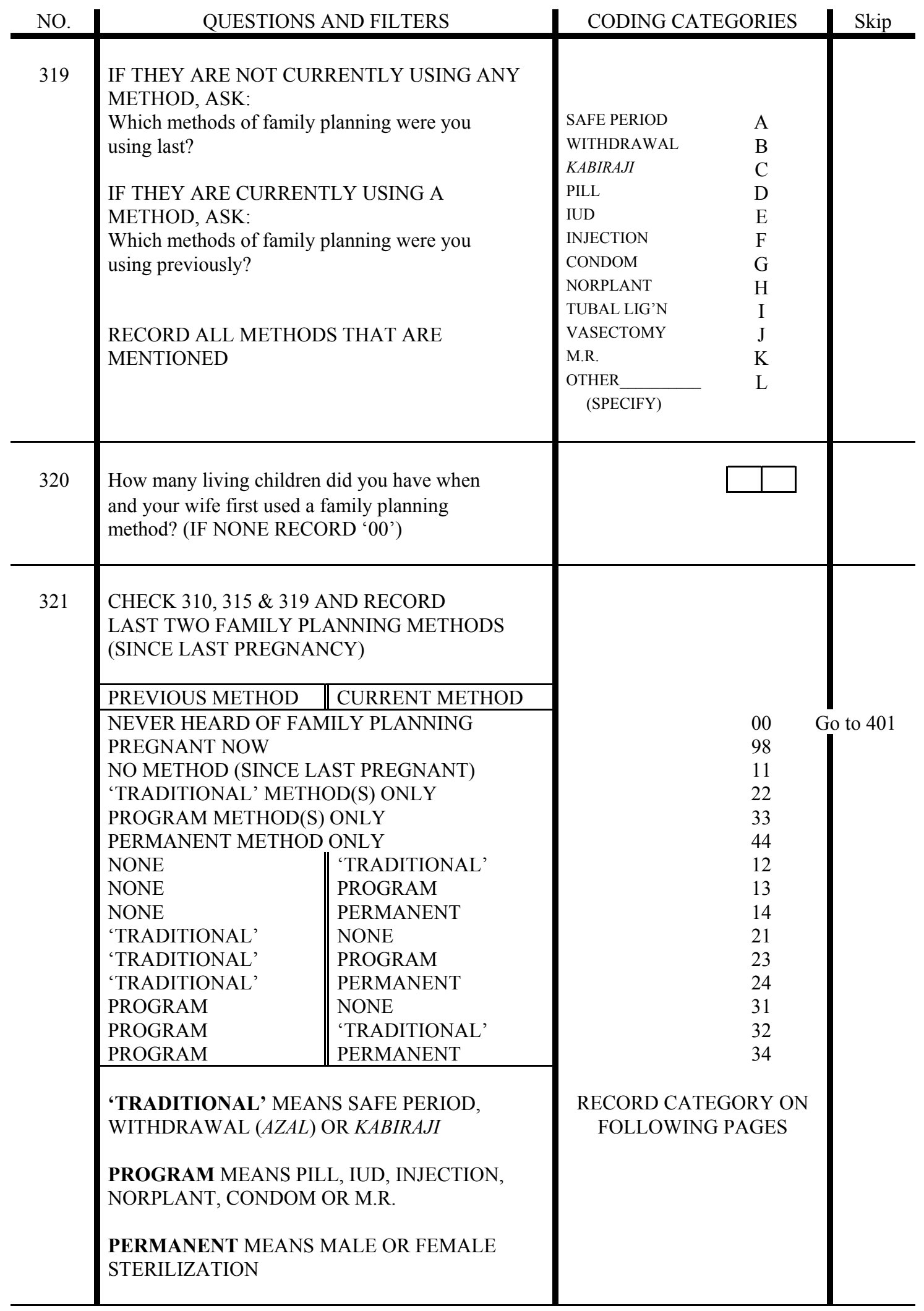


Section 3. Family planning (continued)

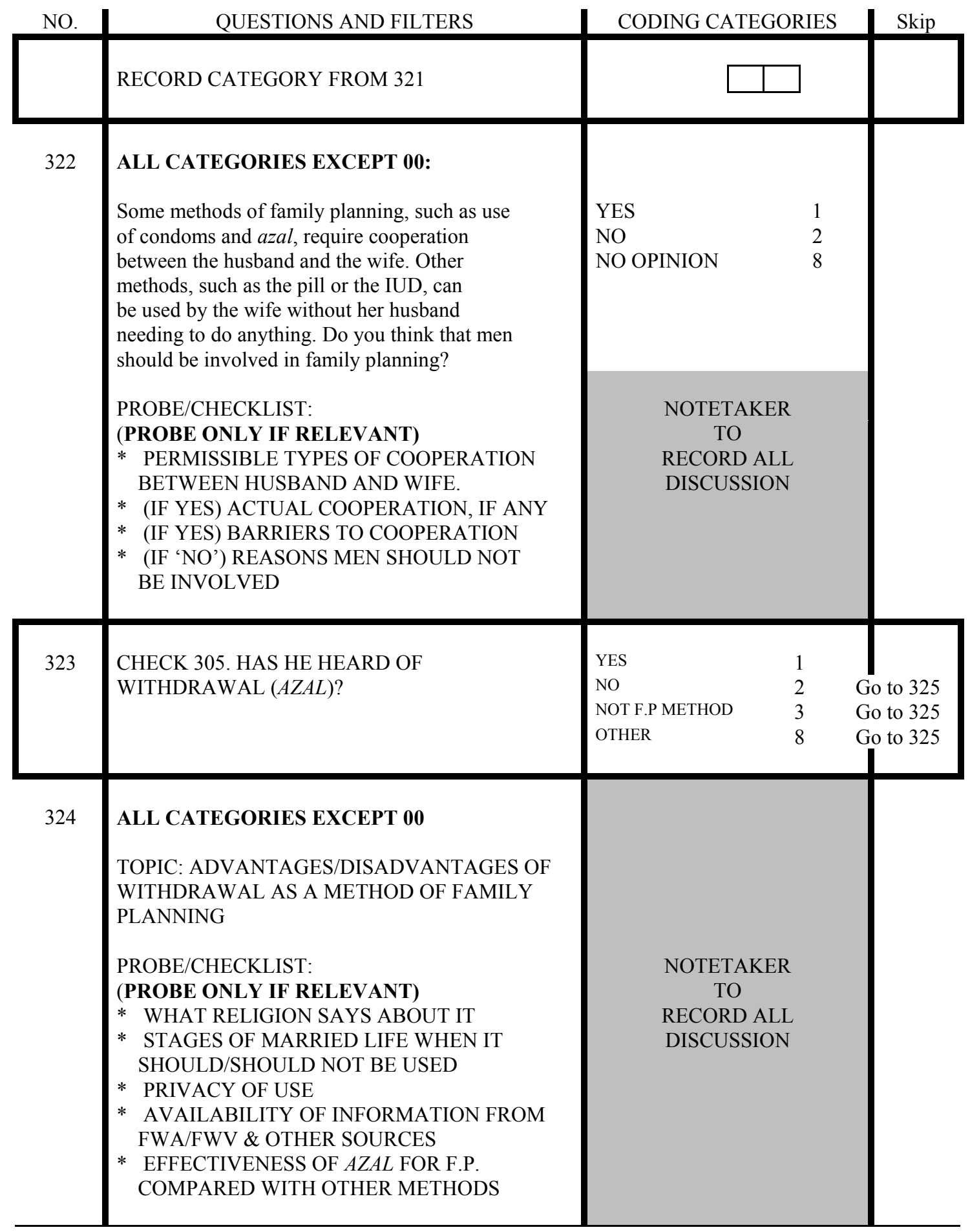


Section 3. Family planning (continued)

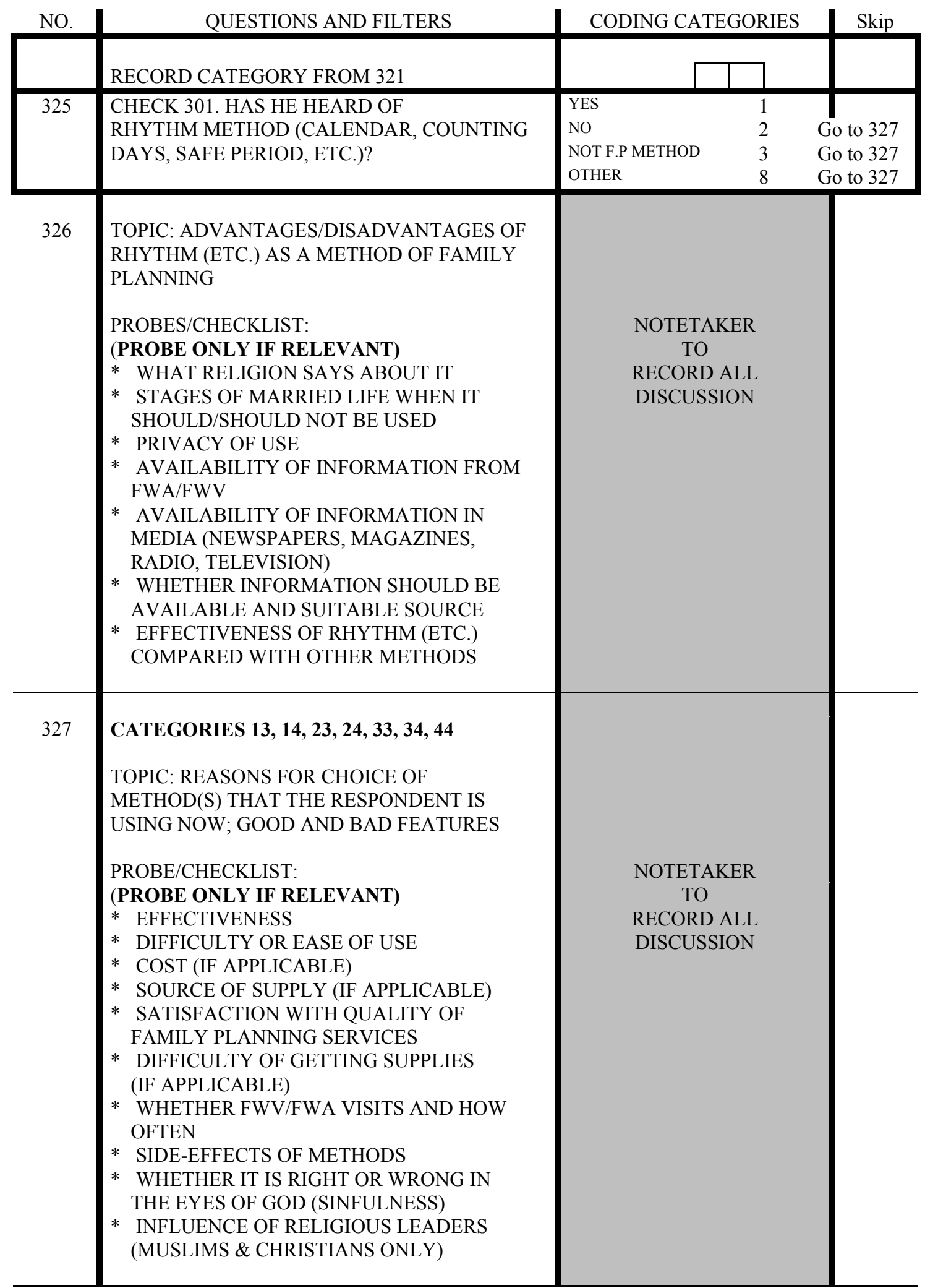

Section 3. Family planning (continued) 


\begin{tabular}{|c|c|c|c|}
\hline NO. & QUESTIONS AND FILTERS & CODING CATEGORIES & Skip \\
\hline & RECORD CATEGORY FROM 321 & & \\
\hline 328 & $\begin{array}{l}\text { TOPIC: DISCUSS WHETHER A COUPLE } \\
\text { SHOULD USE ANY METHOD OF FAMILY } \\
\text { PLANNING BEFORE THEY HAVE CHILDREN. } \\
\text { PROBES/CHECKLIST: } \\
\text { (PROBE ONLY IF RELEVANT) } \\
* \text { PARENTAL ATTITUDES } \\
* \text { ATTITUDE OF RELIGION } \\
* \text { EFFECT ON ABILITY TO HAVE CHILDREN } \\
* \text { PROOF OF ABILITY TO HAVE CHILD } \\
* \text { NUMBER OF CHILDREN NEEDED BEFORE } \\
\text { USE OF FAMILY PLANNING } \\
* \quad \text { ACCEPTABLE METHODS, IF ANY } \\
* \text { ACCESS TO F.P. PROGRAM METHODS } \\
\text { FOR YOUNG PEOPLE }\end{array}$ & $\begin{array}{c}\text { NOTETAKER } \\
\text { TO } \\
\text { RECORD ALL } \\
\text { DISCUSSION }\end{array}$ & \\
\hline 329 & 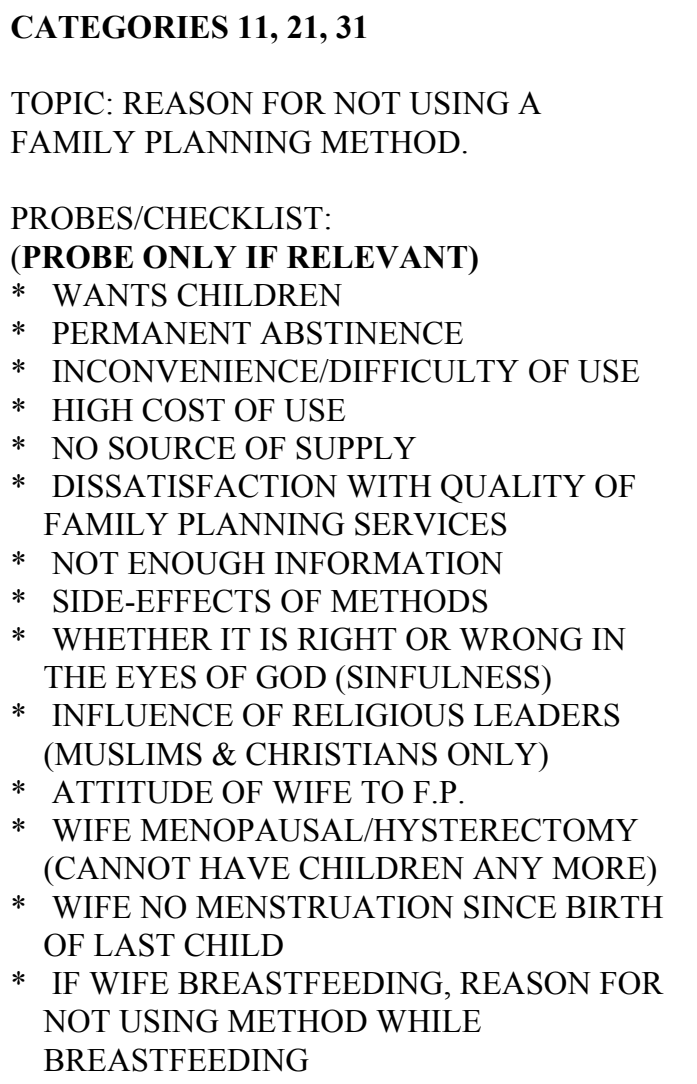 & $\begin{array}{c}\text { NOTETAKER } \\
\text { TO } \\
\text { RECORD ALL } \\
\text { DISCUSSION }\end{array}$ & \\
\hline
\end{tabular}


Section 3. Family planning (continued)

\begin{tabular}{|c|c|c|}
\hline NO. & QUESTIONS AND FILTERS & CODING CATEGORIES \\
\hline & RECORD CATEGORY FROM 321 & \\
\hline 330 & $\begin{array}{l}\text { CATEGORIES 23, } \mathbf{2 4} \\
\text { TOPIC: REASON FOR STOPPING USING } \\
\text { 'TRADITIONAL' METHOD AND ADOPTING A } \\
\text { PROGRAM OR PERMANENT METHOD } \\
\text { PROBES/CHECKLIST: } \\
\text { (PROBE ONLY IF RELEVANT) } \\
\text { * } \\
\text { EFFECTIVENESS } \\
\text { * } \text { CONVENIENCE OF USE } \\
\text { * } \text { ATTITUDE OF WIFE TO METHOD } \\
\text { ACCEPT PROGIVATED BY F.P. WORKER TO } \\
\text { PERMANENT METHOD } \\
\text { * METHOD FAILED (M.R. NECESSARY) }\end{array}$ & $\begin{array}{c}\text { NOTETAKER } \\
\text { TO } \\
\text { RECORD ALL } \\
\text { DISCUSSION }\end{array}$ \\
\hline 331 & 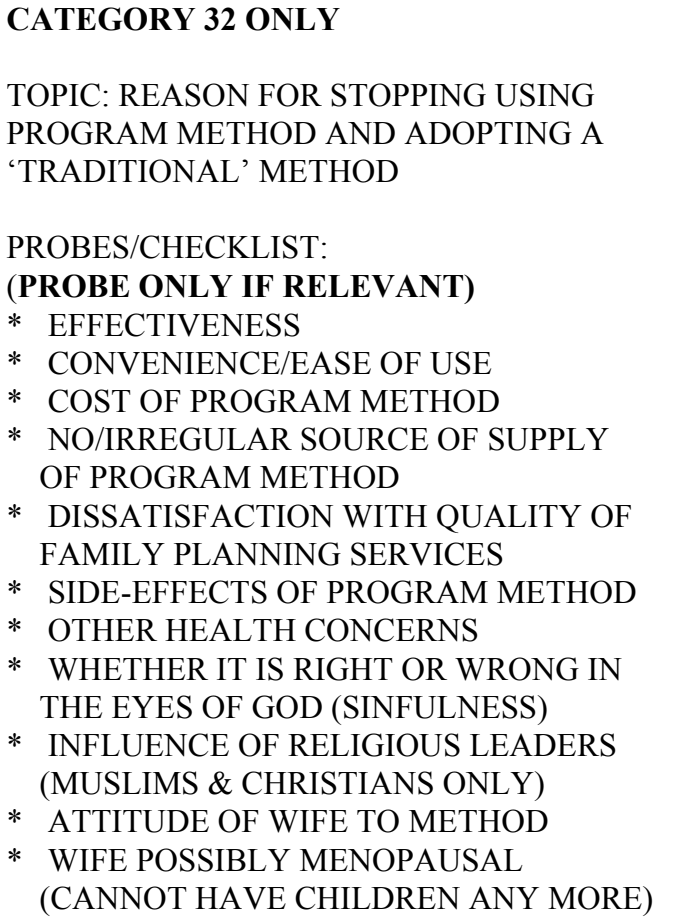 & $\begin{array}{c}\text { NOTETAKER } \\
\text { TO } \\
\text { RECORD ALL } \\
\text { DISCUSSION }\end{array}$ \\
\hline
\end{tabular}


Section 3. Family planning (continued)

\begin{tabular}{|c|c|c|c|c|}
\hline NO. & QUESTIONS AND FILTERS & \multicolumn{2}{|c|}{ CODING CATEGORIES } & Skip \\
\hline & RECORD CATEGORY FROM 321 & & & \\
\hline 332 & $\begin{array}{l}\text { CHECK 201. HAS HIS WIFE EVER GIVEN } \\
\text { BIRTH? }\end{array}$ & $\begin{array}{l}\text { YES } \\
\text { NO }\end{array}$ & $\begin{array}{l}1 \\
2\end{array}$ & 401 \\
\hline 333 & $\begin{array}{l}\text { TOPIC: FAMILY PLANNING METHODS THAT } \\
\text { CAN BE USED WHEN A MAN'S WIFE IS } \\
\text { BREASTFEEDING } \\
\text { PROBES/CHECKLIST: } \\
\text { (PROBE ONLY IF RELEVANT) } \\
* \text { NEED FOR F.P. WHILE BREASTFEEDING } \\
* \\
\text { WHETHER SOME METHODS SHOULD } \\
\text { NOT BE USED WHILE BREASTFEEDING } \\
* \text { EFFECT OF F.P. METHODS ON MILK } \\
\text { FLOW } \\
\text { * EFFECT OF F.P. METHODS ON MILK } \\
\text { QUALITY } \\
\text { ADVICE GIVEN BY FWA/FWV, IF ANY }\end{array}$ & & $\begin{array}{c}\text { NOTETAKER } \\
\text { TO } \\
\text { RECORD ALL } \\
\text { DISCUSSION }\end{array}$ & \\
\hline
\end{tabular}

END OF SECTION 3 


\section{Section 4. Religiosity}

\begin{tabular}{|c|c|c|c|}
\hline NO. & QUESTIONS AND FILTERS & CODING CATEGORIES & Skip \\
\hline & RECORD CATEGORY FROM 321 & & \\
\hline 401 & $\begin{array}{l}\text { ALL CATEGORIES EXCEPT } 00 \\
\text { Often people's beliefs about family life are } \\
\text { influenced by the teachings of their religion and } \\
\text { religious leaders. } \\
\text { TOPIC: INFLUENCE OF RELIGION ON } \\
\text { USE OF FAMILY PLANNING } \\
\text { PROBES/CHECKLIST: } \\
\text { (PROBE ONLY IF RELEVANT) } \\
* \text { METHODS THAT ARE PERMITTED OR } \\
\text { PROHIBITED BY RELIGION } \\
* \text { WHETHER SOME METHODS ARE LESS } \\
\text { SINFUL THAN OTHERS (IF ANY) } \\
* \text { SHAME TO USE SOME METHODS } \\
* \text { TEACHINGS OF RELIGIOUS LEADERS } \\
\text { RELATIVE IMPORTANCE OF RELIGIOUS } \\
\text { TEACHING AND FAMILY'S NEEDS }\end{array}$ & $\begin{array}{c}\text { NOTETAKER } \\
\text { TO } \\
\text { RECORD ALL } \\
\text { DISCUSSION }\end{array}$ & \\
\hline
\end{tabular}

END OF SECTION 4 


\section{Section 5. End of interview}

\begin{tabular}{|c|c|c|}
\hline NO. & QUESTIONS AND FILTERS & CODING CATEGORIES \\
\hline 501 & $\begin{array}{l}\text { Are there any things which you would like to add } \\
\text { to the things which we have discussed? } \\
\text { IF HE SAYS 'NO', PROBE: Sometimes there } \\
\text { are important things which we have forgotten to } \\
\text { ask. Is there anything that is important to you } \\
\text { about family planning that I did not ask you? }\end{array}$ & $\begin{array}{c}\text { NOTETAKER } \\
\text { TO } \\
\text { RECORD ANY } \\
\text { DISCUSSION }\end{array}$ \\
\hline \multirow[t]{3}{*}{502} & $\begin{array}{l}\text { THANK THE RESPONDENT FOR } \\
\text { PARTICIPATING IN THE INTERVIEW. }\end{array}$ & \multirow{3}{*}{$\begin{array}{l}\text { HOUR } \\
\text { MINUTES }\end{array}$} \\
\hline & RECORD THE TIME & \\
\hline & & \\
\hline
\end{tabular}

END OF INTERVIEW 


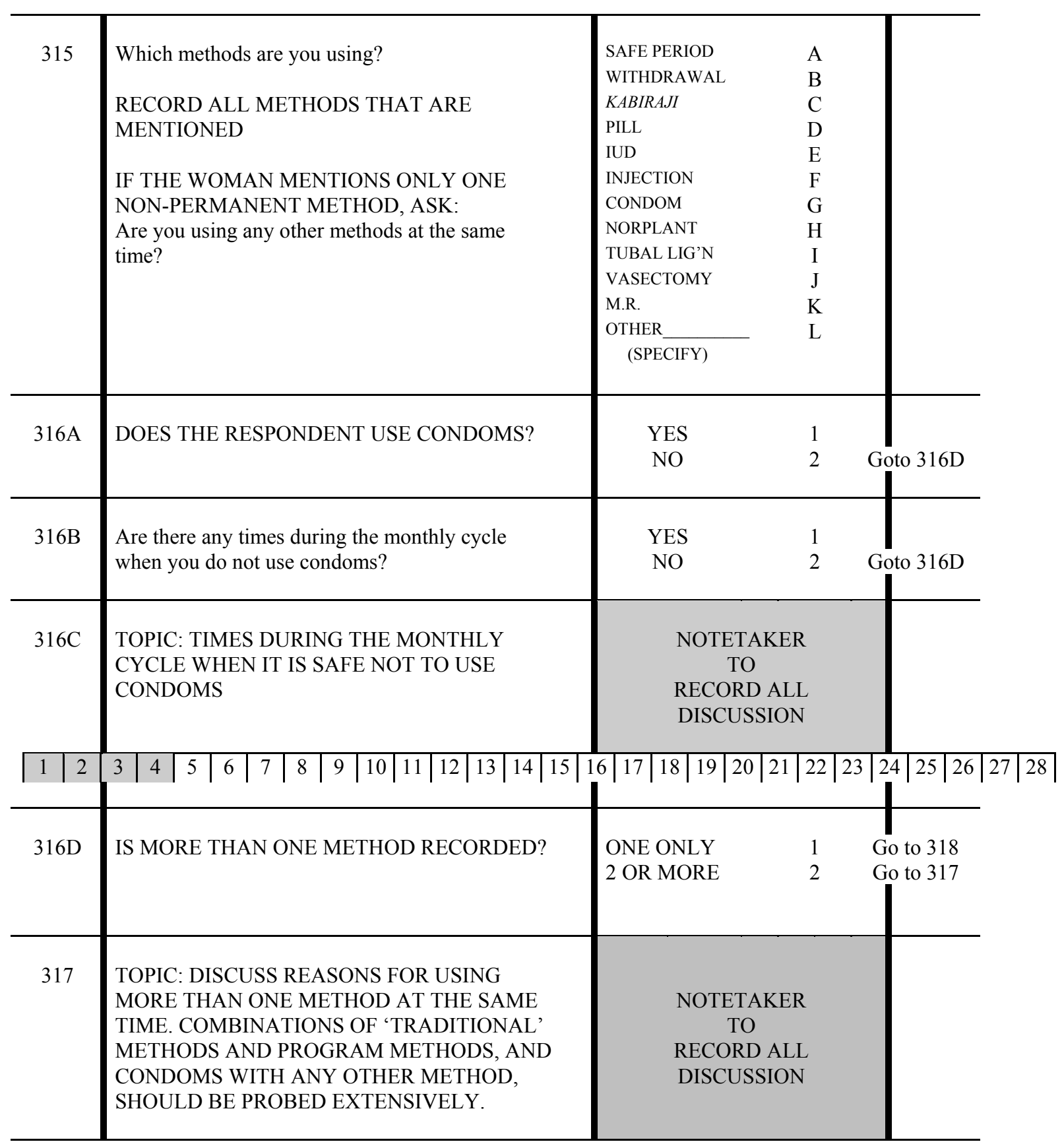




\title{
Appendix 4. Supplementary Reports on Family Planning Method Use
}

\author{
Statements about family planning methods: disagreement between man and woman about \\ whether any method is in use
}

Among cases where either the man or the woman said they were using a method of family planning, but the other partner did not, the first case (household 033) is relatively straightforward. The couple use the oral contraceptive pill and both say so. However, the woman mentioned that she had not been able to take pills during the current menstrual cycle because of irregular supply, and was classified as not currently using a method, while the husband also complained about irregular supply but was not as specific and was classified as a current user. The woman's story of method failure has been given in Chapter 3 and it is not necessary to repeat the details.

The second case is interesting, because of decidedly different response by the man and the woman. The woman said she was an azal user, but the man did not even admit to having heard of withdrawal. His responses to the sequence of questions on use of family planning before the birth of children sheds some light on the reasons.

M034 (25 years old): - (Use of family planning before having children) It is better to choose a method after the birth of a baby. ... How can I say what they think about it ? Those who are illiterate speak of having a baby before the adoption of a method. ... Various kinds of medicine are given to prevent child-birth; this is temporary. If one stops taking medicine, one can conceive. ... I shall adopt a method. What is the harm if one adopts a method after consultation with a doctor? ... I shall resort to a method after consulting with a doctor. ... No, there is no difficulty [in young couples obtaining contraceptives]. But I shall not use them. If we follow a method after the birth of a child, my mother will not fuss. But if we use it now, she will make a fuss about it. I am also not willing. Let us, first, have a baby. Later we shall see to it.

This man's meaning is fairly clear. He evidently did not consider azal (or any other method that did not involve 'medicine' from a doctor) to have a bearing on family planning. Because of the family planning program's constant emphasis on 'modern' methods, it is possible that there is a widespread misunderstanding in Bangladesh that the term 'family planning methods' refers only to modern methods. The design of the sequence of questions in this study was aimed at reducing the misunderstanding, but from the evidence of this interview it was not completely successful. The man obviously also felt that his mother would 'fuss' about the use of a family planning method before the couple had a baby. This perception might also have coloured his responses about use of any method. The woman's account is a stark contrast:

F034 (15 years old, no children): (Advantages/disadvantages of $\boldsymbol{a z a l}$ ) It is good to adopt this method immediately after marriage. I have adopted this method for delaying child birth. ... The woman from my father's house who supplies pills said this [FWA who visits her father's house]. The woman does not come to this house. ... That woman from my father's house has said to me not to sleep with my husband during menstruation; if I sleep with my husband at that time it will harm him. My husband slept with me during menstruation, that's why she told me if I continued to sleep with him at that time, he would lose his sexual power. I wanted to take pills; but she said that if that matter [semen] was thrown outside at the time of intercourse with my husband, I would have no baby. I could not say this to my husband out of my 
shyness. ... The woman from my father's house said that if I adopted this method, I would not have a baby. ... One could stop pregnancy as long as one wanted. ... (Use of family planning before having children) My mother-in-law forbids taking pills. Pills are harmful to health. Many say pills prevent pregnancy [permanently]. That's why mother-in-law does not like pills. ... Pills may destroy the possibility of having babies. If one takes pills immediately after marriage, one may not be pregnant at all. Hence, it is better to take pills after one has a baby. ... In my opinion, if one wants to take pills, one should take it after a baby. Because if one takes pills, one may not have a baby at all. What we do (azal) can be done before one has a baby. There is no problem in our method, that is the method of throwing semen outside. ... Often many women cannot have babies if they take pills. Hence the worker from my father's house has told us to adopt this method of throwing semen outside. If one uses this method, one faces no difficulty in conceiving - that is what is said. ... (Extent of discussion with husband) I discussed with my husband the matter of the taking of pills. I could not raise any other problems. I am rather shy. ... Except for pills, I feel shy to raise any other issues. The doctor [FWA] told me about azal. I said to her I would not be able to broach it to my husband. I said, 'You [the doctor] tell him about it' and she did. ... He agreed to adopt it. ... Both of us, husband and wife, took the decision together. ... Now he himself follows this method [azal].

This woman is only fifteen years of age, and her husband is ten years older. Her account reveals that the extent of discussion with her husband about anything at all is limited, and she had to resort to an indirect approach to have him adopt azal. The role of the FWA in this is highly interesting, not only because she was giving advice to such a young woman, with no children, but also because she was giving advice about a 'traditional' method. Her advice also contained some misinformation about supposed adverse effects of sexual intercourse during menstruation.

Comparing the two accounts, it is finally possible to see that the differences are due to a lack of communication between the partners and reluctance on the part of the man to talk about family planning mainly because he confused the term 'family planning' with program methods only. Concern about his mother's opinion coloured both his response and his young wife's.

In the next case, the woman says she has never heard of the safe period and has never used a method at all, but the man says he is using the safe period method. The main reason for the disparity (apart from the fact that the woman does not perceive any necessity to be using any method of family planning since she remains amenorrhoeic after the birth of her last baby) is that although the man says the correct things about the need for cooperation and discussion with his wife, it is actually he who controls their use of the safe period method.

F046 (33 years old, 5 children ever born): - (Advantages/disadvantages of azal) I can't say when it will be better to use a method after marriage, because I have never used any method. ... (Family planning while breastfeeding) I didn't have menstruation since the birth of my baby. I will not have mura bascha [having a baby without menstruation]. Those who have mura bascha can take a method before their menstruation starts. ... My baby is breastfeeding. I have not had menstruation yet. So, I have not taken any method. There is no necessity of taking any method till the start of menstruation.

M046 (35 years old): - (Male involvement in family planning) Yes, there should be cooperation and discussion. Both of us act through cooperation. We follow the counting of days method so that no baby is born. When she feels [sexual] need, I assist her and when I feel the need, she cooperates with me. Always we use this method after discussion and we both enquire of the disadvantages for each other. ... 
(Advantages/disadvantages of safe period) ... I count the days myself and meet my wife [accordingly]. I talk with my wife about keeping the family small. ... If the counting of days method is followed birth is prevented. I have got its proof.

There is a semantic problem here. It is not possible to 'count days' while lactational amenorrhoea persists, so if the man is currently using the safe period method it can only be in the sense of having the intention to resume counting days as soon as his wife's period returns. This intention is no protection against mura bascha, conception during the first ovulatory cycle, despite his wife's conviction that she is immune from it. Logically, we should insist that it is not possible to follow the safe period method during the woman's amenorrhoea. This particular version of the safe period method involves mutual cooperation to fulfill sexual need during the at-risk portion of the cycle. While the nature of the mutual assistance is not stated, they both had somewhat negative attitudes to the use of azal (not shown in these excerpts).

The next case reveals a primary disagreement between the man and the woman about whether they want more children, and consequent disagreement about whether they are currently using a method or not:

F048 (21 years old, 1 child ever born): - (Reasons for not using family planning) My youngest child is 5 years old. Now we shall have a baby, so we don't follow a method. We want to have a baby, for this reason we are not adopting a method. ... My husband also wants a baby. So after mutual consultation we have given up using a method.

M048 (40 years old): - (Discussion about number of children) Discussion is held [between us]. She says that it would be better if we had another baby. I say we shall have no more babies. We are poor, it will be difficult for us to bring up children, if we have too many. ... We have discussion, the topic is that we should have no more children. ... She begins the discussion. She says it would be better if we had a son. I say no. We have one, it is not necessary to have any more. I am poor and cannot bring up children, if there are too many. ... (Male involvement in family planning) Certainly there is co-operation between the two [of us]. If not, a method cannot be adopted and pregnancy cannot be prevented. ... There is the fullest co-operation between us. ... (Advantages/disadvantages of $\boldsymbol{a z a l}$ ) It is better to adopt a method after having one or two children. But this is not applicable to me. Because I have two children by my first wife. ... (Reasons for switching from program method) My wife felt dizzy when she took pills, she couldn't eat anything, and her whole body had a dizzy sensation. That's why I am using azal. It's safe because semen does not enter inside and she will not feel unwell [from pill side-effects]. ... No, she has no negative attitude. But she wants another baby.

While the man has a daughter and a son by a previous wife, who died, the woman has only a daughter. She wants another child, a son, he does not. She does not want to use any method of family planning and says they agreed on this. He uses azal, which he can do whether she agrees or not. He says 'there is the fullest cooperation between us'. She does not say anything to countermand this assessment. Although he has correct knowledge of the safe period method, and she does not, he says that he does not use it (omitted from the excerpts cited). However they conduct their sex lives, the reason for the disparity in the accounts is that she wants another child and acts accordingly while he does not want another child and is acting to avoid it.

In complete contrast, the woman and the man in the next example agree totally that they want another child, a son. However, while the woman says they are not using any method of family planning, he says they are using the safe period method. 
F049 (30 years old, 2 children ever born): - (Extent of discussion with husband) ... I will adopt a method after having one daughter and one son. [She has a daughter.] ... Both of us have decided together that after having another child we will adopt a method. ... We do not have any sons. So, with the hope of a son we will have another baby and then adopt a method. ... We have talked about Copper-T [IUD]. My husband's other wife has taken a CT. I have one child, so I have also told my husband about the use of Copper-T and he said, 'Let us have a son and then adopt the method'. I also want to do that. ... (Reasons for not using family planning) I have a daughter who is five years old [four by our calculation]. Now I am hoping for a son. I will have another baby. That is why I am not using any method.

M049 (55 years old): - (Discussion about number of children) ...We do not have a son. How will it work [if we do not]? Others have sons but we do not. We have only one daughter. If she dies, there will be no one to light the lamp in our house. So, we do need a son. No other things are discussed. ... We do not have that much discussion. Only we discuss about having a son. ... She [his wife] starts the discussion. Ours is a poor family. We have to work very hard, so we fall asleep while discussing it. But whatever we discuss, the thing is that we want another child.

Why he would be using the safe period method if they are trying to have a son is obscure, yet the rest of the man's narrative is entirely consistent with current use of the safe period method. At one point, having bemoaned his perceived misfortune at having daughters, from his first wife as well as the second, he said 'Still, now I use the safe period'. There is no clear explanation.

In the next case, there is also disagreement between the man and the woman about their use of the safe period method. Again it is the woman who says she has never used any method of family planning, although she has heard of the safe period method and has partly correct knowledge of when the safe period is. The essence of resolving the stories is whether this man and woman still have sexual relations with each other.

F055 (40 years old, 2 children ever born): - (How the safe period method works) I know nothing. I have never followed the counting of days method. How shall I feel about the physical change ? I haven't followed the counting of days method. ... If the counting of days method is followed properly, no baby is born. But husbands don't like to listen to [this advice]. ... (Advantages/disadvantages of safe period) According to our religion Islam, any method to prevent birth is haram [illegal]. Following the method of counting days means torture for the husband. For this reason it is also haram. ... It is better to follow the counting of days method after the birth of one or two children. It is better to use this method at an older age. In the beginning [of the marriage] the husbands don't want to follow the counting of days method. The Muslims cannot follow the counting of days method. The Hindus are allowed to follow the counting of days method. ... (Extent of discussion with husband) One can talk to one's husband first. Those women who are smart they can discuss but those who are very shy they can't discuss. I can discuss with my husband first. ... I don't feel shy of discussing anything with my husband. ... (Reasons for not using family planning) We have had a small number of children automatically [without using contraception]. There would not have been any problem if one or two more children were born. But babies are not born, automatically. So, why should I use a method ? I was sick and my husband was also sick. ... After the birth of my younger daughter I was ill. For that reason I didn't use any method. Intercourse with my husband was suspended automatically. When my husband recovered from illness. I fell ill after that. So, I didn't use any method. My husband had an ulcer and I had menstrual problems. At present I have liver problem also. 
M055 (47 years old): - (How the safe period method works) It is found that when there is more chance of having babies then a 'flower' comes out [lips of the vagina form a flower shape?]. That very 'flower' remains open to attract the seed. If there is 'meeting' [intercourse] during that period, there may be conception. ... My son and daughter both have passed Matriculation. No baby has been born for so long. I follow the counting of days method. Had this method not been effective then more babies would have been born by now. ... From the beginning of menstruation up to the 20th day, there is danger, babies may be born. The period from the 21 st day to the next menstruation are safe days. ... (Male involvement in family planning) There should be cooperation. ... No method becomes effective if there is lack of cooperation from both sides. Many children might have been born. If she doesn't tell me when her menstruation starts, how can I follow the counting of days method? ... She and I both follow counting of days patiently. ... (Advantages/disadvantages of safe period) ... I didn't take more than two children. My younger son has matriculated. If the counting of days method was not effective, I would have had many more sons and daughters. It doesn't have side-effects like pills. ... (Reasons for method choice) If we don't follow the counting of days method, we have many children whom we cannot raise. So, we follow the counting of days method. When my younger son was born, family planning was not so strong. But now family planning is strengthened. There is no problem as we follow the method of counting of days. There are more advantages. The best advantage is that we didn't have more than two children. Now do you see what are the advantages?

This couple's two children are now adult. The man and the woman have both suffered illness. According to the woman, she has never followed the safe period method. According to the man, they have successfully followed the safe period method over a long period of time, apparently under his control, for notice that the woman is supposed to tell him when her menstruation begins each cycle. Even if intercourse has occurred less frequently due to illnesses, as long as they still have intercourse at all it seems reasonable to accept that they are currently using the safe period method. However, it is possible they have stopped sexual relations permanently.

A denial by the woman of having ever used a method of family planning also characterizes the next case. On the other hand, she does appear to admit that her husband has used a method! She also says that she and her husband are trying to have a child. Her husband, on the other hand, says that the child should be delayed and speaks of using a combination of Ayurvedic pills from a kabiraj, a misconceived variant of the safe period method based on cycles of the moon, and withdrawal.

F056 (19 years old, no children): - (Advantages/disadvantages of azal)... It is better to follow the method of withdrawal immediately after marriage. Because pills cause problems in having children afterwards. For this reason, withdrawal is good. ... I learnt [about azal] from my husband. I feel shy in having information from anyone else. I did not hear of it from anywhere else. ... Withdrawal is good. It prevents pregnancy. Pills also prevent pregnancy but to use pills for a long time may cause problems in having babies. Further, I have never used any other method. I can't say anything more about it. ... (Extent of discussion with husband) I can discuss with my husband the prevention of pregnancy at the early stage [of the marriage]. ... I can discuss everything. Why should I feel shame in discussing things with my husband? ... My husband adopted the method. Now he wants a baby, that's why we don't follow a method. ... I told my husband I would do what he wants me to do. He wants a baby. His opinion is more important. ... We decided to delay having a baby. To have a baby at the very earliest [stage of marriage] may cause problems. That's why my husband first adopted a method for a while. Now he wants to have a baby. That's why we are 
not following a method. ... Only once my husband spoke of withdrawal - I heard it from him. ... Now we'll have a baby. My husband said we would have a baby. What can I do now? I also said I would be pleased to have a baby. ... (Reasons for not using family planning) My husband now wants to have a baby. That's the reason why I also like to have it. So we've not adopted a method. ... My husband doesn't like withdrawal. He suffers on account of it. ... He considers that family planning is good. Now he wants a baby. Hence he is not using a method. After the birth of the baby, he will follow a method.

M056 (27 years old): - (Discussion about number of children) We have discussed it. I said we have been married for the last three years. We shall wait two more years. After that, we shall have a baby. We have decided to have not more than two babies. ... (Methods from kabiraj) After marriage, we followed the safe period and withdrawal for two months. After that, we used Ayurvedic pills. I had her take nine pills which last for three years. But since I had doubts as to whether she would be converted [whether the pills would work], we again have switched to the safe period and withdrawal. ... Out of fear that, by chance, I will have a baby, I have given up the Ayurvedic treatment. They prepare pills with the bark of trees, leaves and some other things. I persuaded her to take pills which should last for three years. They gave nine pills. She had to take pills consecutively for nine days. [In this way] pregnancy is avoided for three years and up to five or six years. I had doubts after two months of her taking the pills that she might be pregnant. So, the pills were given up and I have been practising withdrawal and safe period. But if Ayurvedic pills are taken, menstruation becomes regularized - it causes no problem. ... (Male involvement in family planning) The husband should cooperate. If they so do, there will be fewer children. ... Unless both are united, we can't achieve the goal. The co-operation of both is necessary if we follow the methods of safe period or withdrawal. If we don't co-operate, she may become pregnant. ... If we do something after mutual discussion, we can be successful. There is advantage in doing things unitedly. We follow the safe period method. She had Ayurvedic pills after both of us agreed on it. ... (Advantages/disadvantages of $\boldsymbol{a z a l}$ ) Withdrawal is less safe. It cannot be guaranteed that semen does not go inside. It may cause pregnancy. Hence withdrawal is less dependable than other methods. ... (Advantages/disadvantages of safe period) Religion prescribes observance of the safe period. This should be followed. If the safe period is not followed, blind, lame babies may be born. The safe period must be followed throughout life. The darkness [first arrival of the new moon] and the full moon should be observed. Days should be observed. Many other things should be observed. [Explanatory note by interview team: The respondent seems to observe astronomical signs and time of the lunar day. He probably observes these days for health reasons.] ... It should be used at the very beginning of married life. After having two children, this should be followed throughout life. Only when one likes to have a baby, one may relax it. ... It is as effective as other methods if followed correctly. ... (Use of family planning before having children) We shouldn't have any baby within two to five years after marriage. ... Parents do not mind if babies are had after some time of marriage. Everybody now understands what is good and what is bad in life. So the parents do not have strong opinions now-a-days. ... We should adopt family planning methods immediately after marriage. We should not have any baby within five years of marriage.

There are many confusing aspects to these narratives. One reason that the woman might have felt justified in claiming that she has never used a method of family planning could be that it was primarily her husband who had done so. The only thing she did herself was to take some pills, supposedly contraceptive, bought from a kabiraj by her husband. (Only the man said this.) Not even her husband had any real faith in this method, or at least he had doubts soon afterwards. It is interesting to note that the method that he felt was least effective, azal, was 
probably the most effective among the three he claimed to be using. This was among several cases, discussed with us by the interview team, where a young man had unilaterally followed family planning methods to avoid pregnancy in a very young wife until she became more mature.

In the next case, it seems clear that the woman is not using any method, because she is trying to become pregnant again. The man says that she is taking oral pills.

F061 (32 years old, 3 children ever born): - (Extent of discussion with husband) I can discuss all matters with my husband. What may be the cause of shyness with my husband? The wife has to discuss [these things] more than the husband does. Because what is the problem with men? They don't understand anything about the family problems. ... My husband wants to have a baby. I gave birth to three daughters. Both of us have decided that we would have a son. ... My husband told me about the operation [sterilization], I told him that I would not do that. Nor would I use a Copper-T. I took pills for the regularization of menstruation and my husband knew about it. ... I want a son and my husband holds the same opinion. If a son is born this time, I will stop having babies for ever. ... (Reasons for not using family planning) Occasionally the worker comes to my house. She tells me to adopt birth preventing methods. As I want a son, I am not using any method.

M061 (31 years old): - (Discussion about number of children) About the children, we talk about having had three daughters. My wife wants a son. So, my opinion is that I shall take another baby if it is a son. After the birth of our two daughters I wanted to prevent birth. But as she began weeping we had another baby. But at an early age the girl died. So, to fulfill my wife's desire, I shall have another baby. ... My wife tells me what the FWA says. We followed what they advised. But all their instructions cannot be followed. They say, 'Don't take more than two children.' We use the methods they tell us to use. However, they tell us good things. ... (Male involvement in family planning) ... Suppose I have something in my mind and she has something in her mind. So, if we discuss together and take up a method then it will work. For example, if I tell her to take the pill but she doesn't take the pill at night, will that do? If she doesn't want to take pills, I shall have to take a method. ... After both of us had a discussion she said that she would take injections. But they didn't give an injection last month. So, they supplied pills. That is not creating any problem for us. ... (Reasons for method choice) Birth is being prevented, but there is problem. While the pill may be relied upon, she feels weak if she takes pills. ... It prevents birth. But I know of a woman who died in the hospital during delivery because fat accumulated in her womb from taking pills. So, she couldn't give birth in a healthy condition. ... They [FWA] have supplied [pills]. They could not give an injection on time, so they supplied pills. ... She is using injections. But this time as they couldn't give an injection on time, they have supplied pills. We are satisfied with this. They come to every households and supply pills. We also benefit from it.

It is admittedly difficult to make sense of the various strands in the man's story. He seems to agree with his wife that they are trying for another child, 'if it is a son'. From his remarks on the topic of male involvement in family planning, he seems also to be aware that the possession of a supply of pills does not guarantee their use. They agree that he has sought to have her use other family planning methods, but differ on which methods. His statement that she is using injections seems to be wish-fulfillment. For her part, the woman corroborates past pill use, but says it was to regulate her menstruation.

While the woman's story is undoubtedly more valid, there are two important observations which can be made on the basis of these interviews. The first is that pill supply does not 
guarantee pill use. The second is that pill use can be for purposes other than family planning, for example as a temporary expedient to regulate menstruation.

A considerable contrast to the previous few cases of difference between men and women over the method they are using is provided by the next example, of a young couple married about a year and a half, who agree on almost all aspects of their recorded responses, except whether they are seriously using azal to delay their first birth. The case provides a certain level of insight into one reason that young people use 'traditional' methods, namely that if a method failure does occur it will be a welcome event.

F066 (16 years old, no children): - (Advantages/disadvantages of azal) ... It is better to practice the system of ejaculation outside the womb after the birth of one or two children. Husbands want to know about it after a baby is born. However, in my opinion this method may be practiced any time if the husbands agree. ... I have heard about this method from my auntie [mother's sister]. I don't know if there are any other sources. ... This method does not prevent birth. Because one cannot always be careful. So, there exists the chance of conception. ... (Use of family planning before having children) The mothers-in-law of remote villages advise their daughter-inlaws to take the oral pill in order to avoid a conception soon after marriage. In case of early conception, they (mothers-in-law) cut jokes that the daughter-in-law had brought a baby along with her. Then they consider that the daughter-in-law is too mature. ... Many people say that if contraceptives are used to prevent birth just after marriage they may face a problem at the time of giving birth to a child. I do not believe this fully. Contraception takes place if use of the oral pill is discontinued. ... At least one year after marriage a couple should go for a baby. During this one-year period family planning methods may be used. ... The oral pill affects many women. Condoms may be used. Condoms are best. One faces no problem in taking a baby if condoms are used. ... (Extent of discussion with husband) I can discuss with my husband about all the methods. I don't feel shy in talking with my husband. ... My husband may be consulted in all these matters. This discussion is not at all embarrassing. ... If I want to take a child, my husband will agree. ... Once I told my husband to bring condoms and he did. Apart from condoms, I did not discuss about any other method with my husband. ... Whether I would take a baby or not, whether I should use a method or not, my husband does not say anything about that. Whatever I say about contraceptive methods, he just listens. ... (Reasons for not using family planning) A baby may be born, or may not be born, I don't mind either way. I have a dysmenorrheal problem. As a result I cannot have a baby now. However, it will be a pleasure if a child is born. ... My husband does not discuss anything with me. Till today, he has not initiated any discussion with me regarding the prevention of birth or about having a baby.

M066 (21 years old): - (Discussion about number of children) We have no land of our own. I am a day labourer. My married life is one year seven months. I have said to my wife, 'We have limited income. So, we will not take more than two children.' My wife also holds the same opinion. Besides, we have decided that we would delay having a baby. We have decided that we would go for a baby after one year. My wife has dysmenorrhea. ... (Male involvement in family planning) ... If the husband and wife do not agree, ejaculation cannot be made outside the womb. If they want to delay pregnancy, the husband and wife have to be unanimous in the use of the family planning method. In case of disagreement, the method does not work. ... We both, with great patience, use azal. My wife has dysmenorrhoea and in case of dysmenorrhoea, no baby is born. Despite that, we still practice azal as we wish to delay pregnancy. ... (Advantages/disadvantages of azal) If semen is ejaculated outside the womb, matter may fall on different parts of our body. If it falls on any part of the body, it causes a scar there. If ejaculation is done outside the womb, no 
baby is born. It is better to adopt this method if anyone wants to delay pregnancy. ... If anyone wants to delay having children, like me, this method may be practiced just after marriage. Again, after the birth of a baby, if a couple wants to delay the next birth, they can adopt this method. ... If azal is practised, no conception occurs. This method works like the other FP methods. ... (Use of family planning before having children) My parents do not say anything about it in my presence. However, my mother said to my wife, 'You have been married just one and a half years. You should wait for another one or two years before having a child.' I guess that my father also holds the same opinion. Otherwise my mother would have not told my wife to delay having children. ... Taking of oral pills is the best method. But I usually ejaculate outside the womb, because my wife has dysmenorrhoea.

Painful or otherwise dysfunctional menstruation (dysmenorrhea) is reported by many respondents, using a common Bangla term for this condition. There is a consensus view, mentioned in many interviews, that sufferers of this condition cannot conceive. It is probable that the term is used to refer to a large variety of individual symptoms with different causes, and few of them actually associated with reduced fecundability.

This man and woman have avoided pregnancy for one and a half years since marriage, using azal and sometimes condoms, it seems. While he, at least, shows a high level of commitment to continuing to avoid a pregnancy for some time yet, the key statement is the woman's, that 'it will be a pleasure if a child is born'.

The next case of 'disagreement' between the respondents, about whether they are using a method or not, is one where they actually agree that they are using the safe period method; but the woman fundamentally distrusts it and says that she is using no method of family planning. The interview team accepted this position. This woman had tried various program methods, and after perceived bad experience with them she abandoned their use and resisted advice about sterilization from the FWA and also her husband. While she does not trust the safe period method, her husband is apparently following it with success. She is 34 years old and she has already borne six children, but the youngest is now five years old. The woman's tale is one of resignation to the will of Allah after bitter experience, and deserves the extensive excerpt given below:

F079 (34 years old, 6 children ever born): - (Advantages/disadvantages of safe period) I think it will not be sinful. Religion says to adopt this method, while another method [illegal method] is sinful. We are not doing any harm. We are not aborting babies. This is not sinful. We ourselves are following this method painstakingly. ... I do not like this method [safe period] so I do not need to know this [anything about it]. ... The pill causes me dizziness, the injection does not suit me physically. If the safe period can be followed properly then birth will be prevented. But if husbands do not follow it properly then there may be conception. That is why the injection or the pill is better. There is no risk in these methods. ... (Use of family planning before having children) ... I do not use these [methods]. I also do not know about them. Condoms cause infection in the womb. If the pill is discontinued then there will again be conception. I took pills but one month I discontinued and then I had a baby. It is better to take pills. ... (Extent of discussion with husband) If I need to, then I have to talk in detail with my husband. No, I have not discussed until now. Everything can be told to the husband. But some people do it and some do not. ... We can discuss condoms. We can also discuss CT [IUD]. All methods can be discussed with the husband. What is there to be shy of, to talk with the husband? ... I will not adopt any method myself. I had difficulty in adopting a method. Now, whatever Allah does will happen. ... My husband does not put pressure on me for any matter. My husband is in agreement with me. Is it possible if both of us do not decide together? Whatever is 
said [by my husband] has to be followed. But I do not follow it if anything illegal is said. ... After the birth of my eldest daughter [name of FWA] told me to be operated on [sterilized]. But I would not get sterilized so I took the pill. My health deteriorated after taking pills, so I stopped. Because of their motivation I took pills. At that time I did not understand religion. Now I have left it up to Allah. I will have as many children as Allah provides. ... [Name of FWA] said, 'Bhabi, get yourself sterilized' but I did not listen. I am afraid to do these things. My husband told me to get operated on. My husband does not want to have any more children so he told me to adopt that method. ... My husband told me to adopt a method for birth control. I said I do not want to adopt any method. I will take as many children as Allah provides. Now my husband does not say anything. ... (Reasons for not using family planning) There is no reason for not adopting family planning. There will be a child if Allah gives me one. I have not adopted any method after the birth of the youngest child. Automatically, birth is controlled [no conception has occurred without me doing anything]. There will be more children if Allah gives them. I will take as many children as are born. ... I took the pill and had dizziness. My waist became insensitive when I took injection. If I tell [name of FWA] then she talks too much. She tells me to get operated on. Why should I do what does not suit me? If you ask them something they will just speak a lot. If there is any problem and we ask for medicine, they do not give it. ... I took the pill, it caused dizziness. One side of my waist became insensitive after taking injection. So, now let me have as many children as are born. I will not do anything. ...

M079 (43 years old): - (Discussion about number of children) [Our] poverty will increase if there are more children. So we will not take any more children. That is why we are adopting a method. ... Yes, they [FWAs] visit and talk with my wife. They tell my wife, 'Do not have any more children. Otherwise, poverty and problems will remain in the family. Adopt a method.' My wife then tells me. ... It is I who starts the discussion. What shall I say? By the by, when the issue is raised, then we say that we will not have any more children. ... (How the safe period method works) Who notices so much about this [physical signs of at-risk period]? ... It is hoped that conception will not occur. Childbirth is prevented like any other method. ... It is safe after twenty days from the start of menstruation. ... (Male involvement in family planning) We will not take any more children. So a method has to be adopted. That is why we now follow the safe period method. ... Both of us together agreed to adopt the method. ... (Advantages/disadvantages of safe period) This method should be adopted after having two children. As no expenses are involved, this is useful for the family. Health remains good. ... I am not afraid to follow the safe period method. I follow it properly. It also prevents birth like pills or injections. It does not affect health in any way.

In the next case, the couple have had ten children already but only four survive (three daughters and one son). The man wants another son, but in desperation the woman took a kabiraji preparation which is supposed to prevent any further births. The man says they are not using any method of family planning, and claims he does not know why they are not having any more children.

F082 (44 years old, 10 children ever born): - (Extent of discussion with husband) If necessary, I can initiate discussion with my husband. ... One can tell everything to one's husband. My husband has chosen me and married me. I live together with him. So, I don't feel shy of talking about anything to my husband. ... When my babies died in infancy, one of my aunts said to me, 'Your babies die after birth. Pay me Tk. 10 only to prevent birth'. Then my aunt gave me a tablet prepared of indigenous herbs and I swallowed that without telling my husband. ... I decided to use kabiraji medicine without the knowledge of my husband. I informed my husband about it later 
on. My husband didn't tell me anything. ... I gave birth to ten babies of whom four are alive and six have died. After the death of my youngest baby, my aunt said to me, "As you are giving birth quickly [one after the other], your babies are dying. You can take kabiraji medicine from me.' I took the kabiraji medicine from my aunt without telling my husband. Children are born. It is difficult to rear up children and my health is not good. My health will break down if many babies are born. The children also don't survive. For this reason I have prevented birth for ever by taking the kabiraji medicine. ... I didn't discuss with my husband about the use of any method. I have used a method myself. ... I have used the method without telling my husband. I told my husband about it later on. My husband said, 'Oh, no baby is being born because of this. So, you have done this.' My husband didn't say anything more.

M082 (42 years old): - (Discussion about number of children) I don't discuss about the number. What shall I discuss? But this much I understand, that it would be better if a[nother] son and a daughter were given to us by Allah. ... No discussion is held. ... My wife doesn't tell me [what the FWAs say]. ... I start discussion. I say that we have three daughters and one son. It would be better if another male child was born. But my wife doesn't say anything. ... (Methods from kabiraj) No, I haven't heard about these. ... (Male involvement in family planning) Yes. Discussion between husband and wife is necessary. The one who intends to use a method will discuss it. ... There is no cooperation. We don't discuss it. ... (Reasons for not using family planning) I want one more son. But I am not having it. And no baby will be born. Why? That I don't know. It would be a problem if a daughter is born. My wife didn't tell me if she had any problem. ... (Family planning while breastfeeding) It should be used [during breastfeeding]. [Suppose that] I have a small baby. If I don't use any method, another baby may be born. This will affect the health of the small baby and the health of its mother. ... It is necessary to use a method. Babies may be born frequently if a method is not taken.

Notice that what the man says about family planning while breastfeeding seems to be totally out of the context of his other comments, and somewhat in accordance with his wife's statements about avoiding births in quick succession. While his youngest surviving child was twelve years old at the time of the survey, there had been subsequent births of children who died.

The following case refers to a (Muslim) man who has withdrawn from all things worldly to follow the teachings of a saint, and his wife agrees that they rarely have sexual intercourse. $\mathrm{He}$, but not his wife, says that they follow the safe period method when they do have intercourse.

F100 (46 years old, 3 children ever born): - (Advantages/disadvantages of azal) ... I have heard [about azal] from my husband. My husband reads the books of the Hadith, he came to know from there. ... This [semen] is the light. How will conception occur if the light is thrown outside? Birth will be prevented if the light is thrown outside. Birth can be prevented as with pills. ... (Extent of discussion with husband) I have never [initiated] discussion myself. If it is necessary I will be able to discuss. ... I have two children and did not have any more children. I have never discussed family planning methods [with my husband]. Only, my husband told me about throwing of semen outside [azal], that if it is practised then birth is prevented. Besides, I did not need to adopt any methods, as I do not conceive automatically [have difficulty conceiving]. I do not discuss anything with my husband. If necessary, I will be able to discuss about everything, what is there to be ashamed of? ... My husband is a disciple of a saint. After taking lots of medicine my two children were born. Now that my husband has become a disciple of the saint he restrains himself about all matters in order to purify his soul. I have not adopted any method as my husband keeps very 
little physical relationship with me. He has a physical relationship with me once or twice in a period of six months. ... My husband is a disciple of a saint. One's inclination towards pastimes and amusements declines when one has chosen the path of Allah. One keeps oneself away from amusement and covetousness. He has sex with me once every six months, that is why no method is adopted. ... (Reasons for not using family planning) ... After the birth of our youngest child my husband has become the disciple of a saint. He has taken lessons from the saint to restrain himself about all matters. That is why he makes love to me after five or six months. Both of my children were born after I had taken kabiraji medicine. I do not conceive too easily, for this I have not adopted any method.

M100 (55 years old): - (Discussion about number of children) We have discussed [the number of children]. I am a man of the spiritual [Siddhi] world. Both of us decided together and have taken the sacred mantra. After two sons were born, I practised azal. After that, we have followed the safe period method. Both of us were already in agreement. Moreover we took the method following the advice of our guru and I think that this method is good. ... The FWA visits but we have never adopted a modern family planning method. So, no such discussion was held with them. ... My only hope [for old age] is Allah. Children are only excuses. We have reared up our children with so much love and affection, so we do have our hopes in them. And whatever wealth I have is all for them. One of my sons is a service holder [government employee], now he gives me money. Another son is studying in honours in Dhaka. ... (How the safe period method works) During this period women are very much driven by the sexual urge. At this time women want to have men near them, love them more. The way a magnet attracts iron, the same way women also attract men at that time. But the duty of the iron would be to keep itself controlled and away from the magnet. ... I have full faith in this [method]. I am following this at the advice of my guru. I am completely successful and satisfied. ... The last seven days of the menstrual cycle are more safe. ... (Advantages/disadvantages of safe period) It is a problem to have many children. To prevent birth is wealth. ... There is no restriction in religion. It is advised to practise this [method] because it is good for health. ... Many children are not born. No tension is there. One's health remains good. ... One's body weight remains unaffected.

There is a vagueness to this man's claim to use of the safe period method, signalling intent or past practice. The woman has mentioned the use of kabiraji medicine to assist her to have the two sons which she had, many years before. No other instances have been located in the set of interviews.

The next case is one where the man says that he is using azal but his wife claims that she has never heard of it. What she says goes some way towards explaining the discrepancy, but it is also necessary to read carefully the man's statements.

F125 (34 years old, 6 children ever born): - (Extent of discussion with husband) I can discuss everything with my husband, why shouldn't I? I told my husband about the use of Copper-T [IUD]. ... If the need arises, I can talk to my husband about family planning methods. I don't feel shy of discussing anything with my husband. ... As prevention of birth is sinful, my husband doesn't like method use. So, I haven't taken any method. Once I used a Copper-T without telling my husband. When he came to know about it he rebuked me. So, I am not using any method now. ... My husband's decision is important. I used a Copper-T. But as my husband didn't like it, I got it removed. ... Before the birth of my youngest child, I took pills and used a Copper-T without the knowledge of my husband. I didn't have any discussion with him about the use of a method. ... My husband forbids me to use any method in order to prevent birth. But I want to use a method. But as my husband shouts at me, I can't 
use any method. Once I used a Copper-T and my husband scolded me. So, I got the Copper-T removed. ... (Reasons for not using family planning) ... In the eyes of Allah, the use of any method is sinful. My husband tells me that if would be a sin if we prevented birth intentionally. For this reason, my husband doesn't allow me to use any method. ... The imam of our mosque has told me that the use of method with a view to preventing birth is sinful. ... My husband does not like using my method. I used a method before without informing my husband. My husband thinks that method use is sinful. If Allah prevents birth, that is one thing. If not, then let any number of children be born.

M125 (52 years old): - (Discussion about number of children) I have no intentions of increasing the number of children. It creates more problems in the family and it is less profitable. Both of us are of the same opinion that we would not have any more baby. ... Discussion is held. ... (Responsibilities for child care and family health) I initiated the discussion. When I said that we will not have more children my wife agreed. ... (Male involvement in family planning) We both have to discuss. We discuss not to increase the problems in the family. Being unanimous we are using azal. ... By discussing it between us two, we have decided to use azal so as not to have any more baby. ... (Advantages/ disadvantages of azal) This method is safe. Because matter does not go inside. If matter doesn't go inside, no baby is born. ... (Family planning while breastfeeding) It is necessary to use a method [during breastfeeding], because otherwise babies may be born. My baby is too little, it is breastfeeding. So, we use azal. Otherwise another baby may be born. ... Any method may be used. ... (Influence of religion on use of family planning) No, the use of any method [of family planning] is not restricted by religion. ... No, the use of any method is not shameful between husband and wife. Even the operation [sterilization] is not shameful from a social point of view. ... No, they [religious leaders] don't say anything. ... Religious teaching is most important, because family planning is not restricted by religion.

While not apparently related to explaining why the woman said she was not using a method and the man said he was, this man's statements on religion and family planning are highly interesting because they constitute perhaps the most liberal statement encountered in this study. (See Chapter 7 for the more usual pattern of response.) It is in total contrast to what his wife has narrated about him scolding her and shouting at her about the use of program methods, which she had adopted secretly. Did he scold her because she adopted program methods without telling him, or because he was fundamentally opposed to them and was merely telling the interviewers what he thought they might want to hear? There can be no doubt that the accounts given by these two respondents cannot both be accurate. At another point of the interview (not included in the excerpt), the woman referred to the possibility that her husband might beat her. If the man's statements on some things are untrustworthy, what about his claim to be using azal?

There is ultimately no satisfactory way of resolving the conflict between these accounts. Note, however, that the woman is 34 years old, with six children ever born and the youngest only six months old. While this suggests that the couple has not rigorously followed any method in the past, the arrival of the new baby could possibly have changed the man's attitudes towards family planning without the woman being aware yet.

Another example of difficult interpretation of the results of a pair of interviews is provided by the next example. The woman says explicitly that she will talk openly to someone from the 'government' who wants to give money, but not about family planning.

F128 (41 years old, 8 children ever born): - (Use of family planning before having children) Fathers- and mothers-in-law of the present times say that if babies are born 
early [in the marriage], the members of the family will be large, causing problems. So, they give the opinion that babies should be had at a later stage [of the marriage]. Some of them, however, forbid us to use family planning methods as these are sinful. ... One will choose a method according to one's wishes. I've not used a method ... (Extent of discussion with husband) I can discuss openly [with my husband]. Once I wanted to have a tubal ligation and I raised the issue with my husband. ... I don't feel shy in discussing a method. I can discuss everything. But I didn't discuss these things too much and I didn't feel the necessity. ... To adopt a method is sinful. My husband said that ligation and pills would cause disease. I'll have no baby as I've not been producing one during the last seven years. I'm afraid of Allah. That's why I don't use a method. ... I have to listen to the opinions of the husband. I do what my husband asks me to do. My husband has forbidden me to use a method. So, I've not been using it. ... (Reasons for not using family planning) ... I haven't used a method for fear of Allah. Allah will punish me if I prevent pregnancy. ... The Imams say that it is Allah who will stop the birth of babies and will give them. Allah provides for us. Why would you do there things by yourselves. Why should you be a sinner? ... I wanted to be ligated but my husband is afraid of Allah. If pregnancy is prevented, Allah will consider us sinful. That's why my husband didn't allow me to be ligated. ... (Any other matters?) No, I don't want to know anything. If the government gives me money, I'll accept it. But you have come to talk about family planning. So I don't want to know anything from you.

M128 (52 years old): - (Discussion about number of children) Yes, we held discussion. We discussed what would we do to avoid having more children. So we use family planning methods. ... We have decided not to have any more children after mutual discussion. ... She [my wife] raised these issues first. ... (Male involvement in family planning) Men need not adopt a family planning method... A method should be used [by the woman] after obtaining the opinion of the husband. ... Men don't like to use a method. ... (Reasons for method choice) After the youngest child, we have not had a child for the last five years. She used to take pills in the beginning, now she has injection. Pregnancy is stopped. We face no problem. ... Pills caused a lot of problems, then the family planning people advised injection instead of pills. An injection after $2 / 3$ months causes no troubles. It is more convenient. ... Pills are hot. They caused a burning sensation, constipation, a burning sensation at the anus, dizziness. So they (FWA) advised injections instead of pills. She is taking injections. She doesn't face any problem.

As in the previous instance, this man and this woman cannot both be correct. There are three remaining possibilities. The woman may be incorrect, the man may be incorrect, or both of them may be incorrect. Since in this case or the previous case there seems to be no reason to favour one partner's story over the other's, the safest thing to do is to reject both stories and regard the evidence from both pairs of interviews as unreliable.

The following case is much more straightforward. The man and the woman agree that they have been using the safe period method over a long period of time, but the woman is now well into menopause and says that they do not follow any method any more, while the man says that they are still practising the safe period method.

F134 (40 years old, 4 children ever born): - (Advantages/disadvantages of safe period) I've been practising the safe period method for the last eight years and have not been pregnant till now. So, I think that like other methods, it can also prevent pregnancy as long as one wants. ... (Extent of discussion with husband) I can discuss everything with my husband. I myself talked to my husband about using a method after I had my daughter, the first child. ... The husband and wife both take the decision whether we'll have babies or not. But pills do not suit me. Because I suffer 
from high blood pressure. So after talking to my neighbour and FWA, I discussed with my husband about using the safe period method and we both have decided to practise it. But now after a gap of two to three months I have only a little menstruation. For this reason, I have the idea that probably I would not conceive anymore. So both of us feel that it is no longer necessary to follow the safe period method. I won't be able to have a baby now. ... My menstruation has almost come to a stop. I have a little menstruation after two or three months. So both of us have decided together that we need not use a method any more. I discussed with my husband about using pills; but my blood pressure may go up if I take pills. We discussed withdrawal but I thought 'Why should my husband suffer?' For these reasons we as husband and wife decided to use the safe period method... When we adopted the method, my husband agreed with me. Now I have given up the method of safe period and he is in agreement with me. ... (Reasons for not using family planning) My monthly has substantially decreased. After two or three months I have a little of it for one day. My husband has, therefore, said that I won't be able to conceive now and has asked me not to use any method. ... It can be said that my menstruation has come to an end. Because after a gap of two or three months I only have a little of it. So, my husband and I believe that we'll have no more babies. For this reason, we don't use a method.

M134 (43 years old): - (Discussion about number of children) We discussed that we shall have no more babies. We limit the number of babies commensurate to our income. We've three children. We shall bring them up well by providing for their education, treatment etc. If we have more babies than these, there will be housing and financial problem. So, we shall have no more babies. ... The FWA workers measured the blood pressure of my wife and advised her to pay attention to her health. They also advise her to adopt family planning methods. My wife reports these things to me. ... (How the safe period method works) The passion for sexual intercourse increases. One becomes hot. ... [The safe period method] is reliable. If properly followed, it prevents pregnancy. ... The last part of the monthly cycle is safe, because the mouth of the woman's womb closes at that time. Therefore, the possibility of conceiving at this time is $10 \%$ and at the beginning of the cycle it is $90 \%$... (Male involvement in family planning) The husband and wife both should take part [in family planning]. ... A method should be adopted after mutual discussion. There is no problem in cooperation. We both respect each other's opinion. ... Cooperation is needed between [the husband and wife]. Care should be taken if anything is wrong after using any method. ... Both of us have taken the decision that we will not have any more children. And we agreed to use pills, condoms, homeopathic methods and the CT. As these caused problems, after discussion we are maintaining safe period ... (Advantages/disadvantages of safe period) ... Yes, it's reliable for preventing pregnancy and good for health.

The man can well report that he is still using the safe period method, as they have been using it for a long period of time and he is habituated to thinking that this is the method of family planning that he and the woman use. However, he can hardly be doing it in practice any more, because the woman's menstruation is now no longer monthly.

The next case is similar to one which has been discussed already (household 046), in that it involves a man who claims to be using the safe period method, in combination with condoms, but the woman says she is still amenorrheic after the birth of their second baby. There are two possible ways they can use the safe period method in conjunction with condoms. The conservative version is to avoid intercourse altogether during the at-risk period and condoms during the remainder of the cycle. The other way, which appears to be more common in Bangladesh, is to use condoms during the at-risk period and nothing at all during the remainder of the cycle. It is disturbing to note that if they follow the less conservative method, 
their understanding of the at-risk period is almost guaranteed to give them another child, while their intention is to limit the number of children to two.

F136 (21 years old, 2 children ever born): - (Extent of discussion with husband) My husband and I have decided that we would use a method when my menstruation begins. Before that there is no need to use any method. ... I have not had any menstruation since the birth of my youngest son. So, we as husband and wife have decided that we would use a method when menstruation begins. Because a baby doesn't come into the womb if there is stoppage of menstruation. As a result I will not use any method now. ... After the birth of my eldest child I told my husband to use condoms. So, we discussed about condoms. We didn't discuss about any other method. ... My husband holds the same opinion with me. We take decisions about family planning together. ... (Reasons for not using family planning) After the birth of my baby, I have not yet menstruated. My husband desires that when my menstruation begins, we shall use a method in order to prevent birth. ... I have not yet menstruated since the birth of my youngest son. For this reason, I have not yet used any method to prevent birth.

M136 (31 years old): - (Discussion about number of children) I have one son and one daughter, I will not have any more children. I have told [my wife] that it would be better if another son is born. Because of the two children one may die. My wife doesn't want to take any more baby. So, we are using family planning. ... My wife started the discussion first, that we would not have another baby. We shall have to rear up those two children well. It would be difficult to rear them up if many children are born. ... (Male involvement in family planning) The husband should take part. ... Both of us should discuss adopting a method in order to prevent birth. With the advice of the [village] doctor both of us are following the counting of days method.... Both of us took the decision and we are now following the counting of days method. Both of us are unanimous that we would not have another baby. So, we follow the counting of days method. My wife tells me when her menstruation begins and I don't 'meet' [have intercourse] with her during the next fifteen days. ... (Family planning while breastfeeding) It is necessary to use a method during the lactation period. It is necessary to use a method even if no menstruation is started. ... It is not improper to use a method during the lactation period. Babies may be born if a method is not used. The health of the baby as well as its mother will break down.

It is very evident that these interviews come from a man and a woman who have indeed discussed and agreed on the use of family planning, and who are in no fundamental disagreement. Even then, it is difficult to be sure whether they are currently using any method of family planning or not. The man claims to be using the safe period and condoms. For reasons discussed in the earlier case, we can logically dismiss intention to use the safe period method as actual use, during lactational amenorrhea. However, he also claims to be using condoms and is adamant that it is necessary to use a method even if there is no menstruation. The woman refers to previous use of condoms, after the birth of her first child, but says that she is not currently using a method. Her story is probably the more correct version, while her husband is referring to intention.

Some of the differing accounts given by men and women include a suggestion that sexual intercourse between them rarely occurs. This is very explicit in the following case, where the woman had said initially that they were not using any method of family planning, but changed her story a little during the interview, while the man had said initially that he was using condoms, but also modified his story.

F151 (31 years old, 5 children ever born): - (Advantages/disadvantages of azal) ... There's nothing shameful in preventing pregnancy. Everybody prevents pregnancy. ... 
Withdrawal, like pills, prevents pregnancy as long as one wants. ... (Advantages/disadvantages of safe period) ... I used to follow the safe period method. I don't want to know further about it. What I know is enough. ... The safe period method prevents pregnancy like other methods such as pills. I have been going on for six years in this way. ... (Extent of discussion with husband) No, I can't begin the discussion. My husband is a man of bad temper. I never discuss with him anything regarding a method of family planning. ... Earlier, my husband used condoms of his own accord. Now, we only have sexual intercourse after five or six months. When we have sex, we follow the safe period method; but if that day appears to be risky, my husband practises withdrawal. I don't know from what source he has come to know of withdrawal. ... My husband doesn't listen to me, he does these things of his own accord. He doesn't discuss anything with me. ... Everything happens according to my husband's wishes. He doesn't bother about my opinion. ... (Reasons for not using family planning) For the last few years, we have been having sexual intercourse only once in three or four months. I'm very sick. I have pain in the chest often. My husband is very ill-tempered. He beats me severely on a small pretext. I'm not on good terms with my husband we have not been sleeping together for the last 3 months.

M151 (45 years old): - (Discussion about number of children) She [my wife] doesn't want to have babies any more. I also don't want babies. So we have agreed to adopt a method. After the eldest daughter, we had a son. At that time, I wanted that we should have no more babies. But she had a fancy for another daughter. But then we had four sons one after another. Now we don't want any more babies. We discuss this matter always. ... They [FWA/FWV] don't visit us. I live in town most of the time. So I don't know what they say to my wife. I myself am conscious that we should have no more babies. ... I myself begin any discussion. ... (Male involvement in family planning) ... Since in our rural areas, the husband enjoys full powers, the wife should take consent of the husband before using a method. If the husband gives consent, other people cannot hold any bad opinion about them. If the wife faces any problems in using a method, the husband should then adopt a method. ... I have brought under control my sexual power by taking Ayurvedic medicine. My friend concocted medicine with a herbal root., After I took that medicine, my sexual desire began to decrease slowly. Now, I don't feel any urge to have sex, and for the last one year and a half, I have not slept with my wife. I have used such a difficult medicine for preventing pregnancy. ... I've no objection to co-operation. ... (Advantages/ disadvantages of safe period) If the safe period is followed, the pill or any other method is not necessary. It doesn't harm health. ... [Response when asked whether information should be available:] I don't want to know because I wouldn't need this method in the future. ... This method is as effective as the others but it must be followed correctly. If it's used correctly, it's 100\% effective. ... (Reasons for switching from program method) I have been restraining myself from sexual intercourse for the last year and a half. My friend concocted a medicine with the root of a plant for reducing my sexual urge. After taking that medicine, my sexual urge has reduced. I've no desire to have sex in the future also. Now, I don't feel like having sexual intercourse. Pills do not suit my wife. That's why I have adopted this method. ... Injections don't suit my wife. So, she gave up injection and began to take pills. But pills also didn't suit her. So, I've taken Ayurvedic medicine for reducing my sexual urge. ... After she took injections, she began to bleed profusely and felt sick. Afterwards, she took pills but became reduced physically - she became thin and weak. Therefore, I've been controlling myself. ... She feels well now. She also is not eager for sex. We're now paying more attention to bringing up our children. ... Her menstruation has not come to a stop yet. She is still capable of conceiving. 
It is clear that the inconsistencies between them, and within the accounts of each, are due to rare occurrence of sexual intercourse. Notice that the man says that he lives 'in town' most of the time.

Statements about family planning methods: disagreement between man and woman about Whether any method is in use

The cases where the man and woman agree that they are using a method, but do not agree on which method, sometimes appear to be the result of the respondents not using a method at all. In the following example, the woman indicates that she is using a kabiraji method, but the man had claimed they were using the oral contraceptive pill. A close reading shows that he actually refers to having discontinued use of the oral pill.

F009 (30 years old, 3 children ever born): - (Extent of discussion with husband) There are some methods about which I start discussion first. For example, I discuss about the oral pills. I can talk with my husband on everything. ... Everything may be discussed with the husband. There is nothing to feel shy of with my husband... I had a baby, then my sisters-in-law (bhabies) said to me, 'There is a kabiraj. Take medicine from him as soon as a baby is born.' So, willingly I have taken indigenous medicine after the birth of my baby. I took the decision myself. ... I will comply with the orders of my husband. On the contrary, my husband will also listen to me. The decision of both is equally important. ... Discussion was held [with my husband] on copper-T and injection. ... My husband is at one with me. My husband said to me, 'You have done well by preventing birth.'

M009 (46 years old): - (Discussion about number of children) Discussion is held [between us]. She tells me everything. I also do the same. We have adopted a [family planning] method after discussion. If any method creates side-effects, we switch over to other methods. We are unanimous in our decisions. ... Yes, we discuss things, we have discussion of the type as I have told you just now. ... She tells me whatever they [family planning workers] say. They tell her, 'Don't go for another baby. If the number of your children is low, there will be peace in the family. Which method will you prefer to use?' Well, they tell my wife things like this. Those are all feminine discussions. ... At first I said that we don't need any more children. We have to use some method of family planning. Then both of us decided to use a method. ... (Male involvement in family planning) Cooperation is certainly needed. Because I can't prevent birth whenever I like. If she doesn't like to use any method then I will have to adopt the safe-period method. She has to be told about it and both have to be of the same opinion. ... She used to suffer from side-effects when she took oral pills. She had dizziness. So, she asked me what to do. Then I advised her to use injection. She will use injection from next month. ... Azal is not after my choice. I don't get mental satisfaction. I have a great dislike for it. For that reason, although my wife tells me to practice azal, I do not do that. But I have no problem in the case of [program] method use and cooperation. ... (Reasons for method choice) Births are being prevented but it [pill use] is creating inconvenience. The oral pill is creating a problem for health. [My wife's] health is weak. The household work can't be done properly. My wife is feeling like this due to oral pill use. ... She has dizziness. Sometimes vomiting. Her strength is being reduced. She becomes weak after menstruation.

Although they say that they discuss family planning, note carefully that the woman says that there are some methods of family planning which she can discuss with her husband, and gives the example of oral pills, and also that she made the decision to take the kabiraji preparation herself. The man, for his part, seems not to be particularly interested in 'feminine discussions', but he does seem to believe that his role is the important one in decisionmaking. The woman is still breastfeeding her youngest child, aged about $2 \frac{1}{2}$ years, and her 
use of the kabiraji preparation might have been very recent, as her amenorrhea apparently lasted for about two years. These circumstances possibly favour acceptance of her statement about current method use, while accepting the husband's account as indicating an intention to use some method (possibly injection) in the near future. It is clearly difficult to accept either statement fully.

The case of household 017 , where the woman said that her husband had had a vasectomy but the man said that his wife had received a treatment from a kabiraji to make her sterile, has been discussed in Chapter 4.

In the next case, the woman's account appears to be more accurate simply because there are clues in the man's story that accord with elements of his wife's version. She says that they are using the safe period method in conjunction with azal, while he claimed that he had never heard of these methods and so locked himself into an interview in which he attempted to imply that they were using the contraceptive pill.

F025 (22 years old, 2 children ever born): - (How the safe period method works) ... The days before the beginning of menstruation are safe. Ten days after the menstruation is over, conception takes place if one 'meets' [has intercourse] with one's husband. Only the last few days are safe. ... (Reasons for using more than one method) ... Husbands do not maintain patience while following the counting of days method. ... (Advantages/ disadvantages of azal) ... Azal does not cause dizziness [as the pill does]. It is much better to practice it. Use of pills also prevent birth but azal' is better to me. It is more safe. ... (Advantages/ disadvantages of safe period) ... No baby will be born if the safe period method is followed. The pill is more safe, but it doesn't suit my health. So, I follow the counting of days method. ... (Extent of discussion with husband) I can discuss all matters with my husband. We can't discuss about the cutting of abdomen [sterilization] and Copper-T. People see the place of child birth [if these methods are adopted]. It is a matter of shame. It can't be discussed. ... My husband told me [about the safe period method and azal]. My husband also told me to take pills. But I said that pills cause dizziness. Then my husband told me to use this method. Had my husband told me to take pills, I would have used pills. ... My husband listens to me. We two are using azal. I would have used another method had my husband told me. ... My husband listens to me. I also listen to him.

M025 (30 years old): - (Discussion about number of children) Discussion is held [between us]. We will not increase the number of children in the family. I am a normal [poor] person. I don't have enough landed property. I could not increase the property which I inherited from my father. So, what shall I feed them if more babies are born? ... Yes, discussion is held occasionally. We, the husband and wife, discuss how we can keep the family size small. ... The family planning workers say, 'Don't increase the number of children any more. Take pills. Your expenditure will go high if you expand your family.' My wife again tells me all these things. ... I start discussion [on limiting family size]. What shall I feed if many children are born? How shall I maintain the family? How shall I provide them clothing? I have no income. So, I said that we shall have to keep the family size small. ... (Male involvement in family planning) It is necessary to have discussion between [husband and wife]. My wife says that she wouldn't have another baby. I also hold the same opinion. ... My wife says that it would be better if another dose of injection could be taken. The price of injection is four or five hundred taka. [Name of FWA] supplies pills. If I ask my wife whether she has taken the pills, she replies in the affirmative. ... (Reasons for method choice) [Name of FWA] doesn't give any other thing. So, I take pills. The other things are required to be bought from the market with money. Pills work for the prevention of birth. I am getting benefit by using it. ... 
There is not that much of a problem. However, one feels dizziness in the head when pill is taken. ... The pill is not to be bought with money. It is supplied free of cost. However, a lot of money is needed to buy injection.

It does seem that the man would prefer his wife to be taking oral contraceptive pills, which is what he told the interviewers they were using. The woman has possibly used them, as well as injectables, for notice the man's reference to his wife wanting 'another' injection. However, she says that pills cause 'dizziness', and the man also refers to that. It seems improbable that she would construct an elaborate tale of use of the safe period in conjunction with azal unless it were true. Notice also the occurrence in this interview, extremely rare, of reasonable knowledge of the timing of ovulation, but coupled with a very broad reckoning of the at-risk period during the monthly cycle. This pair of interviews illustrates that incompatible accounts can be given by a man and woman who communicate well on family planning matters. The incompatibility of the accounts could be because the man would prefer to be using pills rather than the safe period and azal but he is going along with his wife's preferences.

On several previous occasions, a theoretical but not actual use of a method has featured in explaining the differences between the accounts given by the woman and her husband. In the following case, the man makes it very clear that he has abstained from sexual intercourse with his wife for several years. The woman says she is using the safe period method. Taken together, the two accounts indicate that if they were having sexual relations, they would be using the safe period method.

F028 (39 years old, 3 children ever born): - (How the safe period method works) I haven't observed [physical changes associated with ovulation]. I follow it of my own idea. I have lot of illness. So, I can't understand any symptom. ... I follow this as my husband wants it. I am not having any problem. If this method is used, one can prevent birth as long as one wishes. ... The first ten days of menstruation [from the beginning of the menstrual period] are more safe. I don't consider the later part as safe. During the beginning I think that menstruation has just ended, so there is no chance of having any baby now. At the end I begin to wonder if the way I am following the method is correct. So, I become doubtful. ... (Advantages/ disadvantages of safe period) ... I have been using this method and I hope to continue as usual. I think that by using this method we can prevent birth as long as we wish. ... (Extent of discussion with husband) I can't discuss everything. I feel shy about discussing family Planning. But I told my husband about the following of days method. I talked about the cutting of the abdomen [tubal ligation]. My husband told me to have my abdomen cut. I didn't agree to get my abdomen cut. ... I have given my ijjat [chastity] to my husband. So, why there should be shyness to discuss about methods? I can discuss everything with him. ... My husband told me to have my abdomen cut. But I didn't agree owing to fear. Then I told him about the following of days method. He agreed [to adopt it]. ... Whatever method I wanted to use, my husband agreed to that. He didn't forbid me.

M028 (47 years old): - (Discussion about number of children) No. Discussion of this sort was not held. ... No. My wife doesn't tell me anything about that [meetings with FWA]. I had no discussion with her. ... (Male involvement in family planning) Yes, there should be arguments and suggestions. She may tell me, 'I shall have to take the pill'. Then I tell her, 'Do whatever you deem proper'. My wife says, 'The counting of days method prevents birth. So, we should adopt the counting of days method.' ... (Advantages/disadvantages of safe period) ... This method should be adopted from the beginning [of the marriage]. I had not used this method in the beginning. I made a mistake. ... (Reasons for method choice) The current method we are on is abstinence. The present age of my youngest baby is five years. When my baby was one year old, my wife menstruated and my baby was breastfeeding. Since 
then I have had semen-related problems. So, I don't mix [have intercourse] with my wife since then.

There is no basic disagreement between this man and woman. Notice that the discrepancy between theory and practice in the woman's account would not be an issue if she was using a less direct method of family planning (such as oral contraceptive pills) in case she resumed sexual relations with her husband. She would simply be regarded as a pill user. Notice also that the man should not really be classified as using abstinence as a method of family planning, because he says that he is abstaining from sexual intercourse for reasons related to some physiological problem, not to avoid having children. Classification as a user of the safe period method seems unsatisfactory, but classification as a user of abstinence is also unsatisfactory.

In the following pair of interviews, the woman says that they use azal and she has never heard of the safe period method, but the man says that he uses the safe period method.

F031 (32 years old, 3 children ever born): - (Advantages/disadvantages of azal) ... My husband is a huzur [religious teacher]. People will criticize us if they come to know that we have taken a method. So, we have adopted this method [azal]. No one knows if this method is taken. ... My husband goes out and he learns from there. [Name of FWA] also tells me about this method. Its use prevents birth. ... If this method is followed, one can prevent birth as long as one wishes. It seems to me to be safe. ... (Use of family planning before having children) ... After marriage it is better to use the 'Raja' [brand name] condom before any birth. The 'Raja' condom is safe. There will be no problem if it is taken. ... The women visit every household and supply pills. But it cannot be taken in the presence of all, I feel shy. It will be better if my husband brings it. No one can know. My husband brings it if I tell him to bring. ... (Extent of discussion with husband) Why there should be shyness with my husband? I tell him everything. ... [Name of child]'s father heard about it from outside and then he told me [about azal]. He told me to take pills and take injection, but I didn't agree. So, I have taken this method. It is difficult to feed and clothe if there are too many children in a family. ... My husband told me to take injection and pills. I didn't agree. So, my husband drops matter outside. Both of us agree to use this method. ... I said to him, 'I am the wife of a huzur. People will speak ill of me if I use these [program methods].' Then my husband told me about dropping matter outside. He said that no baby is born if it is dropped outside. If no seed is sown in the field, can there be crops in that field? ... My husband told me at first about the use of this method. Both of us decided to use this method unanimously.

M031 (37 years old): - (Discussion about number of children) Yes, discussion is held [with my wife]. Since Allah has given us only three daughters we will use family planning methods so that no more baby is born in the future. Whatever Allah does, it is for our benefit. There may be some blessing in giving us three daughters. ... Yes, we discuss that no more baby should be born. We discuss which method may help us in preventing babies. ... My wife is illiterate. If I ask her on my own, she says, 'No more baby should be born. So, tell me about family planning methods'. ... I initiate the discussion. For example, when the family planning apas [FWA/FWV] come, I ask my wife, 'Tell me, what did they say?' Then based on that discussion, we talk about the acceptance of family planning methods. ... (How the safe period method works) ... I have heard from a village doctor that if there is no 'mixing' [intercourse] during this period, there is hardly any chance of conception. So, I believe in this method. ... The remaining days after the 25th day of the menstrual cycle are safe. ... (Male involvement in family planning) As we don't want any more babies, it is better for us to 'meet' at a fixed time [use the safe period method]. ... Both of us decided that we will fix the time and 'meet' at that time. ... (Advantages/disadvantages of azal) 
According to religion one can adopt azal if the wife gives her consent. But my wife doesn't agree in this regard. So, I don't adopt it. ... If followed properly, azal is safe. ... (Advantages/disadvantages of safe period) ... It is ninety-nine per cent safe. It prevents birth.

The strangest aspect of the accounts is the reason given by the man for not using azal, namely that his wife does not agree to use it. The very conservative version of the safe period method mentioned here is probably an indication that both the man and the woman are correct, but their disclosure is incomplete.

The same combination, azal mentioned by the woman and safe period mentioned by the man, appears in the next case of disagreement about method being used. The circumstances are quite different from the previous example.

F040 (25 years old, 2 children ever born): - (Advantages/disadvantages of azal) ... [Name of FWA] tells about this method. She says that if it is used, no baby is born. She doesn't say anything more. ... If properly followed, no baby is born. One can't always be careful. A baby may come if this method is used. so another method should be used to prevent birth. ... (Advantages/disadvantages of safe period) ... The counting of days is not a safe method. A baby may come into the belly if this method is used. If the pill is taken, one may be sure that no baby will come into the belly. One can understand if any mistake is made. But if there is any mistake in it [the safeperiod method] it is difficult to understand. ... (Extent of discussion with husband) My husband talks first. I can't say anything. I feel shy. If my husband talks first, then I can discuss also. Then I don't feel shy. ... Everything may be said to my husband. But I can't initiate discussion. If he raises a topic then I don't feel shy to discuss it. ... I take pills. But I have taken this method [azal] for not having a supply of pills. I have a baby in my lap. Will it not be a problem if another baby comes quickly? To rear up two children at a time is troublesome. For this reason, I have discussed with my husband about this method. ... My husband's opinion is more important. I have no pills. So, my husband has told about this method and I have consented to that. ... My husband said that if the semen is dropped outside, no baby is born. A condom may burst during use. As I do not have pills with me for the last few days both my husband and I have taken this method together. ... My husband told me [what to do]. I also hold the same opinion as my husband. Whatever method we take, we both decide together. ... (Reasons for switching from program method) The pill prevents birth. At the same time, the one which I am using [azal] also prevents birth. Because of not having any pills, I am using this method. ... My stock of pills is exhausted. Those who supply pills are not at fault. Some days ago they asked me whether I need any pills or not. I said that I had pills and I would not need pills. The woman supplies pills. Her round is not yet due. So, it is not her fault. ... The woman who supplies pills comes regularly. She follows up. She wanted to give me pills. But I didn't take them. So, they are not at fault. My husband is following the method [azal] because I do not have pills.

M040 (34 years old): - (Discussion about number of children) Yes, discussion is held [between us]. I am a poor man, with limited land. If many children are born, it requires a lot of expenses for their marriage and for their food. It creates hardship. So, those two children are enough for us. ... We discuss the issue that we will not take many babies. ... My wife doesn't tell me [what family planning workers say].... I start discussion myself. Suppose I come back from the market and see that money is short. Then I tell my wife, 'Look, I can't bear the expenses for these two children only. If any more babies are born, how can I feed them?' So, we won't have another baby. ...

(How the safe period method works) When there is the chance of conception, at the end of that period she speaks of the need for 'meeting' [intercourse]. At that time she 
is a little hot tempered. She speaks less. ... I believe in this method, because I have used it many times and found that birth is prevented. ... The last few days of the menstrual cycle are safe, because during that period any semen which will enter into the vagina during meeting will be useless, because it will come out with the next menstruation. This is what I think. ... (Male involvement in family planning) Whichever method is taken, it is taken with the consent of both of us. After arguments and counter-arguments by both of us, I have used this method with her consent. ... Both of us discuss and decide which method we should take. With the consent of both of us, we are following the counting of days method. ... (Advantages/disadvantages of azal) ... What my wife wants is not fulfilled completely. She doesn't get full satisfaction. It also prevents birth, because semen is not entering into the womb. ... (Advantages/disadvantages of safe period) ... The following of days means prevention of baby and prevention of baby means the benefit of the family. If followed properly, it prevents birth. ... (Reasons for switching from program method) ... There is nothing to spend. It is available free of cost. Because of family needs, my wife could not go on the due date. So, at present we are following the counting of days method. There is no other reason. ... We have no problem in getting supplies. The family planning worker supplies methods every month, but then [sometimes] she comes after three or four months. For this reason, we were delayed by a month to take the injection.

While they agree that they recently switched from a program method, they also disagree on which program method it was. The man's story about injectables would be credible only if cluster visitation was in use in the area or the family planning worker was from an NGO which gave doorstep injections, because otherwise getting another injection would not be dependent on being visited by the FWA. The woman's story about the FWA's visits is just as confusing. Why did she tell the FWA that she had an adequate supply of pills when she did not? And just how recently did these things occur? One suspects that if they had indeed used program methods, it might not have been as recently as they both claim. However, as in other instances it is reasonable to conclude that if both azal and the safe period method are mentioned by respondents, then both methods are actually being used.

In the next example, the man and the woman agree that they have been following the safe period method, but the man claims to have switched over to use of pills.

F045 (20 years old, 1 child ever born): - (How the safe period method works) ... I think that at any time a baby may come. I have been using [the safe period method] for the last 19 months. Many a time if it is not followed properly, a baby may come into the belly. Sometimes, while following counting of days, the husband wants to meet during that period when meeting with the husband is prohibited. So, it becomes difficult to follow. ... (Advantages/disadvantages of safe period) ... Everybody's sex drive is not the same. Somebody's demand is less, somebody's is more. It is better to use this method soon after marriage. But there are many people who want to delay childbirth. So, while following this method, if a baby comes into the belly, they will retain it. ... I have learnt about it from the book Swami Strir Milon (Sex between Husband and Wife). ... Those who supply pills do not say anything. ... Just as the other methods [pill, injection] are safe, if properly followed one can prevent birth as long as one wishes by using this method also. There will be no problem. ... (Extent of discussion with husband) Soon after my marriage my husband bought me a book named Swami Strir Milon (Sex between Husband and Wife). I knew about it from that book. Since then I can talk about everything [to my husband]. I have no problem about that. ... I can say everything. Why should I be ashamed in front of my husband? ... After the birth of one baby my husband told me that we would follow the counting of days method so that we might delay the next baby. I consented to his proposal. ... I 
wanted to delay the next baby. I have a little baby in my lap. If I delay the next baby, I can look after the baby in the lap properly. When this one grows up, we would not need to labor hard for our child. If we take a baby at that time, we would be able to take proper care of it. ... I discussed with my husband about the use of injection. I had a discussion with my husband on the issue that breast milk dries up due to the use of pills. And I have discussed whether there is any health hazard due to the use of counting of days method.

M045 (38 years old): - (Discussion about number of children) We seldom hold any discussion about this. We have only one son. We discuss that this one son is enough for us. Both of us hold the same opinion. So, we discuss as to which method may be used. ... She [the FWA] comes. My wife doesn't tell me what she says. ... Look, she [my wife] has no thinking. Whatever I say, she agrees. I start any discussion. ... (How the safe period method works) My wife didn't have regular menstruation before [post-partum amenorrhea]. Now she is menstruating regularly. Well, some [physical] change must occur [during the at-risk period]. When a cow is on heat, it will naturally go to an ox. She wants to 'meet' [have intercourse] more frequently at that time. But I remain alert. ... It is $100 \%$ safe if the safe-period method is properly followed. ... (Male involvement in family planning) Sometimes we discuss the use of a method. We are using a method by discussing among ourselves. Has it [your question] any answer? Well, the answer is to follow the method. ... Yes, this method could not be used without the cooperation of the two of us. To follow this counting of days method, the cooperation of two is necessary. ... I don't act on the advice of others. I act on my own decision. ... (Advantages/ disadvantages of safe period) ... Following of days is the best method. The pill doesn't suit many people. This method is better for them. I don't understand any more. ... (Reasons for method choice) It [the pill] is safe in the educated families. If taken regularly no damage is done. ... There is no disadvantage. It has advantages. It will do if one pill is taken everyday.... The expense is little. At present three strips cost Tk.10/= only. ... It is available from the shops, hospital and the family planning workers. ... Even in the land registration stamp papers, the government has inscribed 'Son or daughter, two are enough'. We are satisfied with the services the government is rendering. ... I buy [the pills]. No problem is caused. ... In the beginning the use of pills causes dizziness. It becomes OK later on. ... (Use of family planning before having children) ... At first a baby should be born. Then methods may be used for four or five years and again another baby may be born. ... (Reasons for switching from traditional method) The use of the pill is safe. Following and counting days is not always possible. ... It serves the purpose if one pill is taken daily. There is no other problem. It is very difficult to follow the counting of days method. Many a time, one can't 'meet' in spite of one's desire for meeting. ... There is no problem now. There was slight dizziness in the beginning. ... What does it have to do with the attitude of my wife? Whatever I say, that will be all right.

A possible explanation for the discrepancy between these accounts is that the man was seeking to answer questions in the way that he believed the interview team wanted them answered. At one point he was asking the interviewers what the answer should be! It is quite possible that he believed that the interview team, like other people who come to talk about family planning, would want to discourage use of traditional methods. His way of coping with this was to say that he had recently abandoned the traditional method. This is speculation, but do notice that he is far more sanguine in his praise of the safe period method than he is about the pill to which he supposedly switched. From his account of his interactions with his wife, it does seem that he has serious communication difficulties, to put as favourable a light as possible on his attitudes. Yet he was sensitive enough to have given her a book which explained to her how her body worked. 
Genuine lack of disagreement is welcome after the previous few cases. In the following example, the woman says she is using pills supplied by a homeopathic practitioner, but the man is not quite as specific so his answers were taken to refer to the usual oral contraceptive pill.

F051 (22 years old, 2 children ever born): - (Extent of discussion with husband) If I fail to tell anything to my husband, then to whom will I say it? If I face any problem, I tell it to him first. ... To whom else excepting my husband shall I tell about the advantages and disadvantages of the family? I don't feel shy discussing family planning with him. ... My health is not good now. After the birth of my youngest baby I went to a [village] doctor. He told me that as I had a baby in my lap and I was physically unwell, I should not have another baby. He told me to see him when my menstruation returned. After menstruation I went to him. And my husband also told me to use method. ... My husband told me to use a method following advice from a homeopathic doctor. Both husband and wife took the decision together. ... I am physically weak. I went to a doctor who told me that I would suffer from health problems if I had another baby then. He said I wouldn't be able to tolerate injection and Maya Bori [contraceptive pill]. He gave me homeopathic medicine. ... I told my husband, 'The doctor has told me not to take pills and injections. My health may worsen if I take these medicines. So, the doctor has asked me to take homeopathic medicines.' My husband said, 'If the doctor has asked you to take homeopathic medicine, well, you can take it.'

M051 (32 years old): - (Discussion about number of children) That [discussion] is held. These two sons are enough for us. We will not have another baby. She is taking pills so that no more baby is born. ... It [what is discussed with the FWA] is their affair. They just say, 'Take pills. Please come to the Kholshi hospital.' ... I initiate discussion. We say that these two are enough. Let us rear up these two well. We will look after ourselves. ... (Male involvement in family planning) Both of us decided together that we would not have another baby. So, we would need to use family planning methods. For this, she is taking pills. ... I enquire if she takes pills regularly. When then are no more left I bring them from a doctor. Both of us discussed before taking this method.... (Reasons for method choice) The apas, who are government workers, came to our house and told [my wife] to go to the clinic to get a Copper-T. But it doesn't suit everybody's health. So, I have told her to take pills. She is taking pills still now. ... Taking of pills prevent birth. The only problem is that it has to be taken every day. ... It requires Tk.10/- if bought from the market. The government workers supply it free of cost. If at any time they discontinue supply, I purchase [the pills] from the bazaar. ... They are available from the hospital. clinic, bazaar and from the government apas. ... Taking of pills causes dizziness. But I have heard that they work as vitamins.

The man in this case seems to make no distinction between 'government' pills and those available from homeopathic practitioners, whom he does not even mention specifically. There is a degree of dissimulation in his story. The reference to the effect of pills as 'vitamins' discloses his interest in alternative medicine. A very similar case is discussed later (household 099).

It is difficult to reconcile what the man and the woman say in the following case. The woman says that she is using both azal and the oral contraceptive pill, for some unspecified reason, while the man says that he is using the safe period method.

F072 (26 years old, 5 children ever born): - (Advantages/disadvantages of $\boldsymbol{a z a l}$ ) ... If the husband can drop [his semen] outside properly, one can prevent birth as long as one wished. But if the husband fails to follow [the method] properly then there is 
every chance of conception. For this reason this method seems to me to be less reliable than the other methods. ... (Reasons for method choice) I am taking pills so that a baby doesn't come into my belly. If I take pills, I can prevent birth as long as I wish. If my husband fails to drop his semen outside properly then a baby comes into the belly. ... I am taking pills as it doesn't cause any damage to my health. My health has improved due to the use of pills. ... (Extent of discussion with husband) I can discuss with my husband all about family planning. I don't have any problem. Why should I feel shy of talking to my husband. ... The worker [FWA] told me to take pills. I told my husband that the woman who supplies pills asked me to take pills. My husband said to me 'You can take it and see what happens. If it is suitable for you, you can continue it.' Since then I have started taking pills. ... Both of us took the decision together.

M072 (31 years old): - (Discussion about number of children) Discussion is held [between us]. We will not take any more babies then we already have. We are ruined. Our children will make it up for us. We will not have another baby. We will bring these children up. There will be poverty in the family if there are many children. ... She [my wife] talks about family planning methods. She tells me to have fewer children. She says that our condition will be miserable if many children are born. She says 'You already have four children. Please don't have any more children.' ... The woman starts [discussion]. She tells me by the by. For example, the family planning workers come and whatever they say, she discusses it with me. The condition of the country is bad, it is not good. If many children are born, a lot of problems will be there in the family. So, a method needs to be taken. ... (How the safe period method works) ... I have full faith in it. It prevents birth. I am continuing to use it still. ... The last days of a menstrual cycle are more safe. I can't tell you the reasons. ... (Male involvement in family planning) My conviction is that a method should be taken by discussing it with my wife. ... I follow the counting of days method properly. I enquire if she has proper account of the counting of days method and she gives me the information. We have adopted the method by discussion with each other. ... (Advantages/disadvantages of azal) ... Methods [of family planning] may be used after the birth of at least one or two children. But our condition is different. I couldn't understand that much [when I was younger] and to get one daughter I have had four children. ... I consider it safe also. Because if no semen goes inside, no baby will be born. ... (Advantages/disadvantages of safe period) For those who can follow it properly, there is no problem, it is safe for them. There are some people who are more foolish than us. This method is not safe for them. Because they can't follow it by counting days properly.

A possible explanation of these conflicting statements is that the safe period method is the first method that the husband says he adopted, and he is 'continuing to use it still'. The version of the safe period method which they used no doubt included habitual use of azal in the at-risk period. There is no reason to doubt the woman's story that she has now taken to using oral pills to avert the possibility of any more births.

In the next example, the man and woman indicate a very cooperative attitude to each other, but the woman says she is using azal while the man says he is observing the safe period method. As noted in other examples, the explanation for cases like this is that they are both talking about a single aspect of what they normally do each month. One reason for thinking so is that the man's version of the safe period method identifies only the last week of the menstrual cycle as safe, and another reason is that while the woman has heard of the safe period method, her knowledge of the location of the safe period in the cycle was incorrect.

F074 (28 years old, 4 children ever born): - (Advantages/disadvantages of azal) This [method] may be practised any time after marriage and no problem is caused. ... 
If pills are taken other people come to know of it, children may also know it. This is a matter of shame. But if this method is adopted other people and children will not know of it and hence there's no shame in it. ... If the husband practises withdrawal, pregnancy may be prevented. Like pills it also prevents pregnancy as long as one wants. ... (Advantages/disadvantages of safe period) [This method] should be adopted after having two children. At that time, if the husband is asked to abstain from sex, he listens to the request. Immediately after marriage, the husband does not like to follow safe period. ... If the safe period method is followed, children cannot know of it. It can be observed secretly. ... The little bit that I know [about the safe period method] is enough. I don't want to know more. ... It's a matter between the husband and the wife. If followed correctly, it can prevent pregnancy as long as one wants, like pills and injections. ... (Extent of discussion with husband) I can initiate discussion with my husband. To whom can I speak, if not to my husband? ... I can discuss all methods for family planning with my husband. There's no shame in talking to the husband about these things. ... Pills cause me dizziness, if I put on Copper-T, I feel a burning sensation in my womb. For this reason, my sister-in-law has suggested withdrawal. I told my husband to practise withdrawal, and he has adopted it. ... We took the decision together. ... I suffer from dizziness and vomiting if I use pills. If a Copper-T is inserted, I feel a burning sensation in the womb. Then I discussed the problem with my sister-in-law who suggested withdrawal. I shall have no more babies so that the size of my family remains small. Since I can't stand other methods, I have decided to adopt it. ... I have told my husband that I have dizziness if I take pills and I feel a burning sensation in my womb if Copper-T is inserted. I discussed with him what method should be adopted. I told him about withdrawal which we have adopted. ... (Reasons for switching from program method) If the husband follows the method of withdrawal, pregnancy can be prevented as long as one wants, it's as effective as pills and injections. ... If a Copper-T is inserted, it causes a burning sensation is my womb, if I take pills, dizziness is caused. But withdrawal which my husband practices does not harm my health. ... The Copper-T and pills do not suit me. How do I gain by blaming others [family planning workers]? They do what is possible for them to do. So, I am satisfied with them. ... I had dizziness when I took pills. A Copper-T was inserted but during menstruation I bled too much; so I took away the Copper-T myself [at my own initiative?]. Now my husband practises withdrawal and I don't have any trouble because of it. ... Government methods are not suitable to me. So my husband agrees with me in his use of this method [withdrawal]. M074 (41 years old): - (Discussion about number of children) We discuss it. I say we shouldn't have any more babies. Let us be happy with what we have. She also has the same opinion. They must be properly brought up. We have four children in all and should bring them up properly. So, we shall have to adopt a method. ... She [my wife] initiates the discussion. She says that if we had had a son first, we would not have had so many children. We had to have three daughters and lastly a son. Now we shall have to bring them up and have no more children. We have to adopt a method. ... (How the safe period method works) She shows greater eagerness to 'mix' [have intercourse] [during the at-risk period]. At that time she is full of endearment and becomes affectionately attentive to me. ... I believe it is quite effective. I've been using it for the last five years, never faced any problem and pregnancy has been prevented. I believe it is $100 \%$ effective. ... The last week of the menstrual cycle is very safe. Why? I can't say. ... (Male involvement in family planning) We adopted a method after mutual consultation between the two of us. I observe whether she faces any physical problem for adopting a method. She vomited when she was taking pills, so that was then discontinued; then I used condoms for some time. Now we observe the safe period. ... (Advantages/disadvantages of azal) I consider it safe because semen does not go inside. ... (Advantages/disadvantages of safe period) Pregnancy 
can be prevented if days are properly observed. I rely on it $100 \%$ because I have been following it for the last five years. I have not faced any problem.

As is usual in these interviews, repetition of a point results in subtle changes in what is being said. In this case there is quite a sudden change in what the woman says about the problems that she had with IUDs. Several times she said merely that it caused a 'burning sensation' in the womb, but right at the end of discussion about these topics, the story changed to one of excessive menstrual bleeding, accompanied with the startling statement that she removed the IUD herself, although her meaning was possibly that it was removed at her own initiative.

The case of household 078, where the woman said that her husband had had a vasectomy but the man said that his wife had received a treatment from a kabiraji to make her sterile, has been discussed in Chapter 4, as a conventional explanation of vasectomy.

In the next example, the woman says that they use azal but the man says that he has never used azal and instead uses condoms. Apart from this fundamental difference, their accounts are very similar. The accounts provide support for suspicion that bursting condoms is code for uncontrolled azal.

F088 (33 years old, 2 children ever born): - (Advantages/disadvantages of azal) ... The attraction between husband and wife remains strong in the beginning of marriage. Many men can't check themselves. So, this method can't be adopted during that time. When one or two children are born, the attachment between husband and wife reduces. This method may be used at that time. ... The use of this method is convenient. But the use of any method is not shameful. All people are adopting family planning. ... It seems to me that so long we shall be able to check [ejaculation of] semen, we shall be able to prevent birth. Like the other methods birth may be prevented if my husband drops [the semen] outside. ... (Extent of discussion with husband) After marriage I felt shy of talking about [family planning] methods. But now I can start discussion first. ... I don't feel shy of talking to my husband about family planning methods. I can discuss everything. ... After the birth of our son, when we decided to prevent birth, at that time my husband told me to take pills. I didn't agree. He told me to use injections. I have heard from women that excessive menstruation takes place if injections are taken. So, I didn't agree to take it. Then my husband said, 'Well, what else can be done now? Now I shall have to drop semen outside.' I also told my husband to use this method. ... My husband and I agree fully in the use of this method. However, I didn't agree to use any other method. Afterwards, both of us decided unanimously to use this method. ... I used to take pills. But my 'gastric' increases when I take pills. I have heard people saying that menstruation takes place twice or thrice a month if the injection is taken. My husband told me to take injections, but I didn't agree. Later on we, both husband and wife, decided to adopt this method [azal] after discussion. We can't rear up our children as brilliant people if many children are born. For this reason, we have adopted this method. ... My husband told me to take pills and use injections. I told my husband, 'I have gastric, so I can't take pills. I shall not take injection as menstruation occurs twice or thrice every month if injection is taken. So, I shall not use any of these.' At that time my husband said that then there is no alternative to dropping semen outside. We didn't have any discussion on any other subject. ... Whatever method I like to take, my husband holds the same opinion as me. My husband told me to take pills and injection but I didn't agree. Then my husband proposed to drop [semen] outside, and I agreed. ... (Reasons for switching from program method) As with pills and injections, babies don't come into the womb if the husband drops [semen] outside. This method is safe for preventing birth. ... I have been suffering from gastric. It may be aggravated if I take pills. For this reason, my husband drops semen outside. It 
doesn't cause any harm to me. ... My husband doesn't like the pills supplied by the government. My husband is of the opinion that pills which are purchased from the market are better. For this reason, I have never taken pills from the family planning workers. But I am not dissatisfied with them.

M088 (43 years old): - (Discussion about number of children) We have discussions [about this]. We say that we have already had two children. We have to rear them up well. We shall not increase the number of the children. My wife doesn't want any more child. What is the necessity of having another baby after having two? ... The FWAs come to our house. But my wife doesn't tell me what they tell her. I also do not get the chance to listen to that. ... My wife starts discussion [with me]. She says that we don't need another baby. We shall have to rear up these two properly. I also hold the same opinion. Both of us have taken the decision that we would not have another baby. ... (Male involvement in family planning) The husband should also participate. To maintain peace and order in the family the opinion of both in respect of giving birth to children should be given importance. ... My wife would suffer from nausea and dizziness after taking pills. Then she became reluctant to take any more pills. Then we both consulted and I started using condoms. ... There is no [religious] bar. Because I have accepted the opinion of my wife and my wife accepts my opinion also that we want to adopt this birth control method. ... (Advantages/disadvantages of $\boldsymbol{a z a l}$ ) Well, what is the necessity of dropping semen outside? ... As I haven't used this method, I can't certify its effectiveness. ... (Reasons for method choice) The condom is safe for the prevention of birth. I am getting the proof. ... The advantage is that it prevents birth. The disadvantage is that it may sometimes burst if people are not careful. ... It is available in the market and in the shops. I buy 10 'Panther' [brand name] at Tk. 5.00 from the market. Because of shyness, my wife doesn't take it from the field workers. ... There is no side-effect in [use of] condoms.

In the next case of disagreement between the woman and the man over which method of family planning they are using, not much interpretation is necessary. The man is a 'village doctor' and the woman actively assists him. Both are knowledgeable about family planning methods, and agree on what methods they have used. The difference is in whether they are currently using oral pills, as the woman says, or whether they are using what the man describes as azal and condoms but which also contains elements of the safe period method.

F093 (29 years old, 2 children ever born): - (How the safe period method works) ... If we think that we won't use pills, then we can follow the method of counting days. And [that way] we can prevent birth as long as we wish. ... (Advantages/disadvantages of azal) ... [Immediately] after marriage this method cannot be used. After the birth of a child semen can be dropped outside. This is because, after marriage, the attraction between the couple is something different. And after a baby's birth the attraction between husband and wife diminishes. Then it is better to drop the sperm outside. ... While dropping the semen outside, some portion may enter into the wife's body. But the pill is safer, this prevents pregnancy. ... (Advantages/disadvantages of safe period) Our religion [Hinduism] asserts that the method of following days is good, because this method keeps health fit. ... It is not possible to maintain [counting of] days [immediately] after marriage. After the birth of one or two babies, the tendency is changed. Then it can be maintained at that time. ... Everything depends on attitude. If I decide that I will not have another baby, then I can prevent pregnancy by using this method. But the pill is safe. The safe period method is not as safe. ... (Reasons for method choice) The pill is more secure than maintaining days. If the pill is taken one can be free from anxiety. Is it possible to prohibit the husband [from having intercourse] for so many days? ... No problem is caused by taking pills. The safe period method also does not cause any health problem. Even I have not found any problem from taking pills. ... I don't have to go 
anywhere to get the pills I am getting them delivered at home [from the FWA]. So I am satisfied with them. ... If the injection is taken, it is mixed with the body. The Copper-T is not liked by me. The pill can be used at any time I didn't find any problem. ... (Extent of discussion with husband) If needed, I can discuss family planning method with my husband. ... I can discuss everything with my husband. There is no problem in discussing with him about family planning methods. ... My husband asked me to use a Copper-T, but I didn't use it. Then he asked me to take injections but I didn't. Later he told me to take pills, which I accepted. I like the pills most. The pill is my favourite. ... We both decided that I will take pills. I am taking pill now to delay the pregnancy. It is not possible to maintain the safe period regularly. I will not be able to bring up the children properly if I have many babies. My health will be affected if I give birth to many babies. If the pill is taken one can be free from anxiety. The pill is safe. ... My husband has discussed with me about all the methods. I said that I will take the pill and he has given me his consent. ... (Reasons for switching from traditional method) The pill is safer than the safe period method. It is not always possible to follow the safe period. So I take pills. ... No problem is caused due to using pills. One can be anxiety free if the pill is taken. It is not possible all the time to follow the safe period. The husband does not want to agree [not to have intercourse].

M093 (38 years old): - (Discussion about number of children) We discuss this. [We agree that] it is good not to have babies anymore. You know, the condition of the country. But we haven't decided yet whether we will have another baby or not. I have two houses, so I want another son. At present I have a son and a daughter. ... I am a [village] doctor and my wife is a half doctor. She herself gives prescriptions of the women. For this reason, family planning workers don't tell her much. My wife herself knows this. ... (Reasons for using more than one method) Sometimes I use condoms and sometimes I use azal. In the time of maximum risk I use condoms. But if no condom is available in my home, I use azal. There is no amusement in using condoms. But nothing can be done about it. A method must be used for the prevention of births. ... Condoms should be used for the first fourteen days after menstruation. After that time a condom can be avoided. But we use them anyway. Because out of the whole month, at any time a baby may come into the womb. ... (Male involvement in family planning) Assistance [from the man to the woman] is needed. A method should be used according to our joint opinion. For example, when my wife was getting problems from taking pills, I started using condoms. Again sometimes I use azal. ... After discussion we adopt a method considering our physical condition. ... (Advantages/disadvantages of $\boldsymbol{a z a l}$ )... Azal has no disadvantages that the condom and pills have. It keeps one's health good. Sometimes there is tension because of misuse of the method. ... This should only be used mostly after having one or two children. Because in the beginning [of the marriage] it is not possible to ask. This should only be used at a later age. ... Azal prevents birth. But there remains suspicion. Again there can be many mistakes. But as for the problems which are caused due to the use of pills and condoms, azal does not give such problems. It causes no physical harm. ... (Advantages/ disadvantages of safe period) ... It is not possible for a newly married couple. It can be used after one or two babies are born. ... This method gives more comfort than the condom. I think this is $90 \%$ unsafe, because they [users] may not follow the calculation [correctly]. ... (Reasons for method choice) Birth can be prevented by using condoms. I had problems in using pills. Pills and injections are much better for the prevention of birth. But my wife had problems in using pills, so I use condoms. ... Physical problems are caused due to the use of pills but condoms do not give such problems. But a condom gives less amusement. One's wife sometimes feels uneasy. ... My wife had a problem from taking pills, she suffered from gastric and a tendency to vomit. For this reason I am using condoms. 
It seems that the likely reason for the disagreement is that the man simply did not know yet that the woman had resumed taking pills, being even less trusting of 'traditional' and direct methods than he was.

In the next case, the woman says that she is using condoms after giving up the use of pills, but the man said he is using the safe period method, which his wife distrusts utterly.

F094 (21 years old, 2 children ever born): - (Advantages/disadvantages of azal) ... Everyone says that the withdrawal method prevents birth. But I think birth is not prevented by withdrawal method. If it prevented birth, then all these methods would not have been introduced. Everyone would have adopted the withdrawal method. ... (Advantages/disadvantages of safe period) ... It is my belief that the safe period method cannot prevent birth. That is why I do not want to know [anything about it]. ... Conception may occur during the safe period. But use of pills and condoms is safe. They prevent birth. ... (Reasons for method choice) Both pill and condom prevent birth. ... Physical weakness and dizziness occurs if the pill is taken. So, we are using condoms. ... (Extent of discussion with husband) ... At first my husband told me to take pills. I face problems if the pill is taken. So, my husband said, 'Then I will use condoms'. I agreed. After that my husband is using condoms.

M094 (30 years old): - (Discussion about number of children) Not much discussion was held. Allah has given us two daughters. And whatever Allah wishes will happen. What else is there to discuss? ... [My wife] says that they [FWA/FWV] have told her, 'You have two daughters. Do not have any more children. Adopt any method [you like].' ... My wife starts the discussion. For example, when workers visit our home she says that they [FWA/FWV] came and advised to adopt a method. And all other people tell us, 'You are very lucky that you have only two daughters. Why should you have any more children?' But I say that whatever Allah does is good for us. ... I have a wish in my mind that Allah will bless me with a son. I will rear him up properly and educate him. How far can daughters be educated? ... (How the safe period method works) ... It is safe. It is advantageous if it can be followed. Conception will not occur if it can be followed accurately. On the other hand it is very difficult to follow this. It can not be followed by young people. And there may be a mistake in counting also. ... The period from 20 days after the start of menstruation is more safe. ... (Male involvement in family planning) Cooperation [between wife and husband] is needed. To do this both should discuss and then adopt a method. We have adopted a method after discussion My wife follows the safe period. I keep an account of the days. ... (Advantages/disadvantages of safe period) ... It is a matter of the human condition. There is a saying that if a person wants to join in a religious war and if he marries just before the war he should go to his wife first rather than going to the war. It is better to adopt a method after the birth of a son. It is difficult to follow the safe period method soon after marriage. Neither husband nor wife get satisfaction. ... It cannot be considered completely safe. If Allah wishes conception may occur any time. Besides, everyone cannot follow the method by counting the days accurately. A problem may occur if the counting of days varies in any way.

While it is possible that a woman can use pills without the knowledge of her husband, she certainly cannot use condoms without him being involved. The man is clearly not strongly committed to the use of family planning, since he is harbouring a hope that he will have a son after the existing two daughters. The only way that the stories could be compatible is that condoms are not necessarily used in the safe period of the month. 
In the next example, the woman says she is using a combination of the safe period method and azal, but the man says that his wife is using an IUD. While at first they seem totally dissonant, the stories actually have a number of points of similarity.

F095 (31 years old, 3 children ever born): - (Reasons for using more than one method) I follow [the last] seven days [of the menstrual cycle]. But if in case I sleep with my husband, he then drops [the semen] outside. ... (Advantages/ disadvantages of $\boldsymbol{a z a l}$ ) ... My husband has used this method. My father-in-law is a haji. If I use any other method, her will come to know that. For this reason, my husband has adopted this method. ... If the method of dropping [semen] outside is adopted, birth may be prevented as long as one wishes. If this method is adopted, it doesn't harm health. But if other methods are taken, that affects health. I have used a method and no baby came into my womb. So, I believe that this method prevents birth like other methods. ... (Advantages/disadvantages of safe period) My parents-in-law are staying with us in this house. If I take pills they will come to know it, which will be shameful for me. My father-in-law is a haji. If he comes to know that I am using pills, he will be angry with me. But if I take this method, nobody will know. ... Birth may be prevented by taking pills. All the methods are safe. This method [safe period], if used properly, would prevent birth like the other methods. ... (Extent of discussion with husband) I can initiate discussion with my husband myself. I told my husband to use a method first. I said, 'As I can't take pills, you better drop semen outside.' My husband agreed. ... I can't take pills. My husband told me to take pills, I didn't agree. Moreover, my sister and my brother's wife serve in the hospital [FWA/FWV]. They advised us to drop semen outside instead of taking any method. If I take any other method, my health will be affected. If I am sick, I can't do any household work. We are farmers. We have to do a lot of household work. So, after discussing with my husband we have adopted the method of dropping outside. ... My husband's opinion is more important. If my husband doesn't like it, can I use any method ? However, we two have taken the decision unanimously. ... My father-in-law is a haji. People will come to know if I use a method. I have one bigha of land. I shall not be able to feed and cloth them if many children are born. As we do not want another baby, we have adopted this method. The wife of my brother and my sister said, 'You have to do a lot of household work. You may face a problem if you use any government method.' Following their advice, we follow the counting of days method.

M095 (38 years old): - (Discussion about number of children) Discussion is held. We have had three sons. We do not want another baby. For this reason I bought 'Marvel' (Marvellon) pills from the market and give them to my wife. ... Both of us [start discussion]. I tell her, 'The present situation of the country is not conducive. I have no landed property. To educate children is very costly. So, we will not have another baby.' ... (How the safe period method works) ... It is $100 \%$ safe. It has no problem. ... The last seven days of the menstrual cycle are safe. But I don't remember why it is more safe. The family planning workers gave me a book [leaflet]. But the book has been lost. I learnt about it from that book. ... Both of us decided that we would not have another baby. So, my wife went to her sister in Narail [district town] and got Copper-T inserted from there. ... Yes, there is cooperation. We have taken this method after discussion. ... (Advantages/disadvantages of $\boldsymbol{a z a l}$ )... There exists doubts in this method. At any moment a small portion of the semen may enter inside. Also this method can't be followed properly. ... (Advantages/disadvantages of safe period) ... This is $100 \%$ safe for the prevention of birth. ... (Reasons for method choice) It [safe period] can't be followed always. Suddenly there may be bodily need [for sex]. So, I gave up following the counting of days method. After the birth of our first baby my wife used a Copper-T for three years. Then she got the Copper- $T$ removed and had a baby. Then she followed the safe period for some time and then she took pills. But she had physical problems due to the use of pills. For this reason 
she went to Narail and got another Copper-T inserted by her sister for a period of five years. Three years have elapsed and no problem is being caused. ... No problem was caused due to the use of pills. The Copper-T has suited my wife's health well. ... There is no side-effect. It has adjusted with the health. Her health broke down and she became ill due to the use of pills. But Copper-T has suited her health.

Notice first the agreement on previous use of the safe period method, described by both in the same way with the last seven days of the menstrual cycle identified as safe. Notice also the agreement about the existence of a sister who works as an FWA or FWV, and the fact that the sister is nominated by both of them as having been involved in their method choice. While the woman is possibly too frightened of the consequences with her father-in-law to admit that she is using an IUD, it is also possible that she might not have one but fears telling her husband that.

The case of household 099 has already been discussed in Chapter 3. It involved a woman who had had two method failures, one with azal and one purported to be caused by a ruptured condom, and who was currently taking pills supplied by a homeopathic practitioner. Her husband, however, does not refer to the fact that the pills his wife is taking are from a homeopathic practitioner:

M099 (40 years old): - (Discussion about number of children) Both of us say that we need no more babies. What we have is sufficient. So, it is important to take a method [of family planning]. ... What they [FWAs] say to my wife, I don't know. ... She herself initiates [discussion with me], saying that there is no need of more babies for us. What we have is enough. We have to make these ones men. ... (Male involvement in family planning) So it should be jointly discussed. For taking any method for birth control, both should discuss. My wife is taking the pill currently. ... I check whether she is taking the pill regularly. ... (Reasons for method choice) ... There is no problem in [using] the pill. There was a physical problem with the CT [IUD].... They [FWAs] come. They come and talk much and they go. They take care [of my wife]. ... There was a physical problem with the CT. During intercourse I did not feel pleasure. So, she is now taking pills. There is no problem with pills.

There is a striking similarity between this story and the story told by the man of household 051. The men of both households claim extreme ignorance of what the family planning workers have told their wives, but in household 051 it is the man who mentions that the FWA advised his wife to use an IUD, despite his claim that he knew nothing of what they discussed. The most likely explanation of these two cases is that the men merely failed to mention that their wives were taking homeopathic pills (especially since a vial of the pills was produced by one respondent), but we should be aware that the pattern of response might signal an oblique conventional explanation, like use of female-sterilizing kabiraji pills in cases of vasectomy, or burst condoms to refer to an unwanted pregnancy caused by something else.

When communication between man and woman is limited, disagreement between them about method use can be because one of them does not know what the other is doing, as in the following example.

F101 (41 years old, 3 children ever born): - (Extent of discussion with husband) I cannot initiate a discussion with my husband. If he speaks first then I can talk. ... I feel shy to talk about any method by myself. But if my husband speaks first then I can discuss about any method. ... After the birth of my youngest son, at first my husband brought pills home for me. I had high blood pressure after taking pills. Then my husband took me to hospital to get a coil inserted on me. But the coil came out. Then 
again my husband took me to hospital and arranged for me to take injection. I used to have a burning sensation in my body after I took injection. I did not have any strength in my legs. After that my husband brought foam tablets home. After the foam tablets were used for three days, the doctor said that the use of tablets will cause a problem. Then my husband said, 'I give up. You do whatever you wish to do.' After that my husband and I together decided that we will adopt a kabiraji method. ... (Reasons for switching from program method) Like other methods birth is also prevented by kabiraji medicine. It has been three years that I have taken kabiraji medicine and still I did not conceive.

M101 (48 years old): - (How the safe period method works) ... The last seven days are more safe. ... (Male involvement in family planning) Of course, it [cooperation] is needed. If we do not cooperate, then more children will be born. When my wife says that she is having menstruation, at that period [the at-risk days] I stay away from her. ... The pill causes problems for her. So, both of us together are following the safe period method. ... (Reasons for switching from program method) Her health deteriorated when she took pills. The condition of her health was very bad, she was about to die with blood pressure. Then she was treated by the doctor of Narail [term for qualified doctor used]. He advised her not to take pills. ... She will never adopt any modern method. It is better the way we are following the safe period method.

This man was not very communicative. There can be little doubt, from the woman's account, that they searched together for a suitable modern method, so it is also probable that the man had also agreed she could take the pills supplied by the kabiraj. It also seems likely that he placed no trust in them, and was following the safe period method without bothering to tell her. She had no knowledge of the method.

The following case refers to a man and woman who are both junior government officials. The woman says she is using the safe period method, but the man refers to using condoms. Reading between the lines, it seems likely that they are both right. The woman's account of a safe period method failure has been given in Chapter Three.

F131 (40 years old, 3 children ever born): - (Advantages/disadvantages of safe period) When one is advanced a bit in age, it becomes shameful to take pills in the presence of children. But if the safe period method is followed, nobody can know of it. ... (Extent of discussion with husband) In the present age, women can initiate discussion. Now, I can initiate discussion, but immediately after marriage, I couldn't initiate discussion. I used a Copper-T after my daughter was born. But I had a lot of bleeding; then I began to follow safe period. But I conceived my younger son. After this, I took pills but I was allergic to it. So I decided to follow the safe period method [again]. ... After discussing the use of Copper-T, I got it inserted. But it didn't suit me. We had discussion about condoms and pills. I hate condoms; my husband also doesn't like them.

M131 (46 years old): - (Discussion about number of children) Yes, we're conscious [of the need to limit our family]. We always discuss matters relating to our children. We did not want any more children after two. That's what we decided upon. But in following the 'red signal' method [safe period] we have had the youngest daughter. So we've decided not to have any more children and I am using condoms. When my wife's health improves, she will take pills. We won't have any more children. ... (How the safe period method works) ... This is a reliable method but it's not possible for me to give a one hundred percent guarantee. But on the whole, it is a reliable method. ... She [my wife] has heart disease. It increases when pills are taken. So I have asked her not to take pills and I am using condoms. Though [using a] condom is not pleasant but, I use it out of consideration for my wife's health. When my wife gets better she will again use pills. ... The days from the 10th to the 21 st day from the 
beginning of menstruation are not safe. The days prior to this period and after it are safe. But the days from the 21st to the 28th or 29th are safer. ... (Advantages/disadvantages of safe period) ... This method causes no side-effects. This is the best advantage of this method. The disadvantage is that days are to be counted correctly and I have to be patient. ... The safe period method is effective in $80 \%$ to $90 \%$ of cases. But modern methods are more effective. But I didn't succeed while practising the safe period. She became pregnant and had to have an MR.... (Reasons for method choice) The condom is quite effective. It prevents pregnancy. There's no cause for doubt. But it is not so pleasant. ... I feel sort of uneasy in using the condom but am using it as it is conducive to my wife's health.

There is a revelation in the man's story which it is easy to miss. He says that after they had the safe period method failure his wife had a menstrual regulation. This is not what she said at all. She said it was their third child who was born after the failure, and she confirmed in her interview that she had not aborted the pregnancy resulting from the failure. The third child was certainly not intentional by the man's account, confirming his wife's story. Since there would be no reason for him to mention that his wife had had an abortion unless it were true, it seems very likely that they had two failures with the safe period method. It is notable that this man had a reasonably good understanding of the safe period, although as noted in Chapter Three the woman's understanding was more tenuous.

In the following case, both the woman and the man seem to modify what they initially say about the method of family planning that they use. The woman begins by saying it is the oral pill, the man that it is condoms. The development of their narratives is intriguing.

F135 (36 years old, 7 children ever born): - (How the safe period method works) ... I think birth may be prevented if this method is followed properly. I do it sometimes myself. No baby came into my womb. For this reason I think that it prevents birth if properly followed. ... (Reasons for method choice) Pills also prevent birth as the counting of days method does. One can use the pill as long as one wishes to prevent birth. ... My husband doesn't want to restrain from sexual intercourse for twenty days [from the start of the menstrual period]. For this reason I take pills. But the use of pills causes me dizziness and a lot of white discharge. So, when the white discharge becomes too much, I discontinue pills and follow the counting of days method for one or two months. I don't have any physical problem due to the use of the counting of days method. ... [Name of FWA] keeps pills for me in a neighbouring house. I collect the pills from that house. ... I have to bring the pills from another person's house. So, I am angry with her who supplies pills. ... Those who supply pills don't come to our house. So, I am to bring pills home from the house of other people. I feel bothered in collecting pills from the house of other people. ... The FWA came four months ago and supplied two cycles of pills. She didn't come after that. ... (Extent of discussion with husband) I myself told my husband about the use of family planning. I told my husband first to use a method for the prevention of birth. ... Once I used a Copper-T and I used to bleed too much due to its use. So, I removed the Copper-T. A big [famous] doctor of Satkania advised me to take pills. I told my husband about that. $\mathrm{He}$ said to me, 'Whichever method suits your health, you are at liberty to use it.' For that reason I decided to take pills. ... We, both husband and wife together, decided to take pills. ... Use of pills causes dizziness and white discharge. So, discussing with my husband, we follow the counting of days method sometimes.

M135 (50 years old): - (Discussion about number of children) We tell each other that we will not increase the number of children any more. With the hope of getting a son, I have had five daughters. Now in total I have six children. To educate them and to arrange their marriage will be very costly. I shall have to rear them up well. ... The family planning workers tell my wife, 'Do not increase the number of your children 
any more. Use a family planning method.' They supply medicine [contraceptives] to my wife. My wife tells me all about it. ... My wife initiates discussion. She says 'What shall we feed them if more children are born? It will be expensive to educate them.' For this reason, the population should be kept low. ... (Male involvement in family planning) ... There is no difference of opinion between the two of us. We have accepted a method by discussing among ourselves. Her health was affected due to the use of pills. Considering the condition of her health, I am now using condoms.

... (Advantages/ disadvantages of safe period) ... From the beginning of menstruation to the fifteenth day, if one can follow the counting of days method, no baby is born. ... (Reasons for method choice) Like pills, use of condoms also prevents birth. ... The advantage is that, unlike the pills, it does not need to be taken daily. It may be used only when we want to 'meet' together [have intercourse]. The problem is that it sometimes bursts and full [sexual] satisfaction can't be hoped for. ... I am satisfied with the services of the family planning workers. They follow us up once a month and supply us medicine. ... When she used pills she felt a hot sensation in her body. She was weak and had a burning sensation and also she had dizziness. For this reason we are using condoms and giving up the use of the pill. There is no side-effect with condoms.

The woman's current use of pills must be in doubt, because she was last supplied two cycles four months previously. There is no disagreement from the man that she used to use pills, and perhaps will again, because he seems to refer to supply by the family planning workers in a continuing sense. However, there remains a large question mark over what method they could have been using instead of pills. The woman says they use the safe period method 'sometimes', and the man says condoms, including reference to bursting of condoms. Neither had correct knowledge of when the safe period was, but it is possible that they both referred to one aspect of what they did, with condoms being used in the perceived at-risk period and no protection during the rest of the month. If so, their incorrect knowledge of the safe period would place the woman at risk of an unwanted pregnancy.

In the following case, the woman says that her husband is practising withdrawal after she had experimented with almost the full range of program methods but still had a large number of children. The man says his wife is taking pills. It is very clear that the man is merely telling the interview team what he thinks they want to hear, namely that 'government methods are better'.

F146 (43 years old, 10 children ever born): - (Extent of discussion with husband) It is me who starts the discussion. I tell my husband, 'My health is not good, you practise withdrawal.' It is me who speaks first about all matters. ... I myself showed interest and took pill from those who supply pills by visiting every household, and then informed my husband. The pill did not suit me. I pressed my husband to use condoms and he did. But the condom is uncomfortable for my husband. Then instead of condoms I started to use a CT [IUD]. Upon hearing that the CT causes bleeding, I was afraid and had it taken out. After that I told my husband to practice withdrawal. ... My opinion is more important. If my husband did not agree to practise withdrawal, then I would have told him, 'You will not be able to stay with me' [have intercourse]. ... We discussed about pills and condoms and also used them. We talked about all other methods. We discussed ligation. We also discussed vasectomy. ... (Reasons for switching from program method) ... Fearing Allah, we are practising withdrawal. In the past we used pills and condoms, because my husband had tried but could not practise withdrawal. After begging much forgiveness of Allah, we then used pills and a CT. But now by the grace of Allah my husband is able to practise withdrawal. The Prophet Muhammad used to practise withdrawal. ... I do not know what other Mullahs say. My husband himself is an Imam in the mosque. He says it is sinful to 
adopt a method of family planning. But he used to say that it will be piousness to have many children. I have shown him the book of Hadith where the rules of the safe period method and azal are mentioned. ... Earlier my husband could not practise withdrawal. Now my husband says that since many children are born, he is now able to practise withdrawal. Now, he has no problem to practise withdrawal.

M146 (60 years old): - (Discussion about number of children) Discussion is held. We have seven daughters and two sons. My wife is still fecund. So, we decided that it will not be proper to have more children. We have made a great mistake. Many children were born and for this reason we are having difficulty to educate them properly. We have adopted a method so that we will not have any more children. ... Now-a-days this type of discussion is held between us. ... It is the mother of my children who first starts the discussion. ... (Male involvement in family planning) In adopting a family planning method, both should participate. ... Both should discuss and agree to adopt a family planning method. If the wife is unable to adopt a method then the husband should adopt a method. Again, if the husband faces any problem then the wife should adopt method. ... She is taking pills with my permission. ... (Advantages/disadvantages of azal) ... Like pills or injections, birth is also prevented if withdrawal is practised. There is no problem in withdrawal. ... (Reasons for method choice) The age of my youngest son is four years. For the last three years my wife is taking pills, and birth is prevented. There is no problem. ... There is no problem with the pill. Government workers (women) bring the pill, this is the advantage. There is no need to spend any money and I do not have to go anywhere to bring it. ... I do not have the ability bear expenses, so she is taking pills supplied by the Government. Whatever the Government does for us is for our well-being. That is why government methods are better.

Notice that this religious leader gives a succinct version of the scriptural provisions about the use of azal, namely that it can only be used by agreement between husband and wife, but applies the sanction to all methods (in discussion of the topic of male involvement).

The last case in this group is one where the woman says that she and her husband are practising azal, and the man says that they are using the safe period method, but it is seems very clear that the version of each method that they are using includes the other method. No more than brief excerpts from the two interviews are needed to show this.

F150 (36 years old, 4 children ever born): - (How the safe period method works) ... The nurses and doctors have said that if the safe period method is followed, pregnancy can be prevented. I've been following this method for the last four years. If it's followed correctly, no problem is caused. ... To me it appears that the first ten days of the return of menstruation are safer [meaning counting from the beginning of menstruation]. ... If the poisonous water [semen] which goes inside the woman is thrown outside [describing $a z a l$ ], pregnancy may be prevented. Like other methods, it, if followed properly, may prevent pregnancy as long as one wants. ... (Advantages/disadvantages of $\boldsymbol{a z a l}$ ) ... No conception will take place if the semen, which enters into the body of women, is dropped outside. It is like all other methods. One can prevent birth as long as one wishes if this method is adopted properly. ... (Extent of discussion with husband) ... I can't stand the pill and CT [IUD]. So, my husband has himself proposed that he will resort to withdrawal for prevention of pregnancy.

M150 (70 years old): - (How the safe period method works) During this time [the at-risk days], the wife tries quite a lot to have sex; there is change in her appearance, she looks quite beautiful at this time, and physically, she appears to be hot. ... The last stage of the monthly cycle is more safe. I think that at the time when there is the possibility of being pregnant, the mouth of the vagina remains open, but when such 
possibility is less, the mouth of the vagina is closed. During the last few days [of the monthly cycle], the mouth of the vagina remains closed. The few days when the mouth of the vagina remains closed, although their number is small, those days of the monthly cycle are quite safe. ... (Male involvement in family planning) We have been following the safe period method for quite a long time. We chose it after having mutual discussion. I don't have any difficulty in using the method. ... The disadvantage is that the man's sexual desire is not fully satisfied. ... (Advantages/disadvantages of $\boldsymbol{a z a l}$ ) ... It's safe. Because if semen does not enter the womb of the wife, pregnancy cannot occur. ... (Advantages/disadvantages of safe period) ... It prevents pregnancy. I've been using it for the last ten or twelve years. I have had no problem.

Tenuous understanding of the safe days of the menstrual cycle is evident in each of the interviews, and it is strikingly different in each account. Nevertheless, since they obviously use azal as well, probably throughout what they perceive to be the at-risk period of the month, they have succeeded in avoiding pregnancy. 


\section{References}

Ahmed, Jahiruddin, Barkat-e-Khuda, Terrence Jezowski, Firman Lubis, SN Mukherjee, AKM Rafiquz-Zaman, John Ross, Gilberte Vansintejan, 1992, Assessment of Clinical Contraception Services in the Bangladesh Family Planning Program, Dhaka, The Association of Voluntary Surgical Contraception

Arnold, F, 1991, 'An assessment of data quality in the Demographic and Health Surveys', in Demographic and Health Surveys World Conference, August 5-7, 1991, Washington DC: Proceedings, Volume 2: 785-806. Columbia, Md: IRD/Macro International Inc.

Caldwell, John, 1985, 'Strengths and limitations of the survey approach for measuring and understanding fertility change: alternative possibilities', in Cleland, John and John Hobcraft (eds.), Reproductive Change in Developing Countries: insights from the World Fertility Survey: 47-48, Oxford, Oxford University Press

Caldwell, John, KHW Gaminiratne, Pat Caldwell, Soma de Silva, Bruce Caldwell, Nanda Weeraratne, Padmini Silva, 1987, 'The role of traditional fertility regulation in Sri Lanka', Studies in Family Planning, 18(1): 1-21

Carne, S, G Chamberlain, J McEwan, 1974, 'Barriers, rhythm and other methods', in S Carne, G Chamberlain, J McEwan, Handbook of Contraceptive Practice: 16-19, Cardiff, Department of Health and Social Security

DeGraff, Deborah S, Victor de Silva, 1991, 'Unmet need for contraception in Sri Lanka', International Family Planning Perspectives, 17(4): 123-30

Faisel, Abu Jamil, and Jahiruddin Ahmed, 1996, 'Role of male as the user of contraceptive methods', in Male Involvement in Family Planning: a challenge for the national programme workshop. Proceedings: 45-52, Dhaka: National Institute of Population Research and Training (NIPORT), Deutsche Gesellschaft fuer Technische Zusammenarbeit (GTZ) GmbH, The Population Council, AVSC International

Gallen, M, Liskin, L, Kak, N, 1986, Men - New Foucus for Family Planning Program, Population Reports series J, no.33, Baltimore: John Hopkins University, Population Information Program

Goldberg, Howard I, Aykut Toros, 1994, 'The use of traditional methods of contraception among Turkish couples', Studies in Family Planning, 25(2): 122-8

Hull, Terence H., forthcoming, 'Indonesian fertility behaviour before the transition: searching for hints in the historical record', in Ts'ui-jung Liu (ed), Asian Population History, Oxford University Press

International Institute for Population Sciences, 1995, National Family Health Survey, 1992: West Bengal, Summary Report, Bombay, International Institute for Population Sciences

IRD/Macro, 1990, Model "A" Questionnaire with Commentary for High Contraceptive Prevalence Countries. DHS-II Basic Documentation Number 1. Columbia, Md: IRD/Macro International Inc.

Jejeebhoy, S, 1990, 'Measuring contraceptive use-failure and continuation: an overview of new approaches', in Measuring the Dynamics of Contraceptive Use: proceedings of the United Nations Expert Group Meeting: 21-25, New York, United Nations 
Kambic, Robert T, Ronald H Gray, Richard St Mart, Claude A Lanctot, Mary C Martin, 1991, 'Use-effectiveness among users of the symptothermal method of family planning', International Family Planning Perspectives, 17(3): 96-99

Mitra, SN, Charles Lerman, Shahidul Islam, 1993, Bangladesh Contraceptive Prevalence Survey - 1991: final report, Dhaka, Mitra and Associates

Mitra, SN, M Nawab Ali, Shahidul Islam, Anne R Cross, Tulshi Saha, 1994, Bangladesh Demographic and Health Survey 1993-94, Dhaka, National Institute of Population Research and Training; Dhaka, Mitra and Associates; Calverton Md, Macro International Inc

Mitra, SN, Ahmed Al-Sabir, 1996, Contraceptive Use Dynamics in Bangladesh, DHS Working Paper No. 21, Calverton, Md, Macro International Inc.

Peel, John, and Malcolm Potts, 1969, Textbook of Contraceptive Practice, Cambridge, Cambridge University Press

Potts, Malcolm, 1985, 'Coitus interruptus', in Stephen L Corson, Richard J Derman, Louise B Tyrer, Fertility Control: 299-305, Boston (Mass), Little, Brown

Rogow, Deborah, Sonya Horowitz, 1995, 'Withdrawal: a review of the literature and an agenda for research', Studies in Family Planning, 26(3): 140-53

Steele, Fiona, Ian Diamond, Dualao Wang, 1996, 'The determinants of the duration of contraceptive use in China: a multilevel multinomial discrete-hazards modeling approach', Demography 33(1): 12-23

World Fertility Survey, 1975, World Fertility Survey: core questionnaires. Basic Documentation, No. 1. The Hague-Voorburg: International Statistical Institute

Wrigley, E A, 1969, Population and History, London, Wiedenfeld and Nicholson 


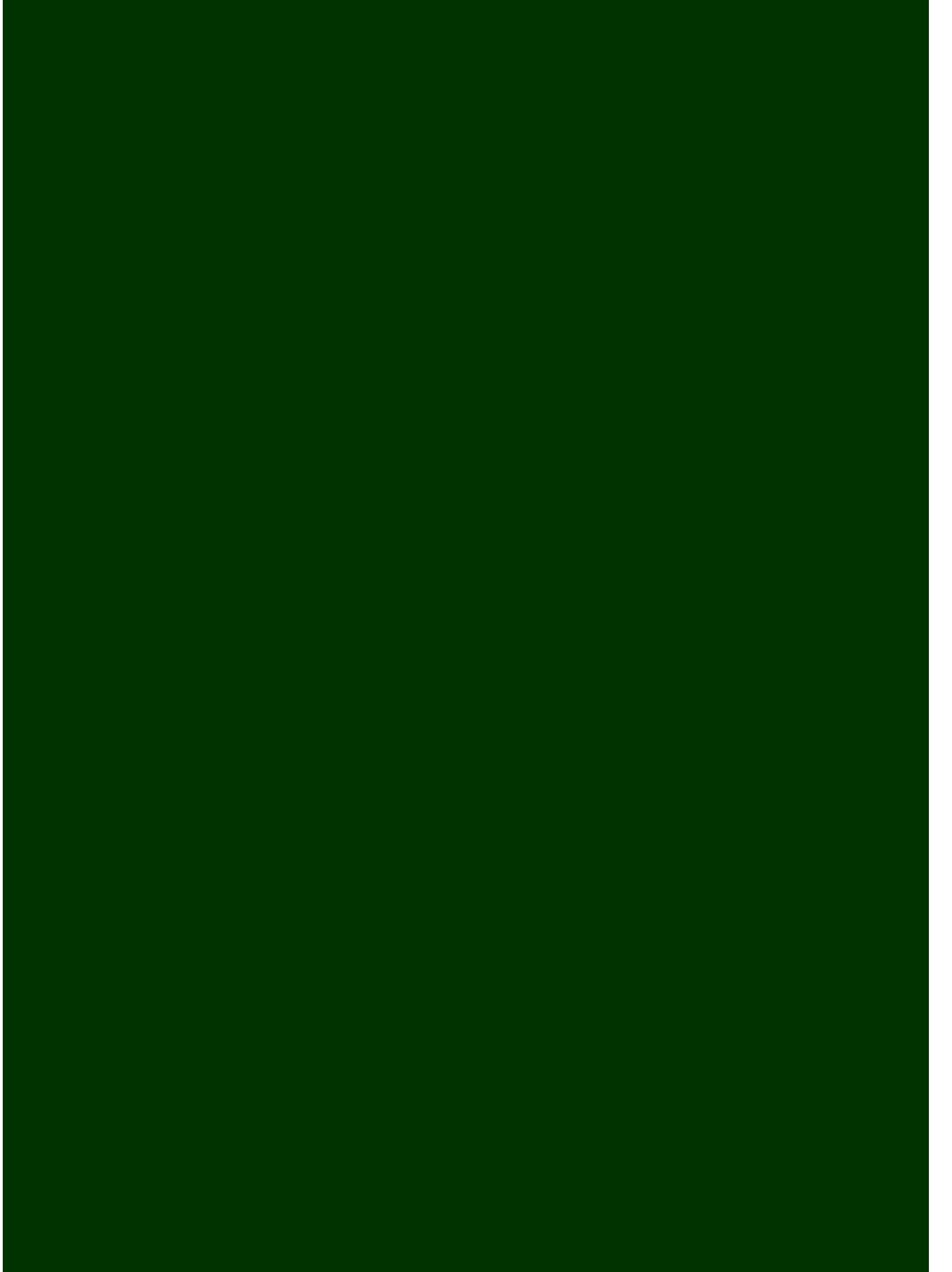

